\title{
OPTIMIZACIÓN DEL PROCESO DE ENGORDE DEL CONEJO PARA EL DESPIECE Y TRANSFORMACIÓN DE LAS CANALES
}

Técnicas Avanzadas en Investigación y Desarrollo Agrario y Alimentario

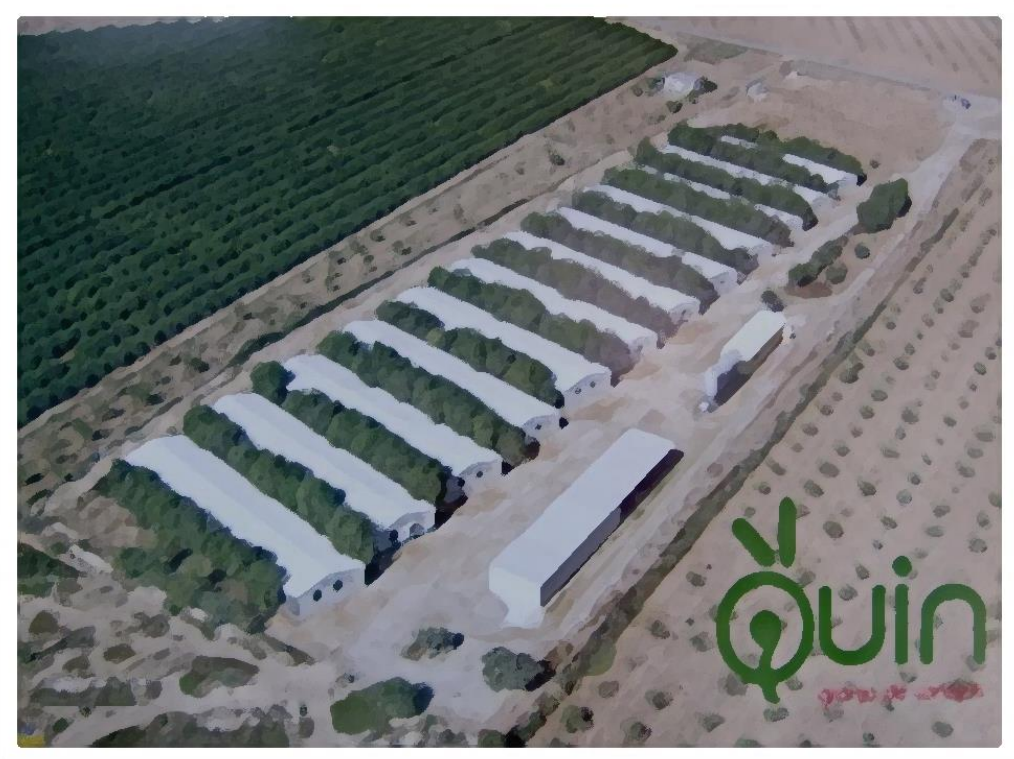

Autor: Ana Mํㅗ Martínez Bas

Director/es: Eva Armero Ibáñez Mathieu Kessler 
Agradecimientos:

La realización del presente trabajo ha sido posible gracias al apoyo económico del proyecto CDTI (IDI-20120024) y al apoyo técnico de la empresa QUIN S.L.

También muestro mi agradecimiento al Institute of Agrifood Research and Technology (IRTA), la Universidad Politécnica de Cartagena y la Escuela Superior de Ingeniería Agronómica por su colaboración. Y a mis compañeros de departamento por su ayuda y apoyo incondicional. 


\section{RESUMEN}

La subida en los precios de energía y alimentación ha supuesto un incremento en los costes de producción de productos ganaderos, afectando a la rentabilidad de las explotaciones cunícolas.

Dada esta situación, en el presente proyecto se plantea buscar alternativas en la comercialización del producto que le den valor añadido, como puede ser el despiece y venta en bandejero, o la transformación de diferentes productos como hamburguesas o embutidos, mejorando así la rentabilidad de las explotaciones ganaderas.

Teniendo en cuenta este planteamiento, el objetivo general que se persigue es la optimización del proceso de crecimiento y cebo de conejos destinados al despiece.

Dado que los factores que más influyen en el proceso de crecimiento, cebo y características carniceras del producto son la línea genética y la alimentación, hemos estudiado como evolucionaban en el tiempo tres líneas genéticas (Hyla-colored, Grimaud e Hyla) alimentadas con dos piensos (uno más energético y otro control) Paralelamente se utilizaron tanto machos como hembras para analizar el efecto del género.

Los caracteres de crecimiento estudiados han sido la evolución del peso e índice de transformación con la edad. En las características del animal se han evaluado despojos y subproductos, características de la canal (rendimiento, conformación medida mediante longitudes, despiece y deposición de grasa) y características de la carne ( $\mathrm{pH}$, textura, color, valor nutricional de la carne y perfil de ácidos grasos).

Para llevar a cabo el estudio, se realizaron 3973 inseminaciones de las tres líneas genéticas, criándose más de 30.000 conejos hasta las 8 semanas de edad. A partir de ese momento, se seleccionaron 2294 conejos (machos y hembras, uno de cada camada) de las tres líneas genéticas. La mitad de cada una de las líneas fue alimentada con el pienso habitual de la granja (pienso control) y la otra mitad con pienso más energético, hasta que alcanzaron las 16 semanas de edad, momento en el que finalizó 
el ensayo. Con los datos obtenidos se procedió a la caracterización de cada línea genética alimentada con diferente pienso para los caracteres de crecimiento y las características cárnicas.

En el estudio de la línea genética, observamos que la línea Hyla-colored presentó mejores caracteres de crecimiento sobre todo por su mejor capacidad de transformación del pienso en carne. Por otro lado, la línea Grimaud mostró alto porcentaje de piel, alto rendimiento a la canal y canales conformadas, con una buena relación músculo-hueso. La línea Hyla-colored también presentó buenas características carniceras, siendo superior a Grimaud en el desarrollo de la región lumbar y menor contenido en grasa diseccionable. La línea Hyla se reveló como una línea con menor ritmo de crecimiento y no destacó por sus características de calidad de canal y carne excepto porque su contenido en ácidos grasos insaturados fue el más elevado.

En cuanto a la conveniencia de la utilización de un pienso más energético y menos fibroso, se observó que mejoraba el índice de transformación y que había pocas diferencias en las características carniceras. Si bien, los animales alimentados con dicho pienso presentaban tendencia a mayores pesos de canales y vísceras (porcentaje de hígado), consecuentemente, canales más engrasadas y mayor contenido de ácido palmítico debido al mayor contenido de aceite de palma de la dieta.

Las hembras presentaron muy buenas características de crecimiento, con menor índice de transformación y menos cabeza que los machos, y con buenas características de carniceras cuando tomaban la dieta $\mathrm{HE}$, desarrollando mayor porcentaje de región lumbar y de patas traseras. Independientemente de la dieta, las hembras tuvieron mayor ratio músculo-hueso, y canales más engrasadas. 


\section{ABSTRACT}

The prices' increase of energy and food has impacted the production costs of livestock products, affecting the profitability of rabbit farms.

In this context, the aim of the current project is to explore alternatives in the commercialization of the product, which would result in added value, such as the cutting carcass product and noble portions in trays, or the transformation of different products such as hamburgers or sausages, in an attempt to improve the profitability of the livestock exploitations.

As a general objective, the focus is on the optimization of the growth process and the feed up of rabbits for meat production.

The factors that have the greatest influence on the process of growth, feed up and carcass characteristics of the product, are the genetic line and feeding. As a consequence, three genetic lines (Hyla-color, Grimaud and Hyla) fed with two feeds (one more energetic and another control) were studied. Morever, both males and females were considered to analyze the effect of gender.

Regarding growth, the evolution of weight and the rate of transformation with age were studied. As for the animal characteristics, the offal and by-products, characteristics of the carcass (yield, conformation through lengths, cutting and deposition of fat) as well as characteristics of the meat $(\mathrm{pH}$, texture, color, nutritional value of the meat and profile of fatty acids) were evaluated.

Along the study, 3973 inseminations of the three genetic lines were carried out, raising more than 30,000 rabbits until 8 weeks of age. At that time point, 2294 rabbits (males and females, one from each litter) of the three genetic lines were further selected. Half of each of the lines was fed with the usual feed of the farm (control feed) and the other half with more energetic feed, until they reached the 16 weeks of age that ended the experiment. The obtained data were used to characterize each genetic line fed with different feed for the growth characters and the meat characteristics. 
As for the genetic line, we observed that the Hyla-colored line presented better growth characteristics, mainly due to its better capacity to transform the feed into meat. On the other hand, the Grimaud line showed high percentage of skin, high performance to the carcass and shaped carcass, with a good muscle-bone relationship. The Hylacolored line also showed good carcass characteristics, being superior to Grimaud in the development of the lumbar region and lower dissectible fat content. The Hyla line proved to be a line with a lower growth rate and did not score well on its quality characteristics of carcass and meat, except for the fact that its content of unsaturated fatty acids was the highest.

Regarding the convenience of using a more energetic and less fibrous feed, it was observed that it improved the transformation index and that there were few differences in the meat characteristics. Nevertheless, the animals fed with this feed tended to present greater weights of carcasses and viscera (percentage of liver), and consequently, greasier carcass and higher content of palmitic acid due to the higher content of palm oil in the diet.

The females showed very good growth characteristics, with a lower transformation rate and less head than the males, and with good meat characteristics when taking the HE diet, developing a higher percentage of the lumbar region and hind legs. Regardless of the diet, the females had a higher muscle-bone ratio, and more oiled channels. 


\section{ÍNDICE}

INTRODUCCIÓN .1

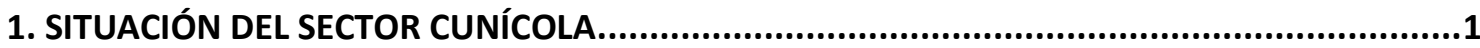

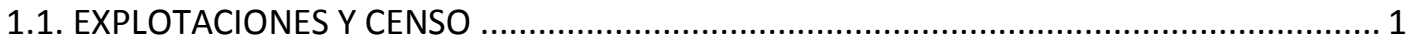

1.1.1. Número de explotaciones de conejos según clasificación zootécnica y distribución por CC.AA.

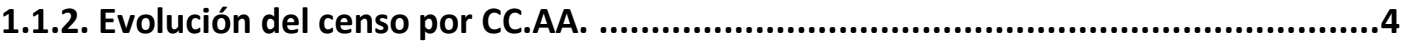

1.2.1. Evolución de la producción de carne de conejo en España .....................................4

1.2. PRODUCCIÓN DE CARNE DE CONEJO EN ESPAÑA Y LA UNIÓN EUROPEA ..................... 5

1.2.2. Evolución de la producción de carne de conejo en la UE.......................................5

1.3. COMERCIO EXTERIOR DE ESPAÑA EN EL SECTOR DE LA CARNE DE CONEJO .................. 7

1.3.1. Comercio español en el sector cunícola $2008 / 2017$............................................

1.4. BALANCE DE ABASTECIMIENTO DE CARNE DE CONEJO EN ESPAÑA............................ 8

1.4.1. Evolución del consumo aparente per cápita y del abastecimiento de carne de

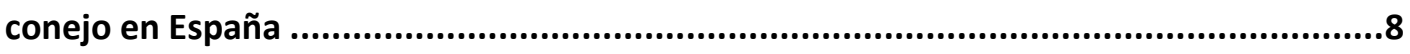

1.5. EVOLUCIÓN SEMANAL DEL PRECIO DE CONEJO EN ESPAÑA …................................. 9

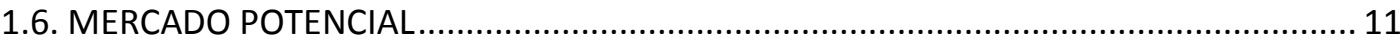

1.6.1. Características generales del mercado (tipo de cliente, motivación de compra, segmentación del mercado al que se dirige: distribuidor, mayorista, cliente final) .......12

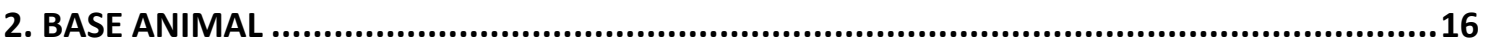

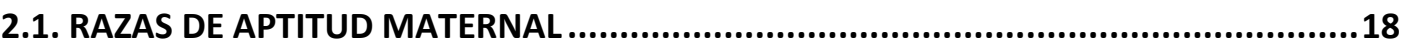

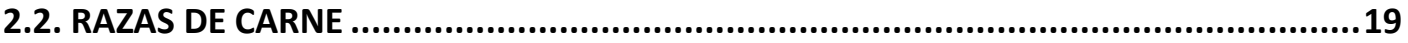

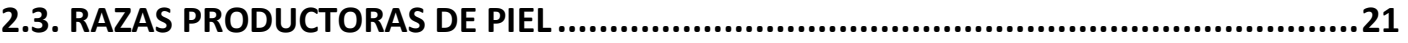

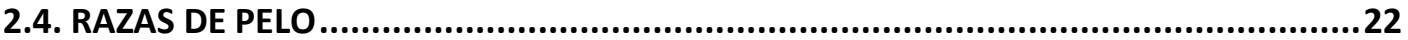

3. CARACTERES DE CRECIMIENTO E ÍNDICE DE TRANSFORMACIÓN ..................................22

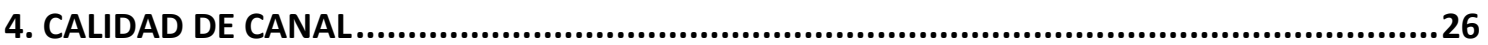

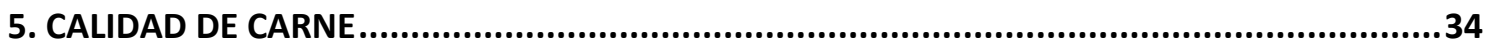

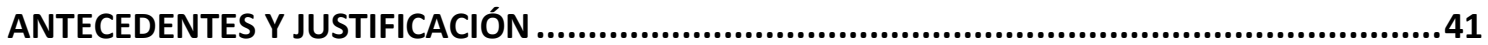




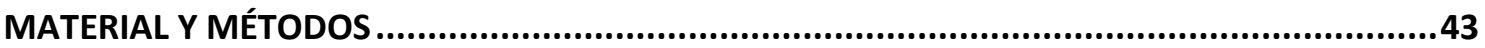

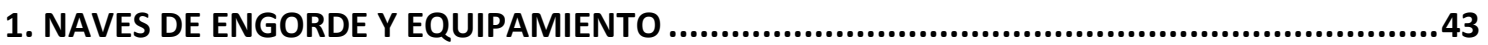

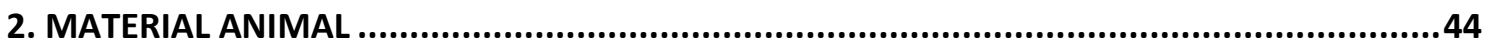

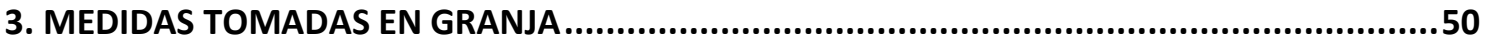

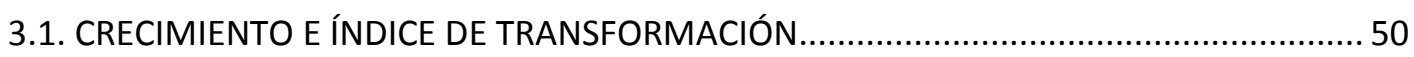

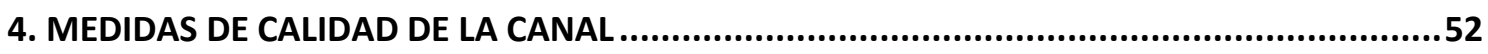

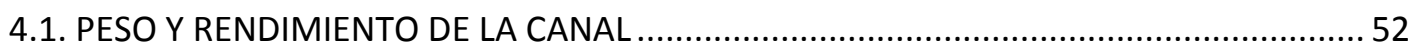

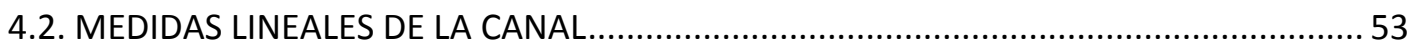

4.3. PIEL, CONJUNTO DE PULMONES, CORAZÓN, TRÁQUEA, ESÓFAGO Y TIMO, RIÑONES,

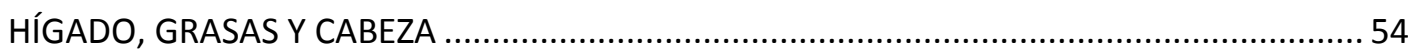

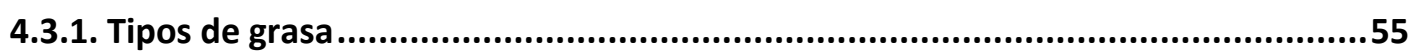

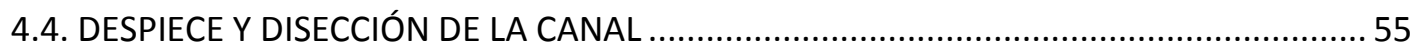

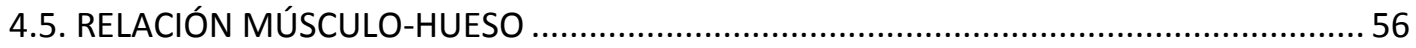

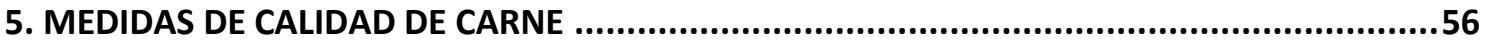

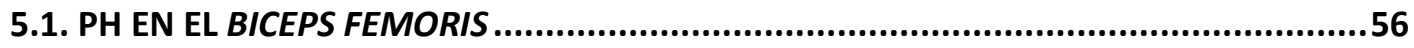

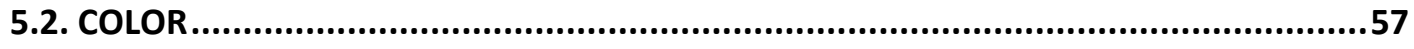

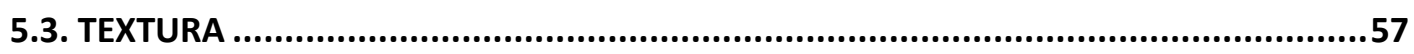

5.4. COMPOSICIÓN QUÍMICA DE LA PATA TRASERA ...........................................58

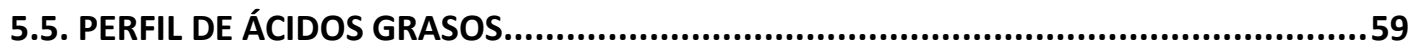

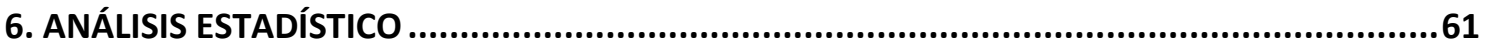

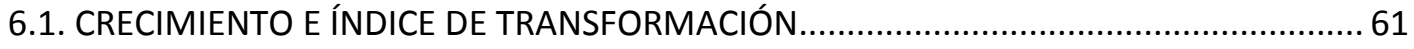

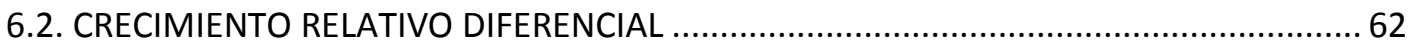

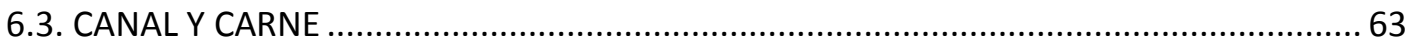

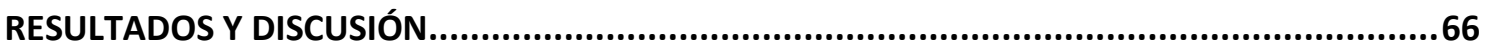

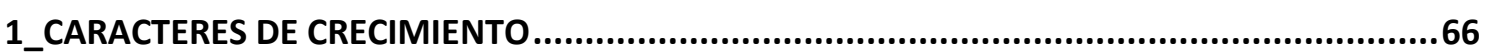

1.1. EVOLUCIÓN DEL PESO, GANANCIA MEDIA DIARIA E ÍNDICE DE TRANSFORMACIÓN .. 66 
2.1. CANAL CALIENTE, CANAL FRÍA, CANAL DE REFERENCIA Y RENDIMIENTO DE CANAL FRÍA.

2.2. LONGITUDES Y COMPACIDAD

2.2.1. Longitud de canal (CL), longitud dorsal (DL), longitud de las patas (TL), circunferencia lumbar (LCL) .87

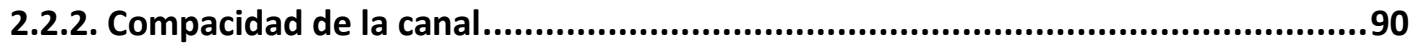

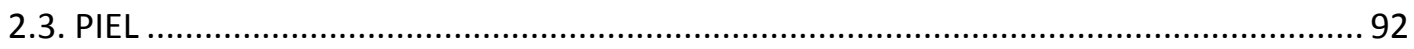

2.4. PULMONES, TRÁQUEA, ESÓFAGO Y CORAZÓN …......................................................... 95

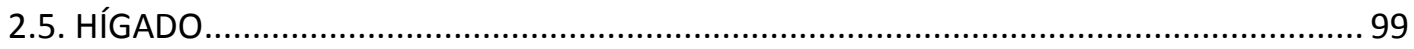

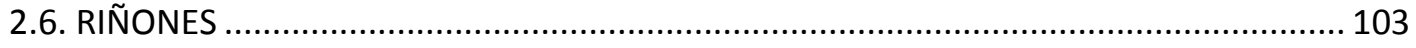

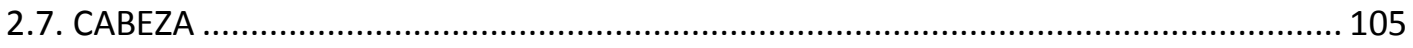

2.8. DESPIECE DE LA CANAL: CAJA TORÁCICA, LOMO, PATAS DELANTERAS Y TRASERAS 109

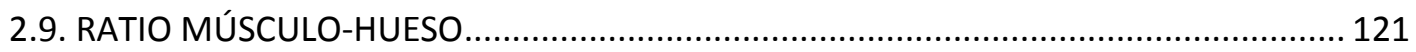

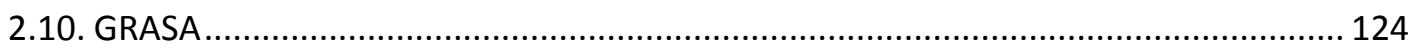

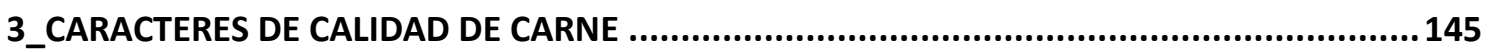

3.1. PH A LOS 45 MINUTOS Y A LAS 24 HORAS POST MORTEM...................................... 145

3.2. COLOR

3.3. TEXTURA: FUERZA MÁXIMA AL CORTE (MSF) Y EN EL RENDIMIENTO DE FUERZA

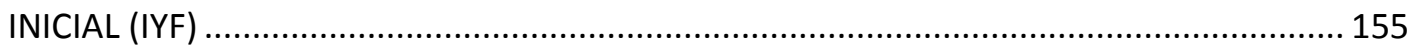

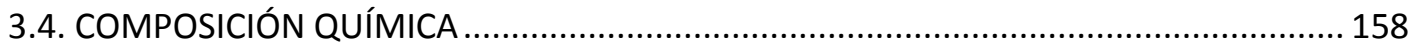

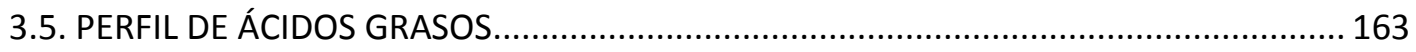

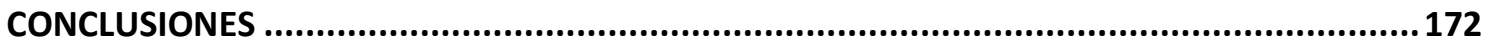

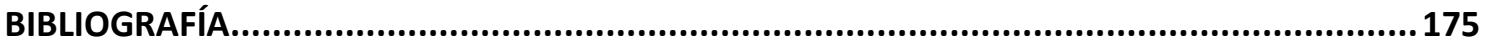




\section{ÍNDICE DE TABLAS}

\section{INTRODUCCCIÓN}

Tabla 1. Número de explotaciones en España y porcentaje que representan sobre el total según clasificación zootécnica 2

Tabla 2. Distribución por CC.AA. del $\mathrm{n}$ o explotaciones cunícolas ........................................................... 3

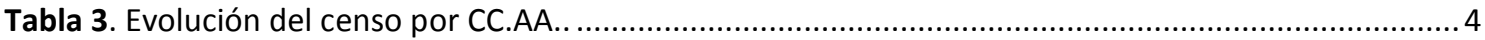

Tabla 4. Evolución de la producción de la carne de conejo en España ...................................................5

Tabla 5. Evolución de la producción de carne de conejo en la UE en miles de toneladas .......................... 7

Tabla 6. Evolución del comercio español en el sector cunícola 2008/2017 en toneladas de carne ............8

Tabla 7. Evolución del consumo aparente per cápita en kilogramos y porcentaje del abastecimiento de

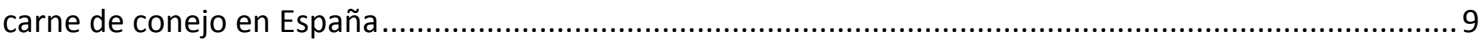

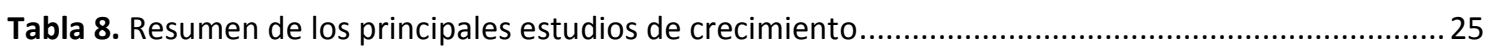

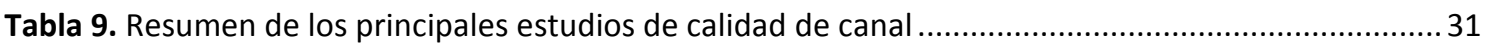

Tabla 10. Resumen de los principales estudios de calidad de carne ................................................ 38

\section{MATERIAL Y MÉTODOS}

Tabla 1. Composición y valor nutricional de los dos piensos de engorde 46

Tabla 2. Número de conejos según edad de sacrificio, tipo de dieta, línea genética y sexo. 50

Tabla 3. Número de muestras para el análisis de la composición química del músculo según edad de sacrificio, línea genética, tipo de dieta y género

Tabla 4. Número de muestras para el análisis de perfil de ácidos grasos según edad de sacrificio, línea genética, tipo de dieta y género.....

Tabla 5. Resumen de las variables calculadas, tamaño muestral y magnitudes en las que se expresan...65

\section{RESULTADOS Y DISCUSIÓN}

Tabla 1. Mínimos estimados cuadrados y errores estándar de los coeficientes alométricos $k$ de Huxley para canal fría y canal de referencia respecto al peso vivo al sacrificio.

Tabla 2. Diferencias entre líneas genéticas para las longitudes de la canal.......

Tabla 3. Diferencias significativas en las longitudes entre las dos dietas: y para las tres líneas genéticas en el rango de semanas donde las diferencias fueron significativas.

Tabla 4. Mínimos estimados cuadrados y errores estándar de los coeficientes alométricos $k$ de Huxley para la piel, conjunto de pulmones, tráquea, esófago y corazón, hígado y riñones respecto al peso vivo al sacrificio.

Tabla 5. Mínimos estimados cuadrados y errores estándar de los coeficientes alométricos $k$ de Huxley para cabeza, patas delanteras, patas traseras, caja torácica y lomo

Tabla 6. Medias globales y errores estándar de los porcentajes de las diferentes partes de la canal a lo largo del periodo estudiado 
Tabla 7. Medias mínimo cuadráticas de las diferentes partes de la canal para las líneas genéticas y dietas en la semana 8 y 16

Tabla 8. Medias mínimo cuadráticas y errores estándar de los coeficientes alométricos $k$ de Huxley para músculo pata trasera y hueso pata trasera

Tabla 9. Mínimos estimados cuadrados y errores estándar de los coeficientes alométricos k de Huxley para diferentes tipos de grasa de la canal con respecto al peso de sacrificio y para la grasa intermuscular más grasa intramuscular con respecto al peso de la pierna trasera 124

Tabla 10. Rango de valores promedio, en gramos y en porcentaje, para los diferentes tipos de grasa en la semana 8 y 16 para todas las líneas genéticas, dietas y sexo. .126

Tabla 11. Contenido de grasa intramuscular y perfil de ácidos grasos de la carne de la pata trasera según línea genética y la dieta a las 8 semanas de edad 170

Tabla 12. Contenido de grasa intramuscular y perfil de ácidos grasos de la carne de la pata trasera según línea genética y la dieta a las 12 semanas de edad 171

\section{ÍNDICE DE FIGURAS}

\section{INTRODUCCIÓN}

Figura 1. Evolución de la producción de la carne de conejo en España.

Figura 2. Evolución de la producción de carne de conejo en la UE en miles de toneladas........................ 7

Figura 3. Evolución del consumo aparente per cápita en kilogramos en España ....................................9

Figuras 4a y 4b. Evolución semanal del precio de carne de conejo joven (€ /kg carne) ......................... 11

Figura 5. Evolución anual y mensual de los $\mathrm{kg}$ de carne conejo consumido en hogares españoles ...........112

Figura 6. Consumo de carne de conejo según el sexo y la edad. ..................................................... 14

Figura 7. Frecuencia en el consumo de carne de conejo .............................................................. 14

Figura 8. Establecimientos donde se adquiere la carne de conejo año 2008 ..................................... 15

Figura 9. Establecimientos donde se adquiere la carne de conejo años 2014-2015 ............................. 16

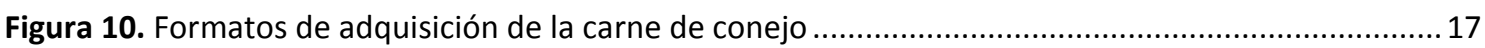

\section{MATERIAL Y MÉTODOS}

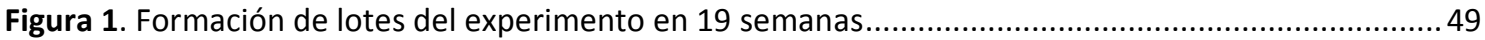

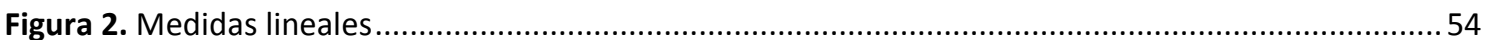

\section{RESULTADOS Y DISCUSIÓN}

\section{1_CRECIMIENTO}

Figura 1. Evolución del Peso Vivo al Sacrifico y la Ganancia Media Diaria con la edad según la línea

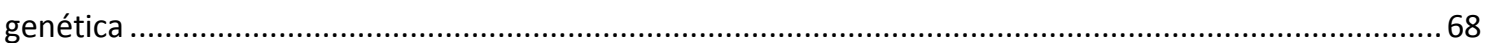

Figura 2. Evolución del índice de Transformación con la edad según la línea genética. . .70 
Figura 3. Evolución del Peso Vivo al Sacrifico y la Ganancia Media Diaria con la edad en función de la dieta.

Figura 4. Evolución del Índice de transformación con la edad en función de la dieta

Figura 5. Efecto de la interacción Línea genética * Dieta en la evolución del Peso Vivo al Sacrificio con la edad

Figura 6. Evolución del Peso Vivo al Sacrifico en función del género. 76

Figura 7. Evolución de la Ganancia Media Diaria con la edad en función del género..... 77

Figura 8. Evolución del Índice de Transformación según el género

\section{2_CALIDAD DE CANAL}

Figura 9. Evolución del Peso Canal Caliente y del Peso Canal Fría con la edad en función de la línea genética y dieta

Figura 10. Evolución del Peso Canal Referencia y del Rendimiento de Canal Fría con la edad en función de la línea genética

Figura 11. Evolución del Peso Canal Fría y del Peso Canal Referencia con la edad en función del género

Figura 12. Evolución del Rendimiento Canal Fría con la edad en función de la dieta..... 86

Figura 13. Evolución de la Longitud canal, la Longitud dorsal, la Longitud de las patas con la edad en función de la línea genética y la dieta

Figura 14. Evolución de la compacidad según dos dietas, las tres líneas genéticas y los dos géneros .....91

Figura 15. Evolución del peso de la piel según la línea genética, la dieta y el sexo ...............................94

Figura 16. Evolución del porcentaje de la piel según la línea genética, la dieta y el sexo 95

Figura 17. Evolución del peso del conjunto pulmones, tráquea, esófago y corazón con la edad en función de la dieta y la línea genética

Figura 18. Evolución del porcentaje del conjunto pulmones, tráquea, esófago y corazón con la edad en

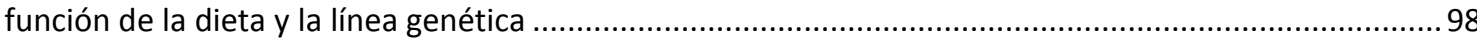

Figura 19. Evolución del peso del hígado con la edad de las diferentes líneas genéticas y dietas .......... 101 Figura 20. Evolución del porcentaje del hígado con la edad: a) Línea genética x Dieta, b) Línea genética Grimaud alimentada con los dos tipos de dieta, c) Línea genética Hyla-colored alimentada con los dos tipos de dieta y d) Línea genética Hyla alimentada con los dos tipos de dieta 102

Figura 21. Evolución del peso y del porcentaje de los riñones con la edad en función la línea Genética .104

Figura 22. Evolución del peso y del porcentaje de los riñones con la edad en función de la dieta ..........104

Figura 23. Evolución del peso y del porcentaje de los riñones con la edad en función del género..........105

Figura 24. Evolución del peso de la cabeza y del porcentaje con la edad en función de la línea genética

Figura 25. Evolución del peso de la cabeza y del porcentaje con la edad en función de la dieta.....

Figura 26. Evolución del peso de la cabeza y del porcentaje con la edad en función del género 108 
Figura 27. Evolución del peso de la caja torácica y del porcentaje con la edad en función de la línea genética

Figura 28. Evolución del peso del lomo y del porcentaje con la edad en función de la línea genética y la dieta.

Figura 29. Evolución del peso de las patas delanteras y del porcentaje con la edad en función de la línea genética y la dieta

Figura 30. Evolución del peso de las patas traseras y del porcentaje con la edad en función de la línea genética y la dieta

Figura 31. Evolución del peso y del porcentaje de la caja torácica con la edad en función del género y la dieta.

Figura 32. Evolución del peso y del porcentaje del lomo con la edad en función del género y la dieta.. 118

Figura 33. Evolución del peso de las patas delanteras y del porcentaje con la edad en función del género y la dieta

Figura 34. Evolución del peso y del porcentaje de las patas traseras con la edad en función del género y la dieta 120

Figura 35. Evolución del ratio músculo-hueso con la edad en función de la línea genética 122

Figura 36. Evolución del ratio músculo-hueso con la edad en función de la dieta

Figura 37. Evolución del ratio músculo-hueso con la edad en función del género 123

Figura 38. Evolución del peso de grasa escapular con la edad en función de la línea genética y dieta .128 Figura 39. Interacción línea genética x dieta: Evolución del porcentaje de grasa escapular con la edad para las diferentes líneas genéticas y dietas y desglosada para las tres líneas genéticas. 129

Figura 40. Evolución del porcentaje de grasa escapular con la edad de las líneas genéticas para cada dieta

Figura 41. Evolución del peso de grasa inguinal con la edad en función de la línea genética..... 130

Figura 42. Interacción línea genética x dieta: Evolución del porcentaje de grasa inguinal con la edad para las diferentes líneas genéticas y dietas y desglosada para las tres líneas genéticas

Figura 43. Evolución del porcentaje de grasa inguinal con la edad en función de la línea genética .......132

Figura 44. Evolución del Peso de grasa perirrenal con la edad en función de la línea genética

Figura 45. Interacción línea genética x dieta: Evolución del Peso de grasa perirrenal con la edad en función de la línea genética.....

Figura 46. Evolución del porcentaje de grasa perirrenal con la edad en función de la línea genética....135

Figura 47. Evolución del Peso de grasa diseccionable con la edad en función de la línea genética ........136

Figura 48. Interacción línea genética $x$ dieta: Evolución del Peso de grasa perirrenal respecto a la canal de referencia con la edad en función de la línea genética

Figura 49. Evolución del porcentaje de grasa diseccionable con la edad en función de la línea genética

Figura 50. Evolución del Peso de grasa escapular y del porcentaje con la edad en función en función del género 
Figura 51. Evolución del Peso de grasa perirrenal y evolución del porcentaje con la edad en función en función del género 142

Figura 52. Evolución del Peso de grasa inguinal y evolución del porcentaje con la edad en función en función del género 143

Figura 53. Evolución del Peso de grasa diseccionable y evolución del porcentaje con la edad en función en función del género 144

\section{3_CALIDAD DE CARNE}

Figura 54. Evolución del pH a los 45 minutos p.m. en el Biceps femoris con la edad para las diferentes líneas genéticas 145

Figura 55. Evolución del pH a los 45 minutos p.m. en el Biceps femoris con la edad para las diferentes dietas y según el género 146

Figura 56. Evolución del pH a las 24 horas p.m. en el Biceps femoris con la edad para las diferentes líneas genéticas y las diferentes dietas

Figura 57. Evolución del pH a las 24 horas p.m. en el Biceps femoris con la edad para los diferentes géneros y las diferentes dietas 150

Figura 58. Evolución del color (coordenada $\mathrm{L}^{*}$ ) con la edad para las diferentes líneas genéticas y las diferentes dietas.

Figura 59. Evolución del color (coordenadas $\mathbf{a}^{*} \mathbf{y} \mathbf{b}^{*}$ ) con la edad para las diferentes líneas genéticas y las diferentes dietas y ambos sexos

Figura 60. Evolución de la fuerza máxima al corte con la edad para las diferentes líneas genéticas y las diferentes dietas.

Figura 61. Evolución de rendimiento de fuerza inicial con la edad para las diferentes líneas genéticas y las diferentes dietas 156

Figura 62. Evolución del porcentaje de humedad con la edad para las diferentes líneas genéticas y las diferentes dietas.

Figura 63. Evolución del porcentaje de grasa inter-intramuscular, proteína y colágeno con la edad para las diferentes líneas genéticas y las diferentes dietas 159

Figura 64. Evolución del porcentaje de proteína y colágeno con la edad para las diferentes dietas..... 160

Figura 65. Evolución del porcentaje de proteína y colágeno con la edad según el género 161 



\section{INTRODUCCIÓN}

\section{SITUACIÓN DEL SECTOR CUNÍCOLA}

La cunicultura, como actividad pecuaria, ha experimentado en los últimos años una importante evolución y ha alcanzado una considerable relevancia y un creciente interés.

La carne de conejo representa el quinto tipo de carne más consumido tras el porcino, aves, vacuno y ovino-caprino. España es uno de los principales productores mundiales de carne de conejo y, junto con Italia y Francia, forma parte del grupo líder de países a nivel continental. El balance exterior de este tipo de carne ha sido habitualmente favorable para el sector nacional.

La normativa europea en materia cunícola, especialmente en los aspectos de mercados y comercialización, es escasa y de tipo general. Durante los últimos años el sector cunícola español ha llegado a una realidad productiva, económica, sanitaria y medioambiental que ha hecho necesario llevar a cabo una ordenación sectorial desde el punto de vista normativo.

A continuación, se describe la situación del sector cunícola en cuanto a producciones, censos y comercio de la carne de conejo entre otros apartados.

\subsection{EXPLOTACIONES Y CENSO}

\subsubsection{Número de explotaciones de conejos según clasificación zootécnica $y$} distribución por CC.AA.

Según el anuario de la Subdirección General de Productos Ganaderos de mayo de 2014 sobre indicadores económicos del sector cunícola desde 2009 hasta 2014 en España ha disminuido en 1231 el total de explotaciones registradas. Siendo las explotaciones de gazapos las que más han sufrido este descenso pasando de $85,53 \%$ a 73,6\% (tabla 1).

Según la tabla 2, anterior a 2015 algunas comunidades (Asturias, Baleares 2010 y 2014, Cantabria, Madrid, Murcia, Navarra, País Vasco y La Rioja) no tenían un censo propio y sus censos se suman y constituyen el porcentaje llamado "Resto". En esta tabla 
publicada por el Ministerio de Agricultura, Pesca y Alimentación (MAPAMA) en mayo de 2018 el número de explotaciones desde 2010 a 2014 ha descendido en Aragón, Canarias y Cataluña; manteniéndose constante en Castilla La Mancha, Castilla León, C. Valenciana y Extremadura, y aumentando en Andalucía duplicando su porcentaje de 3,41 a $6,52 \%$.

En 2018 se ha reducido en 1068 el número total de explotaciones.

Andalucía ha incrementado el número de estas explotaciones desde 216 a 417 y la comunidad autónoma que más ha descendido su porcentaje de granjas cunícolas es Cataluña, que ha descendido en un 6,14\% de 2014 a 2018.

Murcia, que anteriormente formaba parte del $6,4 \%$ de la suma de explotaciones de varias comunidades, en 2018 cuenta con un censo propio de 42 explotaciones, lo que supone un $1,87 \%$ del total.

Tabla 1. № de explotaciones (№) en España y porcentaje que representan sobre el total según clasificación zootécnica. (Datos REGA actualizados a 01/04/2014).

\begin{tabular}{|c|c|c|c|c|c|c|c|c|c|c|c|c|}
\hline \multirow[b]{2}{*}{ Tipo } & \multicolumn{2}{|c|}{2009} & \multicolumn{2}{|c|}{2010} & \multicolumn{2}{|c|}{2011} & \multicolumn{2}{|c|}{2012} & \multicolumn{2}{|c|}{2013} & \multicolumn{2}{|c|}{2014} \\
\hline & № & $\%$ & № & $\%$ & № & $\%$ & № & $\%$ & № & $\%$ & № & $\%$ \\
\hline Selección & 24 & 0,53 & 24 & 0,61 & 23 & 0,60 & 25 & 0,69 & 23 & 0,66 & 23 & 0,69 \\
\hline Multiplicación & 74 & 1,63 & 67 & 1,69 & 62 & 1,63 & 63 & 1,73 & 59 & 1,69 & 47 & 1,42 \\
\hline I. A. & 22 & 0,48 & 20 & 0,50 & 20 & 0,53 & 18 & 0,49 & 21 & 0,60 & 18 & 0,54 \\
\hline Gazapos & 3888 & 85,53 & 3271 & 82,54 & 3087 & 81,11 & 2866 & 78,69 & 2650 & 75,69 & 2440 & 73,60 \\
\hline Caza & 206 & 4,53 & 224 & 5,65 & 237 & 6,23 & 251 & 6,89 & 252 & 7,20 & 257 & 7,75 \\
\hline Compañía & 22 & 0,48 & 19 & 0,48 & 17 & 0,45 & 19 & 0,52 & 18 & 0,51 & 18 & 0,54 \\
\hline Otras & 24 & 0,53 & 24 & 0,61 & 22 & 0,58 & 21 & 0,58 & 21 & 0,60 & 21 & 0,63 \\
\hline S.C. & 286 & 6,29 & 314 & 7,92 & 338 & 8,88 & 379 & 10,41 & 457 & 13,05 & 491 & 14,81 \\
\hline Total & 4.546 & & 3.963 & & 3.806 & & 3.642 & & 3.501 & & 3.315 & \\
\hline
\end{tabular}

I.A. Centros de inseminación artificial, S.C. Sin clasificación 
Tabla 2. Distribución por CCAA del no explotaciones cunícolas. (Datos REGA actualizados a 01/04/2014 y datos MAPAMA para 2018). (* Asturias, Baleares 2010 y 2014, Cantabria, Madrid, Murcia, Navarra, País Vasco y La Rioja no hay dato de censo individual, todas se incluyen en el porcentaje de explotaciones llamadas Resto)

\begin{tabular}{|c|c|c|c|c|c|c|c|c|}
\hline & 2010 & & 2014 & & 2015 & & 2018 & \\
\hline CC.AA. & № EXPLOTAC & $\%$ & № EXPLOTAC & $\%$ & № EXPLOTAC & $\%$ & $\begin{array}{c}\text { № } \\
\text { EXPLOTAC }\end{array}$ & $\%$ \\
\hline Andalucía & 172 & 4,34 & 216 & 6,52 & 214 & 6,5 & 417 & 18,56 \\
\hline Aragón & 365 & 9,21 & 263 & 7,93 & 240 & 7,2 & 171 & 7,61 \\
\hline Asturias* & & & & & & & 7 & 0,31 \\
\hline Baleares* & & & 136 & 2,99 & & & 8 & 0,36 \\
\hline Canarias & 213 & 5,37 & 168 & 5,07 & 147 & 4,4 & 102 & 4,54 \\
\hline Cantabria* & & & & & & & 20 & 0,89 \\
\hline Cast-Mancha & 225 & 5,68 & 220 & 6,64 & 501 & 15,1 & 110 & 4,9 \\
\hline Cast y León & 304 & 7,67 & 294 & 8,87 & 285 & 8,6 & 206 & 9,17 \\
\hline Cataluña & 1536 & 38,76 & 1102 & 33,24 & 844 & 25,5 & 609 & 27,1 \\
\hline Extremadura & 200 & 5,05 & 216 & 6,52 & 267 & 8,1 & 41 & 1,82 \\
\hline Galicia & 331 & 8,35 & 286 & 8,63 & 273 & 8,2 & 240 & 10,68 \\
\hline Madrid* & & & & & & & 15 & 0,67 \\
\hline Murcia* & & & & & & & 42 & 1,87 \\
\hline Navarra* & & & & & & & 35 & 1,56 \\
\hline País Vasco* & & & & & & & 33 & 1,47 \\
\hline La Rioja* & & & & & & & 18 & 0,8 \\
\hline C. Valenciana & 248 & 6,26 & 235 & 7,09 & 212 & 6,4 & 173 & 7,7 \\
\hline Resto & 369 & 9,31 & 315 & 9,5 & 331 & 10 & & \\
\hline Total & 3.963 & & 3.315 & & 3.315 & & 2.247 & \\
\hline
\end{tabular}




\subsubsection{Evolución del censo por CC.AA.}

El censo desde junio desde 2010 hasta abril de 2016 ha aumentado en 390.652 animales según indica la tabla 3. Mientras que Andalucía y la Región de Murcia se han mantenido más o menos constantes en sus censos. Aragón, Castilla León y Galicia han aumentado el número de cabezas censadas. Así, cabe destacar el drástico aumento de Aragón que pasa de 148.421 cabezas a 579.660 en 2014, manteniéndose bastante constante desde entonces.

Tabla 3. Evolución del censo por CCAA. (Registro General de Explotaciones Ganaderas (REGA).

\begin{tabular}{lcccccccc}
\hline CC.AA. & JUN-10 & ABR-11 & ABR-12 & ABR-13 & ABR-14 & ABR-15 & ABR-16 & AB-17 \\
\hline Andalucía & 141.219 & 131.231 & 95.933 & 108.285 & 115.386 & 111.958 & 66.149 & 44.140 \\
\hline Aragón & 148.121 & 148.078 & 147.938 & 508.693 & 579.660 & 579.143 & 560.423 & 499.249 \\
\hline Canarias & 91.030 & 79.521 & 65.590 & 59.609 & 54.874 & & & \\
\hline Cast-Mancha & 537.321 & 482.555 & 490.262 & 496.586 & 468.954 & 422.669 & 411.778 & 406.965 \\
\hline Cast y León & 988.866 & 1.038 .557 & 1.121 .578 & 1.055 .173 & 1.067 .218 & 1.254 .380 & 1.408 .714 & 1.389 .692 \\
\hline Cataluña & 1.840 .394 & 1.819 .248 & 1.763 .099 & 1.673 .776 & 1.517 .598 & 1.465 .762 & 1.453 .354 & 1.453 .359 \\
\hline Galicia & 823.898 & 682.826 & 1.105 .603 & 1.194 .207 & 1.191 .410 & 1.237 .935 & 1.090 .954 & 955.527 \\
\hline R. de Murcia & 142.228 & 139.929 & 143.650 & 123.331 & 150.117 & 156.571 & 84.387 & 87.953 \\
\hline C F Navarra & 272.011 & 274.329 & 227.004 & 213.098 & 180.758 & 150.115 & 148.040 & 148.052 \\
\hline C.Valenciana & 653.663 & 661.540 & 679.668 & 687.289 & 653.194 & 640.622 & 591.496 & 564.228 \\
\hline País Vasco & & & & & & 187.401 & 212.606 & 201.300 \\
\hline Resto & 219.597 & 184.941 & 279.789 & 685.285 & 301.456 & 244.425 & 221.099 & 216.719 \\
\hline Total & $\mathbf{5 . 8 5 8 . 3 4 8}$ & $\mathbf{5 . 6 4 2 . 7 5 5}$ & $\mathbf{6 . 1 2 0 . 1 1 4}$ & $\mathbf{6 . 8 0 5 . 3 3 2}$ & $\mathbf{6 . 2 8 0 . 6 2 5}$ & $\mathbf{6 . 4 5 0 . 9 8 1}$ & $\mathbf{6 . 2 4 9 . 0 0 0}$ & $\mathbf{5 . 9 6 7 . 1 8 4}$ \\
\hline & & & & & & & \\
\hline
\end{tabular}

\subsubsection{Evolución de la producción de carne de conejo en España}

La producción de la carne de conejo en España durante los últimos años tuvo su mayor valor en 2012 con 53.411 miles de cabezas sacrificadas (ver tabla 4), aunque desde 2013 se produjo un descenso en 5553 miles de cabezas.

Según la figura 1 la evolución del peso de la canal en toneladas se muestra paralela a la evolución de cabezas sacrificadas, aunque entre 2010 y 2012 hubo un ligero aumento del peso de canal respecto a los años anteriores donde el número de cabezas sacrificadas fue más constante. 
Tabla 4. Evolución de la producción de la carne de conejo en España. (MAPAMA, mayo 2018).

\begin{tabular}{ccc}
\hline AÑOS & $\begin{array}{r}\text { CABEZAS SACRIFICADAS } \\
\text { (miles) }\end{array}$ & PESO CANAL (T) \\
\hline 2008 & 51.435 & 60.960 \\
\hline 2009 & 51.330 & 61.195 \\
\hline 2010 & 52.633 & 63.506 \\
\hline 2011 & 52.668 & 64.139 \\
\hline 2012 & 53.411 & 64.578 \\
\hline 2013 & 52.470 & 62.745 \\
\hline 2014 & 52.327 & 63.790 \\
\hline 2015 & 51.800 & 63.461 \\
\hline 2016 & 48.507 & 59.859 \\
\hline 2017 & 45.882 & 56.782 \\
\hline
\end{tabular}

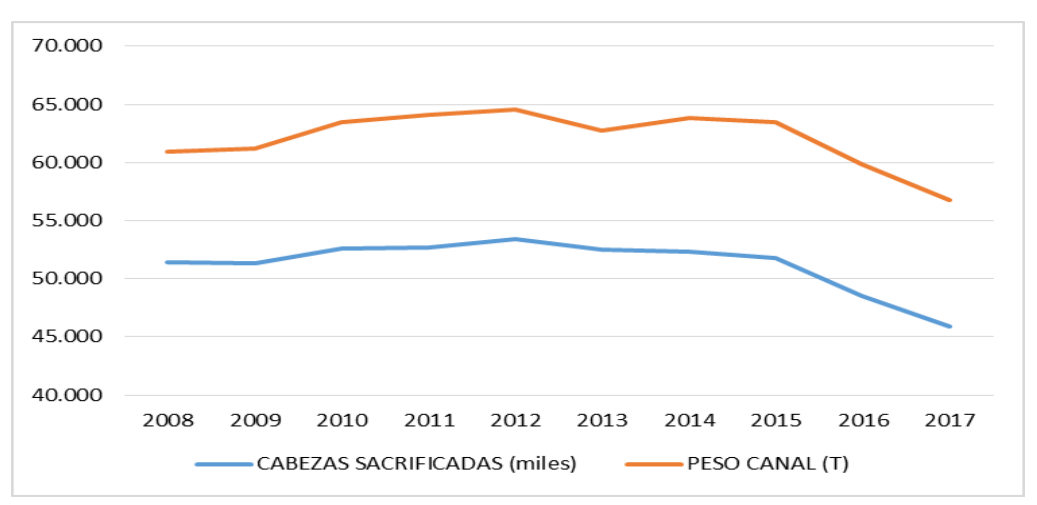

Figura 1. Evolución de la producción de la carne de conejo en España. (MAPAMA, mayo 2018).

\subsection{PRODUCCIÓN DE CARNE DE CONEJO EN ESPAÑA Y LA UNIÓN EUROPEA}

\subsubsection{Evolución de la producción de carne de conejo en la UE}

Dentro de la UE, España ha sido el tercer productor de carne de conejo con un valor de 62,7 miles de toneladas producidas en 2013, llegando a ser el segundo productor en 2015 y 2016 superando a Italia (figura 2).

El primer país productor, Italia, está sufriendo un descenso importante en producción pasando de 130 a 75 miles de toneladas desde 2012.

Francia se mantiene constante en la producción siendo el tercer país productor. 
Tabla 5. Evolución de la producción de carne de conejo en la UE en miles de toneladas. (Estadísticas del MAGRAMA y Comisión de la Unión Europea.)

\begin{tabular}{ccccccccccccc}
\hline PAÍSES & $\mathbf{2 0 0 5}$ & $\mathbf{2 0 0 6}$ & $\mathbf{2 0 0 7}$ & $\mathbf{2 0 0 8}$ & $\mathbf{2 0 0 9}$ & $\mathbf{2 0 1 0}$ & $\mathbf{2 0 1 1}$ & $\mathbf{2 0 1 2}$ & $\mathbf{2 0 1 3}$ & $\mathbf{2 0 1 4}$ & $\mathbf{2 0 1 5}$ & $\mathbf{2 0 1 6}$ \\
\hline Bélgica & 15 & 15 & 12 & 10 & 10 & 10 & 10 & 10 & 10 & 10 & 10 & 7 \\
\hline R.Checa & 27,0 & 25,3 & 23,3 & 20,5 & 18,0 & 16,0 & 12,0 & 6,8 & 9,2 & 9 & 9 & 6 \\
\hline Grecia & 4,8 & 4,8 & 4,8 & 5,0 & 5,0 & 5,0 & 5,0 & 5,0 & 5,0 & 5 & 5 & 4 \\
\hline España & $\mathbf{7 0 , 5}$ & $\mathbf{7 2 , 3}$ & $\mathbf{7 4 , 7}$ & $\mathbf{6 1 , 0}$ & $\mathbf{6 1 , 2}$ & $\mathbf{6 3 , 5}$ & $\mathbf{6 4 , 1}$ & $\mathbf{6 4 , 6}$ & $\mathbf{6 3 , 3}$ & $\mathbf{6 4 , 3}$ & $\mathbf{6 3}$ & $\mathbf{5 9 , 6}$ \\
\hline Francia & 110,0 & 105,0 & 102,0 & 97,0 & 93,0 & 90,0 & 88,5 & 86,0 & 85,5 & 84,5 & 81 & 79 \\
\hline Italia & 138,0 & 125,0 & 132,0 & 132,0 & 130,0 & 130,0 & 130,0 & 130,0 & 75,0 & 65 & 55 & 55 \\
\hline Holanda & 8,0 & 8,0 & 7,0 & 7,0 & 6,0 & 6,0 & 6,0 & 6,0 & 6,0 & 6 & 6 & 4 \\
\hline Polonia & 4,2 & 1,2 & 4,2 & 4,2 & 4,2 & 4,2 & 1,2 & 4,2 & 4,2 & 4,2 & 4,2 & 3 \\
\hline Eslovaquia & 3,6 & 3,6 & 3,6 & 3,6 & 3,6 & 3,6 & 3,6 & 3,6 & 3,6 & 3,6 & 3,6 & 1,3 \\
\hline Resto & 0,2 & 0,1 & 0,1 & 0,2 & 0,2 & 0,3 & 0,2 & 0,2 & 0,2 & 0,2 & 5,8 & $-2,8$ \\
\hline U.Europea & $\mathbf{3 8 1 , 3 0}$ & $\mathbf{3 6 0 , 3 0}$ & $\mathbf{3 6 3 , 7 0}$ & $\mathbf{3 4 0 , 5 0}$ & $\mathbf{3 3 1 , 2 0}$ & $\mathbf{3 2 8 , 6 0}$ & $\mathbf{3 2 0 , 6 0}$ & $\mathbf{3 1 6 , 4 0}$ & $\mathbf{2 6 2 , 0 0}$ & $\mathbf{2 5 1 , 8 0}$ & $\mathbf{2 4 2 , 6 0}$ & $\mathbf{2 1 6 , 1 0}$ \\
\hline
\end{tabular}

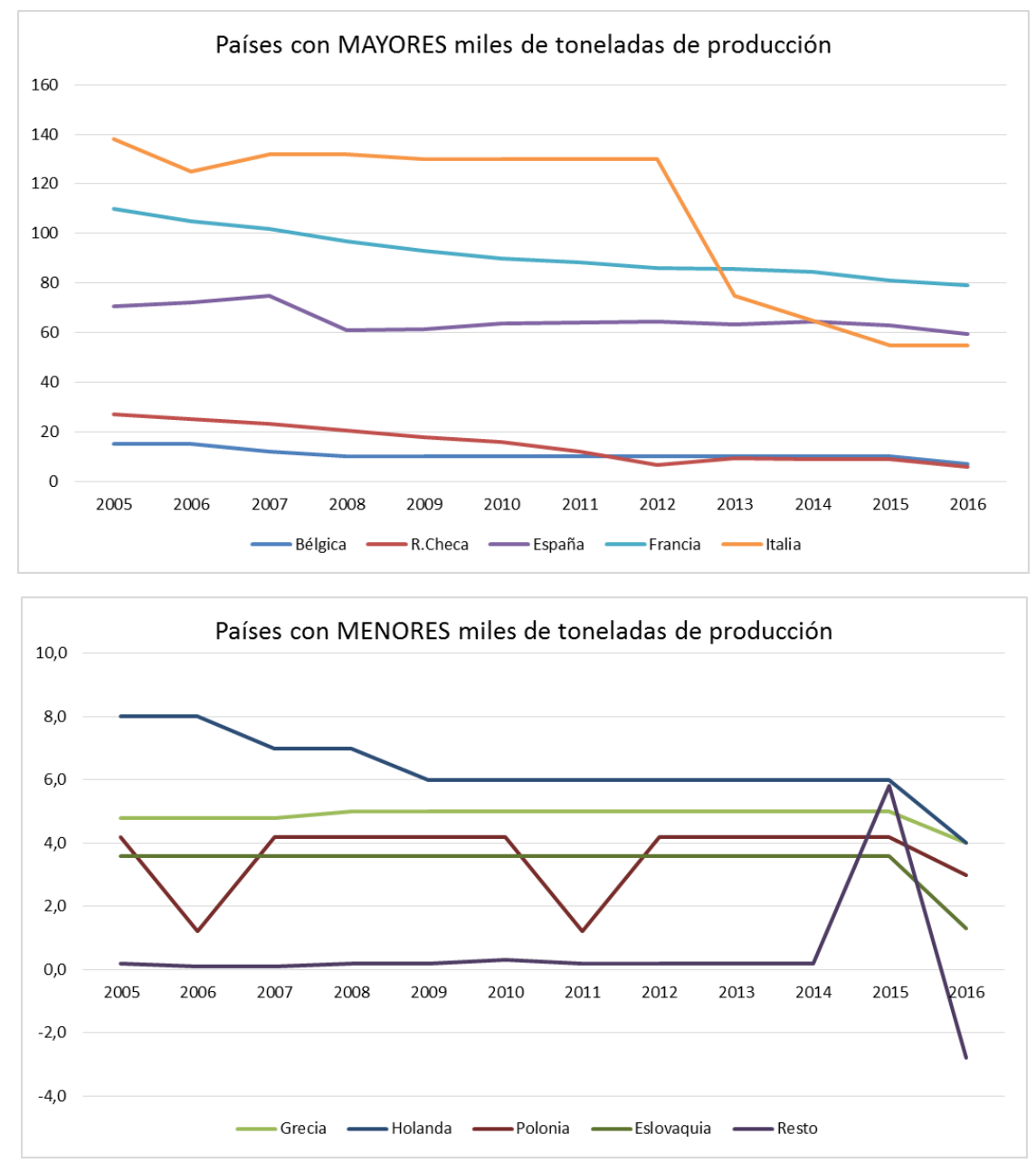

Figura 2. Evolución de la producción de carne de conejo en la UE en miles de toneladas. (Estadísticas del MAGRAMA y Comisión de la Unión Europea.) 


\subsection{COMERCIO EXTERIOR DE ESPAÑA EN EL SECTOR DE LA CARNE DE CONEJO}

\subsubsection{Comercio español en el sector cunícola 2008/2017}

Tradicionalmente el saldo del comercio exterior en el sector cunícola español es, en conjunto, positivo. Ahora bien, en los últimos años el valor absoluto de dicho saldo ha disminuido gradualmente. Desde 2008 hasta 2017, el número total de importaciones ha aumentado paulatinamente, excepto en 2015 que las importaciones fuera de la UE descendieron.

Desde 2008 a 2017 han aumentado en 13131 toneladas las exportaciones totales.

Cabe destacar que en 2011 hubo un descenso en las exportaciones tanto a la UE como a países terceros. La situación en los últimos años de las exportaciones es más o menos constante.

Tabla 6. Evolución del comercio español en el sector cunícola 2008/2017 en toneladas de carne (MAPAMA, mayo 2018)

\begin{tabular}{ccccccc}
\hline AÑO & IMPORT. UE & IMPORT. EXTRAUE & IMP. TOTAL & \multicolumn{1}{l}{ EXP. UE } & EXP. EXTRAUE & EXP. TOTAL \\
\hline $\mathbf{2 0 0 8}$ & 2.195 & 575 & 2.770 & 8.030 & 721 & 8.751 \\
\hline $\mathbf{2 0 0 9}$ & 1.578 & 716 & 2.294 & 6.668 & 741 & 7.409 \\
\hline $\mathbf{2 0 1 0}$ & 1.470 & 385 & 1.855 & 12.920 & 691 & 13.677 \\
\hline $\mathbf{2 0 1 1}$ & 1.519 & 274 & 1.793 & 10.306 & 713 & 11.019 \\
\hline $\mathbf{2 0 1 2}$ & 2.347 & 375 & 2.721 & 18.781 & 725 & 19.506 \\
\hline $\mathbf{2 0 1 3}$ & 2.371 & 222 & 2.593 & 20.557 & 567 & 21.124 \\
\hline $\mathbf{2 0 1 4}$ & 2.853 & 190 & 3.042 & 22.942 & 1.227 & 24.170 \\
\hline $\mathbf{2 0 1 5}$ & 1.830 & & 1.830 & 20.817 & 665 & 21.482 \\
\hline $\mathbf{2 0 1 6}$ & 2.133 & 17 & 2.150 & 22.634 & 709 & 23.343 \\
\hline $\mathbf{2 0 1 7}$ & 4.181 & 30 & 4.212 & 21.130 & 752 & 21.882 \\
\hline
\end{tabular}




\subsection{BALANCE DE ABASTECIMIENTO DE CARNE DE CONEJO EN ESPAÑA}

\subsubsection{Evolución del consumo aparente per cápita y del abastecimiento de carne de}

\section{conejo en España}

La evolución del consumo aparente per cápita en kilogramos ha sufrido un descenso pronunciado desde el siglo anterior. Sin embargo, en los últimos años el consumo es bastante constante, con valores en torno a 1,3 kilogramos por habitante y año. Además, el porcentaje de autoabastecimiento no ha sufrido un cambio tan pronunciado y alcanzó en 2014 el 114,2\%.

Tabla 7. Evolución del consumo aparente per cápita en kilogramos y porcentaje del abastecimiento de carne de conejo en España (MAGRAMA, mayo 2018)

\begin{tabular}{ccc}
\hline AÑO & $\begin{array}{c}\text { CONSUMO (KG/HABY } \\
\text { AÑO) }\end{array}$ & $\begin{array}{c}\text { ABASTECIMIENTO } \\
(\%)\end{array}$ \\
\hline 2004 & 1,6 & 106,4 \\
\hline 2005 & 1,50 & 105,40 \\
\hline 2006 & 1,6 & 104,5 \\
\hline 2007 & 1,60 & 104,50 \\
\hline 2008 & 1,3 & 103,5 \\
\hline 2009 & 1,3 & 102,70 \\
\hline 2010 & 1,3 & 105,9 \\
\hline 2011 & 1,3 & 104,80 \\
\hline 2012 & 1,3 & 110,8 \\
\hline 2013 & 1,2 & 112,1 \\
\hline 2014 & 1,2 & 114,2 \\
\hline 2015 & 1,2 & 114,1 \\
\hline 2016 & 1,3 & 113,4 \\
\hline 2017 & 1,2 & 110,5 \\
\hline
\end{tabular}

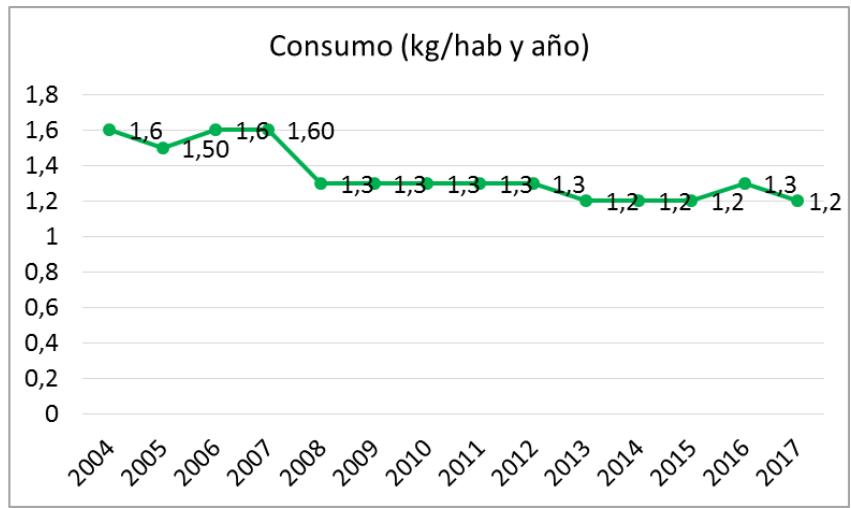

Figura 3. Evolución del consumo aparente per cápita en kilogramos en España (MAGRAMA, mayo 2018) 


\subsection{EVOLUCIÓN SEMANAL DEL PRECIO DE CONEJO EN ESPAÑA}

La producción del conejo es un sector marcado por la estacionalidad (figura 4), en el que durante una parte del año, cuando hay exceso de oferta, vende por debajo de costes, pero cuando hay más demanda que oferta, compensa sus costes con la subida de los precios.

Nuestro trabajo surgió en 2012, ya que el sector cunícola iba arrastrando aproximadamente desde septiembre de 2010 un incremento en los costes de producción debido fundamentalmente a la subida del precio de los cereales registrado en los mercados. En 2012 hubo un claro descenso del precio de venta en el segundo semenstre del año. Estas subidas y bajadas son un reflejo de los incrementos y descensos del precio del cereal; así como del precio que fijen las cadenas de distribución (que no es fácil de predecir).

Los costes de producción de los ganaderos cunícolas se sitúan en torno a los 1,8 euros el kilogramo, y a lo largo del año el precio de venta del mismo oscila entre los 1,4 -1,5 euros el kilo de mínimo y los 1,9 -2,1 euros de máximo. El año actual está siendo muy paralelo en precio por semanas al año anterior, aunque a partir de la semana 21 hubo un aumento del precio que se mantuvo constante hasta la semana 34.

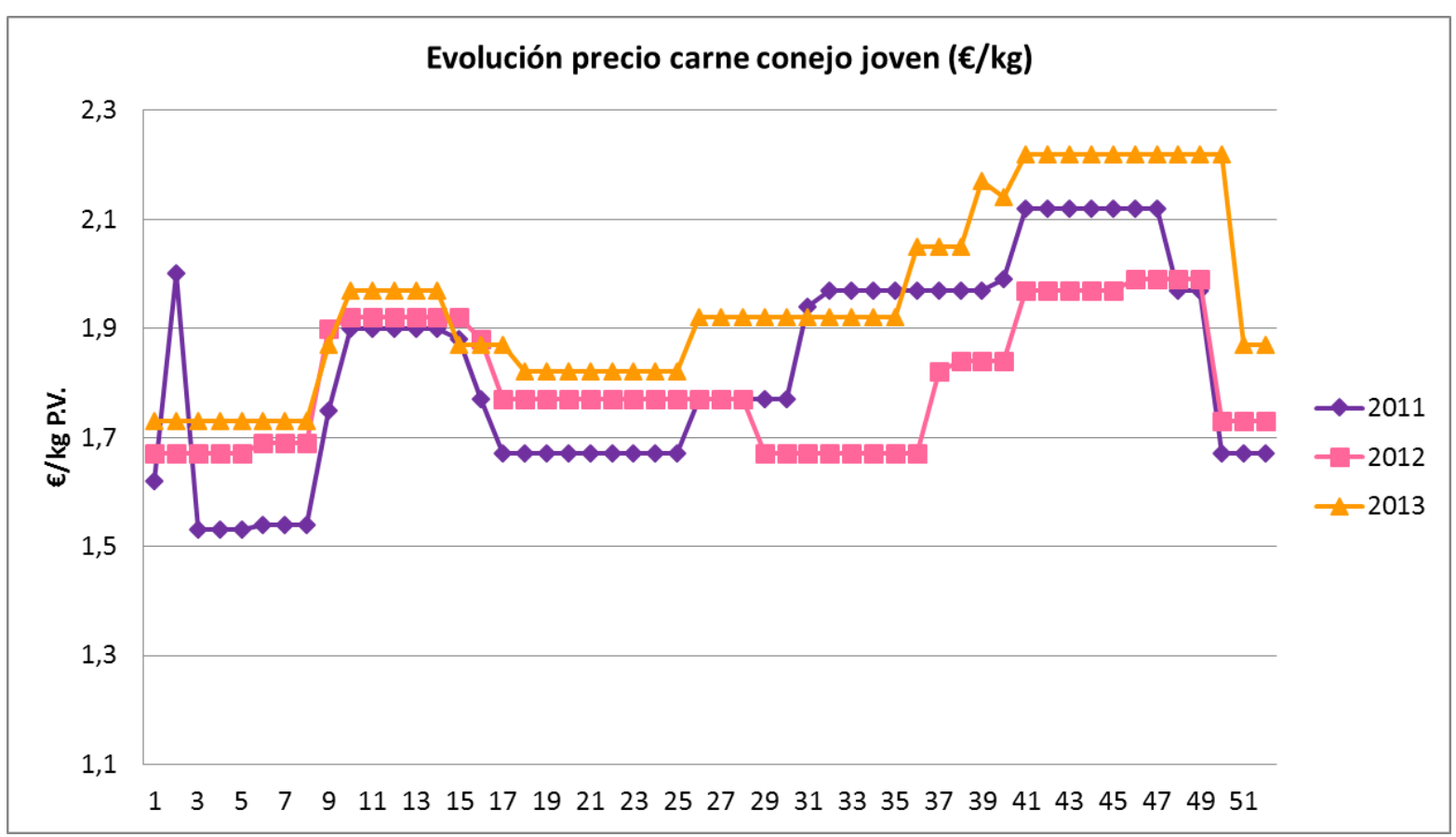




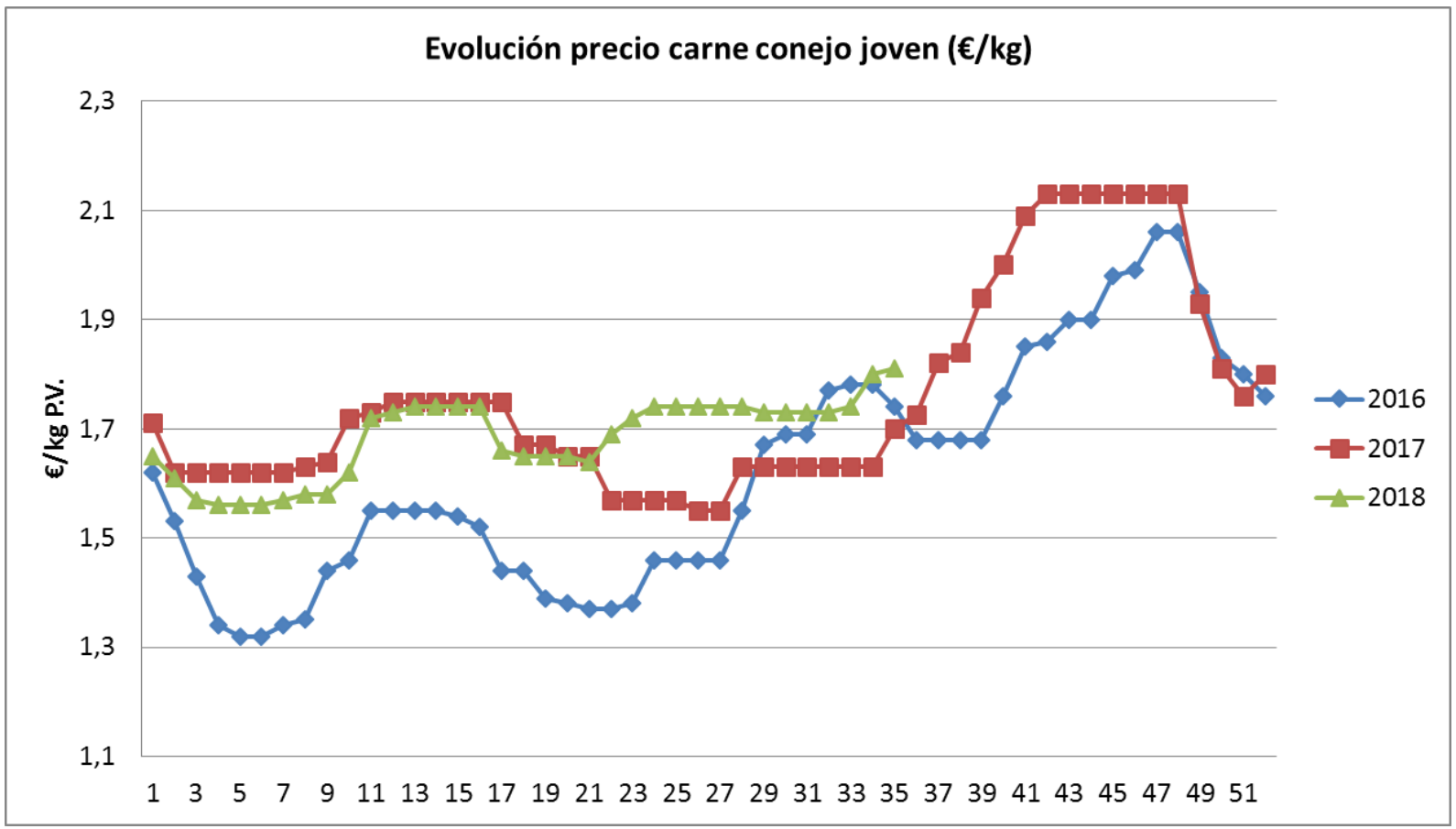

Figuras 4a y 4b. Evolución semanal del precio de carne de conejo joven (€ /kg carne) (ASESCU, septiembre 2018)

La bajada en los precios de venta también se ve influida por el consumo, como vemos en la figura 5. Desde 2011 hasta 2016 el consumo en los hogares españoles ha descendido paulatinamente en un 9,3\%. 


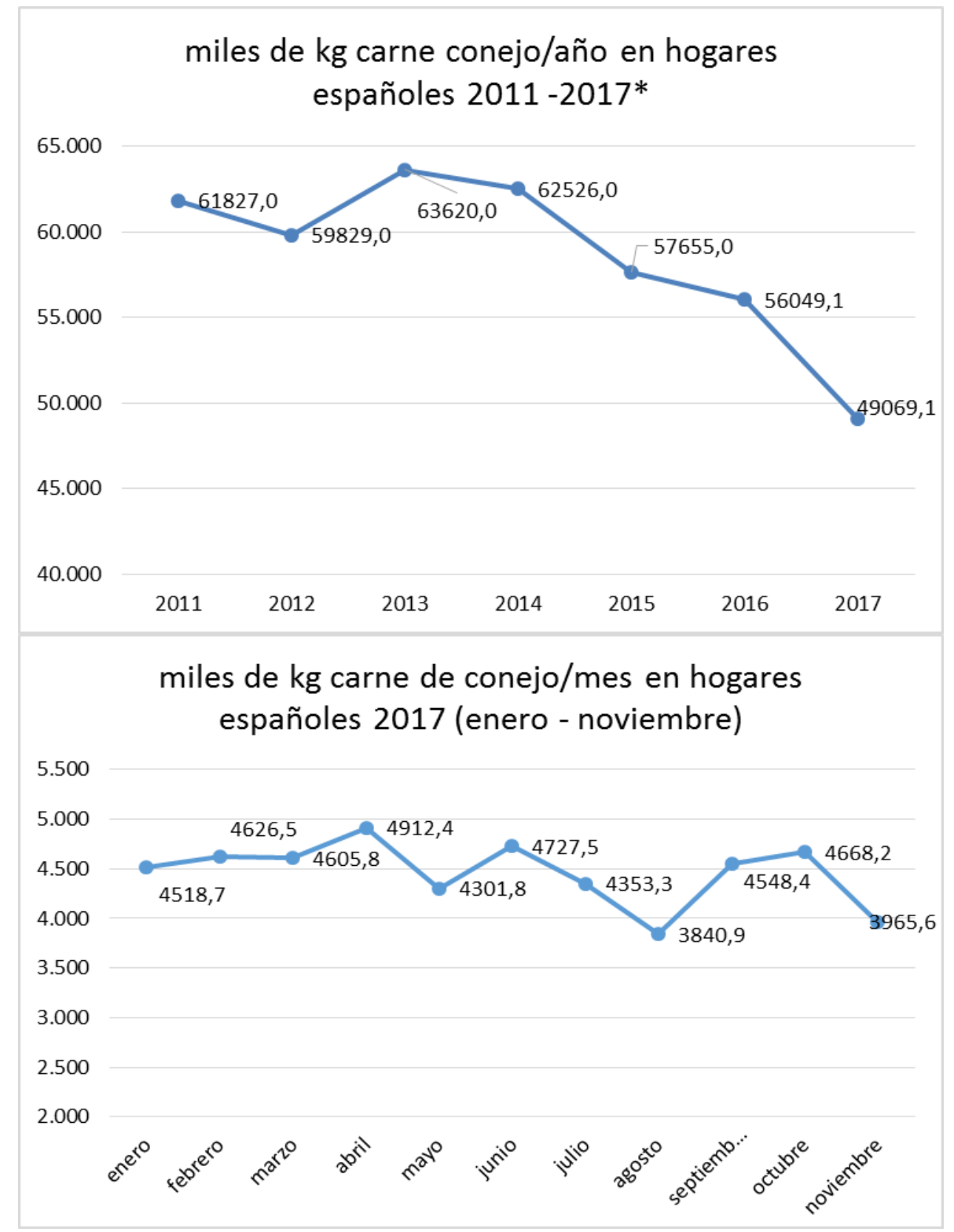

Figura 5. Evolución anual y mensual de los kg de carne conejo consumido en hogares españoles. Año 2017* de enero a noviembre.

\subsection{MERCADO POTENCIAL}

A pesar de que la carne de conejo se considera como una producción menor dentro del conjunto de la ganadería comunitaria, es un sector que tiene una gran importancia para la sostenibilidad económica y el desarrollo de aquellas zonas rurales de España donde se concentra su producción y consumo.

El producto admite un gran abanico de aplicaciones en cuanto a su formato hacia el consumidor y comporta además ventajas nutricionales en comparación con otros tipos de carne. 
Los consumidores de carne de conejo se muestran especialmente de acuerdo con que es un alimento muy saludable, bajo en calorías, fácil de digerir y que tiene un bajo contenido en colesterol.

En particular, comparando la carne de conejo con otros tipos, las ventajas que se asocian al conejo coinciden en gran medida con las características que se identifican con este tipo de carne:

- Es rico en ácidos omega 3, que permite reducir el riesgo de padecer enfermedades cardiovasculares.

- Es una carne con bajo contenido en colesterol.

- Posee importantes minerales como el hierro, el zinc y el magnesio.

- Tiene un alto contenido en vitaminas del grupo B, tales como la cianocobalamina (B12), la niacina (B3) y la piridoxina (B6).

- Sus proteínas, de alto valor biológico, son necesarias en todos los periodos de la vida.

- Es una carne de fácil digestibilidad, pobre en colágeno y baja en grasa.

- Tiene muy bajo contenido en sodio.

- Es baja en calorías. Contiene alrededor de $133 \mathrm{kcal}$ por cada $100 \mathrm{~g}$.

- Es un alimento con una gran versatilidad gastronómica, ya que admite una amplia variedad de formas de preparación.

\subsubsection{Características generales del mercado (tipo de cliente, motivación de compra,}

\section{segmentación del mercado al que se dirige: distribuidor, mayorista, cliente final)}

Según el Estudio de mercado "Observatorio del consumo y distribución alimentariamonográfico de conejo" realizado por el Ministerio Agricultura, Pesca y Alimentación (2008) por sexo, las mujeres consumen más carne de conejo que los hombres (figura 6). Por edad, los mayores de 46 años son los que más consumen alcanzando el porcentaje más alto (72,5\%) en el caso de los mayores de 66 años. 


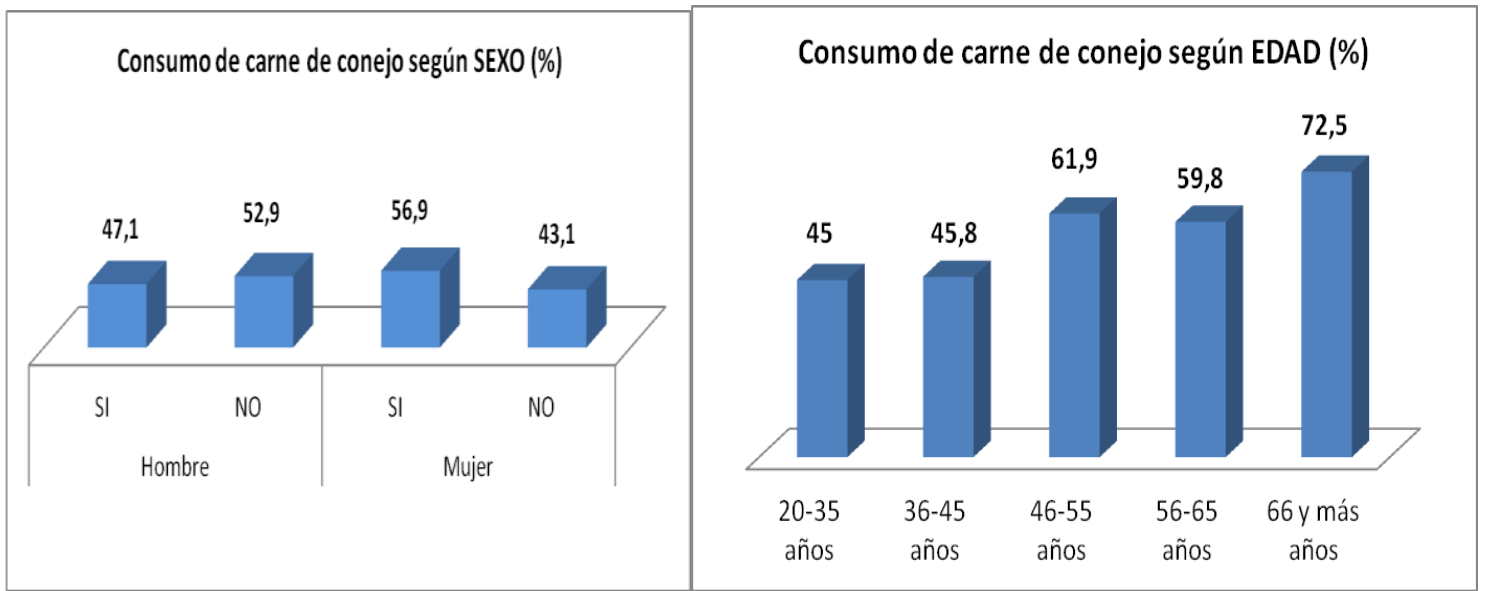

Figura 6. Consumo de carne de conejo según el sexo y la edad. (MAPA, 2008)

Por hábitat, las poblaciones con menos de 10.000 habitantes son las que presentan el consumo más elevado mientras que las poblaciones con más de 100.000 habitantes las que menos consumo presentan. El principal motivo para consumir este tipo de carne es el sabor.

En cuanto a la frecuencia de consumo, 6 de cada 10 consumidores de carne de conejo la toma como mínimo 2 veces al mes (figura 7).

Por sexo, los hombres la toman con más frecuencia que las mujeres. Por edad, los más mayores son los que lo consumen más a menudo.

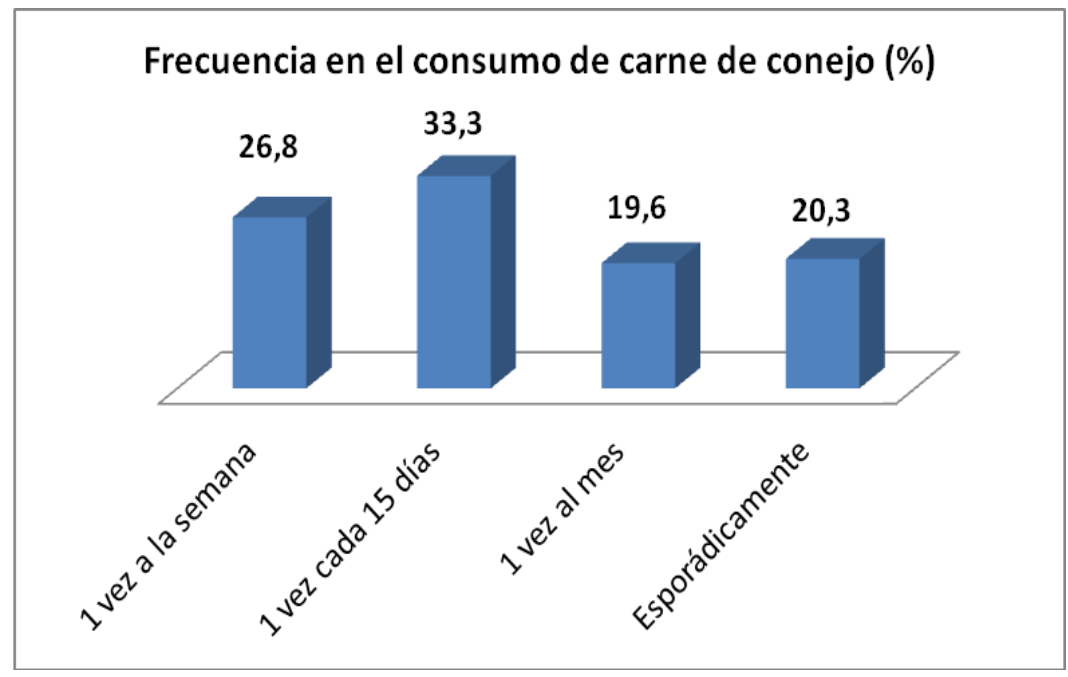

Figura 7. Frecuencia en el consumo de carne de conejo (MAPA, 2008)

La carne de conejo se consume a lo largo de todo el año, no hay una estación específica donde se dispare su consumo. 
Respecto a los establecimientos donde principalmente se adquiere esta carne, en 2008 se vio que donde más se adquiría era en tiendas de barrio (figura 8), seguidos del supermercado y el mercado.

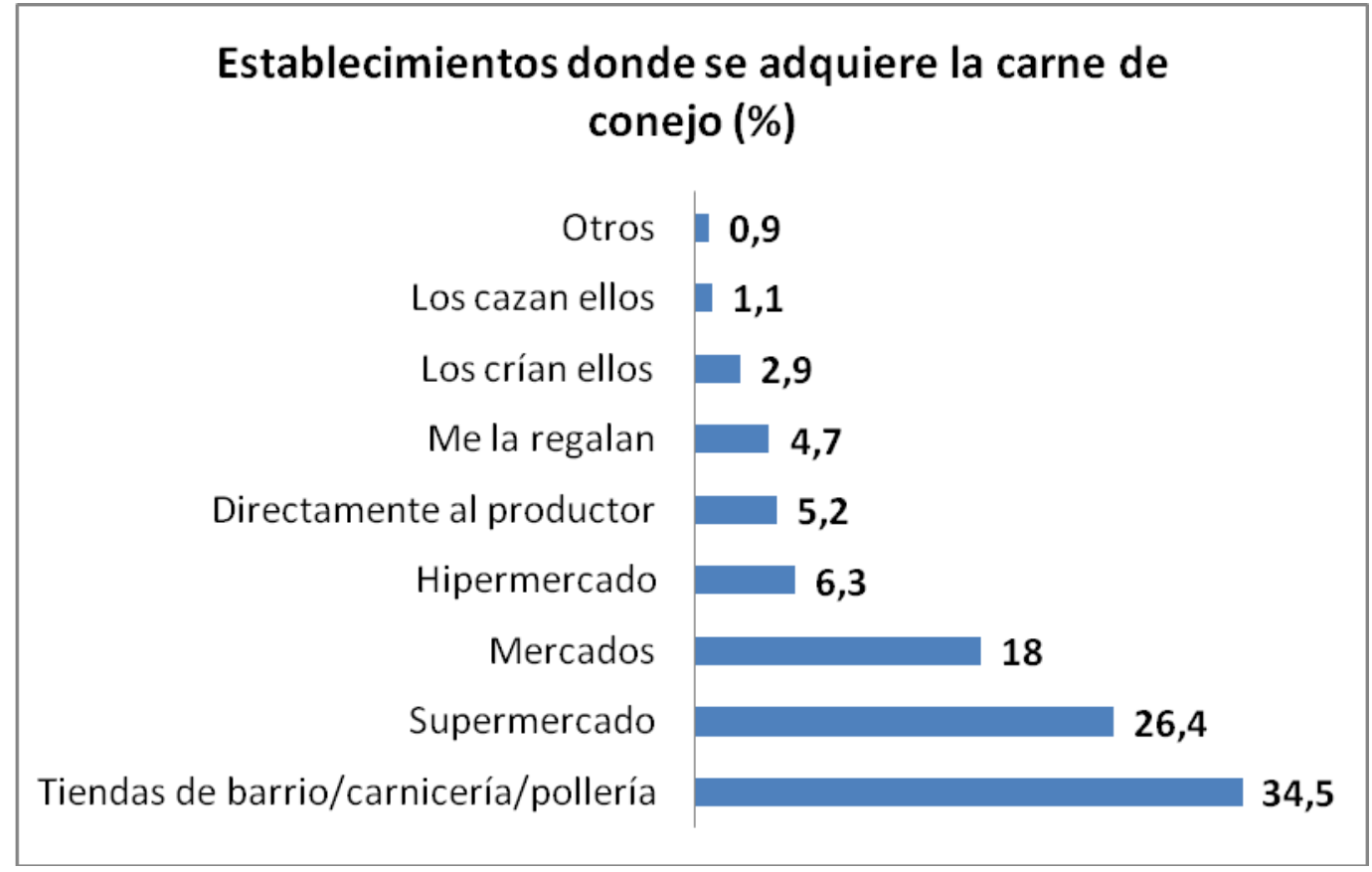

Figura 8. Establecimientos donde se adquiere la carne de conejo (MAPA, 2008)

En el último estudio del MAPAMA (2015) sobre los establecimientos con más cuota de mercado, hubo algunos cambios (figura 9). En este intervalo de 6-7 años el establecimiento que más vendió carne de conejo fue el supermercado/autoservicio con un $39,6 \%$ de volumen de ventas, con lo que ha pasado de un segundo a un primer puesto, mientras que las tiendas de barrio (carnicerías/charcuterías) se han convertido en la segunda plataforma principal de venta de esta carne, aunque el volumen de ventas ha pasado de $34,6 \%$ a $15,6 \%$. Los mercados y plazas también disminuyeron sus ventas desde un $18 \%$ a $5 \%$. Además, se ha incorporado con fuerza el autoconsumo o compra por internet, siendo la tercera forma de adquirir la carne de conejo, lo que refleja los hábitos de compra de la sociedad actual. 


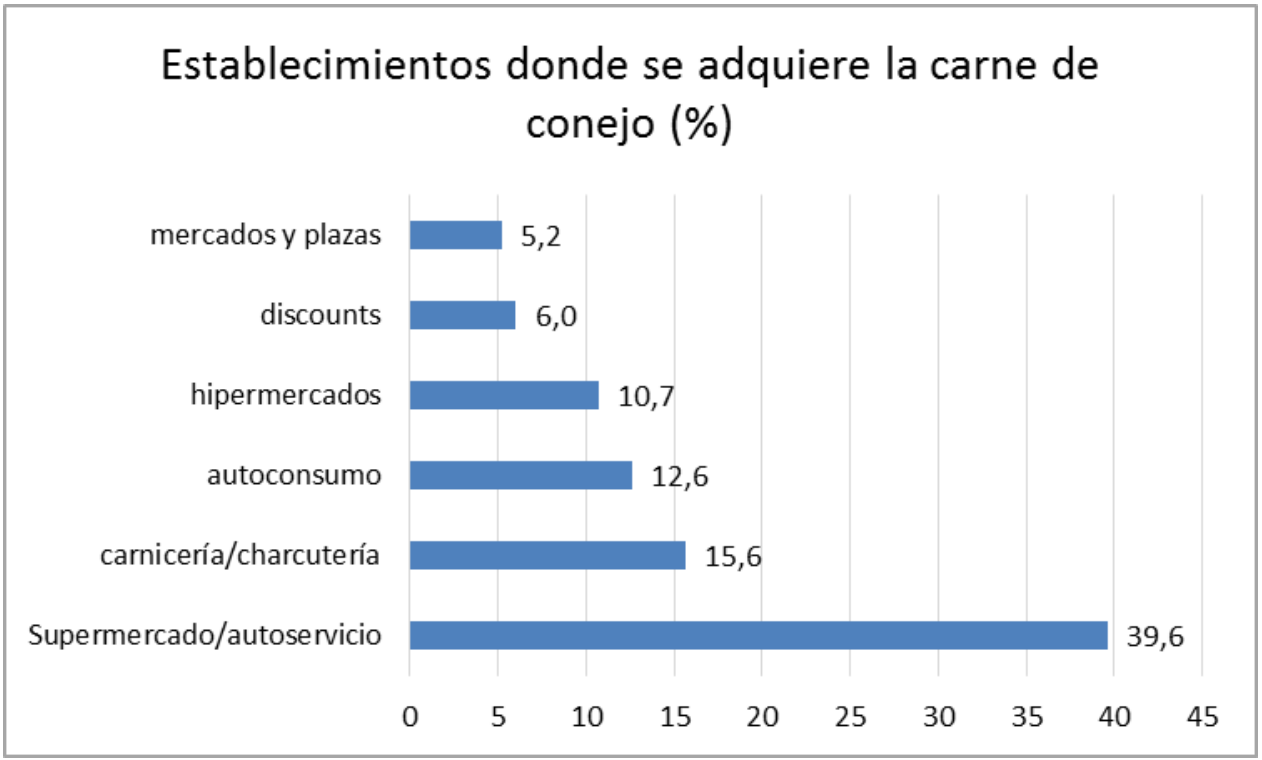

Figura 9. Establecimientos donde se adquiere la carne de conejo (MAPAMA, 2017 - datos 2014 y 2015)

El aspecto de la pieza y el precio son los principales factores que influyen en la elección de este producto. Los formatos preferidos en que se adquiere son el conejo entero y el conejo entero troceado. Esto se debe a que muchos consumidores no conocen otro formato de venta de esta carne. Casi 7 de cada 10 consumidores de carne de conejo la adquiere al corte, en establecimientos con mostrador y atención del carnicero. Los resultados son homogéneos por edad, aunque el mayor consumo de carne en bandejas lo encontramos entre los consumidores con edades entre 36 y 45 años.

Los últimos datos sobre el formato de venta de la carne de conejo (figura 10) reflejan que el más vendido era el conejo entero, seguido de la canal troceada, las tendencias de mercado nos hacen disponer hoy día en algunos establecimientos habituales de formatos nuevos (canal troceada en bandejas, muslos...incluso hamburguesas, salchichas y brochetas) que hacen la cocina más fácil y atrevida. 


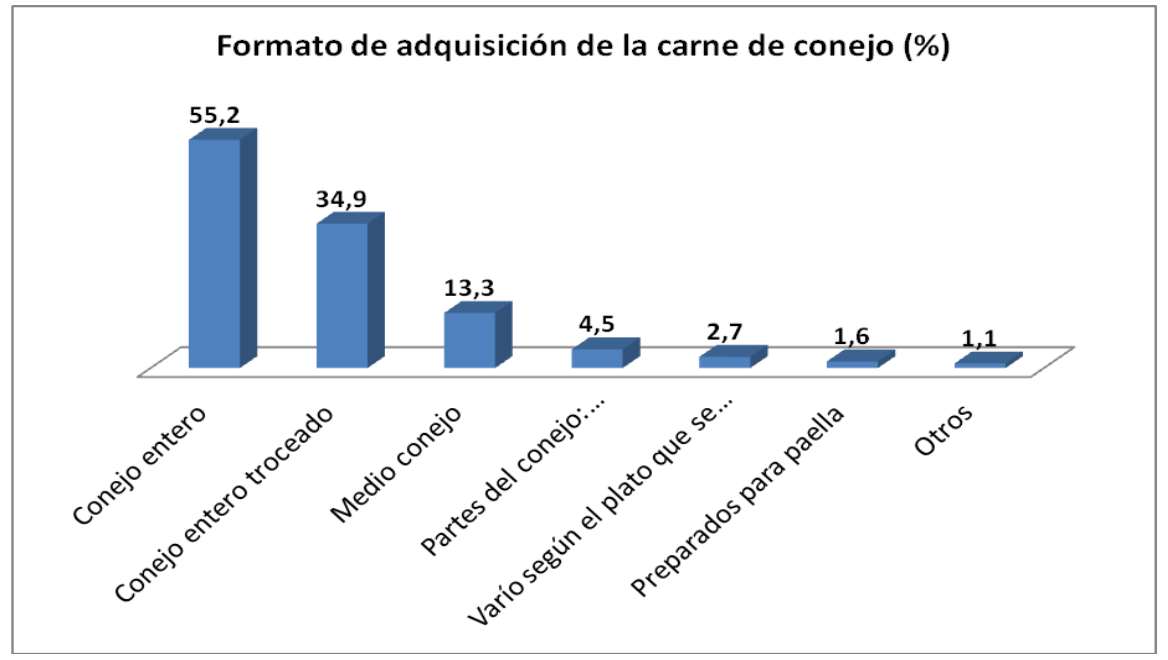

Figura 10. Formatos de adquisición de la carne de conejo (\%) (MAPA, 2008)

En una sociedad donde los problemas cardiovasculares y la obesidad, han aumentado considerablemente, es donde la carne de conejo es más necesaria que nunca. En una sociedad con una creciente preocupación por incluir en su día a día productos saludables, resulta paradójico que todos los parámetros de consumo de carne de conejo estén registrando una evolución negativa. En apenas una década se ha pasado de un consumo, en el año 2008, de 63.872 toneladas, a las 56.049 toneladas consumidas en el 2016. Además, en este mismo periodo, el consumo per cápita en España de la carne de conejo ha bajado desde los 1,46 kg/hab/año hasta los 1,27 kg/hab/año (Ministerio de Agricultura y Pesca, Alimentación y Medio Ambiente).

De ahí que la Unión Europea ante esta situación y el presente descenso del consumo de esta carne haya hecho una apuesta importante para animar a los consumidores a redescubrir la carne de conejo, sobre todo en España y Portugal. (http://ecomercioagrario.com/la-carne-de-conejo-reclama-su-presente-y-apuesta-porsu-futuro 16 mayo 2018).

\section{BASE ANIMAL}

El conejo pertenece a la Clase Mammalia, al Orden Lagomorpha y a la Familia Leporidae, presentando aun siendo de distinta raza, características morfológicas más o menos uniformes y características productivas bien diferenciables que veremos a continuación. 
Según Buxadé, en el grado en que las distintas razas de conejo tengan características productivas bien definidas serán de utilidad para el cunicultor a la hora de elegir los animales en los que basar su producción.

Las características para la producción presentan sus principales diferencias en las capacidades de: crecer más o menos rápido, aprovechar el pienso con más o menos eficiencia, reproducirse con más o menos intensidad y resistir mejor o peor los medios adversos.

Por tanto, los múltiples cruces genéticos son para perfeccionar estas características productivas para obtener producciones máximas. Así, la multitud de razas puras obtenidas se clasifican según su aptitud, diferenciándose en razas productoras de piel y razas productoras de pelo. No obstante, algunas razas son consideradas de doble aptitud, siendo éste el caso de las productoras de piel y pelo, ya que además se aprovecha su carne.

También suelen clasificarse por su tamaño; en primer lugar se encuentran las razas gigantes (en las que los adultos presentan un peso vivo mínimo de $5 \mathrm{~kg}$ ), luego las razas medianas (cuyo peso mínimo varía de 2,5 a 3,5) y por último, razas pequeñas (que no alcanzan los $2,5 \mathrm{~kg}$ de peso vivo).

De la gran variedad de razas existentes de conejos, son las razas de tamaño mediano las que tienen usos comerciales para la reproducción debido a su alta prolificidad, y razas grandes son las que se usan como sementales debido a su alto índice de crecimiento.

Los esquemas de selección en conejos se basan en cruzamientos a tres vías, en el que se seleccionan dos líneas para el tamaño de la camada y se cruzan para producir una hembra híbrida, y se selecciona una línea por crecimiento (ganancia media diaria) para producir los machos terminales del cruzamiento. Las líneas seleccionadas por tamaño de camada las llamamos de aptitud maternal y las seleccionadas por crecimiento de aptitud cárnica.

A continuación, se muestran las principales líneas genéticas de conejos clasificadas según aptitud. 


\subsection{RAZAS DE APTITUD MATERNAL}

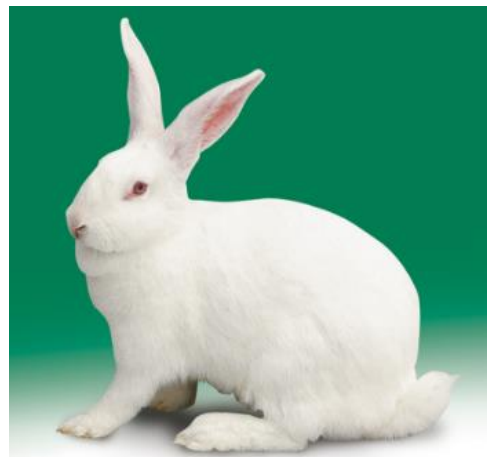

Hyla NG (New Generation): La hembra HYLA, se caracteriza por una prolificidad equilibrada. Su tamaño y su capacidad de ingestión le permiten optimizar sus aptitudes lecheras para obtener gazapos pesados y resistentes al destete. Responde a una alta prolificidad. № gazapos vivos /camada: 8,5-10,5. № gazapos

destetados/camada: 8,5-9,5. Peso al destete: 995 -1090 g.

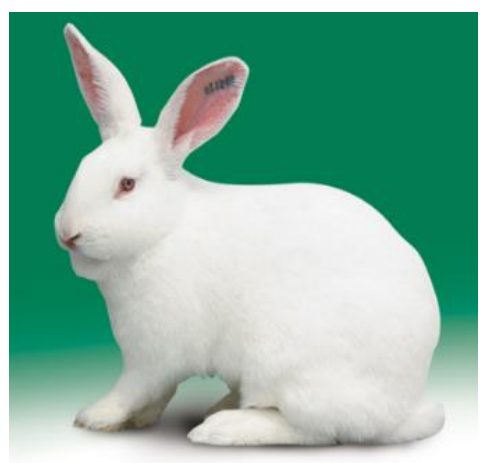

Hyla GP: La hembra HYLA GP cruzada con el macho GP, produce las conejas Hyla GP en la propia explotación. Incrementa la fertilidad de HYLA NG ya que tiene un cuerpo más fuerte y más resistente a las enfermedades, demostrando ser más fértil en un $0,8 \%$. № gazapos vivos /camada: 9,5-10,5. № gazapos destetados/camada: 8,5 -

9,5. Peso al destete: $995-1090 \mathrm{~g}$.

\section{Líneas de la Universidad Politécnica de Valencia}

La línea Amarilla o A: es una línea sintética cuyo origen es la raza Nueva Zelanda, La línea Verde o V: línea sintética procedente del cruce de las razas de Nueva Zelanda y California

Ambas son de capa blanca y seleccionadas por tamaño de camada al destete.

\section{Líneas del Instituto de Investigación y Tecnología Agroalimentarias (IRTA)}

La línea del Prat: es una línea sintética de capa blanco seleccionada por tamaño de camada al destete. 


\subsection{RAZAS DE CARNE}

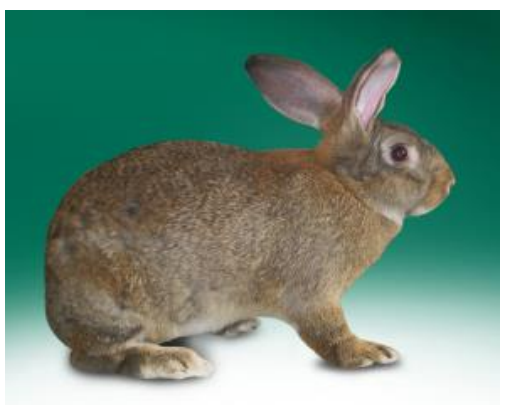

Hyla colored: Macho de color con ojos negros, para la producción cárnica, con óptimo crecimiento y rendimiento canal.

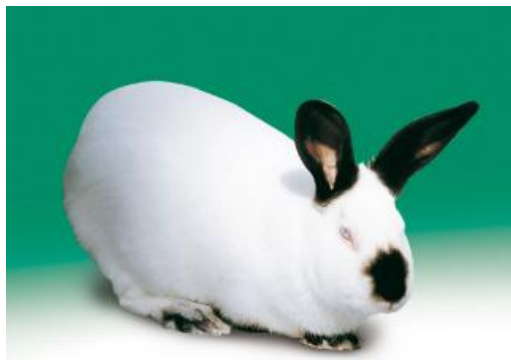

Hyla MAX: El macho Hyla, seleccionado para optimizar el rendimiento canal y el crecimiento es el cruce ideal con sus hembras para obtener gazapos pesados a la venta. Rendimiento canal: 57-59 \%. Peso al destete: 995-1090 g. Peso a los 70 días: 2505-2635 g

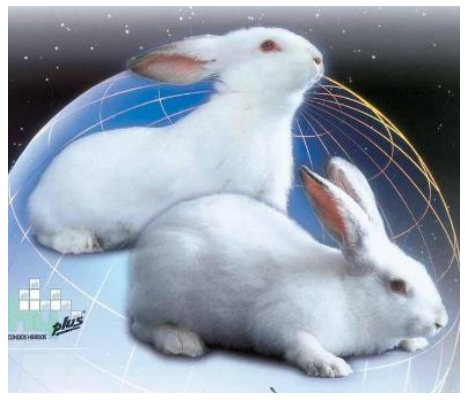

Grimaud: Pelaje gris, ojos negros, madurez sexual a las 22 semanas. Peso a los 77 días: $3300-3400$ g. Rendimiento canal: $59-60 \%$

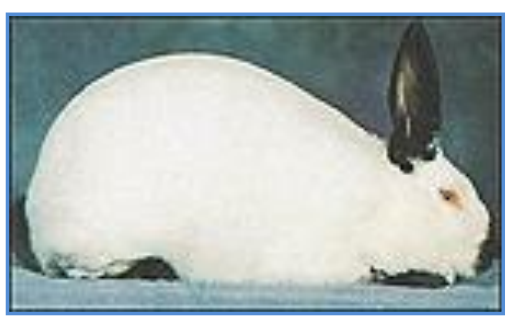

Californiano: Peso adulto desde 3,4 a 4,3 kg. Capa de color blanco excepto en el hocico, orejas, patas y cola negra. La cabeza es redondeada con el cuello corto. Las orejas son largas, erectas y redondeadas en el extremo. Ojos de color rosa. Las hembras pueden presentar ligera papada. Raza de carne de muy buena calidad.

\section{Líneas de la Universidad Politécnica de Valencia}

La línea rosa o R: línea sintética de capa blanca formada mediante cruzamientos de híbridos comerciales utilizados como machos terminales, seleccionada por tasa de crecimiento entre el destete ( 4 a semana) y sacrificio (9a semana) de vida. 


\section{Líneas del Instituto de Investigación y Tecnología Agroalimentarias (IRTA)}

La línea Caldes: es una línea sintética de color blanco seleccionada por ganancia media diaria. En la actualidad se ha dividido en tres líneas seleccionadas por eficiencia alimentaria: línea RFI (seleccionada para menor residual feed intake), ADGR (seleccionada por mayor average daily gain cuando los animales son racionados) y GRP (seleccionada por RFI del grupo)

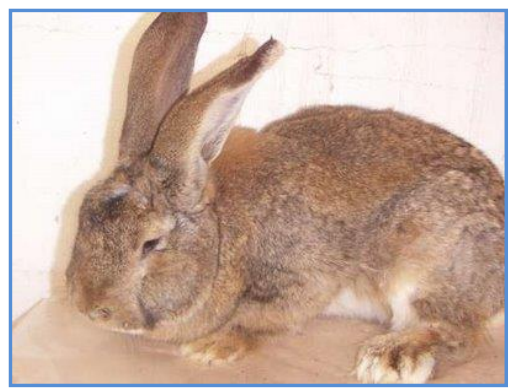

Gigante de España: Peso, 5-8 kg. Capa color leonado, sedosa; existe una variedad blanca. Cabeza grande, gruesa y acarenada. Orejas largas y anchas, derechas y terminadas en punta. Ojos de color pardo. Las hembras presentan ligera papada. № gazapos vivos al destete: 7-8. Rendimiento canal $>60 \%$.

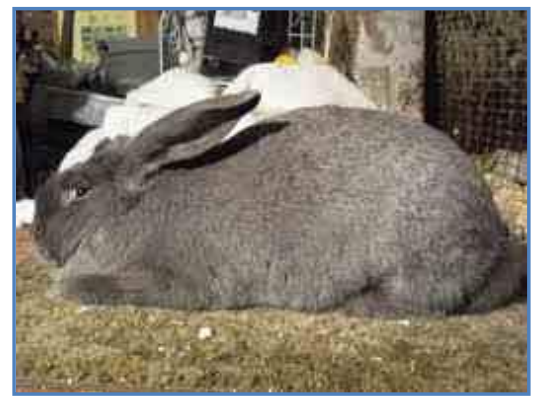

Gigante de Flandes: Peso, 6-8 kg. Pelo corto, liso, capa color gris-marrón, cambiando con las distintas variedades existentes. Cabeza redondeada. Orejas largas $y$ anchas, en forma de $\mathrm{V}$ con puntas redondeadas; erguidas. Papada imperceptible en el macho y ligera en la hembra. Esta raza no se utiliza para la producción industrial, dado que su carne es algo fibrosa, además su crecimiento es lento y son animales poco rústicos. Se utiliza como raza mejoradora de tamaño.

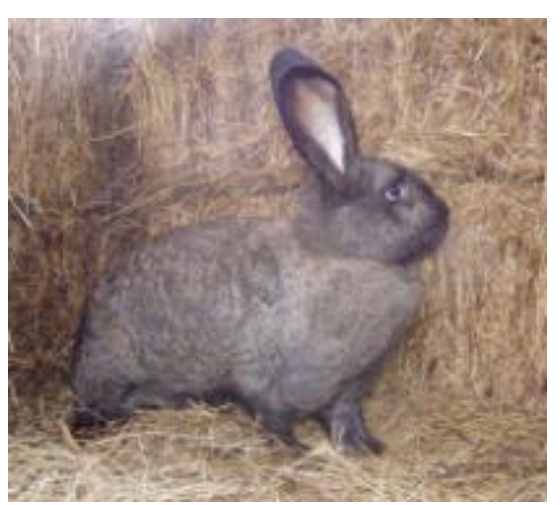

Gigante húngaro: Esta raza evolucionó a partir de la cría intencional de conejos salvajes hace unos doscientos años. Alta fertilidad y buena descendencia. Su desarrollo de la carne y la capacidad de conversión de alimento están por detrás de las razas híbridas actuals, pero hay un programa de mejora genética en desarrollo. Peso

adulto de 5 a $7 \mathrm{~kg}$. 


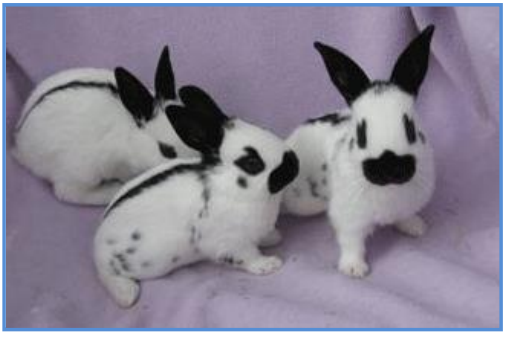

Mariposa Francés: Peso, 3,5-4 kg. La capa es blanca de fondo con manchas negras, en el lomo en forma de raya; tiene un círculo alrededor de los ojos y una mancha en la nariz en forma de mariposa. Las orejas son negras. El cuarto trasero del animal está lleno de manchas negras, que se extienden por todo el cuerpo. Ojos de color castaño. Orejas anchas muy gruesas y erguidas y algo separadas. Papada muy desarrollada. Existen además las variedades inglesa y suiza.

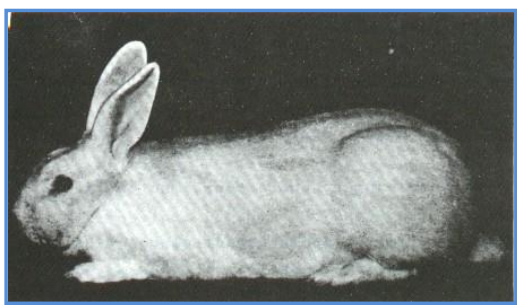

Neozelandés: Peso, 4-5 kg. Capa blanca, pelo suave brillante, piel tupida y suave. Cabeza redondeada con cuello corto. Orejas redondeadas en el extremo y erguidas. Ojos con iris de color rosa. Las hembras pueden presentar una papada mediana. Su producción es básicamente cárnica, pero su piel es comercializable.

\subsection{RAZAS PRODUCTORAS DE PIEL}

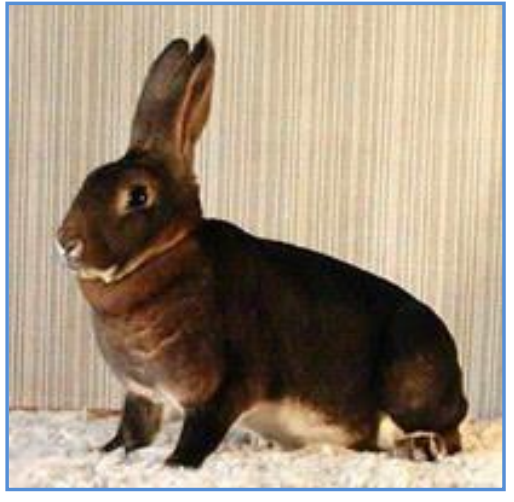

Castores: Peso, 3-5 kg. La cabeza del macho es más fuerte y menos alargada que la de la hembra. Orejas largas, juntas y puntiagudas. Ojos castaños. En la hembra se tolera una papada pequeña. Debe presentar carencia de capa o pelo largo; el subpelo ha de ser denso y sedoso. Color castaño, con la banda lateral del dorso más obscura. El vientre es más claro, casi blanco.

Se han obtenido diversas variedades con colores negro, blanco, leonado, etc., a base de hibridaciones; éstas mantienen el color de la raza del cruce. La carne es de buena calidad.

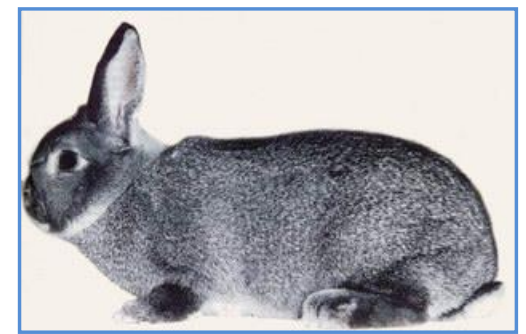

Chinchilla: Peso, 2-3 kg. Cabeza mediana y fina en las hembras. Orejas medianas, erectas e inclinadas levemente hacia atrás. Color negro, gris y blanco. El 
pelo es oscuro en la base; es blanco y negro en el extremo, dándole el aspecto de chinchilla. Existen variedades azul habana y leonado. La carne es sabrosa. (Esta raza no tiene nada que ver con la chinchilla de los Andes).

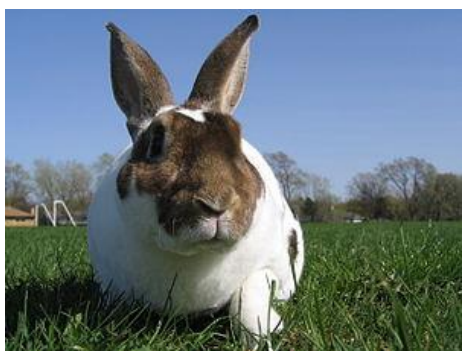

hembra tiene una papada.

Rex: Tamaño mediano con un cuerpo redondo y un rango de peso ideal de 3,4-4.8 kg. Cabeza ligeramente más ancha que otras razas de conejo, orejas verticales proporcionadas y pies proporcionalmente más pequeños. Al igual que con la mayoría de las razas más grandes, la

\subsection{RAZAS DE PELO}

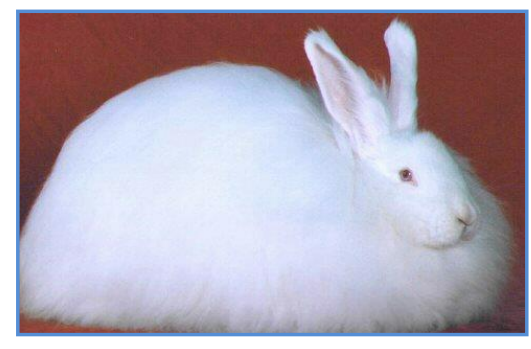

Angora: Peso, 2 kg. Cabeza grande y redondeada. Las orejas son cortas, derechas y separadas en forma de V. Ojos de color rosa. Cuerpo totalmente cubierto de pelo, que es largo, tupido y sedoso; no se ve la piel. Según la variedad el color es negro, blanco, (siendo éste el más apreciado), gris, azul oscuro, etc.

Las líneas más habituales en producción de carne de conejo proceden de las razas California y Neozelandés.

\section{CARACTERES DE CRECIMIENTO E ÍNDICE DE TRANSFORMACIÓN}

En el estudio del crecimiento Tumová et al. (2013), Dalle Zotte et al. (2015) y Szendrö et al. (2015) compararon cómo afectaban diferentes líneas genéticas (mejoradas por velocidad de crecimiento frente a líneas de aptitud maternal) en caracteres de crecimiento (ganancia media diaria, peso al sacrificio e índice de transformación) y Dalle Zotte et al. (2015) también vieron el efecto de dos dietas diferentes (11,99 vs 9,67 MJ ED / kg MS) de un híbrido comercial Hy+ seleccionado por tasa de crecimiento frente a una línea seleccionada por prolificidad (INRA 9077). Además Szendrö et al. (2015) encontraron una interacción entre la línea genética y la dieta entre la semana 7 
y 9 para la ganancia media diaria entre dos líneas genéticas (Large, seleccionada por aptitud maternal y Hung, cruzada con la línea Gigante Húngaro).

Nasr et al. (2017) y Robert et al. (2017) estudiaron el efecto en el peso al sacrificio de diferentes líneas genéticas. En el caso de Nasr et al. (2017) estudiaron nueve genotipos de cruces factoriales entre 3 razas puras (New Zealand White - NZW y Californian - CA seleccionadas por aptitud maternal y Rex -RX seleccionada por la calidad de su pelo) para comprobar si mejoraban el peso al sacrificio desde la semana 4 a la 10 de edad. Bianospino et al. (2006) estudiaron las diferencias entre una línea sintética, una línea de Botucatu (línea genética de cruce sintético de Gigante Alemán Blanco con Botucatu, originaria de Norfolk) (Straightbred), y otro grupo resultante del cruce de machos de Botucatu con hembras de Gigante Blanco Alemán (Crossbred); en el peso de canal de referencia y el peso de la canal fría. En general se observó que tanto el efecto de la línea genética sobre el ritmo de crecimiento depende de las líneas comparadas ya que cada línea ha tenido un proceso de selección diferente por un determinado tiempo. Gidenne et al. (1995) y Pascual et al. (2014) estudiaron el efecto del contenido en fibra en el crecimiento de conejos en la ganancia media diaria y el índice de transformación. En el caso de Gidenne et al. (1995) estudiaron una dieta control (Fibra Bruta: $133 \mathrm{~g} / \mathrm{kg}$ MS) frente a una dieta baja en fibra (Fibra Bruta: $92 \mathrm{~g} / \mathrm{kg} \mathrm{MS}$ ) en animales de 28 a 77 días viendo que no afectó el nivel de fibra en la ganancia de peso; y Pascual et al. (2014) en cambio sí vieron un efecto de la fibra a los 63 días en el peso vivo, alcanzando menor peso a mayor nivel de fibra. En relación, en el trabajo de vieron que a partir de cierto nivel de energía del pienso (desde 2694,2 hasta $2904,4 \mathrm{kcal} / \mathrm{kg}$ ) ya no existe un efecto sobre el crecimiento de los conejos. El efecto del género sobre caracteres de crecimiento fue estudiado por Feki et al. (1996), de la semana 4 a la 9, y Lazzaroni et al. (2009), de la semana 9 a la 16, que no encontraron diferencias en la evolución del peso y en el IT entre machos y hembras. 
Tabla 8. Resumen de los principales estudios de crecimiento.

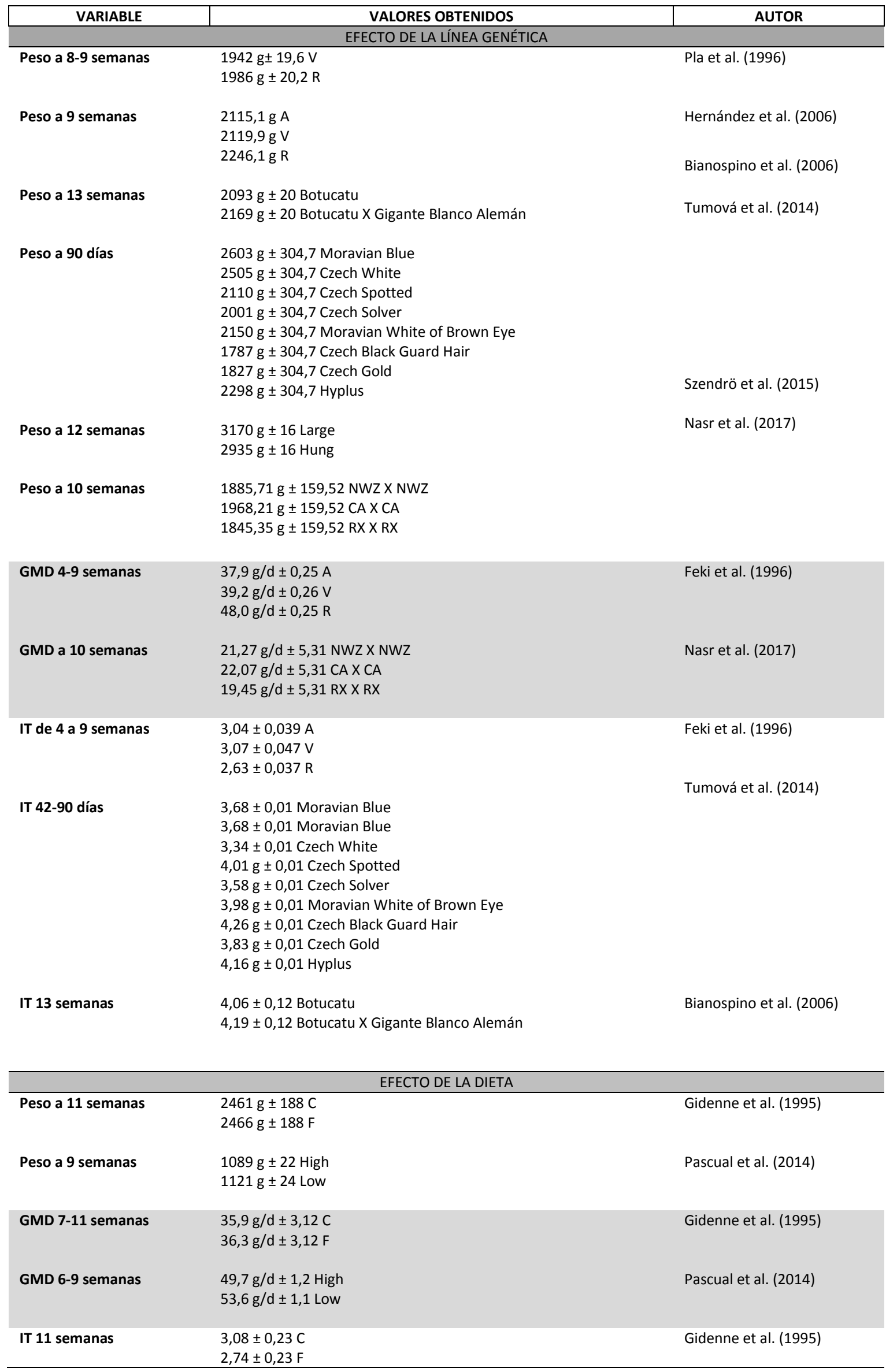


Continuación tabla 8. Resumen de los principales estudios de crecimiento

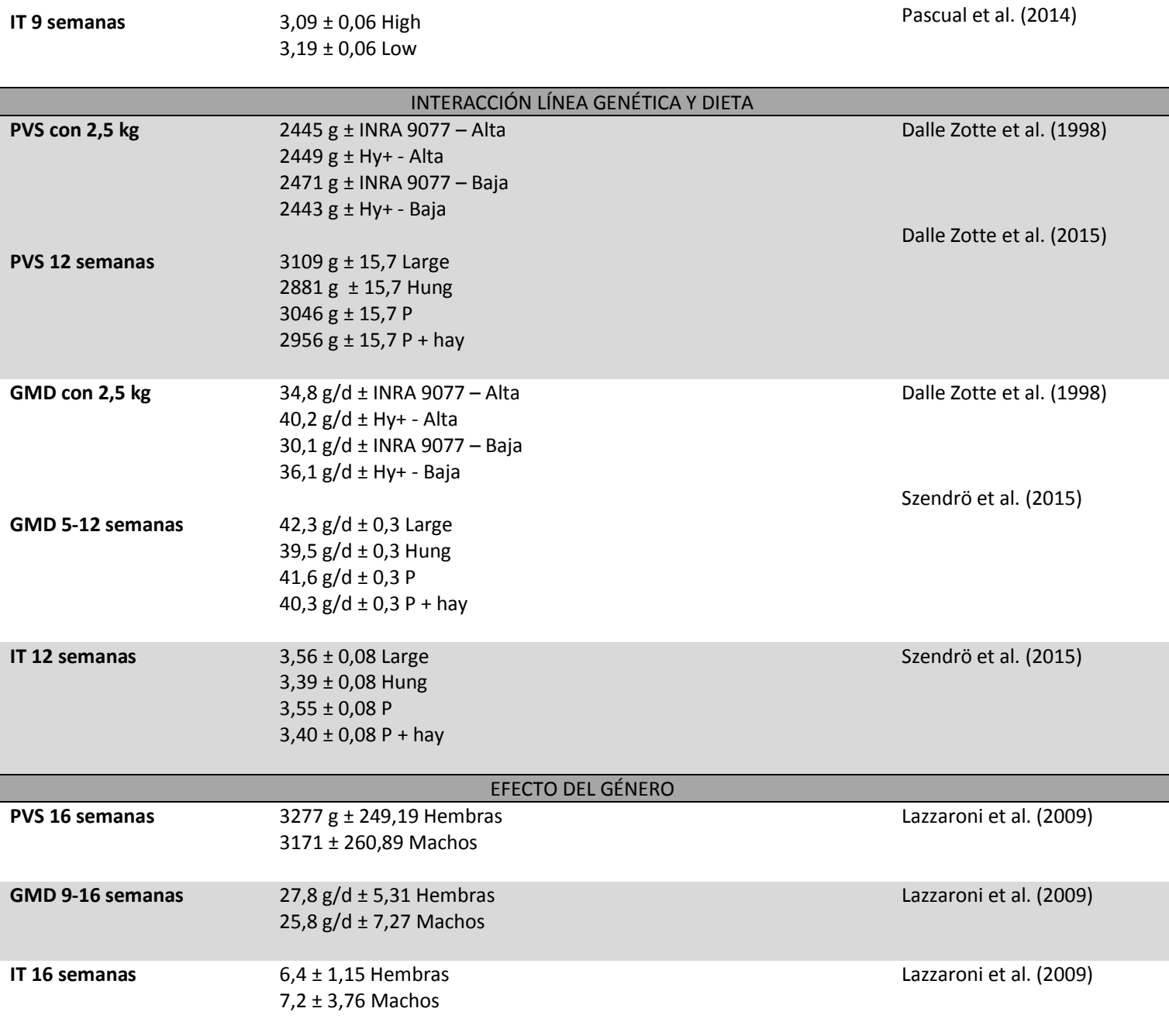

Aptitud maternal: A: Linea Amarilla UPV; CA: California; INRA 9077; Large; NWZ: New Zeland White; V: Línea verde UPV, Aptitud cárnica: Hung (gigante húngaro); Hy+; R: línea rosa UPV; calidad de pelo RX. Rex

C: dieta control (FB 13,3 \%); F: baja en fibra (FB 9,2 \%); High: alta en FND 227 g/kg MS; Low: baja en FND (161 g/kg MS); Alta: 11,99; Baja: 9,67 MJ ED /kg MS; P: pellet comercial; P + hay: con suplemento de heno. 


\section{CALIDAD DE CANAL}

En caracteres de calidad de carne, a las 9 semanas tanto Gómez et al. (1998) como Pla et al. (1996) encontraron diferencias significativas en el peso de la canal de referencia según diferentes líneas genéticas estudiadas teniendo mayor peso las líneas de aptitud maternal, y Dalle Zotte y Ouyhaoun (1998) también obtuvo este efecto en el rendimiento de la canal fría ya que obtuvieron mayores porcentajes para animales sacrificados a los $2,5 \mathrm{~kg}$ seleccionados por prolificidad que animales seleccionados por tasa de crecimiento. Además Martínez-Vallespín et al. (2013) y Pascual et al. (2014) encontraron que las dietas con elevados niveles de fibra digestible (157 g/kg MS) disminuían el peso de la canal fría y de referencia.

Lazzaroni et al. (2009) no encontraron diferencias significativas entre machos y hembras en el desarrollo de la piel, el hígado y los riñones. Robert et al. (2017) en su estudio comparativo de dos líneas Hyla (A y B) seleccionadas por ganancia media diaria y Nasr et al. (2017) entre una línea California (seleccionada por aptitud maternal) y la línea Rex (seleccionada por la calidad de su piel) encontraron diferencias significativas a las 10 semanas en el desarrollo de la piel entre líneas genéticas, en este último caso obteniendo menor porcentaje de piel respecto al peso vivo la línea Rex que California. En relación, Gómez et al. (1998) y Feki et al. (1996) para animales con 60 días tanto en el desarrollo de la piel como de las vísceras de la caja torácica, encontraron diferencias significativas, obteniendo mayor peso de estas vísceras las líneas de aptitud maternal que las líneas seleccionadas por velocidad de crecimiento mientras que el peso de los riñones fue inferior para las líneas de aptitud maternal. Y Pascual et al. (2014) estudiaron el desarrollo del porcentaje de piel y del hígado según dos dietas (32,9 y 37,9 \% FND sobre MS) para conejos entre 6 y 9 semanas obteniendo más piel y más hígado a menor cantidad de fibra.

Pla et al. (1996) y Gómez et al. (1998) estudiaron las medidas lineales de la canal en función del origen genético. Gómez et al. (1998) encontraron diferencias significativas en la longitud dorsal ( $D L$ ) y la longitud de la patas traseras $(T L)$ en conejos con $2 \mathrm{~kg}$ de peso vivo comercial entre una línea seleccionada por aptitud maternal por su tamaño de camada al destete durante 18 generaciones frente a una línea seleccionada por 
velocidad de crecimiento entre 28 y 63 días de edad durante 20 generaciones, mostrando tendencia a ser más alargado el dorso (DL) y la circunferencia lumbar (LCL) y menos alargado la zona de las patas traseras (TL) en la línea seleccionada por aptitud maternal. En consecuencia también tuvo mayor índice de compacidad.

Mientras que Pla et al. (1996) no encontraron diferencias significativas en la longitud dorsal (DL) a las 8 y 9 semanas entre una línea seleccionada por tamaño de camada (V: $251 \mathrm{~mm} \pm 1,2)$ y una línea seleccionada por tasa de crecimiento ( $R: 249 \mathrm{~mm} \pm 1,1$ ) alimentadas ambas con una dieta de $16,5 \%$ de proteína; 3,4\% de grasa y $15,5 \%$ de fibra, pero sí en TL ( $R: 74 \mathrm{~mm} \pm 0,4 ; V: 78 \mathrm{~mm} \pm 0,5$ ) en conejos con 8 y 9 semanas y en LCL teniendo más tendencia a ensanchar cadera las líneas seleccionadas por aptitud maternal.

Los depósitos de grasa como es lógico van aumentando con la edad como observaron Dalle Zotte et al. (1998) y (2015) que estudiaron el efecto de la línea genética según diferentes dietas en la acumulación de grasa y observaron que las líneas de aptitud maternal a pesos en torno a 2,5 kg (1998) y a las 12 semanas (2015) acumulan más grasa escapular y perirrenal que las líneas mejoradas por velocidad de crecimiento. El peso de la grasa perirrenal suele ser más abundante que el resto de depósitos (inguinal y escapular), por lo que suele ser una es una buena predicción en el total de grasa diseccionable (Varewyck y Bouquet, 1982 y Hernández et al., 1994).

Mientras que Gómez et al. (1998), Hernández et al. (2006) vieron que las líneas de aptitud maternal acumulaban mayores pesos de grasa perirrenal (Gómez et al, 1998) y también escapular e inguinal (Hernández et al, 1994) en animales alimentados por una misma dieta y sacrificados en torno a los $2 \mathrm{~kg}$ de edad.

Pascual et al. (2014) y Xiccato et al. (2013) vieron la evolución de las grasas para líneas seleccionadas por velocidad de crecimiento y alimentados con dos dietas con diferentes niveles de fibra, Pascual et al. (2014) indican que una reducción en el porcentaje de grasa diseccionable puede deberse al incremento en fibra altamente digestible a expensas de una disminución de almidón. Aunque Xiccato et al. (2013) no encontró ningún efecto del nivel de la fibra soluble en el porcentaje de la grasa 
diseccionable en su estudio para conejos agrupados en distintas densidades por jaula (12 vs 16 animales/m2) a las 11 semanas de edad.

Hernández et al. (2006) y Lazzaroni et al. (2009) estudiaron la interacción género y dieta en la evolución de las grasas de la canal, encontrando diferencias netre machos y hembras grasa perirrenal y grasa diseccionable (Lazzaroni et al. 2006) entre 9 y 16 semanas alimentados por un pienso comercial y Hernández et al. (2006) a partir de la semana 9 en el depósito de grasa inguinal, depositando las hembras un 0,21 \% más de grasa inguinal que los machos, pero no encontraron diferencias en la grasa perirrenal.

En cuanto al despiece de la canal, Gómez et al. (1998), Feki et al. (1996) y Robert et al. (2017) estudiaron el efecto de las diferentes partes de la canal en diferentes líneas genéticas. Gómez et al. (1998) y Feki et al. (1996) entre dos líneas seleccionadas por tamaño de camada al destete ( $\mathrm{A}$ y $\mathrm{V}$ ) y otra línea seleccionada por tasa de crecimiento a los $2 \mathrm{~kg}$ de peso comercial no encontraron diferencias significativas en el peso de la cabeza pero Gómez et al. (1998) sí encontraron diferencias significativas en el peso de la caja torácica presentando mayor peso de caja torácica la línea mejoradas por tamaño de camada al destete mientras que en el peso de las patas delanteras y traseras obtuvieron mayor peso de patas delanteras la línea seleccionada por velocidad de crecimiento.

Pascual et al. (2014), Robert et al. (2017), Dalle Zotte et al. (1998) (2015) estudiaron el efecto de dos dietas con diferentes niveles de fibra en las diferentes partes del despiece y Pascual et al. (2014) no encontraron diferencias significativas en el porcentaje de lomo, la caja torácica y las patas traseras a las 12 semanas para líneas seleccionadas por velocidad de crecimiento pero sí encontraron efecto en el porcentaje de la cabeza, patas delanteras y en el ratio músculo-hueso con mayores porcentajes de cabeza y patas delanteras y menor ratio músculo-hueso en animales alimentados por la dieta con menor contenido en fibra. Por otro lado, Dalle Zotte y Ouhayoun (1998), sí encontraron diferencias en el peso del lomo cuando era alimentada por diferentes dietas pero no encontraron en el ratio músculo - hueso entre una línea seleccionada por prolificidad (INRA 9077) respecto a una línea seleccionada por tasa de crecimiento $(\mathrm{Hy}+)$ cuando los animales eran alimentados por 
una dieta altamente energética $(\mathrm{H})$ o una dieta control $(\mathrm{L})$, mientras que Dalle Zotte et al. (2015) sí encontraron efecto de la línea genética en el ratio músculo - hueso entre una línea mejorada por ganancia media diaria (Large: 6,10 $\pm 0,04 \mathrm{~g} / \mathrm{g}$ ) y línea (Hung: $5,81 \pm 0,04 \mathrm{~g} / \mathrm{g}$ ) seleccionada por el gran tamaño que alcanzan los machos, llamados 'Gigantes Húngaros' a las 12 semanas. Pascual et al. (2014) y Robert et al. (2017) en el estudio de dos líneas macho de Hyla (A y B) seleccionadas por ganancia media diaria y por rendimiento de canal a las 10 semanas de edad no hallaron diferencias significativas en el peso de las patas traseras. En cambio, Gómez et al.,(1998) sí encontraron diferencias entre una línea seleccionada por tamaño de camada al destete (V) obteniendo mayor peso de patas traseras que la una seleccionada por velocidad de crecimiento (R) en conejos sacrificados con el peso comercial de $2 \mathrm{~kg}$.

El efecto del género en el despiece fue estudiado por Lazzaroni et al. (2009) que encontraron diferencias significativas en el porcentaje de cabeza, siendo mayores los porcentajes de los machos $(5,4 \pm 0,37 \%)$ que las hembras $(4,7 \pm 0,21 \%)$. En el resto del despiece no encontraron efecto del género. 
Tabla 9. Resumen de los principales estudios de calidad de canal

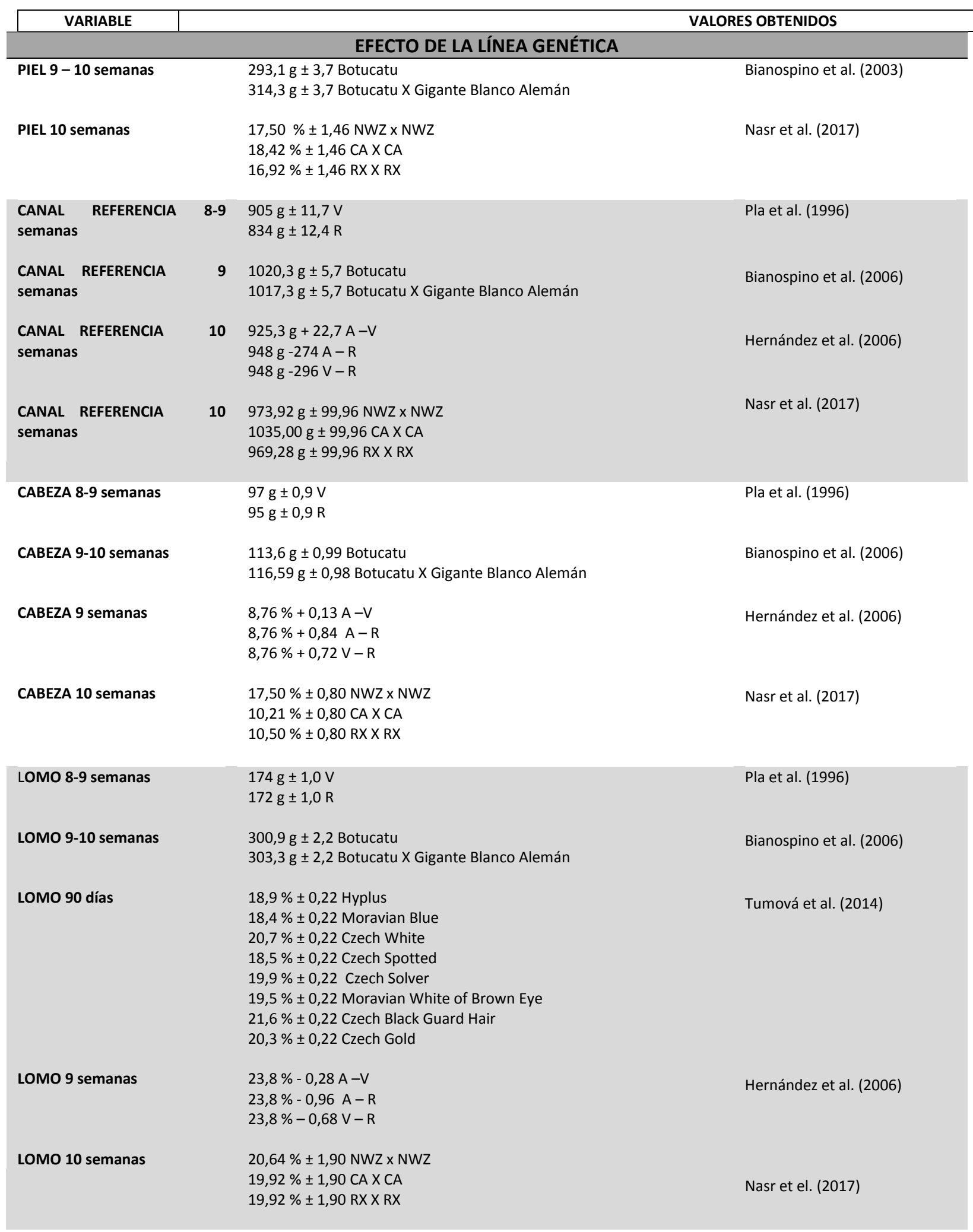


Continuación tabla 9. Resumen de los principales estudios de calidad de canal

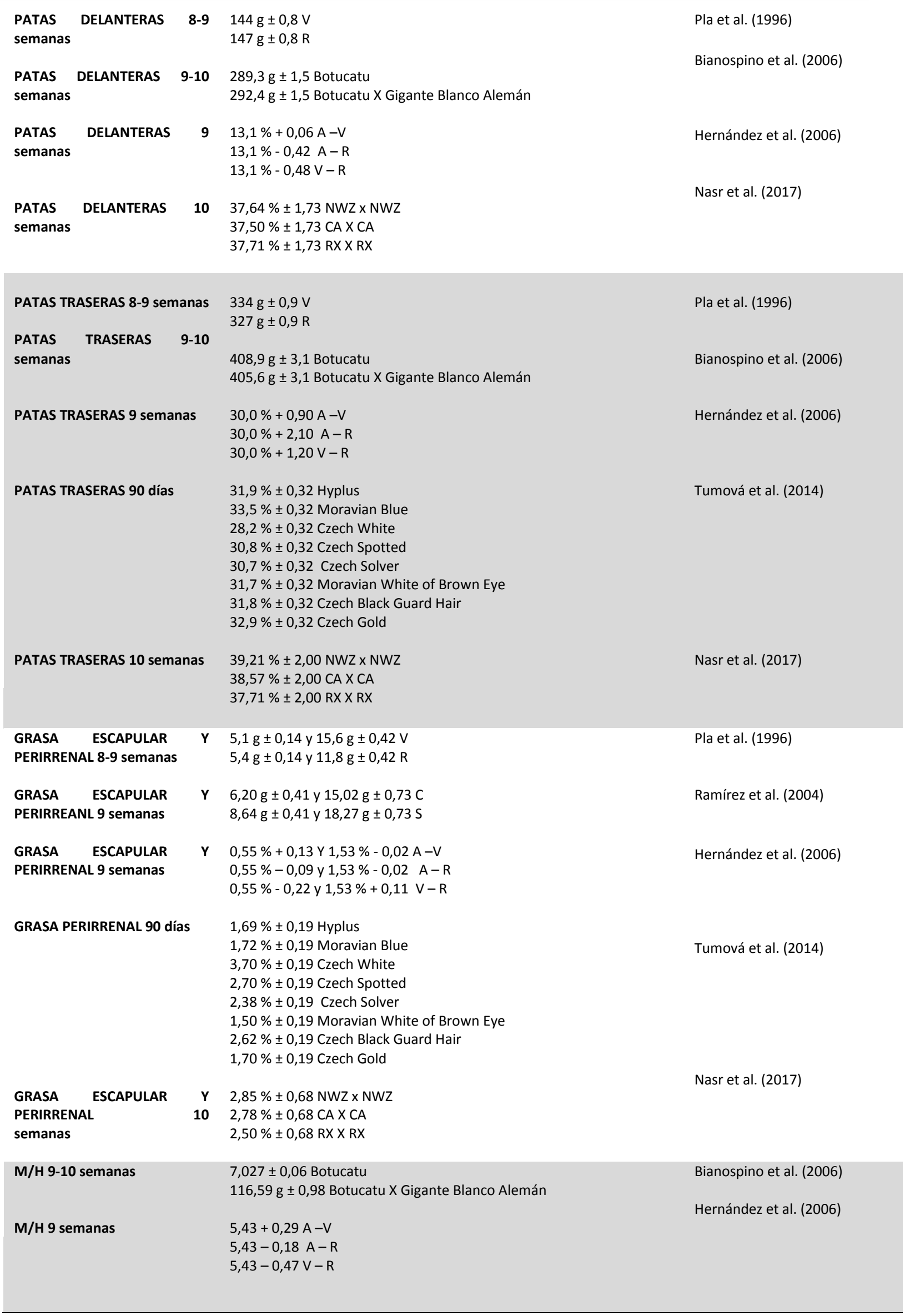


INTRODUCCIÓN

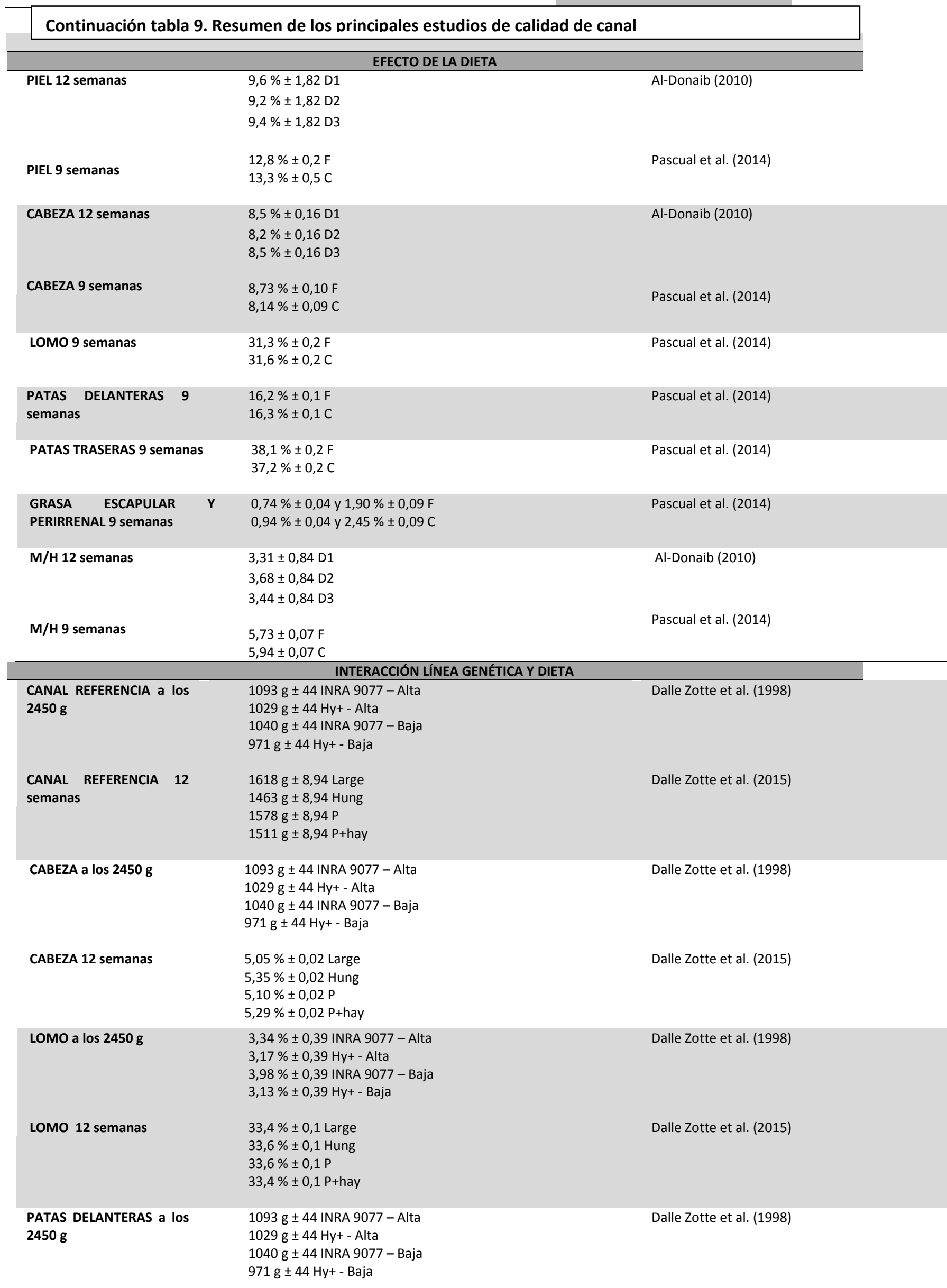




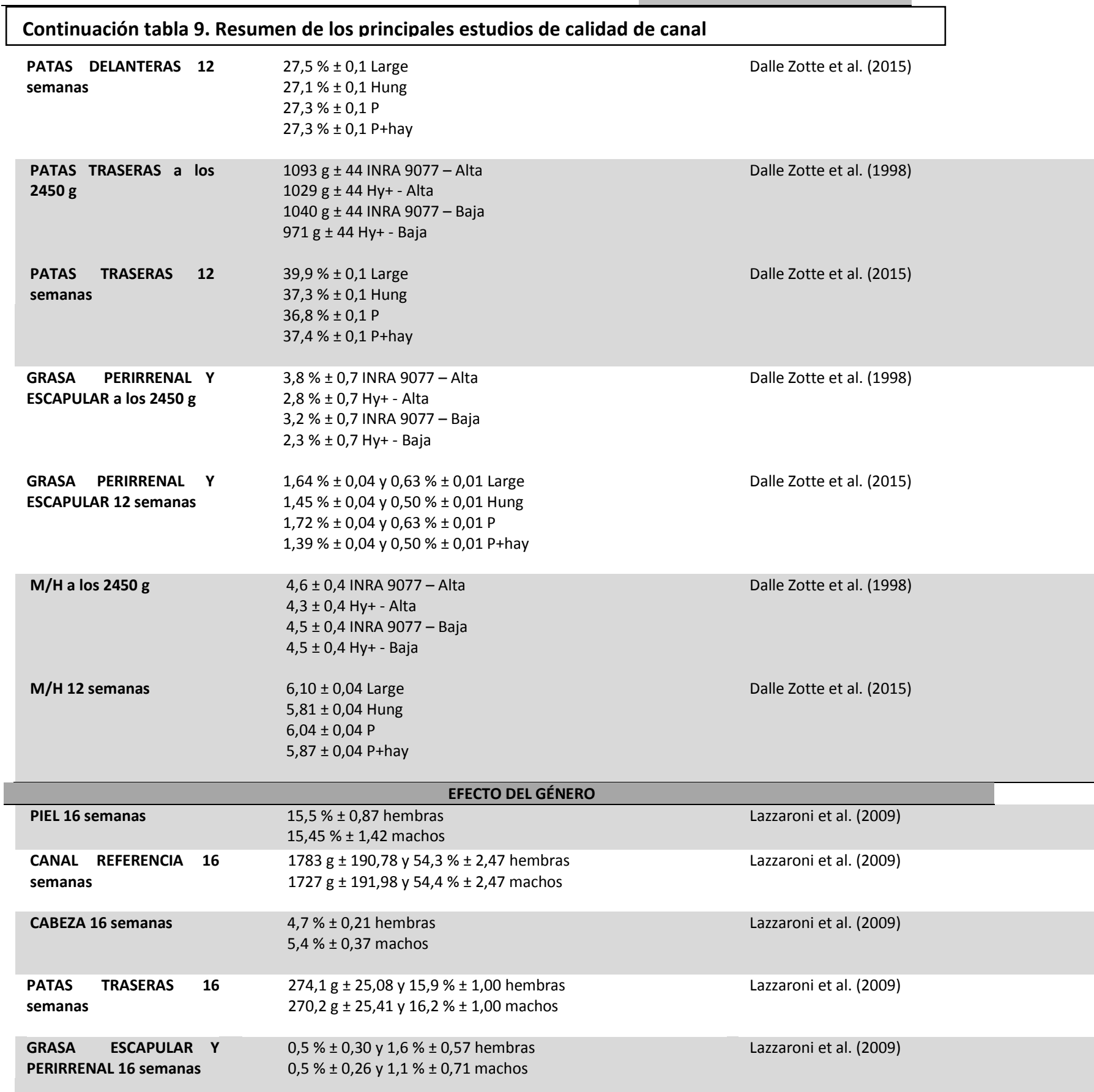

Aptitud maternal: A: Linea Amarilla UPV; CA: California; INRA 9077; Large; NWZ: New Zeland White; V: Línea verde UPV, Aptitud cárnica: Hung (gigante húngaro); Hy+; R: línea rosa UPV; calidad de pelo RX. Rex

C: dieta control (FB 13,3 \%); F: baja en fibra (FB 9,2 \%); High: alta en FND 227 g/kg MS; Low: baja en FND (161 g/kg MS); Alta: 11,99; Baja: 9,67 MJ ED /kg MS; P: pellet comercial; P + hay: con suplemento de heno; S: dieta estándar, E: Suplemento vitamina, O: Suplemento orégano; OR: Suplemento romero; A: baja en fibra (14,28 \% FB); media en fibra (18,04\% FB); C: alta en fibra (20,48\% FB); AA: alta fibra digestible (260 g FD/kg MS); BB: baja fibra digestible (180 g FD/kg MS) 


\section{CALIDAD DE CARNE}

En parámetros de calidad de carne, Pla et al, (1998) y Nasr et al. (2017) estudiaron el efecto de diferentes líneas seleccionadas por tasa de crecimiento y tamaño de camada en el descenso del pH en el Biceps femoris a las 24 horas p.m teniendo mayor descenso la línea seleccionada por velocidad de crecimiento que dos líneas seleccionadas por aptitud maternal (Pla et al, 1998), ya que según Dalle Zotte, et al. 2005 y como ocurrió en el estudio de Nasr et al. (2017) para conejos con 10 semanas de nueve genotipos de un cruce factorial de las razas New Zealand White, California y Rex, el descenso en el pH conforme avanza la edad, por tanto el peso, lo que se explica por el incremento del metabolismo de la energía glicolítica.

Dalle Zotte y Ouhayoun (1998) y Pascual et al. (2014) vieron además la interacción línea genética y dieta alimentadas por dos dietas con diferentes niveles de fibra bruta $(H 17,8$ y L 22,5 \% MS) en el caso de Dalle Zotte y Ouhayoun (1998) y encontraron que el pH del músculo de la pata a las 24 horas p.m. no estaba afectado por el origen genético (prolificidad vs velocidad de crecimiento) y la dieta cuando los animales se sacrificaban a la misma edad y peso, en su caso al alcanzar los 2,5 kg de peso vivo. Pascual et al. (2014) observaron este mismo efecto en el pH a las 24 horas p.m en el Longissimus lumborum en animales con 9 semanas

Lazzaroni et al. (2009) no encontraron diferencias significativas entre machos y hembras en el pH a los 60 minutos y a las 24 horas p.m. (M: 6,3 $\pm 0,18 ; F: 6,4 \pm 0,15$ ) para conejos Carmagnola entre 9 y 16 semanas criados a dos densidades diferentes $\left(0,12 \mathrm{~m}^{2} /\right.$ animal; $0,25 \mathrm{~m}^{2}$ /animal).

Dalle Zotte et al. (2015), Pla et al. (1998) y Nasr et al. (2017) que compararon los valores luminosidad $L^{*}$, rojo $\left(a^{*}\right)$ y amarillo $\left(b^{*}\right)$ entre diferentes líneas genéticas encontraron que la luminosidad $\left(L^{*}\right)$ fue mayor y el rojo menor $\left(a^{*}\right)$ para animales seleccionados por tamaño de camada al destete que animales seleccionados por ganancia media diaria a las 9 semanas (Dalle Zotte et al. 2015), y 12 semanas de edad (Pla et al. 1998). Mientras que Nasr et al. (2017) analizó líneas seleccionadas por aptitud maternal y seleccionadas por la calidad de la piel no encontraron diferencias significativas en $L^{*}, a^{*}$ y $b^{*}$. 
Por otro lado, Xiccato et al. (2011) que estudiaron el efecto de disminuir la concentración de proteína cruda (de 162 a $152 \mathrm{~g} / \mathrm{kg}$ ) incrementando el ratio de fibra soluble-almidón (de 0,2 hasta 1,5) en conejos de la línea Grimaud sacrificados a los 75 días. Encontraron que el nivel de proteína no afectó a las características de carne, mientras que el incremento del ratio fibra soluble-almidón si produjo un descenso ligero en los parámetros de color, descendiendo en el caso de $b^{*}$ desde 1,64 hasta $0,38 \pm 2,18$.

Lazzaroni et al. (2009) estudiaron el efecto del género en conejos de 9 a 16 semanas de la línea California CA seleccionada por tamaño de camada al destete pero no encontraron diferencias significativas en $L^{*}, a^{*}$ y $b^{*}$, aunque obtuvieron mayores valores de $b^{*}$ y $L^{*}$ en las hembras ( $\left.b^{*}: 5,2 \pm 0,93 ; L^{*}: 48,7 \pm 2,65\right)$ que los machos (b*: 4,6 $\pm 1,39 ; L^{*}: 47,4 \pm$ $2,66)$, mientras que para $a^{*}$ fue al contrario.

En el estudio de la textura, Ramírez et al. (2004) y Pla et al. (1998) estudiaron la fuerza máxima de corte (MSF) y el rendimiento de fuerza inicial (IYF) en diferentes líneas genéticas alimentadas por la misma dieta. En el caso de Ramírez et al. (2004) compararon el efecto de la selección por velocidad de crecimiento a las 9 semanas comparado con un grupo control y encontraron diferencias significativas en IYF, indicando que la carne del grupo selección presentó más resistencia al corte. Mientras que Pla et al. (1998) que estudiaron dos líneas seleccionadas por tamaño de camada al destete ( $A$ y V) frente a una línea seleccionada por ganancia media diaria desde el destete (R) a las 4 semanas hasta las 9 semanas por una misma dieta (16\% proteína cruda, 15,5\% fibra bruta y 3,4 \% de grasa) opinan que las diferencias en estos parámetros vienen dadas por el origen genético más que por la madurez del animal.

El contenido de proteína y humedad en la carne de la pata viendo el efecto en diferentes líneas genéticas y edades fue estudiado por Pascual et al. (2007) y Dalle Zotte al. (2015); mientras que Cardinali et al. (2015) estudiaron estos parámetros comparando dietas con suplementos de vitamina $E$, orégano y romero. Pascual et al. (2007) observaron que un ligero cambio en la edad de sacrificio (2000 g \pm 200$)$, pudo hacer variar estos porcentajes de grasa y humedad mientras que el contenido de proteína parece mantenerse constante. Dalle Zotte et al. (2015) observaron que el contenido de proteína fue mayor en la línea seleccionada por ganancia media diaria que en la seleccionada por velocidad de 
crecimiento. Pascual et al. (2014) compararon dos dietas con diferente nivel de energía en conejos de 12 semanas procedentes de líneas seleccionadas por velocidad de crecimiento, obtuvieron menor porcentaje de humedad de la carne de la pata trasera con el pienso más energético.

En nuestro estudio además de parámetros de crecimiento se han estudiado parámetro de crecimiento relativo de las diferentes partes del cuerpo y los tejidos, en este caso utilizando el modelo alométrico descrito por Huxley (1932) que proporciona una serie de parámetros diferentes para la comparación de poblaciones de animales. También hemos incluido medidas de rendimiento de canal, evaluando la canal y las diferentes partes del despiece (cabeza, lomo, patas y vísceras), las longitudes y color de la misma y por último medidas de tipo biológico y fisiológico como el $\mathrm{pH}$, la textura, y el contenido en humedad, proteína y grasas, terminando con el análisis del perfil de ácidos grasos. En todos los casos se han evaluado tres líneas genéticas, dos líneas seleccionadas por velocidad de crecimiento (Grimaud e Hyla-colored) y una seleccionada por prolificidad (Hyla), que fueron alimentadas con dietas, una dieta control y una dieta más energética desde la semana 8 a la 16 de edad. Con el objetivo de la búsqueda de una línea genética y una alimentación adecuada para producir canales de conejo con mayor peso al sacrificio para la obtención de productos alternativos que abran la puerta a nuevos mercados con formatos de presentación de la carne de conejo (salchichas o hamburguesas, por ejemplo), que ya están disponibles en muchos supermercados. 
Tabla 10. Resumen de los principales estudios de calidad de canal

\begin{tabular}{|c|c|c|}
\hline VARIABLE & VALORES OBTENIDOS & AUTOR \\
\hline \multicolumn{3}{|c|}{ EFECTO DE LA LÍNEA GENÉTICA } \\
\hline \multirow[t]{2}{*}{ pH 8-9 semanas - 24 h p.m. } & $5,85 \pm 0,018 \mathrm{~V}$ & Pla et al. (1996) \\
\hline & $5,86 \pm 0,015 R$ & \\
\hline \multirow[t]{4}{*}{ pH con $2450 \mathrm{~g}-24$ h p.m. } & $5,80 \pm 0,11$ INRA $9077-$ Alta & Dalle Zotte et al. (1998) \\
\hline & $5,76 \pm 0,11 \mathrm{Hy}+-$ Alta & \\
\hline & $5,73 \pm 0,11$ INRA 9077 - Baja & \\
\hline & $5,77 \pm 0,11 \mathrm{Hy}+-$ Baja & \\
\hline \multirow[t]{2}{*}{ pH 9-10 semanas - 24 h p.m. } & $5,575 \pm 0,020$ Botucatu & Bianospino et al. (2006) \\
\hline & 5,613 $\pm 0,020$ Botucatu X Gigante Blanco Alemán & \\
\hline \multirow{3}{*}{ pH 9 semanas - 24 h p.m. } & $5,54+0,005 A-V$ & Hernández et al. (2006) \\
\hline & $5,54-0,06 A-R$ & \\
\hline & $5,54-0,06 V-R$ & \\
\hline \multirow[t]{3}{*}{ pH 10 semanas - 24 h p.m. } & $5,99 \pm 0,14 N W Z \times N W Z$ & Nasr et al. (2017) \\
\hline & $5,94 \pm 0,14 \mathrm{CA} \times \mathrm{CA}$ & \\
\hline & $5,91 \pm 0,14 \mathrm{RX} \times \mathrm{RX}$ & \\
\hline \multirow[t]{2}{*}{$L^{*}, a^{*}$ y $b^{*} 8-9$ semanas } & $56,9 \pm 0,117 ; 3,1 \pm 0,16$ y $3,9 \pm 0,33 \mathrm{~V}$ & Pla et al. (1996) \\
\hline & $57,1 \pm 0,38 ; 2,9 \pm 0,15$ y $2,8 \pm 0,24 R$ & \\
\hline \multirow[t]{2}{*}{$L^{*}, a^{*}$ y $b^{*} 9$ semanas } & $54,90 \pm 0,31 ; 2,84 \pm 0,10$ y $0,21 \pm 0,24 \mathrm{C}$ & Ramírez et al. (2004) \\
\hline & $54,52 \pm 0,31 ; 2,85 \pm 0,10 y-0,54 \pm 0,24 S$ & \\
\hline \multirow[t]{3}{*}{$L^{*}, a^{*}$ y $b * 9$ semanas } & $53,0+0,39 ; 5,98-0,96$ y $3,32-0,36 \mathrm{~A}-\mathrm{V}$ & Hernández et al. (2006) \\
\hline & $53,0-0,63 ; 5,98+1,14$ y $3,32-0,36 A-R$ & \\
\hline & $53,0-1,00 ; 5,98+2,11$ y $3,32+0,008 V-R$ & \\
\hline \multirow[t]{3}{*}{$L^{*}, a^{*}$ y $b^{*} 10$ semanas } & $48,10 \pm 3,09 ; 4,40 \pm 1,14$ y $7,90 \pm 0,88$ NWZ x NWZ & Nasr et al. (2017) \\
\hline & $46,30 \pm 3,09 ; 3,60 \pm 1,14$ y $9,00 \pm 0,88$ CA X CA & \\
\hline & $46,20 \pm 3,09 ; 3,60 \pm 1,14$ y $7,80 \pm 0,88 \operatorname{Rex} R X X R X$ & \\
\hline \multirow[t]{9}{*}{ \% proteína y grasa 90 días } & $21,9 \% \pm 0,19$ y $2,47 \% \pm 6,005$ Hyplus & Tumová et al. (2014) \\
\hline & $21,8 \% \pm 0,543$ y $2,55 \% \pm 6,005$ Moravian Blue & \\
\hline & $22,0 \% \pm 0,19$ y $2,84 \% \pm 6,005$ Czech White & \\
\hline & $22,3 \% \pm 0,19$ y $3,59 \% \pm 6,005$ Czech Spotted & \\
\hline & $22,6 \% \pm 0,19$ y $2,27 \% \pm 6,005$ Czech Solver & \\
\hline & $22,9 \% \pm 0,19$ y $2,20 \% \pm 6,005$ Moravian White of Brown & \\
\hline & Eye & \\
\hline & $22,4 \% \pm 0,19$ y $2,33 \% \pm 6,005$ Czech Black Guard Hair & \\
\hline & $22,7 \% \pm 0,19$ y $2,25 \% \pm 6,005$ Czech Gold & \\
\hline \multirow[t]{2}{*}{ \% proteína 9 semanas } & $-0,10 \mathrm{~g} / 100 \mathrm{~g}$ músculo $\pm 0,1 \mathrm{AH}-\mathrm{VV}, \mathrm{LV}-\mathrm{VV}$ & Mínguez et al. (2017) \\
\hline & $-0,00 \mathrm{~g} / 100 \mathrm{~g}$ músculo $\pm 0,1$ resto de cruces & \\
\hline \multirow[t]{3}{*}{ \% SFA 4-9 semanas } & $34,93-2,86 \mathrm{~A}-\mathrm{V}$ & Hernández et al. (2008) \\
\hline & $34,93-2,47 A-R$ & \\
\hline & $34,93+0,39 V-R$ & \\
\hline \multirow[t]{2}{*}{ \% SFA 9 semanas } & $35,73 \pm 0,31 \mathrm{C}$ & Ramírez et al. (2005) \\
\hline & $36,86 \pm 0,33 \mathrm{~S}$ & \\
\hline \% MUFA y PUFA 9 semanas & $64,27 \pm 0,31 \mathrm{C}$ & Ramírez et al. (2005) \\
\hline
\end{tabular}


$63,14 \pm 0,33$ (S) velocidad de crecimiento

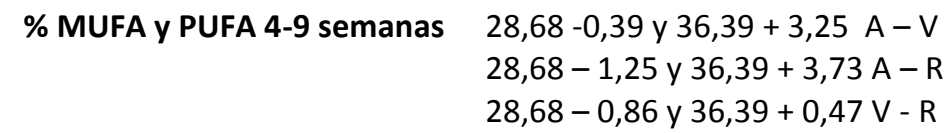

Hernández et al. (2008)

\begin{tabular}{|c|c|c|}
\hline PUFA/SFA 9 semanas & $1,06 \pm 0,03 \mathrm{C}$ & Ramírez et al. (2005) \\
\hline PUFA/SFA 9 semanas & $\begin{array}{l}1,30 \pm 0,03 \mathrm{~S} \\
-0,03 \mathrm{~g} / 100 \mathrm{mg} \text { músculo } \pm 0,02 \mathrm{AH}-\mathrm{VV} \\
0,02 \mathrm{~g} / 100 \mathrm{mg} \text { músculo } \pm 0,02 \mathrm{LV}-\mathrm{VV}\end{array}$ & Mínguez et al. (2017) \\
\hline Total $n-6$ a las 9 semanas & $\begin{array}{l}34,26 \pm 0,62 C \\
31,58 \pm 0,65 S\end{array}$ & Ramírez et al. (2005) \\
\hline Total $n-6$ a las 9 semanas & $\begin{array}{l}19 \mathrm{~g} / 100 \text { g músculo } \pm 9 \text { AH - VV } \\
-4 \mathrm{~g} / 100 \text { g músculo } \pm 9 \mathrm{LV}-\mathrm{VV}\end{array}$ & Mínguez et al. (2017) \\
\hline$n-6 / n-3$ a las 9 semanas & $\begin{array}{l}11,47 \pm 0,30 \mathrm{C} \\
10,67 \pm 0,32 \mathrm{~S}\end{array}$ & Ramírez et al. (2005) \\
\hline$n-6 / n-3$ a las 9 semanas & $\begin{array}{l}0,1 \mathrm{~g} / 100 \text { g músculo } \pm 0,1 \mathrm{AH}-\mathrm{VV} \\
-0,1 \mathrm{~g} / 100 \text { g músculo } \pm 0,1 \mathrm{AV}-\mathrm{VV}, \mathrm{LV}-\mathrm{VV}\end{array}$ & Mínguez et al. (2017) \\
\hline & EFECTO DE LA DIETA & \\
\hline pH 9 semanas - 24 h p.m. & $\begin{array}{l}5,90 \pm 0,20 \mathrm{C} \\
5,79 \pm 0,20 \mathrm{~F}\end{array}$ & Gidenne et al. (1995) \\
\hline pH 9 semanas - 24 h p.m. & $\begin{array}{l}5,65 \pm 0,01 \text { High } \\
5,66 \pm 0,01 \text { Low }\end{array}$ & Pascual et al. (2014) \\
\hline$L^{*}, a *$ y b* 9 semanas & $\begin{array}{l}50,35 \pm 0,35 ; 5,83 \pm 0,26 \text { y } 2,77 \pm 0,17 \text { High } \\
49,63 \pm 0,36 ; 6,71 \pm 0,26 \text { y } 3,19 \pm 0,16 \text { Low }\end{array}$ & Pascual et al. (2014) \\
\hline MSF e IYF 9 semanas & $\begin{array}{l}3,88 \mathrm{~kg} / \mathrm{cm}^{2} \pm 0,15 \text { y } 1,34 \mathrm{~kg} / \mathrm{s}^{*} \mathrm{~cm}^{2} \pm 0,07 \mathrm{C} \\
3,99 \mathrm{~kg} / \mathrm{cm}^{2} \pm 0,15 \text { y } 1,69 \mathrm{~kg} / \mathrm{s}^{*} \mathrm{~cm}^{2} \pm 0,07 \mathrm{~S}\end{array}$ & Ramírez et al. (2004) \\
\hline $\begin{array}{l}\text { \% Humedad, proteína y grasa } \\
9 \text { semanas }\end{array}$ & $\begin{array}{l}73,7 \pm 0,2 ; 21,1 \pm 0,1 \text { y } 3,81 \pm 0,15 \text { High } \\
72,9 \pm 0,2 ; 21,2 \pm 0,1 \text { y } 4,71 \pm 0,14 \text { Low }\end{array}$ & Pascual et al. (2014) \\
\hline \% proteína a los 80 días & $\begin{array}{l}22,0 \pm 0,49 \mathrm{~S} \\
22,2 \pm 0,49 \mathrm{E} \\
22,1 \pm 0,49 \mathrm{O} \\
22,2 \pm 0,49 \mathrm{OR}\end{array}$ & Cardinali et al. (2015) \\
\hline
\end{tabular}

\begin{tabular}{|c|c|c|}
\hline$\%$ SFA con $2,3 \mathrm{~kg}$ & $\begin{array}{l}39,50 \pm 1,42 \mathrm{~A} \\
39,18 \pm 1,88 \mathrm{~B} \\
40,43 \pm 1,54 \mathrm{C}\end{array}$ & Carrilho et al. (2009) \\
\hline$\%$ SFA con 2765 g & $\begin{array}{l}37,29 \% \pm 0,394 \mathrm{AA} \\
37,29 \% \pm 0,394 \mathrm{BB}\end{array}$ & $\begin{array}{l}\text { Papadomichelakis et al. } \\
\text { (2010) }\end{array}$ \\
\hline$\%$ MUFA con $2,3 \mathrm{~kg}$ & $\begin{array}{l}25,64 \pm 1,70 \mathrm{~A}: \text { baja en fibra }(14,28 \% \mathrm{FB}) \\
24,93 \pm 2,30 \mathrm{~B}: \text { media en fibra }(18,04 \% \mathrm{FB}) \\
26,52 \pm 2,59 \mathrm{C}: \text { alta en fibra }(20,48 \% \mathrm{FB})\end{array}$ & Carrilho et al. (2009) \\
\hline
\end{tabular}




\begin{tabular}{|c|c|c|}
\hline \multicolumn{3}{|c|}{ Continuación tabla 10. Resumen de los principales estudios de calidad de carne } \\
\hline$\%$ MUFA con $2765 \mathrm{~g}$ & $\begin{array}{l}25,84 \% \pm 0,580 \mathrm{AA} \\
24,31 \% \pm 0,580 \mathrm{BB}\end{array}$ & $\begin{array}{l}\text { Papadomichelakis et al. } \\
\text { (2010) }\end{array}$ \\
\hline$\%$ PUFA con 2,3 kg & $\begin{array}{l}30,38 \pm 2,13 \mathrm{~A} \\
30,29 \pm 2,79 \mathrm{~B} \\
29,34 \pm 4,15 \mathrm{C}\end{array}$ & Carrilho et al. (2009) \\
\hline \% PUFA con $2765 \mathrm{~g}$ & $\begin{array}{l}29,61 \% \pm 0,655 \mathrm{AA} \\
31,16 \% \pm 0,655 \mathrm{BB}\end{array}$ & $\begin{array}{l}\text { Papadomichelakis et al. } \\
\text { (2010) }\end{array}$ \\
\hline PFA/SFA con $2,3 \mathrm{~kg}$ & $\begin{array}{l}0,78 \pm 0,07 A \\
0,77 \pm 0,07 B \\
0,73 \pm 0,13 C\end{array}$ & Carrilho et al. (2009) \\
\hline PFA/SFA con $2765 \mathrm{~g}$ & $\begin{array}{l}0,80 \% \pm 0,024 \mathrm{AA} \\
0,84 \% \pm 0,024 \mathrm{BB}\end{array}$ & $\begin{array}{l}\text { Papadomichelakis et al. } \\
\text { (2010) }\end{array}$ \\
\hline$\% \mathrm{n}-6 \operatorname{con} 2,3 \mathrm{~kg}$ & $\begin{array}{l}28,53 \pm 2,22 \mathrm{~A} \\
28,00 \pm 2,87 \mathrm{~B} \\
27,00 \pm 4,19 \mathrm{C}\end{array}$ & Carrilho et al. (2009) \\
\hline n $-6 \operatorname{con} 2,3 \mathrm{~kg}$ & $\begin{array}{l}12,88 \pm 1,78 \mathrm{~A} \\
12,30 \pm 1,79 \mathrm{~B} \\
11,65 \pm 2,23 \mathrm{C}\end{array}$ & Carrilho et al. (2009) \\
\hline & EFECTO LÍNEA GENÉTICA Y DIETA & \\
\hline pH a los 2450 g - 24 h p.m. & $\begin{array}{l}5,80 \pm 0,11 \text { INRA } 9077-\text { Alta } \\
5,76 \pm 0,11 \mathrm{Hy}+- \text { Alta } \\
5,73 \pm 0,11 \text { INRA } 9077-\text { Baja } \\
5,77 \pm 0,11 \mathrm{Hy}+- \text { Baja }\end{array}$ & Dalle Zotte et al. (1998) \\
\hline pH 12 semanas - 24 h p.m. & $\begin{array}{l}6,09 \pm 0,02 \text { Large } \\
6,15 \pm 0,02 \text { Hung } \\
6,09 \pm 0,02 P \\
6,16 \pm 0,02 \text { P+hay }\end{array}$ & Dalle Zotte et al. (2015) \\
\hline $\mathrm{L}^{*}, \mathrm{a} * \mathrm{y}$ b* a los $2450 \mathrm{~g}$ & $\begin{array}{l}54,8 \pm 1,8 ; 6,1 \pm 1,3 \text { y } 4,3 \pm 1,0 \text { INRA } 9077 \text { - Alta } \\
54,1 \pm 1,8 ; 7,3 \pm 1,3 \text { y } 4,9 \pm 1, H y+- \text { Alta } \\
56,2 \pm 1,8 ; 4,8 \pm 1,3 \text { y } 3,7 \pm 1, I N R A 9077 \text { - Baja } \\
54,9 \pm 1,8 ; 6,9 \pm 1,3 \text { y } 4,5 \pm 1, H y+- \text { Baja }\end{array}$ & Dalle Zotte et al. (1998) \\
\hline$L^{*}, a^{*}$ y b* a las 12 semanas & $\begin{array}{l}50,5 \pm 0,34 ; 4,99 \pm 0,19 \text { y }-0,07 \pm 0,10 \text { Large } \\
52,0 \pm 0,34 ; 4,18 \pm 0,19 \text { y } 0,24 \pm 0,10 \text { Hung } \\
51,9 \pm 0,34 ; 5,03 \pm 0,19 \text { y } 0,18 \pm 0,10 P \\
50,6 \pm 0,34 ; 4,13 \pm 0,19 \text { y }-0,02 \pm 0,10 \text { P+hay }\end{array}$ & Dalle Zotte et al. (2015) \\
\hline
\end{tabular}

MSF 12 semanas
\% Humedad, proteína y grasa
12 semanas

$$
\begin{aligned}
& 3,19 \mathrm{~kg} / \mathrm{cm}^{2} \pm 0,11 \text { Large } \\
& 3,16 \mathrm{~kg} / \mathrm{cm}^{2} \pm 0,11 \text { Hung } \\
& 3,57 \mathrm{~kg} / \mathrm{cm}^{2} \pm 0,11 \mathrm{P} \\
& 2,76 \mathrm{~kg} / \mathrm{cm}^{2} \pm 0,11 \text { P+hay }
\end{aligned}
$$

$73,7 \% \pm 0,06 ; 21,9 \% \pm 0,03$ y $2,45 \% \pm 0,08$ Large $73,8 \% \pm 0,06 ; 21,8 \% \pm 0,03$ y $2,41 \% \pm 0,08$ Hung $73,6 \% \pm 0,06 ; 21,9 \% \pm 0,03$ y $2,63 \% \pm 0,08 \mathrm{P}$ $73,9 \% \pm 0,06 ; 21,8 \% \pm 0,03$ y $2,23 \% \pm 0,08 P+$ hay
Dalle Zotte et al. (2015)

Dalle Zotte et al. (2015) 
Continuación tabla 10. Resumen de los principales estudios de calidad de carne

$35,9 \pm 0,19$ Hung

$35,5 \pm 0,19 P$

$36,2 \pm 0,19$ P+hay

\% MUFA 12 semanas

$33,6 \pm 0,35$ Large

Dalle Zotte et al. (2015)

$32,4 \pm 0,35$ Hung

$33,9 \pm 0,35 P$

$32,0 \pm 0,35$ P+hay

\begin{tabular}{ll} 
UFA/SFA 12 semanas & $1,73 \pm 0,01$ Large \\
& $1,70 \pm 0,01$ Hung \\
& $1,74 \pm 0,01 P$ \\
& $1,69 \pm 0,01$ P+hay \\
& \\
\hline Total n-6 a las 12 semanas & $24,9 \pm 0,33$ Large \\
& $25,4 \pm 0,33$ Hung \\
& $24,7 \pm 0,33 P$ \\
& $25,7 \pm 0,33$ P+hay
\end{tabular}

Dalle Zotte et al. (2015)

$n-6 / n-3$ a las 12 semanas

$9,54 \pm 0,19$ Large

Dalle Zotte et al. (2015)

$10,1 \pm 0,19$ Hung

$9,90 \pm 0,19 P$

$9,73 \pm 0,19$ P+hay

Dalle Zotte et al. (2015)

\section{EFECTO GÉNERO}

pH 12 semanas - 1 h.p.m. y 5,8 $\pm 0,03$ y 6,4 0,17 hembras

24 h p.m. $\quad 5,8 \pm 0,04$ y $6,4 \pm 0,15$ machos

Lazzaroni et al. (2009)

$L^{*}, a^{*}$ y b* 16 semanas

$56,8 \pm 2,59 ; 8,2 \pm 2,48$ y $4,0 \pm 1,21$ hembras

Lazzaroni et al. (2009)

$58,1 \pm 2,88 ; 6,4 \pm 2,40$ y $2,4 \pm 2,08$ machos

\begin{tabular}{ll}
\hline \% SFA 16 semanas & $\begin{array}{l}45,42 \pm 2,02 \text { hembras } \\
45,18 \pm 3,10 \text { machos }\end{array}$ \\
\hline \% MUFA 16 semanas & $\begin{array}{l}37,78 \pm 3,48 \text { hembras } \\
32,85 \pm 3,49 \text { machos }\end{array}$ \\
\hline PUFA/SFA 16 semanas & $0,44 \pm 0,05$ hembras \\
& $0,49 \pm 0,14$ machos \\
\hline Total $n-6$ a las 16 semanas & $15,92 \pm 2,02$ hembras \\
& $18,02 \pm 4,44$ machos
\end{tabular}

Lazzaroni et al. (2009)

$n-6 / n-3$ a las 16 semanas

$4,28 \pm 0,83$ hembras

$4,65 \pm 1,14$ machos

Lazzaroni et al. (2009)

Lazzaroni et al. (2009)

Lazzaroni et al. (2009)

Lazzaroni et al. (2009)

Aptitud maternal: A: Linea Amarilla UPV; CA: California; INRA 9077; Large; NWZ: New Zeland White; V: Línea verde UPV, Aptitud cárnica: Hung (gigante húngaro); Hy+; R: línea rosa UPV; calidad de pelo RX. Rex

C: dieta control (FB 13,3 \%); F: baja en fibra (FB 9,2 \%); High: alta en FND 227 g/kg MS; Low: baja en FND (161 g/kg MS); Alta: 11,99; Baja: 9,67 MJ ED /kg MS; P: pellet comercial; P + hay: con suplemento de heno; S: dieta estándar, E: Suplemento vitamina,

O: Suplemento orégano; OR: Suplemento romero; A: baja en fibra (14,28 \% FB); media en fibra (18,04\% FB); C: alta en fibra (20,48\% FB); AA: alta fibra digestible (260 g FD/kg MS); BB: baja fibra digestible (180 g FD/kg MS) 


\section{ANTECEDENTES Y JUSTIFICACIÓN}

En la producción comercial de carne de conejo, los costes de alimentación por conejo en animales sacrificados a los 63 días, representan un 45,3\% del total (Blasco et al., 2018). Esto hace que el coste de la alimentación tenga una alta repercusión en el coste de producción. Así cuando el precio de la alimentación incrementa, los costes de producción superan el precio de venta de carne; y el sistema se vuelve inviable. Por tanto, uno de los principales objetivos en producción de carne de conejo es mejorar la eficiencia alimentaria o el índice de transformación de la dieta en carne. Para la elaboración de ciertos productos de valor añadido es necesario obtener canales más pesadas de lo habitual, a pesar de que el índice de transformación va aumentando conforme aumenta la edad, contando que la selección ha ido mejorando caracteres cuantitativos de producción, como la tasa de crecimiento y el desarrollo de musculatura prestando menos atención a los aspectos cualitativos de la carne (Ramírez, et al. 2003).

En nuestro estudio además de parámetros de crecimiento se han estudiado parámetro de crecimiento relativo de las diferentes partes del cuerpo y los tejidos, en este caso utilizando el modelo alométrico descrito por Huxley (1932) que proporciona una serie de parámetros diferentes para la comparación de poblaciones de animales. También hemos incluido medidas de rendimiento de canal, evaluando la canal y las diferentes partes del despiece (cabeza, lomo, patas y vísceras), las longitudes y color de la misma y por último medidas de tipo biológico y fisiológico como el $\mathrm{pH}$, la textura, y el contenido en humedad, proteína y grasas, terminando con el análisis del perfil de ácidos grasos. En todos los casos se han evaluado tres líneas genéticas, dos líneas seleccionadas por velocidad de crecimiento (Grimaud e Hyla-colored) y una seleccionada por prolificidad (Hyla), que fueron alimentadas con dietas, una dieta control y una dieta más energética desde la semana 8 a la 16 de edad. Con el objetivo de la búsqueda de una línea genética y una alimentación adecuada para producir canales de conejo con mayor peso al sacrificio para la obtención de productos alternativos que abran la puerta a nuevos mercados con formatos de presentación de 
la carne de conejo (salchichas o hamburguesas, por ejemplo), que ya están disponibles en muchos supermercados.

Por tanto se plantean los siguientes objetivos:

El objetivo general del proyecto es la optimización del proceso de engorde del conejo a partir de la octava semana de edad con la finalidad de obtener canales pesadas (3$4 \mathrm{~kg}$ ) adecuadas para su despiece y transformación en productos alternativos de carne de conejo que abran las puertas a nuevos mercados.

En este sentido, se ha llevado a cabo el estudio de la evolución con la edad y el peso de los tres principales factores que pueden influir en el proceso de engorde del conejo, así como las posibles interacciones entre estos. Los factores estudiados fueron:

- La línea genética. Los animales procedían del cruzamiento en el que se utilizaron como líneas parentales tres líneas genéticas: dos líneas de aptitud cárnica (Grimaud e Hyla colored), y una línea de aptitud maternal (HYLA).

- La dieta del conejo. Se ensayaron dos tipos de piensos de engorde con distintos niveles energéticos.

- EL género. Se engordaron tanto machos como hembras.

Por tanto, derivaron los objetivos específicos de cómo estos factores y sus interacciones influían sobre:

$\checkmark$ Caracteres productivos en granja: crecimiento de los animales, consumo de pienso, índice de transformación, bajas e incidencias sanitarias.

$\checkmark$ Calidad de canal: rendimiento canal, pérdidas por oreo, grasa total diseccionable (perirrenal, escapular e inguinal), despiece, porcentaje de piezas nobles y peso de los distintos órganos, relación músculo-hueso de la pierna trasera.

$\checkmark$ Calidad de carne: $\mathrm{pH}$, color, capacidad de retención de agua, terneza, y contenido en grasa, proteína y colágeno, y perfil de ácidos grasos. 


\section{MATERIAL Y MÉTODOS}

\section{NAVES DE ENGORDE Y EQUIPAMIENTO}

La empresa cunícola Quin, Sociedad Cooperativa, situada en Fuente Álamo, ha puesto a nuestra disposición sus instalaciones y los animales. Esta empresa cuenta con una capacidad para 4.000 hembras reproductoras más sus gazapos, repartidos en 14 naves, una de reposición. Todas las naves (foto 1 ) son abiertas y orientadas con su eje longitudinal en sentido Este - Oeste, de $10 \times 52 \mathrm{~m}^{2}$, de estructura metálica, con cerramiento de bloques de hormigón en la fachada Norte - Sur, y en las fachadas laterales sólo se dispone de una malla de sombreo. La cubierta es de chapa metálica aislada con poliuretano y el sistema de iluminación consta de: tubos fluorescentes de 36 W para llevar a cabo a un fotoperiodo de 8 a 10 horas de luz con 10 lux para los gazapos. La refrigeración es mediante un sistema cooling (foto 2) con paneles en la fachada norte, y mediante aspersores situados en las fachadas laterales. No posee sistema de calefacción y cada una de ellas cuenta con tres filas de jaulas de alambre galvanizado (foto 3) que tienen como dimensiones: $90 \times 45 \times 40 \mathrm{~cm}^{3}$. Cada jaula tiene un comedero y un bebedero automático; y además la posibilidad de que se le acople un nido de plástico PVC. Los nidos, (45 × $30 \times 15 \mathrm{~cm}^{3}$, ancho $\times$ largo $\times$ alto) son preparados y colocados 6 días antes del parto; las capas que rellenan el nido y que hacen más confortable los primeros días de los gazapos son: una primera capa de viruta de madera y otra capa, más gruesa de borra de lana. Además, las conejas antes de parir suelen rellenar también los nidos con pelo que se extraen de ellas mismas. Cada jaula y su nido están comunicados por una puerta de bloqueo manual, que es útil para el manejo diario. Así se programa cada mañana una lactancia controlada una vez la coneja ha parido. 


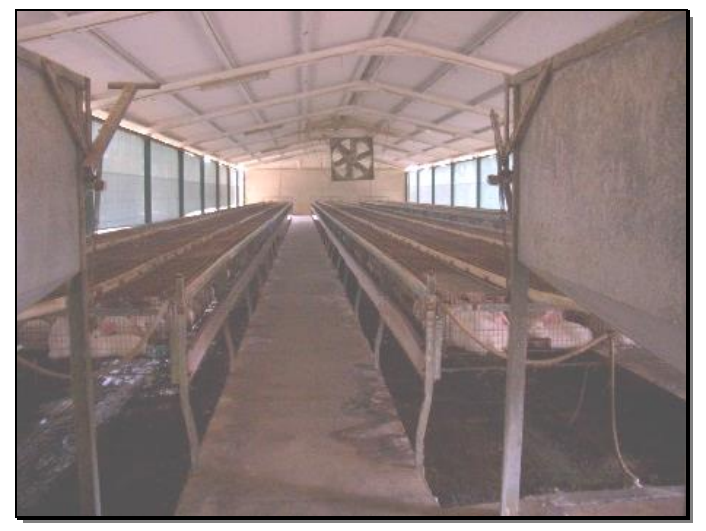

Foto 1. Interior de nave

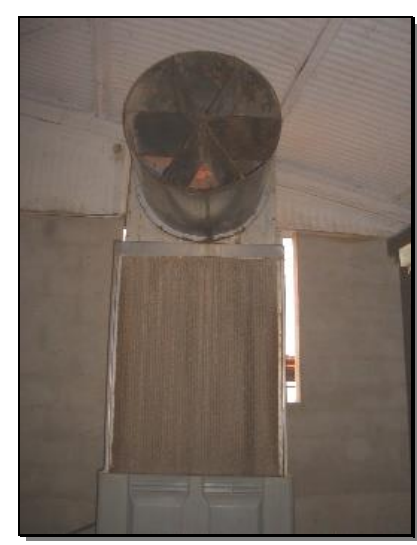

Foto 2 . Sistema de refrigeración.

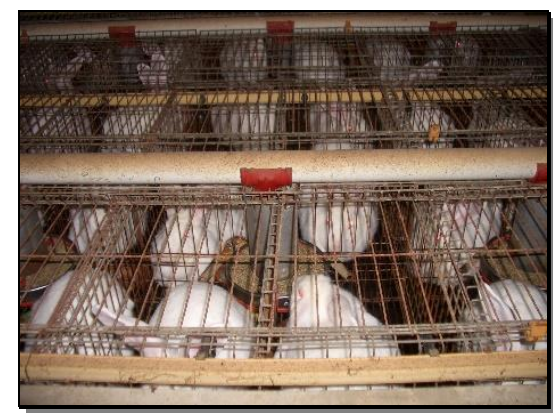

Foto 3. Jaulas.

\section{MATERIAL ANIMAL}

El experimento incluyó un total de 2294 conejos con edades comprendidas entre la semana 8 a la 16 (ambas inclusive) procedentes de tres líneas genéticas, ambos géneros (machos y hembras) y fueron alimentados con dos dietas (dieta de control y alta energía). Las líneas genéticas comparadas fueron: HYLA Grand Parental Doe (HYGPD) seleccionada por número de gazapos nacidos vivos y el peso al destete de la camada, HYLA COLORED (HY-CO) y GRIMAUD PS119 (GR), ambas seleccionadas para 
la ganancia diaria promedio desde el destete hasta el sacrificio y el rendimiento de la canal al sacrificio.

Para obtener los 2294 conejos del experimento, 2497 conejas de raza pura (HY-GPD, Francia) fueron inseminadas con semen de machos HY-GPD, HY-CO o GR quedando gestantes 2440 hembras. La ovulación fue inducida por la administración de una inyección intramuscular de $20 \mu \mathrm{g}$ de GnRH (Gonadoreline, Fertagyl ${ }^{\circledR}$, Intervet Laboratories) en el momento de la inseminación. Las camadas fueron homogeneizadas a ocho gazapos. Los conejos de la misma camada permanecieron juntos con su madre hasta que tuvieron siete semanas. En este momento, 2294 conejos fueron seleccionados al azar de estas camadas, solo un conejo por camada (macho o hembra). Se movieron a jaulas individuales $(45 \times 90 \times 40 \mathrm{~cm} 3$; ancho $\mathrm{x}$ largo $\mathrm{x}$ alto) de malla de alambre galvanizado, y se mantuvieron sin actividad reproductiva. Los conejos se pesaron semanalmente de la semana 8 a la semana 16 de edad.

Desde el destete hasta el sacrificio, todos los animales fueron alimentados ad libitum con dos dietas comerciales diferentes (dieta de control = dieta $\mathrm{C}$ y dieta de alta energía = dieta HE). La energía metabolizable fue de $2100 \mathrm{kcal} / \mathrm{kg}$ para la dieta C y $2400 \mathrm{kcal} / \mathrm{kg}$ para dieta HE (tabla 1) debido a su mayor contenido en almidón y a su menor contenido en fibra. 
Tabla 1. Composición y valor nutricional de los dos piensos de engorde.

\begin{tabular}{|c|c|c|}
\hline \multirow[t]{2}{*}{ MATERIAS PRIMAS \% } & \multicolumn{2}{|c|}{ DIETA* } \\
\hline & C & HE \\
\hline Salvado trigo & 22 & 25 \\
\hline Pulpa remolacha & 8 & 20 \\
\hline Alfalfa deshidratada & 14 & 18 \\
\hline Harina girasol & 20 & 16,5 \\
\hline Cascarilla de soja & 15 & 3,5 \\
\hline Cilindro arroz & 3 & 5 \\
\hline Paja & 7,5 & 1,5 \\
\hline Cebada cervecera & 8 & 7,5 \\
\hline Aceite crudo de palma & 0,4 & 1,3 \\
\hline Garrofa & & 0,3 \\
\hline Sal & 0,4 & 0,4 \\
\hline Carbonato cálcico & 1,13 & 0,35 \\
\hline CVM & 0,07 & 0,07 \\
\hline Lisina & & 0,07 \\
\hline \multicolumn{3}{|c|}{ VALOR NUTRICIONAL } \\
\hline MS (\%) & 89 & 89 \\
\hline PB (\%) & 15 & 16 \\
\hline GB (\%) & 2,5 & 3 \\
\hline FB (\%) & 25 & 17 \\
\hline ALM (\%) & 8 & 12 \\
\hline FAD (\%) & 25 & 22 \\
\hline FND (\%) & 40 & 35 \\
\hline CENIZAS (\%) & 11 & 11 \\
\hline ED (Kcal/kg) & 2100 & 2400 \\
\hline Lisina & $4,8 \mathrm{~g}$ & $4,9 \mathrm{~g}$ \\
\hline Metionina & $1,9 \mathrm{~g}$ & $1,8 \mathrm{~g}$ \\
\hline Treonina & $3,4 \mathrm{~g}$ & $3,5 \mathrm{~g}$ \\
\hline Leucina & $6,1 \mathrm{~g}$ & $5,7 \mathrm{~g}$ \\
\hline $\mathrm{Ca} / \mathrm{P}$ & 2,1 & 1,7 \\
\hline $\mathrm{Ca}$ & $10,6 \mathrm{~g}$ & $8,8 \mathrm{~g}$ \\
\hline $\mathbf{P}$ & $5,1 \mathrm{~g}$ & $5,2 \mathrm{~g}$ \\
\hline \multicolumn{3}{|c|}{ PERFIL DE ÁCIDOS GRASOS (\%) } \\
\hline C14:0 & 0,6 & 0,7 \\
\hline C16:0 & 21,7 & 28,2 \\
\hline C16:1 & 0,5 & 0,5 \\
\hline C18:0 & 2,9 & 3,2 \\
\hline C18:1 & 24,4 & 29,8 \\
\hline C18:2 & 42,0 & 31,9 \\
\hline C18:3 & 5,6 & 4,1 \\
\hline C20:0 & 2,3 & 1,6 \\
\hline
\end{tabular}

* Dieta $\mathrm{C}=$ dieta control; y Dieta HE = dieta con alto nivel de energía

CVM: corrector vitamínico-mineral, MS: Materia Seca, PB: Proteína Bruta; GB: Grasa Bruta, FB: Fibra Bruta; ALM: Almidón, FAD: Fibra Ácido Digestible, FND: Fibra Neutro Detergente. 


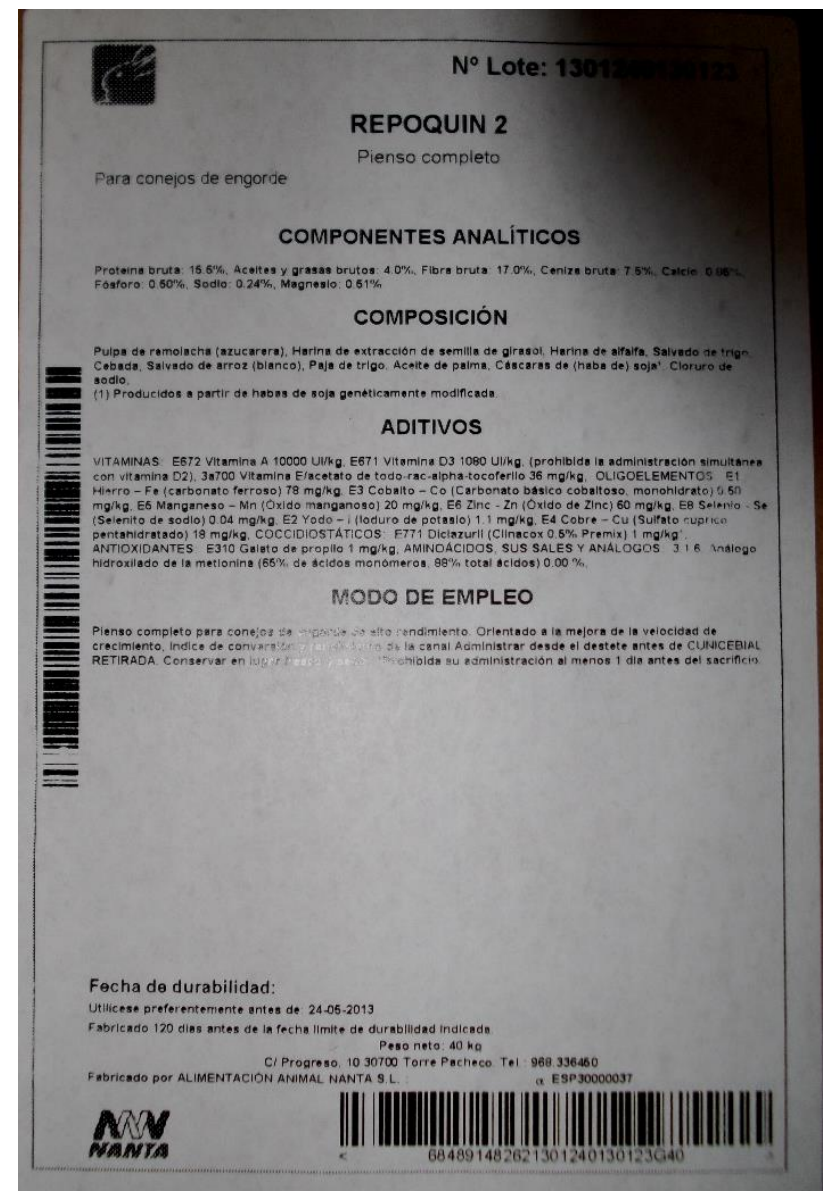

Foto 4. Etiqueta de la dieta Repoquin 2 (Dieta).

Como parte del manejo reproductivo de la granja, se utiliza la técnica del manejo en bandas, que consiste en agrupar a las hembras en lotes de manejo que se encuentran en el mismo estado fisiológico, para ello es necesario que todas las hembras de un mismo lote sean inseminadas el mismo día (viernes) de tal forma que todas paran en días próximos (lunes o martes) entre semana lo que permite asistir los partos y disminuir la mortalidad perinatal, y así también todos los destetes y ventas de conejos de un lote son realizados al mismo tiempo. Además de presentar la enorme ventaja de agrupar las tareas de la explotación, esta técnica ha sido necesaria para el desarrollo de la inseminación artificial en conejos y también permite el vacío sanitario, ya que al venderse los conejos al mismo tiempo, las naves se quedan vacías y se puede limpiar, desinfectar y dejar descansar la nave durante un período mínimo de 7 días. 
Esta organización permitió que este ensayo se integrara dentro de las actividades diarias programadas de la granja. Así, las inseminaciones se realizaron cada viernes en la nave correspondiente, dedicando expresamente como máximo unas 300 I.A. semanales para la prueba y organizándose nuestros lotes de engorde.

Esta organización en lotes permitió un reparto del trabajo (figura 1), escalonando la introducción y la salida de los animales durante 19 semanas, haciendo la siguiente lotificación y realizar el engorde en una misma nave (evitando así el efecto nave)

El organigrama siguiente muestra por semanas los 13 lotes de entrada y 15 de salida que se dieron en la prueba y cómo se organizaron a lo largo del tiempo. 

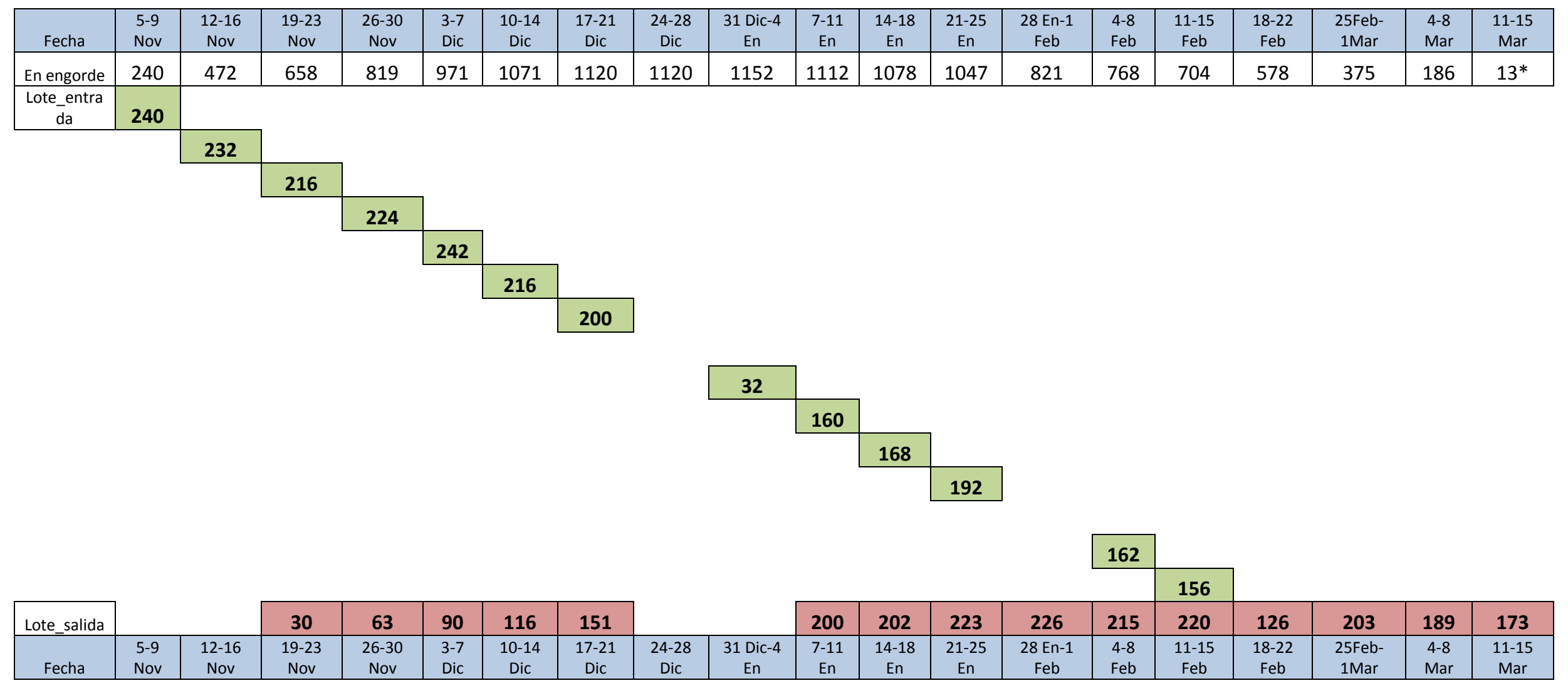

Figura 1. Formación de lotes del experimento en 19 semanas. 13* Estos 13 gazapos no quedaron en la nave de engorde, ya que son la suma de todos los gazapos que fueron baja a lo largo de estas 19 semanas. 
Los 2294 animales analizados, se distribuyeron como indica la tabla siguiente.

Tabla 2. Número de conejos según edad de sacrificio, tipo de dieta, línea genética y sexo.

\begin{tabular}{|c|c|c|c|c|c|}
\hline \multirow{2}{*}{$\begin{array}{c}\text { EDAD DE SACRIFICIO } \\
\text { (SEMANAS) }\end{array}$} & \multirow[t]{2}{*}{ LÍNEA } & \multicolumn{2}{|c|}{ PIENSO C } & \multicolumn{2}{|c|}{ PIENSO HE } \\
\hline & & MACHOS & HEMBRAS & MACHOS & HEMBRAS \\
\hline \multirow[t]{3}{*}{8} & $\mathrm{GR}$ & 21 & 24 & 26 & 28 \\
\hline & HYcol & 24 & 24 & 24 & 20 \\
\hline & HY & 24 & 22 & 24 & 23 \\
\hline \multirow[t]{3}{*}{9} & GR & 25 & 25 & 28 & 25 \\
\hline & HYcol & 24 & 20 & 23 & 24 \\
\hline & HY & 24 & 24 & 25 & 24 \\
\hline \multirow[t]{3}{*}{10} & GR & 25 & 23 & 24 & 23 \\
\hline & HYcol & 26 & 26 & 24 & 28 \\
\hline & HY & 25 & 23 & 24 & 25 \\
\hline \multirow[t]{3}{*}{11} & GR & 23 & 23 & 23 & 21 \\
\hline & HYcol & 25 & 24 & 20 & 21 \\
\hline & HY & 23 & 21 & 23 & 24 \\
\hline \multirow[t]{3}{*}{12} & GR & 22 & 23 & 24 & 23 \\
\hline & HYcol & 28 & 21 & 22 & 16 \\
\hline & HY & 19 & 22 & 24 & 21 \\
\hline \multirow[t]{3}{*}{13} & GR & 24 & 25 & 33 & 26 \\
\hline & HYcol & 24 & 25 & 25 & 24 \\
\hline & HY & 12 & 21 & 24 & 23 \\
\hline \multirow[t]{3}{*}{14} & $\mathrm{GR}$ & 23 & 23 & 23 & 24 \\
\hline & HYcol & 22 & 23 & 23 & 26 \\
\hline & HY & 26 & 14 & 22 & 23 \\
\hline \multirow[t]{3}{*}{15} & GR & 11 & 20 & 10 & 17 \\
\hline & HYcol & 16 & 23 & 24 & 24 \\
\hline & HY & 17 & 23 & 10 & 14 \\
\hline \multirow[t]{4}{*}{16} & GR & 10 & 12 & 9 & 9 \\
\hline & HYcol & 10 & 12 & 9 & 8 \\
\hline & HY & 11 & 11 & 9 & 10 \\
\hline & & 564 & 577 & 579 & 574 \\
\hline Total & & & 2294 & & \\
\hline
\end{tabular}

\section{MEDIDAS TOMADAS EN GRANJA}

\subsection{CRECIMIENTO E ÍNDICE DE TRANSFORMACIÓN}

Se realizaron pesadas semanales $(\mathbf{P V}=$ peso vivo) de cada animal individualmente (foto 5) y la Ganancia Media Diaria (GMD) considerando el peso de la semana menos el peso de la semana anterior, es decir para el primer peso que consideramos (semana 8) se halló la diferencia de peso de la semana 8 respecto a la semana 7, y así respectivamente hasta la semana 16. 
En la nave de engorde cada comedero (foto 6) era compartido por 4 gazapos que eran de la misma edad, Línea Genética y género.

Se pesó el consumo de pienso (CP) por comedero correspondiente. Con ambos parámetros se calculó el índice de transformación (IT) del pienso en kg de peso vivo, dividiendo el CP semanal entre el incremento de peso semanal de los 4 conejos de ese comedero.

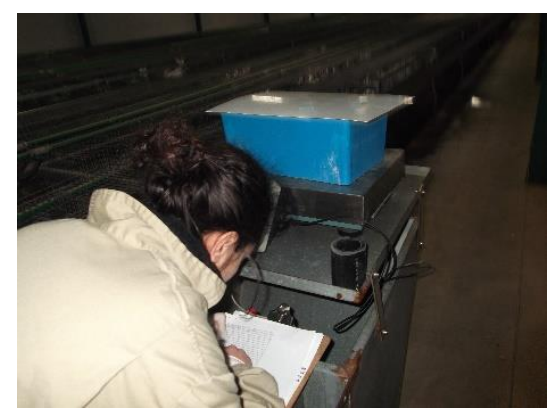

Foto 5. Pesada de un conejo.

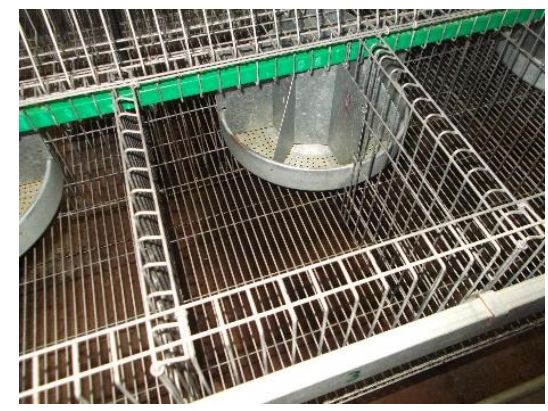

Foto 6. Comedero.

Además se llevó un control de las distintas patologías y anomalías que pudieron aparecer, así como de las bajas. Cuando los animales iban a ser sacrificados, tras el periodo de ayuno, se volvieron a pesar, obteniendo el peso vivo al sacrificio (PVS).

Para todas las pesadas de los animales se utilizó la báscula que se muestra en la foto 7 , que tiene precisión de 1 gramo.

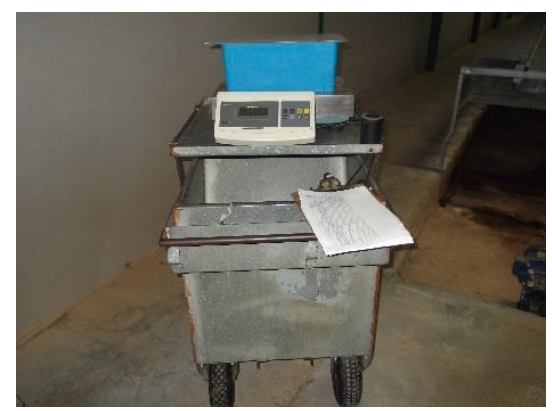

Foto 7. Báscula y carro. 


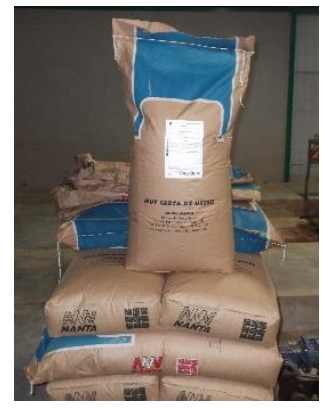

Foto 8 . Sacos de $40 \mathrm{~kg}$ con pienso utilizado en la prueba.

Una vez los animales eran aturdidos por descarga eléctrica $(100 \mathrm{~V}, 50 \mathrm{~Hz})$ eran sacrificados por exanguinación. Posteriormente se realizaron distintas medidas de calidad de canal y de carne en el matadero; y se procedió a la toma de muestras que después sirvieron para evaluar su calidad de carne en el laboratorio.

\section{MEDIDAS DE CALIDAD DE LA CANAL}

\subsection{PESO Y RENDIMIENTO DE LA CANAL}

A los 45 minutos post-mortem (p.m.), al final de la línea de sacrificio, se pesó la canal caliente (PCC) y se midió el pH a los 45 minutos. Esta canal debe ir desangrada, sin piel, sin partes distales de las patas, sin contenido gastrointestinal ni urogenital (Blasco \& Ouyahoun, 1993). También se pesó la piel (Ppiel).

Tras estas medidas, las canales fueron transportadas en un camión frigorífico hasta la cámara frigorífica (fotos 9-10) anexa al laboratorio a 4 으.

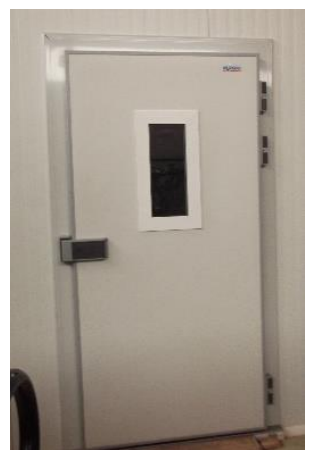

Foto 9. Cámara frigorífica 


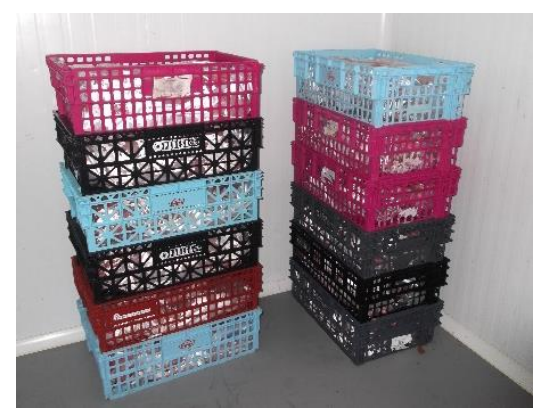

Foto 10. Canales almacenadas en interior de la cámara frigorífica

A las 24 horas post mortem (p.m.), se pesó la canal fría (PCF) (foto 11).

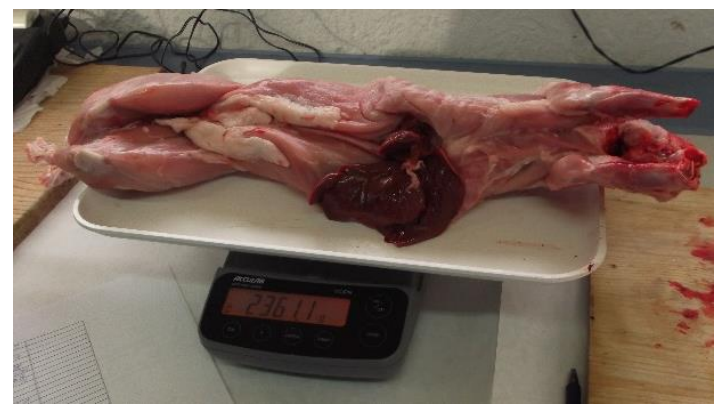

Foto 11. Peso Canal Fría

Con los pesos de las canales caliente y fría, se calculó el rendimiento canal ( $\boldsymbol{\eta}_{\text {canal }}$ ) con la siguiente expresión:

$$
\eta_{\text {canalfria }}=100 * \mathrm{PCF} / \mathrm{PVS}
$$

\subsection{MEDIDAS LINEALES DE LA CANAL}

Antes del despiece de la canal se realizaron las medidas siguientes según Blasco \& Ouyahoun (1993) (figura 2) (foto 12):

DL (Dorsal Lenght) $\rightarrow$ longitud medida entre la vértebra atlas y la 7ạ vértebra lumbar.

TL (Thigh Length) $\rightarrow$ longitud medida entre la 7ạ vértebra lumbar y la parte distal del isquion.

$\mathrm{CL}$ (Carcass Lenght) $\rightarrow$ longitud de la canal expresado como la suma de DL $+\mathrm{TL}$

LCL (Lumbar Circunference) $\rightarrow$ perímetro de la canal a nivel de la 7ạ vértebra lumbar. 
Se calculó la compacidad con la siguiente ecuación:

Compacidad $=$ Peso canal referencia $/(D L+T L)$

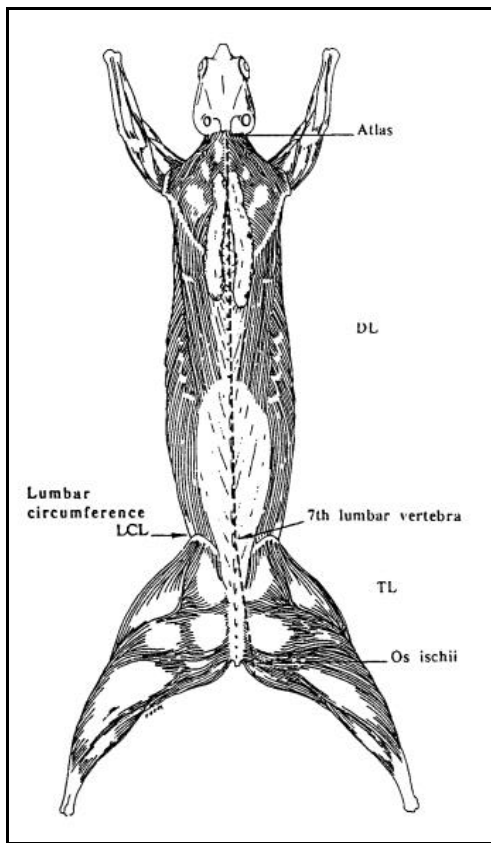

Figura 2. Medidas lineales (Blasco \& Ouhayoun, 1993)

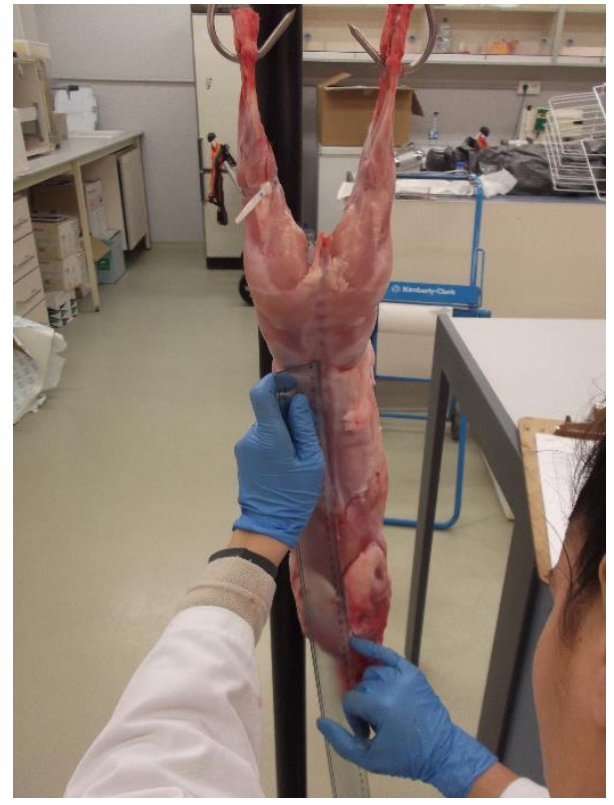

Foto 12. Midiendo canal

\subsection{PIEL, CONJUNTO DE PULMONES, CORAZÓN, TRÁQUEA, ESÓFAGO Y TIMO,} RIÑONES, HÍGADO, GRASAS Y CABEZA

Después se procedió a separar y pesar la cabeza (Pcabeza), el hígado (Phígado), los riñones (Priñones) y el conjunto tráquea, pulmones, corazón, timo y esófago (Presto). Se calculó el Peso Canal de Referencia (PCR) (Pascual et al., 2007) como PCR = PCF Pcabeza - Phígado - Priñones - Presto; y el porcentaje de cada una de estas partes respecto a PVS:

- \%CAB: Porcentaje de cabeza

$$
\% C A B=100 * \text { Pcab/PVS }
$$

○ \%HIG: Porcentaje de hígado

$$
\% \mathrm{HIG}=100 * \text { Phig/PCF }
$$

○ \%RIÑ: Porcentaje de riñones

$$
\% \text { RIÑ }=100 * \text { Priñ/PCF }
$$


○ \%COR: Porcentaje de conjunto de órganos consistente en el timo, la tráquea, el esófago, los pulmones y el corazón

$$
\% \text { COR }=100 * \text { Pcor } / \text { PCF }
$$

\subsubsection{Tipos de grasa}

A continuación, se procedió a la disección de la grasa perirrenal, escapular e inguinal. Anotando el peso de cada una de ellas: PGesc, PGing y PGper. Con estos tres pesos se obtuvo el Peso Grasa diseccionable, definido como: PGdis = PGesc + PGing + PGper

○ \%Gdis: Porcentaje de grasa diseccionable $\%$ Gdis $=100 *$ PGD/PCF

- \%Gesc: Porcentaje Grasa escapular $\%$ Gesc $=100 *$ PGesc $/ \mathrm{PCF}$

- \%Gper: Porcentaje Grasa perirrenal $\%$ Gper $=100 *$ PGper/PCF

- \%Ging: Porcentaje Grasa inguinal $\%$ Ging $=100 *$ PGing $/$ PCF

\subsection{DESPIECE Y DISECCIÓN DE LA CANAL}

Se realizó el despiece y el pesado, según los criterios establecidos por Blasco \& Ouyahoun, (1993) en patas delanteras y traseras (Ppdelanteras, Pptraseras), lomo (Plomo), conjunto de la caja torácica, que incluye: pecho, costillas y pared abdominal (Pcaja) (foto 13).

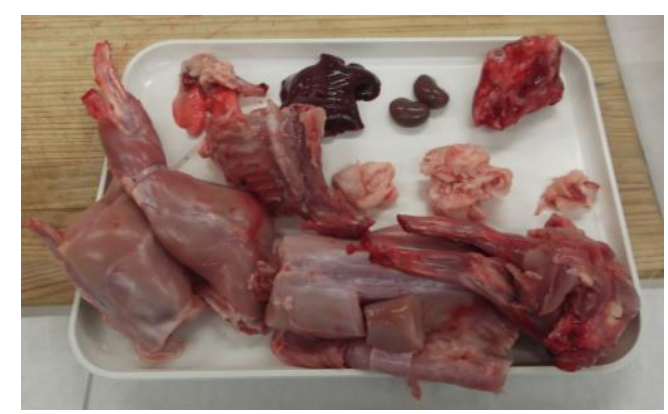

Foto 13. Despiece

○ \%ptraseras: Porcentaje patas traseras \%ptraseras $=100 *$ Pptraseras $/$ PCF 
○ \%pdelanteras: Porcentaje patas delanteras $\%$ pdelanteras $=100 *$ Ppdelanteras $/$ PCF

○ \%caja: Porcentaje caja torácica $\%$ caja $=100 *$ Pcaja $/$ PCF

○ \%lomo: Porcentaje de lomo $\%$ lomo $=$ Plomo/PCF

\subsection{RELACIÓN MÚSCULO-HUESO}

Además, se realizó la disección de una pata trasera sobre la que se estimó la relación músculo-hueso $(\mathbf{M} / \mathbf{H})$. Para el cálculo de este ratio se pesaron: la pata completa (Ppata), el músculo (M) y el hueso (H). Una vez extraído el músculo, se envasó al vacío y se congeló a $-20^{\circ} \mathrm{C}$ para su posterior análisis de contenido en humedad, grasa, proteína y colágeno.

\section{MEDIDAS DE CALIDAD DE CARNE}

\subsection{PH EN EL BICEPS FEMORIS}

Se midió el pH en el Biceps femoris a los 45 minutos (pHBf_45') al final de la línea de sacrificio (foto 14) y a las 24 horas (pHBf_24h) tras la refrigeración (foto 15), mediante un $\mathrm{pH}$-metro $\mathrm{HI}-98230$ (HANNA ${ }^{\mathrm{R}}$ ) equipado con un electrodo metálico ISFET (Ion Sensitive Field Effect Transistor) (foto 16).

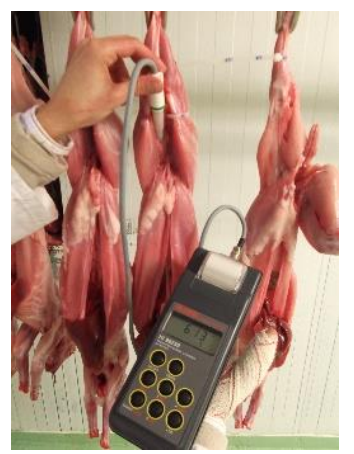

Foto 14. Midiendo el pH45'

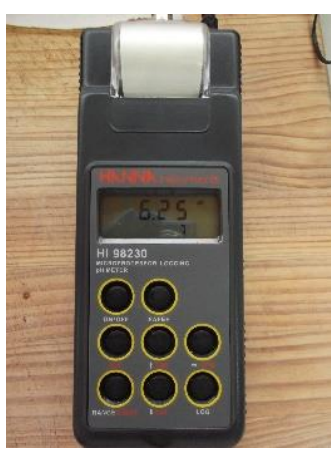

Foto 15. $\mathrm{pH}$-metro

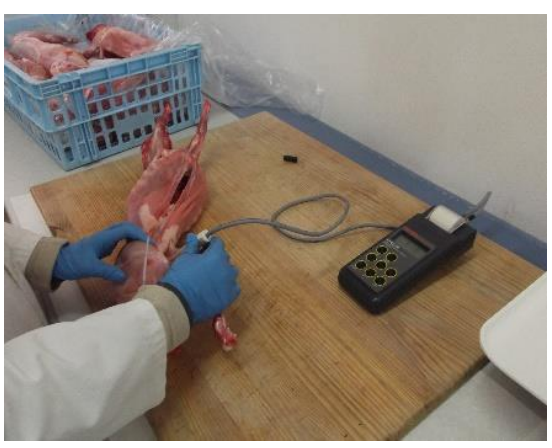

Foto 16. $\mathrm{pH} 24 \mathrm{~h}$ 


\subsection{COLOR}

Se midió el color con un colorímetro Minolta CR-300 (Minolta Camera, Osaka, Japón) sobre los músculos Longissimus dorsi a la altura de la 4a vértebra lumbar y Biceps femoris, y sobre la grasa perirrenal. Los valores se han expresado como luminosidad $\left(L^{*}\right)$, cromatismo (C*ab) y ángulo Hue ( $\left.H^{*} a b\right)(C I E, 1976)$. (foto 17)

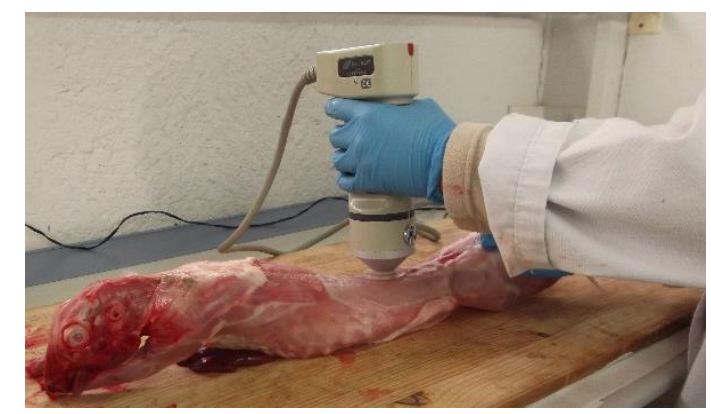

Foto 17. Colorímetro

\subsection{TEXTURA}

Se obtuvo una porción de lomo $\left(1 \times 1 \mathrm{~cm}^{2}\right.$ y $2 \mathrm{~cm}$ de longitud en sentido de las fibras musculares, foto 18)

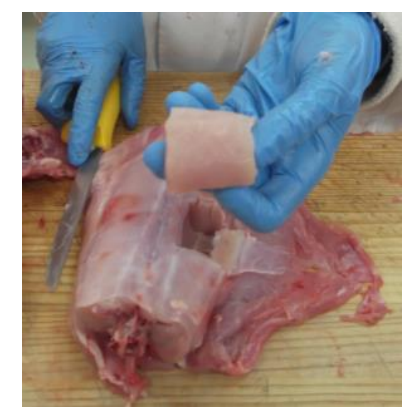

Foto 18. Extracción trozo de lomo

Posteriormente se cocieron a 80 ㄷ C durante una hora al baño María. Una vez cocidos se evaluó la terneza de la carne mediante la prueba de corte según el método WarnerBratzler (WB) (Honikel, 1997) (foto 19). Con este método obtuvimos la Fuerza máxima alcanzada para el corte completo de la muestra, denominado Fuerza máx (MSF_MaximumShearForce) $\left(\mathrm{kg} / \mathrm{cm}^{2}\right)$; y el primer punto de ruptura, relacionado con los componentes miofibrilares, llamado Resistencia máx (IYF_InitialYieldForce) $\left(\mathrm{kg} / \mathrm{s}^{*} \mathrm{~cm}^{2}\right)$. 


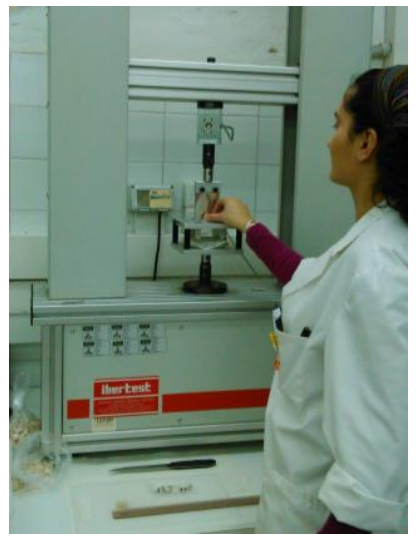

Foto 19. Texturómetro

\subsection{COMPOSICIÓN QUÍMICA DE LA PATA TRASERA}

Dado que las medidas de composición química (grasa, proteína y colágeno) son más laboriosas de obtención nos aseguramos como mínimo analizar una parte de la muestra representativa y suficiente para estimar los efectos simples. Para conocer la composición química del músculo se determinó el porcentaje de humedad (ISO R1442), proteína (ISO R-397) y grasa (ISO 1443). Para la determinación del colágeno se hizo el análisis de la hidroxiprolina (ISO 3496) y la distribución de las muestras analizadas fueron 618 distribuidas como indica la tabla 3. 
Tabla 3. Número de muestras para el análisis de la composición química del músculo según edad de sacrificio (semanas), línea genética (LG), tipo de dieta (C-dieta control y HE-dieta altamente energética) y género (machos y hembras).

\begin{tabular}{|c|c|c|c|c|c|}
\hline \multirow{2}{*}{$\begin{array}{l}\text { EDAD DE SACRIFICIO } \\
\text { (SEMANAS) }\end{array}$} & \multirow{2}{*}{ LÍNEA } & \multicolumn{2}{|c|}{ PIENSO C } & \multicolumn{2}{|c|}{ PIENSO HE } \\
\hline & & MACHOS & HEMBRAS & MACHOS & HEMBRAS \\
\hline & GR & 6 & 5 & 6 & 5 \\
\hline \multirow[t]{3}{*}{8} & HYcol & 6 & 6 & 5 & 6 \\
\hline & HY & 6 & 5 & 6 & 6 \\
\hline & GR & 6 & 6 & 6 & 5 \\
\hline \multirow[t]{3}{*}{9} & HYcol & 6 & 6 & 5 & 6 \\
\hline & HY & 5 & 6 & 6 & 6 \\
\hline & $G R$ & 5 & 6 & 6 & 6 \\
\hline \multirow[t]{3}{*}{10} & HYcol & 6 & 5 & 6 & 5 \\
\hline & HY & 6 & 6 & 6 & 5 \\
\hline & $\mathrm{GR}$ & 6 & 5 & 5 & 6 \\
\hline \multirow[t]{3}{*}{11} & HYcol & 5 & 6 & 6 & 6 \\
\hline & $\mathrm{HY}$ & 6 & 6 & 6 & 6 \\
\hline & GR & 5 & 6 & 6 & 6 \\
\hline \multirow[t]{3}{*}{12} & HYcol & 6 & 6 & 5 & 5 \\
\hline & HY & 5 & 6 & 6 & 5 \\
\hline & GR & 6 & 6 & 6 & 6 \\
\hline \multirow[t]{3}{*}{13} & HYcol & 5 & 5 & 5 & 6 \\
\hline & $\mathrm{HY}$ & 6 & 6 & 6 & 6 \\
\hline & $\mathrm{GR}$ & 6 & 6 & 6 & 5 \\
\hline \multirow[t]{3}{*}{14} & HYcol & 6 & 6 & 6 & 6 \\
\hline & HY & 6 & 5 & 5 & 6 \\
\hline & $\mathrm{GR}$ & 6 & 6 & 6 & 6 \\
\hline \multirow[t]{3}{*}{15} & HYcol & 5 & 6 & 6 & 6 \\
\hline & HY & 6 & 5 & 6 & 6 \\
\hline & $\mathrm{GR}$ & 6 & 6 & 6 & 6 \\
\hline \multirow[t]{3}{*}{16} & HYcol & 6 & 6 & 5 & 6 \\
\hline & HY & 5 & 6 & 5 & 6 \\
\hline & & 154 & 155 & 154 & 155 \\
\hline Total & & & 618 & & \\
\hline
\end{tabular}

\subsection{PERFIL DE ÁCIDOS GRASOS}

De 150 muestras de carne de patas traseras congeladas, 25 muestras por cada línea genética de ambas dietas (Control $=\mathrm{C}$ y Altamente energética $=\mathrm{HE}$ ), para dos edades de sacrificio ( 8 semanas y 12 semanas) y machos y hembras, se realizó un análisis de su perfil de ácidos grasos (Tabla 4). 
Tabla 4. Número de muestras para el análisis de perfil de ácidos grasos según edad de sacrificio (semanas), línea genética (LG), tipo de dieta (C-dieta control y HE-dieta altamente energética) y género (machos y hembras).

\begin{tabular}{cccccc}
\hline \multirow{2}{*}{$\begin{array}{c}\text { EDAD DE SACRIFICIO } \\
\text { (SEMANAS) }\end{array}$} & LÍNEA & \multicolumn{2}{c}{ PIENSO C } & \multicolumn{2}{c}{ PIENSO HE } \\
\cline { 3 - 6 } & & MACHOS & HEMBRAS & MACHOS & HEMBRAS \\
\hline \multirow{2}{*}{8} & GR & 6 & 6 & 6 & 7 \\
& HYcol & 6 & 6 & 7 & 6 \\
& HY & 7 & 6 & 6 & 6 \\
\hline \multirow{2}{*}{12} & GR & 6 & 7 & 6 & 6 \\
& HYcol & 7 & 6 & 6 & 6 \\
& HY & 6 & 6 & 6 & 7 \\
\hline & & 38 & 37 & 37 & 38 \\
\hline
\end{tabular}

Las muestras de carne fueron picadas, congeladas y liofilizadas. El protocolo de análisis de ácidos grasos fue el de los esteres metílicos de ácidos grasos (FAMEs) usando una solución de $\mathrm{KOH}$ en metanol (IOfS, 2002). La síntesis directa de FAME (Fatty Acid Methyl Esters) se hizo siguiendo un protocolo adaptado de O'Fallon et al. (2007). Se utilizó ácido tridecanoico como estándar interno, posteriormente se separaron y se analizaron por cromatografía de gases. Los análisis se realizaron en un cromatógrafo de gases 6890 (Agilent Technologies, Palo Alto, CA, EE. UU.) equipado con un muestreador de Propósitos Múltiples GERSTEL (MPS2) y un espectrómetro de masas 5975 con un cuadrupolo hiperbólico (Agilent Technology). El extracto $(0,8 \mu l)$ de FAMEs se inyectó y se separó en una columna capilar DB-23 (Agilent Technologies) de $60 \mathrm{~m}$ (longitud) $\times$ 0,25 $\mathrm{mm}$ (diámetro interno) × 0,25 $\mu \mathrm{m}$ (película) en modo de presión constante. Se utilizó helio de grado cromatográfico como gas portador. La temperatura del inyector era de 240 ㄷ. La entrada funcionaba en modo dividido con una relación de división de 1:20. La temperatura inicial del horno fue de $50{ }^{\circ} \mathrm{C}$ y se mantuvo durante 1 minuto, aumentó a $175^{\circ} \mathrm{C}$ a $25{ }^{\circ} \mathrm{C}$ por minuto y luego aumentó a $235^{\circ} \mathrm{C}$ a $4{ }^{\circ} \mathrm{C}$ por minuto, con un tiempo de espera de $10 \mathrm{~min}$. Los espectros de masas se recogieron en el intervalo de exploración m / z 40-400. Las mediciones se realizaron utilizando una fuente de iones de bombardeo de electrones con una energía de electrones de $70 \mathrm{eV}$. Las temperaturas de línea de transferencia, fuente y cuadrupolo se ajustaron a 280 , 230 y $150{ }^{\circ} \mathrm{C}$, respectivamente. Los cromatogramas y los espectros de masas se 
evaluaron usando el software ChemStation (G1791CA, Versión D.03.00, Agilent Technol.). Los picos se identificaron mediante la comparación de los tiempos de retención con los estándares FAME (mezcla Supelco 37 Component FAME, Sigma Aldrich, EE. UU.). Los ácidos grasos individuales se expresan como un porcentaje del total de ácidos grasos detectados.

\section{ANÁLISIS ESTADÍSTICO}

\subsection{CRECIMIENTO E ÍNDICE DE TRANSFORMACIÓN}

Para la evolución del peso del animal, se consideró un modelo mixto, también llamado de efectos aleatorios, partiendo del modelo más completo:

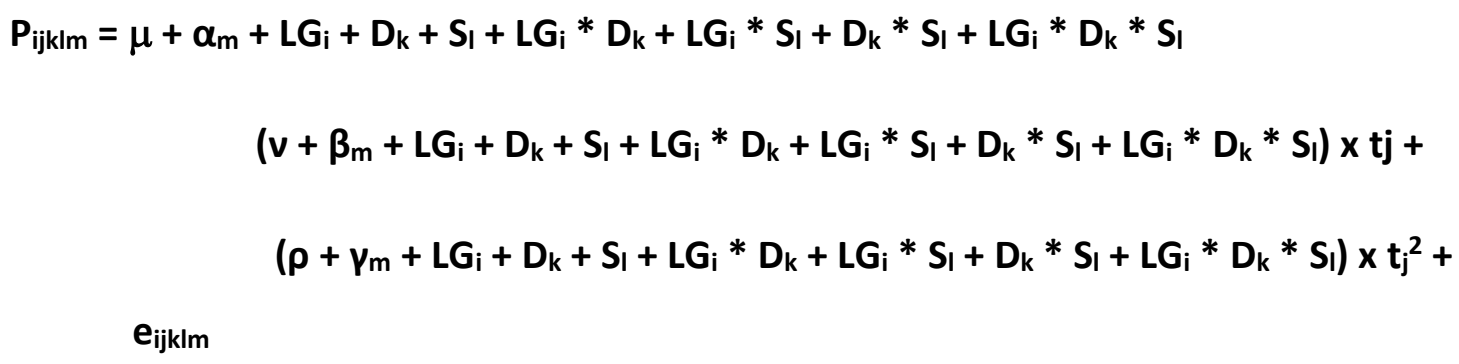

$\mathrm{P}_{\mathrm{ijk} k \mathrm{~m}}$ es el peso del animal $\mathrm{m}$, perteneciente a la línea genética $\mathrm{i}$, alimentado con la dieta k, del género I y a la edad j, LG es el efecto de la línea genética (HYcol, GR o HY), D es el efecto de la dieta (Control o HE), $\boldsymbol{S}$ es el sexo (hembra o macho), $\boldsymbol{\alpha}_{\mathrm{m}}, \boldsymbol{\beta}_{\mathrm{m}}$ Y $\boldsymbol{\gamma}_{\mathrm{m}}$ representa los efectos aleatorios asociados al animal, modelados como variables aleatorias normales independientes. Al igual que en el modelo anterior, e $\mathrm{e}_{\mathrm{ij} / \mathrm{m}}$ es el residual, que asumimos de distribución normal.

$\mathbf{L G}_{\mathbf{i}} * \mathbf{D}_{\mathbf{k}}, \mathbf{L G}_{\mathbf{i}} * \mathbf{S}_{\mathbf{I}}, \mathbf{D}_{\mathbf{k}} * \mathbf{S}_{\mathbf{I}}$ denota la interacción entre los factores línea genética y dieta, línea genética y sexo o dieta y sexo. $\mathbf{L G}_{\mathbf{i}} * \mathbf{D}_{\mathbf{k}} * \mathbf{S}_{\mathbf{I}}$ representa la interacción de orden 3 entre los factores línea genética, dieta y sexo. El término $e_{i j k l}$ es el error, que asumimos de distribución normal.

Los resultados fueron analizados con el paquete Ime4 (Bates et al., 2015) de R (2018) a partir del cual se obtuvieron las estimaciones de los coeficientes.

Seguimos el mismo procedimiento para la selección del modelo: comenzamos con el modelo completo que incluía todos los factores y posibles interacciones entre la línea 
genética, la dieta y el género, y progresivamente los modelos con menos parámetros se computaron y compararon utilizando el criterio de información Akaike (AIC) (Blasco, 2017).

Para el Índice de Transformación, el elemento de muestreo es el comedero, compartido por 4 conejos de mismo sexo. Para el análisis de los datos, consideramos también un modelo mixto de efectos aleatorios completo:

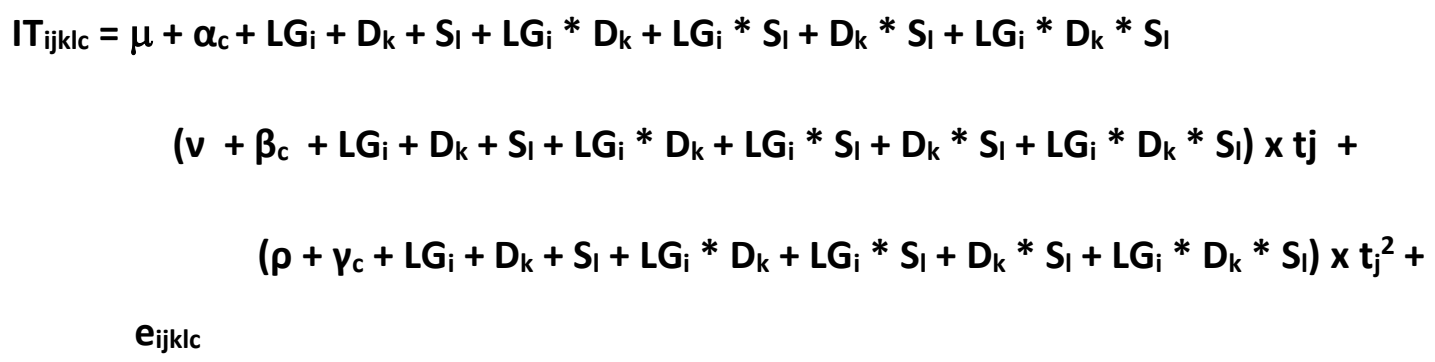

$\mathrm{IT}_{\mathrm{ijklc}}$ es el índice de transformación del comedero c, con cuatro conejos pertenecientes a la línea genética i, alimentados con la dieta $k$, del género I y a la edad j, LG es el efecto de la línea genética (HYcol, GR o HY), D es el efecto de la dieta (Control o HE), S es el sexo (hembra o macho), $\boldsymbol{\alpha}_{c}, \boldsymbol{\beta}_{\mathrm{c}}$ y $\boldsymbol{\gamma}_{\mathrm{c}}$ representa los efectos aleatorios asociados al animal, modelados como variables aleatorias normales independientes, modelado como variable aleatoria normal independiente.

$\mathbf{L G}_{\mathrm{i}} * \mathbf{D}_{\mathbf{k}}, \mathbf{L} \mathrm{G}_{\mathrm{i}} * \mathbf{S}_{\mathrm{I}}, \mathbf{D}_{\mathbf{k}} * \mathrm{~S}_{\mathrm{I}}$ denota la interacción entre los factores línea genética y dieta, línea genética y sexo o dieta y sexo. $\mathbf{L G}_{\mathbf{i}} * \mathbf{D}_{\mathbf{k}} * \mathbf{S}_{\mathbf{I}}$ representa la interacción de orden 3 entre los factores línea genética, dieta y sexo. El término $e_{i j k l}$ es el error, que asumimos de distribución normal.

\subsection{CRECIMIENTO RELATIVO DIFERENCIAL}

Cada variable de interés (variable y, generalmente el peso del componente) se relacionó con el todo (variable $x$, usualmente el peso vivo al sacrificio) mediante la ecuación alométrica de Huxley (1932): $y=b x^{k}$, donde b es un parámetro que relaciona la escala de medida del todo $(x)$ y el componente $(y)$, $k$ siendo el coeficiente alométrico. De acuerdo con esta ecuación, cuando $k<1$ el componente está madurando temprano, cuando $\mathrm{k}>1$ el componente está madurando tarde, y cuando 
$\mathrm{k}=1$ hay isometría, lo que indica que el componente y el conjunto maduran a la misma velocidad.

En la mayoría de los casos, y es el peso del componente y x representa el PVS (Peso Vivo Sacrificio), excepto en el caso en que y representa el porcentaje de IIMF (grasa inter e intramúscular) para el que $\mathrm{x}$ es el peso de la pata trasera. Para las medidas lineales de la canal y se toma como el valor cúbico de la variable considerada (Pascual et al., 2008).

El modelo completo considerando todos los datos fue:

$\log y_{i j l m}=\beta_{i j l}+k_{i j l} \log x_{i j l m}+e_{i j l m}$

donde log $\mathrm{y}_{\mathrm{ijlm}}$ es el logaritmo en base 10 del conejo $\mathrm{m}$ dentro de la línea genética grupal i, dieta j, sexo I para el componente estudiado, $\beta_{\mathrm{ijl}}$ es el valor de log b para la línea genética grupal $\mathrm{i}$, dieta $\mathrm{j}$, sexo $\mathrm{l}$, $\mathrm{k}_{\mathrm{ijl}}$ es el coeficiente alométrico de Huxley de la línea genética de grupo i, dieta j, sexo I, $\log x_{i j l m}$ es el logaritmo en base 10 del PVS o el peso de la pata trasera para el mismo individuo, mientras que $e_{i j l m}$ es el residual, que asumimos de distribución normal.

Todos los análisis se realizaron utilizando el software estadístico R (2018), con sus funciones para el análisis de modelos lineales. Una referencia es Faraway (2014)

\subsection{CANAL Y CARNE}

Cabe señalar que todo el experimento se llevó a cabo con una gran cantidad de animales para considerar en los modelos posibles interacciones entre los efectos, aunque no se encontró interacción significativa. Para la selección del modelo, comenzamos con el modelo completo que incluía todos los factores y posibles interacciones entre la línea genética, la dieta y el género:

$$
\begin{aligned}
V_{i j k l m}=\mu+\alpha_{m}+L G_{i}+D_{k}+S_{I}+L G_{i} * D_{k}+L G_{i} * S_{I}+D_{k} * S_{I}+L G_{i} * D_{k} * S_{I} \\
\left(v+\beta_{m}+L G_{i}+D_{k}+S_{I}+L G_{i} * D_{k}+L G_{i} * S_{I}+D_{k} * S_{I}+L G_{i} * D_{k} * S_{I}\right) \times t j
\end{aligned}
$$


$V_{\mathrm{ijk} k m}$ es la variable del animal $\mathrm{m}$, perteneciente a la línea genética $\mathrm{i}$, alimentado con la dieta k, del género l y a la edad j, LG es el efecto de la línea genética ( $H Y c o l, G R \circ H Y$ ), $D$ es el efecto de la dieta (Control o HE), $\boldsymbol{S}$ es el sexo (hembra o macho), $\boldsymbol{\alpha}_{\mathbf{m}}$ y $\boldsymbol{\beta}_{\mathbf{m}}$ representa el efecto aleatorio asociado al animal, modelado como variable aleatoria normal independiente. Al igual que en el modelo anterior, $\mathrm{e}_{\mathrm{ij} / \mathrm{m}}$ es el residual, que asumimos de distribución normal.

$\mathbf{L G}_{\mathrm{i}} * \mathbf{D}_{\mathbf{k}}, \mathbf{L G}_{\mathrm{i}} * \mathrm{~S}_{\mathrm{I}}, \mathbf{D}_{\mathbf{k}} * \mathrm{~S}_{\mathrm{I}}$ denota la interacción entre los factores línea genética y dieta, línea genética y sexo o dieta y sexo. $\mathbf{L G}_{\mathbf{i}} * \mathbf{D}_{\mathbf{k}} * \mathbf{S}_{\mathbf{l}}$ representa la interacción de orden 3 entre los factores líena genética, dieta y sexo. El término $\mathrm{e}_{\mathrm{ijkl}}$ es el error, que asumimos de distribución normal.

Partiendo de este modelo completo ("full model"), progresivamente los modelos con menos parámetros se computaron y compararon utilizando el criterio de información Akaike (AIC) (Blasco, 2017), para acabar con un modelo simplificado. 
Tabla 5. Resumen de las variables calculadas, tamaño muestral (n) y magnitudes en las que se expresan.

VARIABLES: EXPRESADO EN: $n:$ VARIABLES:

EN:

\begin{tabular}{|c|c|c|c|c|c|}
\hline \multicolumn{3}{|c|}{ CRECIMIENTO } & \multirow{2}{*}{$\begin{array}{l}\text { CALIDAD CANAL } \\
\text { (cont.) }\end{array}$} & \\
\hline PV & $\mathrm{g}$ & 9278 & & & \\
\hline CP & $\mathrm{g} /$ comedero & 2332 & Patasdelanteras & $g, \%$ & 2284 \\
\hline IT & $\begin{array}{l}\mathrm{kg} \text { pienso/kg } \\
\text { carne }\end{array}$ & 2332 & Patastraseras & $g, \%$ & 2281 \\
\hline PVS & g & 9278 & Caja torácica & $g, \%$ & 2285 \\
\hline $\begin{array}{c}\text { CALIDAD } \\
\text { CANAL }\end{array}$ & & & Lomo & $\mathrm{g}, \%$ & 2284 \\
\hline PCC & $\mathrm{g}$ & 2303 & Pata & $g, \%$ & 2280 \\
\hline$\eta_{\text {canal }}$ & & 2288 & $M$ & g & 2261 \\
\hline Ppiel & $\mathrm{g}$ & 2299 & H & g & 2258 \\
\hline$\eta_{\text {piel }}$ & & 2290 & $\mathrm{M} / \mathrm{H}$ & & 2247 \\
\hline PCF & g & 2299 & Humedad & $\%$ & 660 \\
\hline$\eta_{\text {canalfria }}$ & & 2287 & Proteína & $\%$ & 660 \\
\hline PCR & $g, \%$ & 2279 & Grasa & $\%$ & 660 \\
\hline Longitudes & $\mathrm{cm}$ & 2203 & Colágeno & $\%$ & 660 \\
\hline Gesc & $g, \%$ & 2281 & CALIDAD CARNE & & \\
\hline Ging & $\mathrm{g}, \%$ & 2284 & pHBf_45' & & 2303 \\
\hline Gper & $g, \%$ & 2282 & pHBf_24h & & 2287 \\
\hline Gdis & $g, \%$ & 2278 & Color & $L^{*}, C^{*}, H^{*}$ & 1011 \\
\hline Hígado & $g, \%$ & 2285 & Terneza: & & 2303 \\
\hline Riñones & $g, \%$ & 2280 & MSF & $\mathrm{kg} / \mathrm{cm}^{2}$ & 1331 \\
\hline $\begin{array}{l}\text { Vísceras } \\
\text { corazón }\end{array}$ & $g, \%$ & 2274 & IYF & $\mathrm{kg} / \mathrm{s}^{*} \mathrm{~cm}^{2}$ & 1336 \\
\hline Cabeza & $g, \%$ & 2287 & Ácidos grasos & $\%$ & 150 \\
\hline
\end{tabular}

PV: Peso Vivo, CP: Consumo Pienso, IT: Índice Transformación, PVS: Peso Vivo Sacrificio, PCC: Peso Canal Caliente, ncanal: rendimiento canal, Ppiel: peso piel; npiel: rendimiento Piel, PCF: Peso Canal Fría, ncanalfría: rendimiento canal fría, PCR: Peso Canal Referencia, Gesc: Peso y porcentaje de grasa escapular; Ging: peso y porcentaje de grasa inguinal, Gper: peso y porcentaje de grasa perirrenal, Gdis: peso y porcentaje de grasa diseccionable, Hígado: peso y porcentaje de hígado, Riñones: peso y porcentaje de riñones, Vísceras corazón: peso y porcentaje de conjunto de tráquea, esófago, timo, pulmones y corazón, Cabeza: peso y porcentaje de cabeza, Patasdelanteras: peso y porcentaje de patas delanteras, Patastraseras: peso y porcentaje de patas traseras, Caja torácica: peso y porcentaje de caja torácica, , Lomo: peso y porcentaje de lomo, Pata: Peso Pata trasera, M: peso del músculo de la pata trasera, $\mathbf{H}$ : peso del hueso de la pata trasera, $\mathbf{M} / \mathbf{H}$ : relación músculo-hueso, pHBf_45': pH en el Biceps femoris a los 45 minutos del sacrificio, pHBf_24h: pH en el Biceps femoris a las 24 horas del sacrificio, MSF: Maximun Shear Force o Máxima Fuerza de corte, IYF: Initial Yield Force o Fuerza de ruptura inicial 


\section{RESULTADOS Y DISCUSIÓN}

\section{1_CARACTERES DE CRECIMIENTO}

\subsection{EVOLUCIÓN DEL PESO, GANANCIA MEDIA DIARIA E ÍNDICE DE TRANSFORMACIÓN EFECTO DE LA LÍNEA GENÉTICA}

En este apartado se va a describir el efecto de la línea genética si bien más adelante se matizará cuando se trate la interacción que presenta la línea genética con la dieta.

En la evolución del peso no hubo diferencias significativas en las primeras semanas del ensayo (de la semana 8 a la 10) entre las tres líneas genéticas comparadas (figura 1). Las tres líneas genéticas empezaron con los siguientes pesos medios a la semana 8, Hyla-colored: 1844 g \pm 10,41; Grimaud: 1823 g $\pm 10,91$ e Hyla: 1848 g $\pm 12,32$. En la semana 12, las líneas mejoradas por crecimiento (HYcol y GR) tuvieron mayor peso que la línea de aptitud maternal (HY). Y desde la semana 13 a la 15 GR tuvo mayor peso que HY, e Hyla se mantuvo con pesos intermedios (figura 1). Al final, en la semana 16 los pesos medios fueron GR: $3899 \mathrm{~g} \pm$ 23,64; HYcol: $3742 \mathrm{~g} \pm$ 42,11; e HY: $3619 \mathrm{~g} \pm$ 59,80. Dalle Zotte et al. (2015) y Szendrö et al. (2015) encontraron diferencias significativas entre dos líneas seleccionadas por ganancia media diaria, observando que la línea Large mostraba mayor peso a la semana 12 (3109 g $\pm 15,7)$ que la otra línea Hung $(2881$ g \pm 15,7) cuyo origen era una línea autóctona de Hungría conocida por el gran tamaño que alcanzaban los machos, denominados 'Gigantes Húngaros'. Comparando con nuestros resultados, la línea Large presentó valores similares a las líneas HYcol y GR, y la línea Hung fue parecida a la línea HY. Robert et al. (2017) en el estudio comparativo del peso y el porcentaje del despiece y del rendimiento de la piel para dos líneas macho de Hyla (A y B) seleccionadas por ganancia media diaria desde los 35 a los 70 días de edad y por rendimiento de canal encontraron diferencias significativas en el peso al sacrificio a las 10 semanas respecto a las dos líneas genéticas (línea A: 2776 g \pm 8,40; línea B: 2874,4 g \pm 8,42). Bianospino et al. 2006 estudiaron las diferencias entre una línea sintética de Botucatu (Straightbred), y otro grupo resultante del cruce de machos de Botucatu con hembras de Gigante Blanco 
Alemán (Crossbred); y no encontraron diferencias significativas en el peso de canal de referencia (Straightbred: 1020,3 g $\pm 5,7$; Crossbred: $1017,3 \mathrm{~g} \pm 5,7$ ) y el peso de la canal fría (Straightbred: 1253,1 g \pm 4,9; Crossbred: 1261,0 g $\pm 4,9$ ) cuando fue corregida por el peso al sacrificio.

Por otro lado, Nasr et al. (2017) estudiaron nueve genotipos de cruces factoriales entre 3 razas puras (New Zealand White - NZW y Californian - CA seleccionadas por aptitud maternal y Rex -RX seleccionada por la calidad de su pelo) para comprobar si mejoraban diferentes caracteres de crecimiento desde la semana 4 a la 10 de edad; y no encontraron diferencias significativas en el peso al sacrificio en todos los cruces realizados, obteniendo para sus líneas mejoradas por aptitud maternal pesos inferiores (NZW x NZW : 1885,71 g $\pm 159,52$ y CA x CA: 1968,21 g $\pm 159,52$ ) a los obtenidos en nuestro estudio para HY a las 10 semanas $(2406 \mathrm{~g} \pm 3,04)$.

Por tanto el efecto de la línea genética sobre el ritmo de crecimiento depende de las líneas comparadas ya que cada línea ha tenido un proceso de selección diferente por un determinado tiempo. 


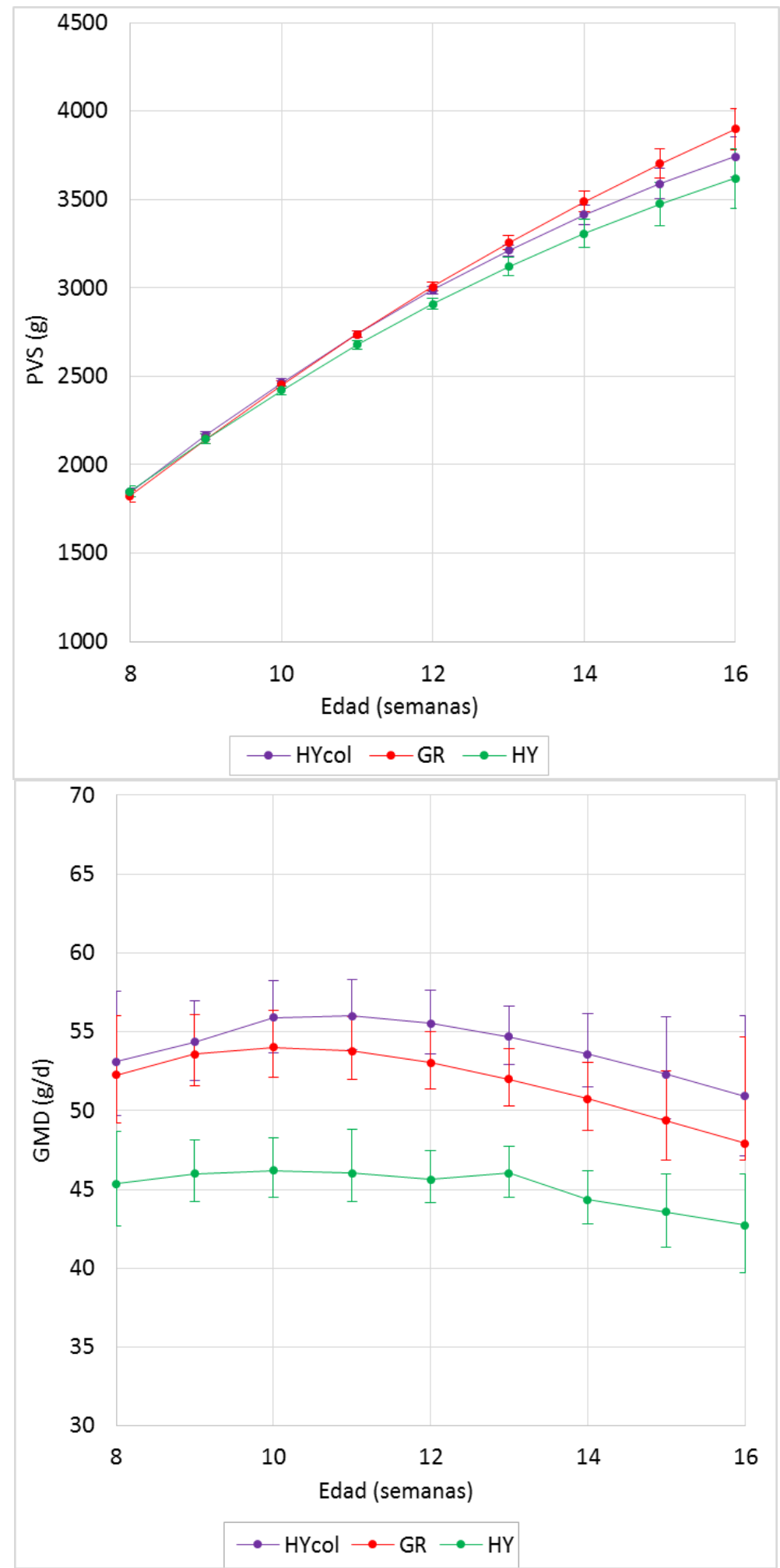

Figura 1. Evolución del Peso Vivo al Sacrifico (PVS) (g) y la Ganancia Media Diaria (GMD) (g/día) con la edad (semanas) según la línea genética (HYcol: Hyla-colored, GR: Grimaud, HY: Hyla; Medias mínimo cuadráticas e intervalos de confianza). 


\section{Ganancia Media Diaria}

Las dos líneas seleccionadas por velocidad de crecimiento (HYcol y GR) presentaron mayor Ganancia Media Diaria (GMD g/día) que la línea de aptitud maternal (HY) a lo largo de todo el periodo estudiado (figura 1), con diferencias que oscilan entre 70-140 g/día en la semanas $8 ; 26-31$ g/día en la semana 11 y $41-52$ g/día en la semana 16 . En las líneas HYcol y GR la GMD fue creciente hasta la semana 10-11, momento a partir del cual empieza a disminuir. Nuestros resultados están de acuerdo con Feki et al. (1996) que encontraron diferencias en la ganancia media diaria entre dos líneas seleccionadas por caracteres reproductivos (tamaño de camada al destete, líneas A y V) y una línea seleccionada por caracteres de crecimiento (selección por peso a una determinada edad, R) estudiadas en dos bloques de semanas de edad del animal destetado, desde la semana 4 a la 6 y desde la semana 7 a la semana 9 . Vieron que desde la semana 4 a la 6 ya había diferencias significativas entre las tres líneas ( $A: 35,0$ $\mathrm{g} \pm 0,34 ; \mathrm{R}: 45,5 \mathrm{~g} \pm 0,33$ y $\mathrm{V}: 37,6 \mathrm{~g} \pm 0,34)$, y desde la semana 7 a la semana 9 se mantuvieron estas diferencias ( $\mathrm{A}: 37,9 \mathrm{~g} \pm 0,25 ; \mathrm{R}: 48,0 \mathrm{~g} \pm 0,26$ y $\mathrm{V}: 39,2 \mathrm{~g} \pm 0,25$ ). Siendo $\mathrm{R}$ la que presentaba mayor ritmo de crecimiento con diferencias respecto a la línea $\mathrm{V}$ de $8,8 \mathrm{~g} / \mathrm{d}$ y de $10,1 \mathrm{~g} / \mathrm{d}$ respecto a la línea $\mathrm{A}$. HY presentó una GMD más constante desde la semana 8 hasta la 13, momento a partir del cual empieza a descender, haciéndolo más lentamente que las líneas HYcol y GR.

\section{$>$ Índice de transformación}

El Índice de Transformación (IT) en la semana 8 tomó un valor promedio que osciló en el intervalo 3,26 - 3,77 para la línea HYcol a 3,60 - 4,10 para la HY. Posteriormente mostró incrementos que fueron crecientes, desde 0,45 de la semana 8 a la 9 hasta 0,79 de la semana 15 a la semana 16 (figura 2).

La línea genética HYcol presentó menor IT que la línea HY en las semanas de la 9 a la 13 ambas inclusive; a partir de la semana 13 la precisión de la estima empeoró, debido a que disminuyó el número de datos, y la diferencia HYcol-HY no llegó a ser significativa. Respecto a la línea GR presentó un valor de IT intermedio no llegando a ser diferente a ambas líneas Hyla (figura 2). Szëndro et al. (2015) no observaron efecto de la línea genética en el índice de transformación entre las semanas 5 y 12 para dos 
líneas (semana 12: Large: 4,76 $\pm 0,12$ y Hung: 4,07 $\pm 0,12(P: 0,082)$ ) seleccionados para mejorar el crecimiento. En nuestro caso hubo diferencias significativas entre la línea de aptitud maternal (Hyla) y una de las líneas seleccionadas por velocidad de crecimiento (Hyla-colored) entre las semanas 9 y 13 . Y nuestros valores de IT a la semana 12 fueron superiores (HYcol: 5,53 \pm 0,40; GR: 5,83 $\pm 0,40$; HY: 6,01 $\pm 0,43$ ) que los de Szëndro et al. (2015).

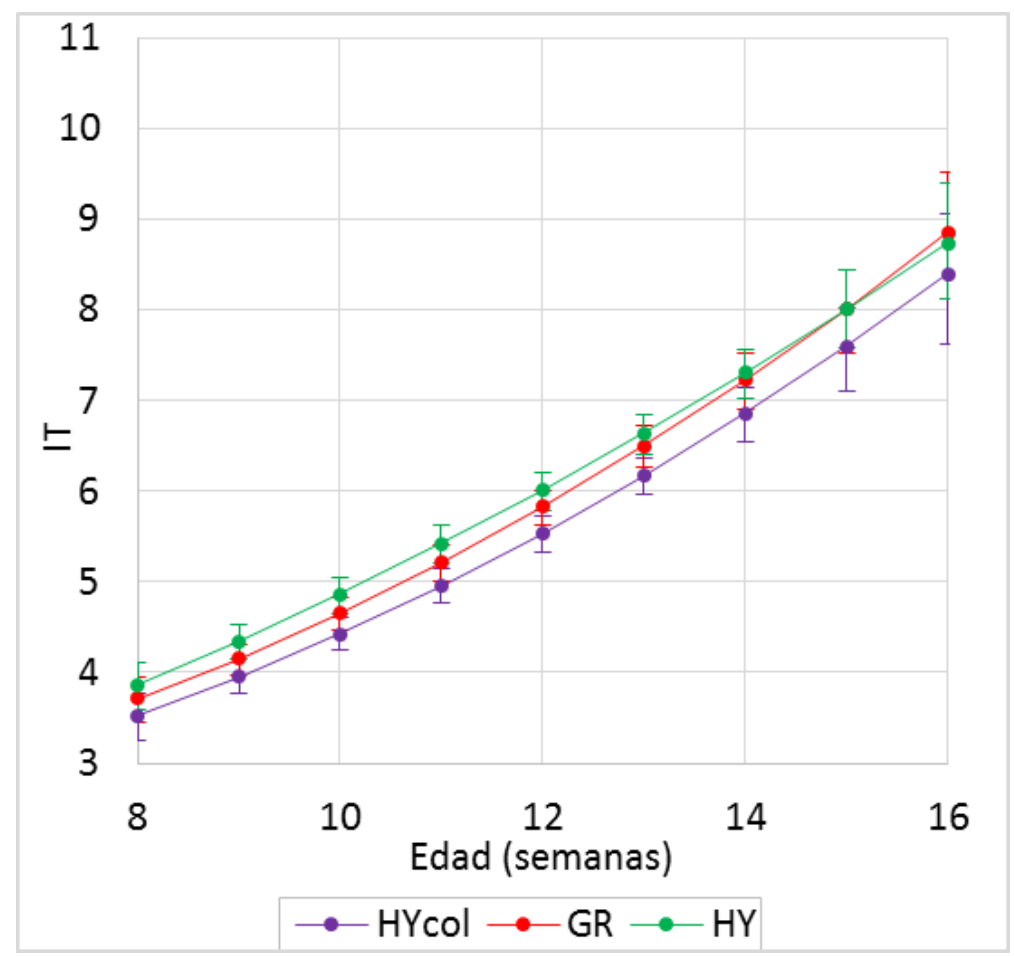

Figura 2. Evolución del índice de Transformación (IT) con la edad (semanas) según la línea genética. (HYcol: Hyla-colored, GR: Grimaud, HY: Hyla; Medias mínimo cuadráticas e intervalos de confianza).

\section{EFECTO DE LA DIETA}

\section{Evolución del peso y Ganancia Media Diaria}

Los conejos alimentados con el pienso control (C; ED $2100 \mathrm{Kcal} / \mathrm{kg}$, FND $=40 \%$ sobre MS) ya casualmente desde la primera semana de estudio pesaron menos (semana 8: $1938 \mathrm{~g} \pm 20,38$ ) que los alimentados con el pienso más energético (semana 8: $1954 \mathrm{~g} \pm$ 20,00) $(\mathrm{HE}=\mathrm{High}$ Energy; ED $2400 \mathrm{Kcal} / \mathrm{kg}, \mathrm{FND}=35 \%$ sobre $\mathrm{MS})$ y esta diferencia se incrementó a lo largo del periodo estudiado (figura 3). A la semana 11 los animales alimentados con la dieta control pesaron 2756 g $\pm 23,15$ y los de la dieta más energética pesaron $2878 \mathrm{~g} \pm 23,76$. Y en la última semana los pesos fueron $3717 \mathrm{~g} \pm$ 
45,75 con la dieta C y $3862 \mathrm{~g} \pm 62,48$ para la dieta HE. En nuestro caso los conejos alimentados con una dieta más energética alcanzaron más peso que los alimentados por la dieta control; al contrario que Gidenne et al. (1995) que estudiaron el efecto del contenido en fibra en el crecimiento de conejos, y señalaron que el grupos de conejos alimentados por una dieta control (Fibra Bruta: 133 g/kg MS; ED: 12,1 MJ/kg MS y almidón: 342 g/kg MS) frente a una dieta baja en fibra (Fibra Bruta: 92 g/kg MS; ED: 14,1 MJ/kg MS y almidón: $396 \mathrm{~g} / \mathrm{kg} \mathrm{MS)} \mathrm{no} \mathrm{les} \mathrm{afectó} \mathrm{la} \mathrm{fibra} \mathrm{en} \mathrm{la} \mathrm{ganancia} \mathrm{de} \mathrm{peso} \mathrm{de}$ los conejos durante el periodo de engorde de 28 a 77 días; alcanzando un peso a los 77 días de 2461 g \pm 188 con la dieta control y 2466 g \pm 188 con la dieta baja en fibra, que a su vez es la dieta más energética.

Pascual et al. (2014) en el estudio en caracteres de crecimiento de dietas con niveles de fibra diferentes, obtuvieron que los conejos alimentados con el pienso más fibroso (Fibra Neutro Digestible (FND): 374 g/kg MS sobre MS, Fibra Ácido detergente (FAD): $217 \mathrm{~g} / \mathrm{kg}$ MS y almidón: $69 \mathrm{~g} / \mathrm{kg}$ MS) ganan menos peso (31,5 g/día) desde la semana 6 a la semana 9 que los alimentados con menor contenido en fibra (FND: $329 \mathrm{~g} / \mathrm{kg} \mathrm{MS}$ sobre MS, Fibra Ácido detergente (FAD): 215 g/kg MS y almidón: 170 g/kg MS), alcanzando un menor peso vivo al sacrificio a los 63 días (2286 \pm 26 vs. $2365 \pm 25$ g).

Paralelamente, a lo largo del periodo estudiado se observó un efecto de la dieta sobre la ganancia media diaria de peso en todas las semanas, excepto en la semana 8 y en la semana 16 (figura 3), siendo mayor con la dieta más energética. La diferencia mínima fue de $50,9 \mathrm{~g} \pm 8,70$ en la semana 9 y la máxima fue de hasta $70,6 \mathrm{~g} \pm 7,20$ en la semana 13. A diferencia de Dalle Zotte et al. (1996) que en su estudio vieron que el tratamiento con diferentes piensos no influyó significativamente en el peso a los 55,80 y 87 días y consecuentemente en la tasa de crecimiento de conejos alimentados con dietas con diferentes niveles energéticos ( $E D=11.28,11.40,11.93$ y $12.16 \mathrm{MJ} / \mathrm{kg} \mathrm{DM}$ ). En el trabajo de Dalle Zotte y Ouhayoun (1998) los piensos utilizados fueron más energéticos (desde 2694,2 hasta 2904,4 kcal/kg) que en nuestro caso (2100 y 2400 $\mathrm{kcal} / \mathrm{kg}$ ), lo que parece indicar que a partir de un nivel de energía ya no existe un efecto sobre el crecimiento de los conejos. 


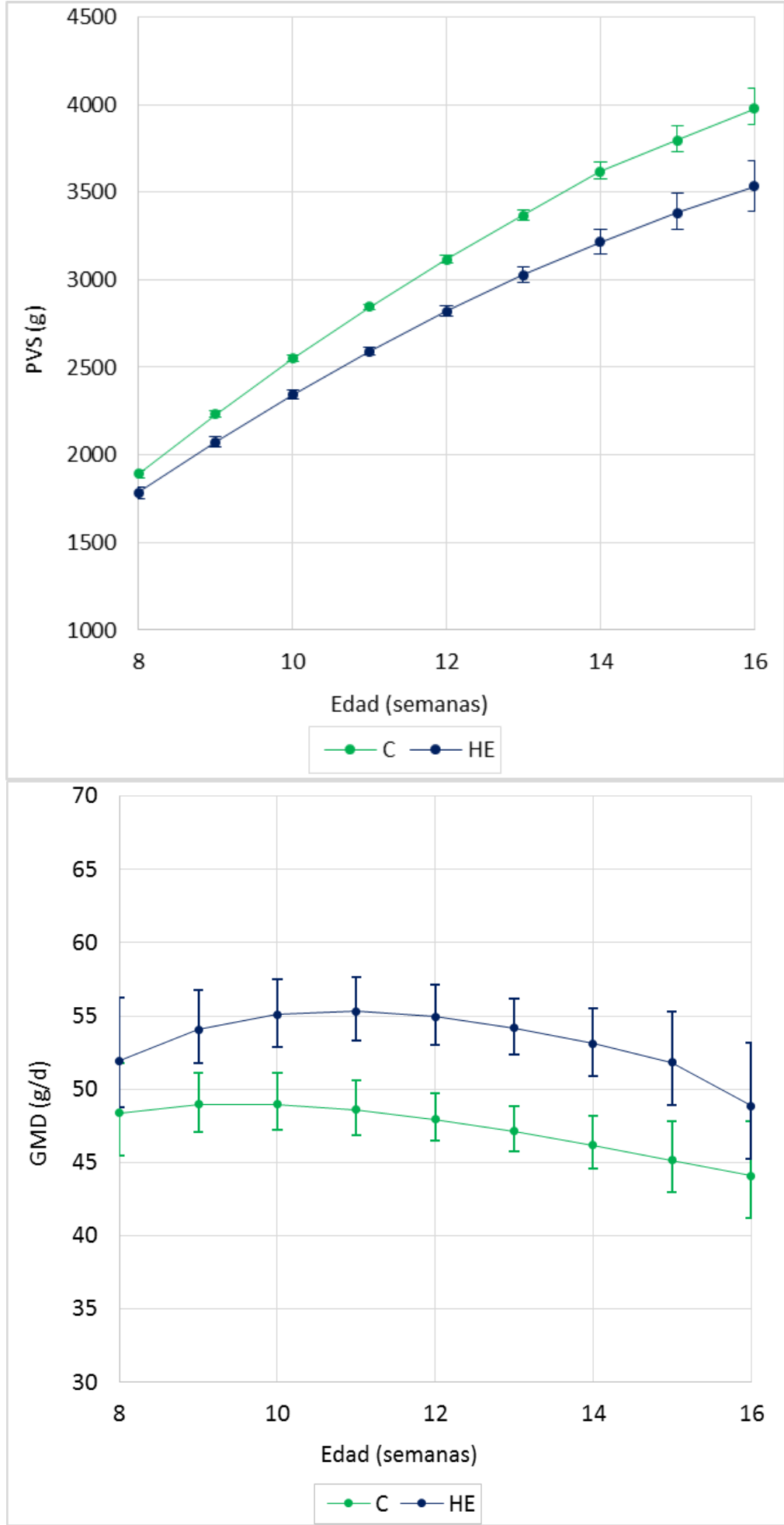

Figura 3. Evolución del Peso Vivo al Sacrifico (PVS) (g) y la Ganancia Media Diaria (GMD) (g/día) con la edad (semanas) en función de la dieta (C: Control, HE: Altamente energética) (Medias mínimo cuadráticas e intervalos de confianza) 


\section{Índice de transformación}

De la semana 10 a la 14 incluidas los conejos que fueron alimentados con la dieta $\mathrm{HE}$ presentaron menor IT que los alimentados con la dieta C (figura 4), con diferencias que oscilaron de 0,46 en la semana 10 a 0,76 en la semana 14. Pascual et al. (2014) no encontraron diferencias en el IT $(3,09$ vs $3.19 \pm 0,06)$ de la semana 6 a la semana 9 para conejos alimentados con diferentes cantidades de fibra $(37,4 \%$ vs. $32,9 \%$ FND/MS), si bien si encontraron un efecto de la fibra de los 17 a los 42 días mejorando el IT a mayor porcentaje de fibra $(1,72 \pm 0,02$ vs $1,96 \pm 0,04$, respectivamente). El trabajo de Pascual et al. (2014) no está desglosado por semanas para poder comparar sus resultado con los nuestros, si bien sus resultados parecen coherentes con nuestros datos en las semanas 8 y 9 (semana 8: dieta C 3,82 $\pm 0,49$, dieta HE 3,58 $\pm 0,51$; semana 9: dieta C 4,33 $\pm 0,36$, dieta HE 3,97 $\pm 0,36)$.

Szendrö et al. (2015) no encontraron un efecto de la inclusión del heno ad libitum en el IT desde la semana 5 a la semana 12. En este trabajo el IT en el intervalo comprendido de la semana 7 a la 9 osciló entre 3,36 - 3,50, valores similares a los que obtuvimos nosotros en la semana 8 . Sin embargo, en nuestro trabajo a partir de la semana 8 tuvimos incrementos de IT semanales en torno a 0,5 ; aumentando desde la semana 8 (dieta C: $3,82 \pm 0,49$; dieta HE: 3,58 $\pm 0,51$ ) a la 12 (dieta C: 6,11 $\pm 0,42$; dieta HE: 5,47 \pm 0,40 ) un promedio para ambas dietas de 2,09 $\pm 0,46$ mientras que en el estudio de Szendrö los incrementos hasta la semana 12 fueron menores (valores obtenidos por Szendrö et al., 2015 en la semana 12: 4,27 - 4,56; y en nuestro trabajo 5,47 para dieta HE y 6,11 para dieta C).

Los conejos que se alimentaron con el pienso más energético alcanzaron mayores pesos que los alimentados con el pienso control (figura 3) en todas las semanas. En nuestro caso, con el pienso $\mathrm{C}$ se partió de pesos iniciales menores lo que hace que finalmente lleguen a menores pesos finales, además los incrementos de peso (figura 3) son peores y además convirtieron peor, por lo que el Índice de Transformación (IT) fue mayor (figura 4). 


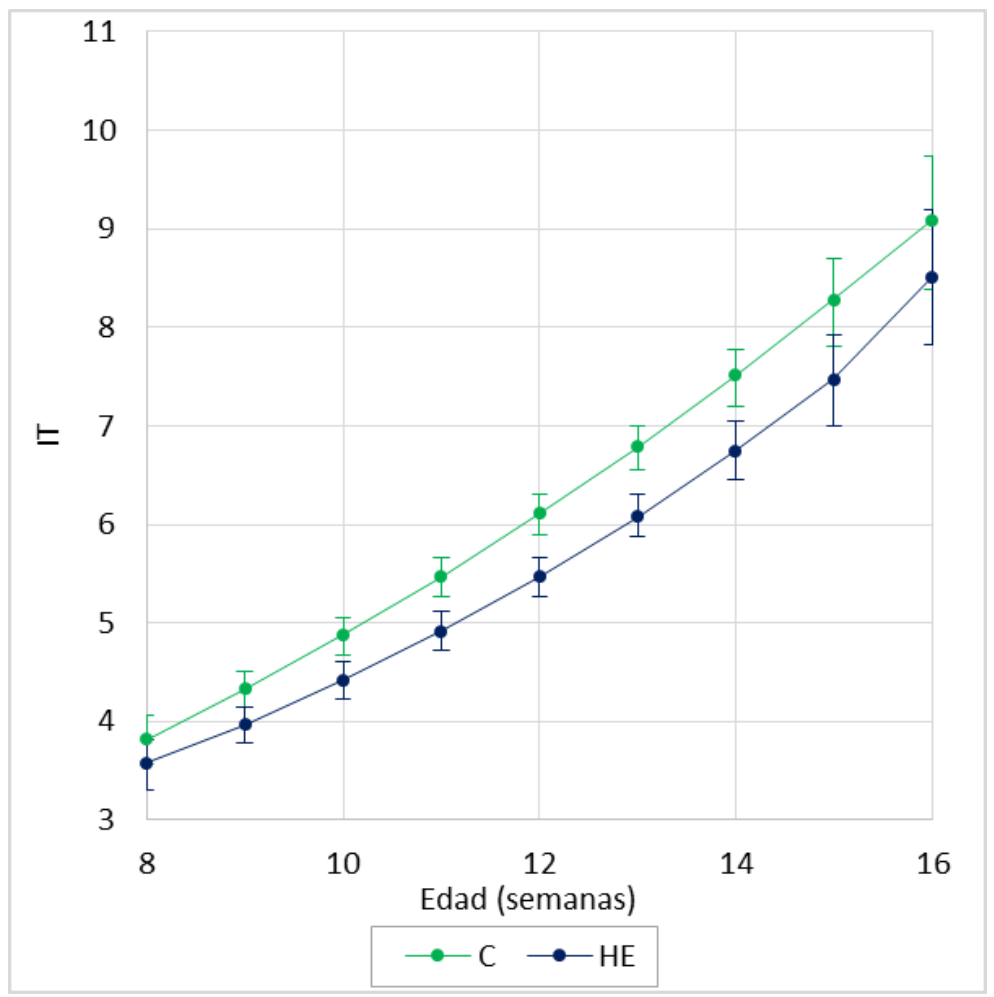

Figura 4. Evolución del Índice de transformación (IT) con la edad (semanas) en función de la dieta (C: Control, HE: Altamente energética) (Medias mínimo cuadráticas e intervalos de confianza).

\section{INTERACCIÓN LÍNEA GENÉTICA X DIETA}

Si bien se ha analizado el efecto de la línea genética y de la dieta de forma independiente, apareció que la interacción entre estos dos factores era significativa, y por tanto los resultados deben ser matizados. En este sentido se observó que el efecto de la dieta dependía de la línea genética considerada. Así, mientras que HYcol no mostraba mayor peso que HY cuando no se consideraba la dieta, al incluir la interacción línea $\mathrm{X}$ dieta ambas líneas seleccionadas por crecimiento presentaron mayor peso que Hyla con ambas dietas (figura 5); y además el cambio a una dieta más energética (HE) suponía un incremento del ritmo de crecimiento para las líneas de aptitud cárnica. Por tanto el tipo de dieta resulta decisivo para que las líneas puedan expresar un mayor potencial de crecimiento.

Szendrö et al. (2015) encontraron una interacción entre la línea genética y la dieta entre la semana 7 y 9 para la ganancia media diaria entre dos líneas genéticas (Large y 
Hung) y señalaron que la interacción no fue destacada porque los efectos fueron estudiados en un periodo de tiempo corto (de 5 a 12 semanas).

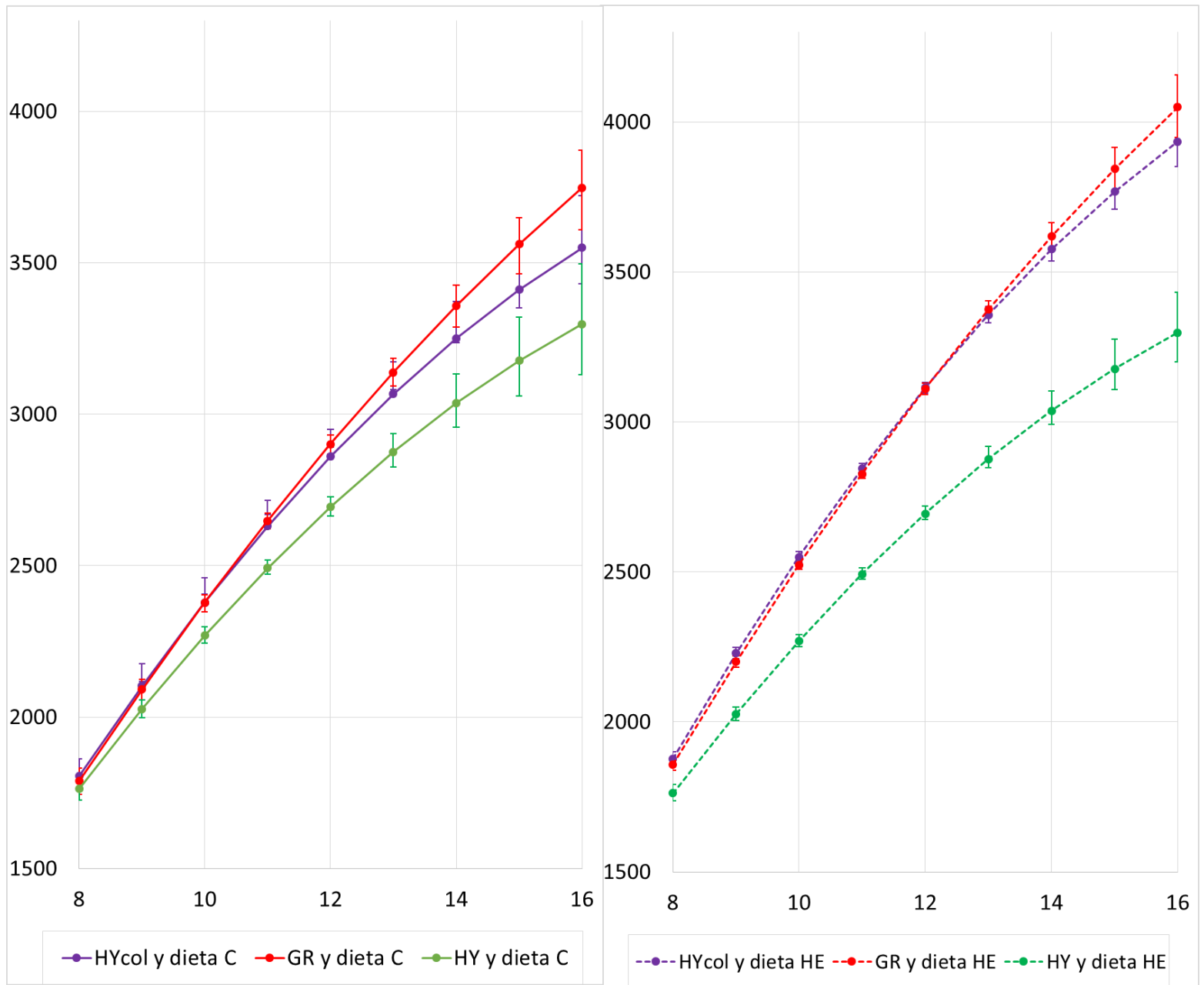

Figura 5. Efecto de la interacción Línea genética * Dieta en la evolución del Peso Vivo al Sacrificio (PVS) (g) con la edad (semanas): modelo estimado (línea continua) e intervalo de confianza (línea discontinua)

\section{EFECTO DEL GÉNERO}

Al inicio del estudio, semanas 8 y 9, no se observó efecto del género en el peso (figura 6), y a partir de la semana 10 las hembras pesaron más que los machos (semana 10; hembras: $2479 \mathrm{~g} \pm 24$; machos: $2412 \mathrm{~g} \pm 20$ ), diferencia que fue aumentando a lo largo del periodo estudiado (semana 12; hembras: $3033 \mathrm{~g} \pm 25$; machos: $2901 \mathrm{~g} \pm 23$ ). Finalmente en la semana 16 las hembras alcanzaron un peso de $3925 \mathrm{~g} \pm 125$ y los machos de $3545 \mathrm{~g} \pm 130$. Sin embargo, en Dalle Zotte et al. (1996) observaron que el peso de los machos era mayor que el de las hembras a los 87 días (hembras: $2253 \mathrm{~g} \mathrm{y}$ machos: $2320 \mathrm{~g})$. 
Para la ganancia media diaria (figura 7) hay diferencias significativas a partir de la semana 13, creciendo más rápidamente las hembras que los machos. En concordancia con la ganancia de peso, partir de la semana 14 es cuando hay diferencias significativas según el género en el índice de conversión (IT) (figura 8), siendo las hembras más eficientes la transformación del pienso.

Si bien, Feki et al. (1996), de la semana 4 a la 9, y Lazzaroni et al. (2009), de la semana 9 a la 16, no encontraron diferencias en la evolución del peso y en el IT entre machos y hembras.

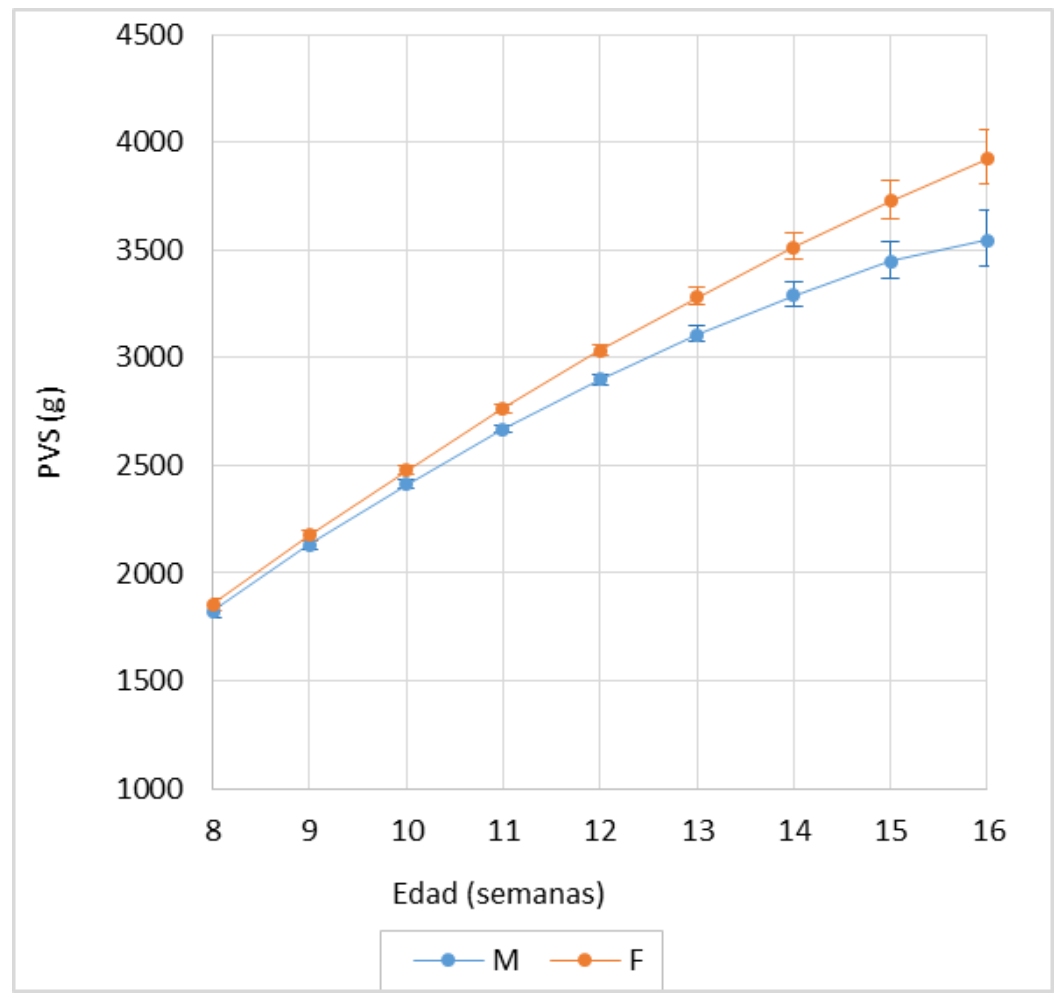

Figura 6. Evolución del Peso Vivo al Sacrifico (PVS) (g) en función del género (F: hembras, M: machos) (Medias mínimo cuadráticas e intervalos de confianza) 


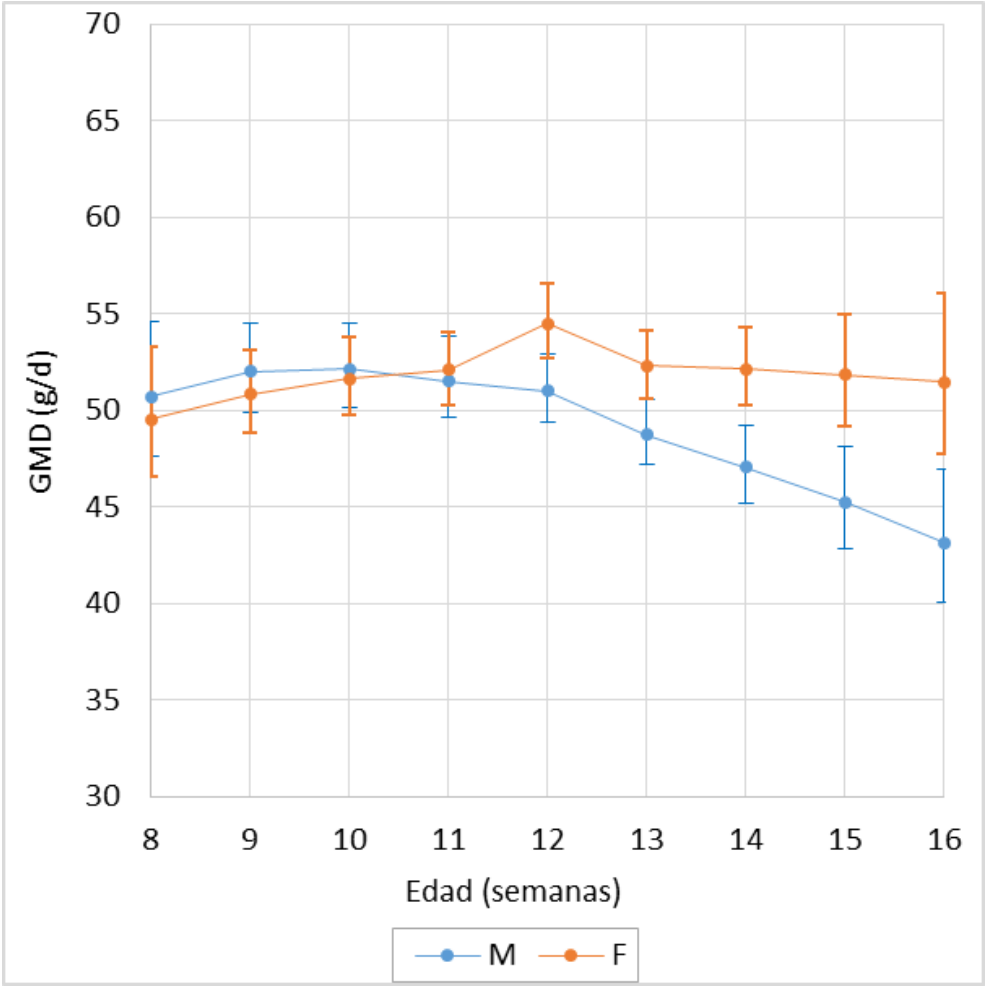

Figura 7. Evolución de la Ganancia Media Diaria (GMD) (g/día) con la edad (semanas) en función del género ( $F$ : hembras, $M$ : machos) (Medias mínimo cuadráticas e intervalos de confianza).

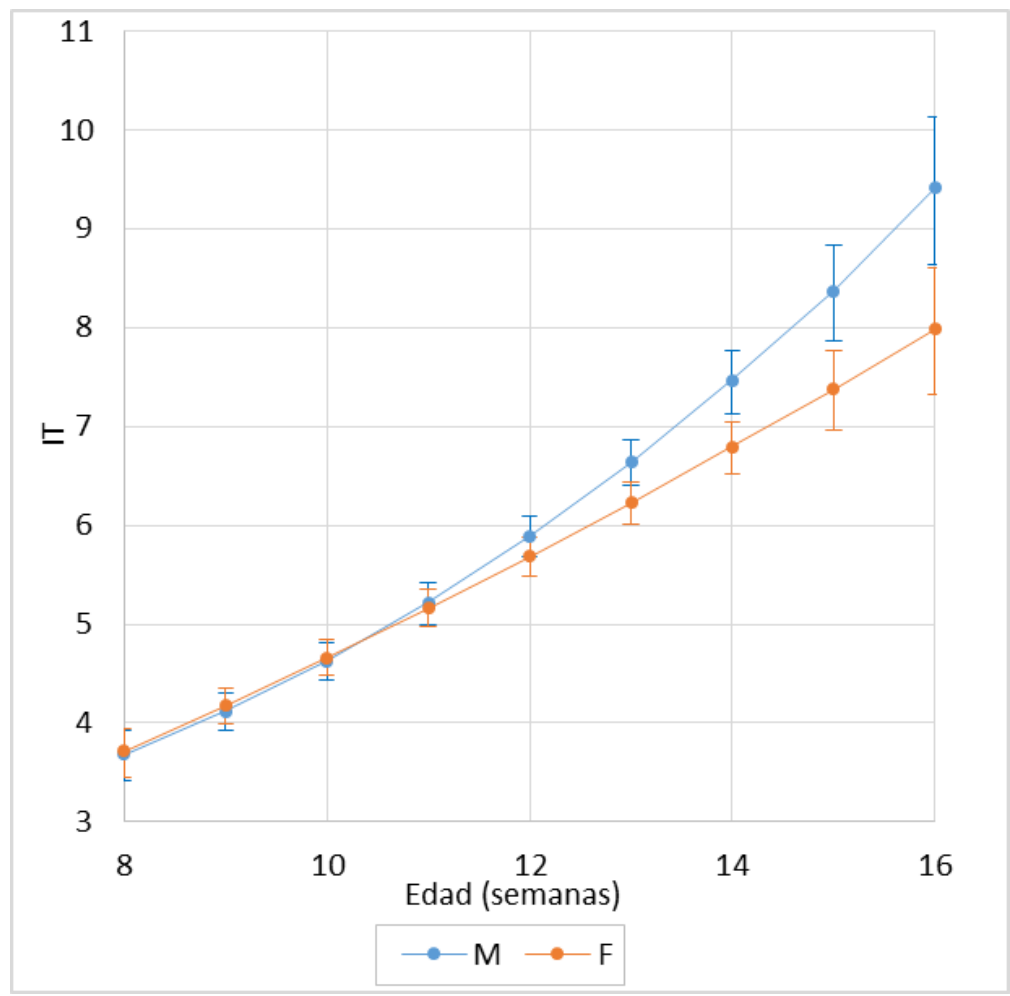

Figura 8. Evolución del Índice de Transformación (IT) según el género ( $F$ - hembras, M - machos) (Medias mínimo cuadráticas e intervalos de confianza). 


\section{2_CARACTERES DE CALIDAD DE CANAL}

\subsection{CANAL CALIENTE, CANAL FRÍA, CANAL DE REFERENCIA Y RENDIMIENTO DE CANAL} FRÍA

Según lo indicado por el coeficiente alométrico $k$ (tabla 1), la canal fría y canal de referencia tienen un patrón de crecimiento casi isométrico, es decir, que crecieron a la misma tasa media que el resto del cuerpo.

Los valores $k$ de canal fría $(1,005 \pm 0,005)$ y canal de referencia $(1,036 \pm 0,010)$ fueron similares a los valores mostrados por Pascual et al. (2008) para conejos de 4 a 40 semanas ( $C F=1,08 \pm 0,01 ; C R=1,16 \pm 0,01)$. El valor $k$ fue ligeramente mayor para $C R$ que para CF debido a que el hígado, los riñones, la caja torácica y la cabeza son de crecimiento temprano, y no se incluyen en la canal fría.

Tabla 1. Mínimos estimados cuadrados (MEC) y errores estándar (ES) de los coeficientes alométricos $k$ de Huxley para canal fría (CF) y canal de referencia (CR) respecto al peso vivo al sacrificio.

\begin{tabular}{ccc}
\hline COMPONENTE & MEC & ES \\
\hline CF & 1,005 & 0,005 \\
CR & 1,036 & 0,010 \\
\hline
\end{tabular}

Fuente: Martínez-Bas et al. 2018

Al igual que para el peso vivo, se observó que la interacción línea genética y dieta era significativa (figuras 9 y 10 ) tanto para el peso de la canal caliente (PCC) como para la fría (PCF) y la de referencia (PCR). En líneas generales, el peso de canal caliente, fría y de referencia fue superior para las líneas mejoradas por velocidad de crecimiento que para la línea de aptitud maternal, y esta diferencia se vio incrementada cuando eran alimentados con la dieta HE.

Para PCC, en la dieta C la línea GR parte de un PCC ligeramente superior al de HY (GR: $1268 \mathrm{~g} \pm 17,7 ; \mathrm{HY}: 1136 \mathrm{~g} \pm 18,1)$, y ya a partir de la semana 9 HYcol y GR presentaron mayor valor que HY, siendo esta diferencia cada vez mayor a lo largo del ensayo, finalizando en la semana 16 con diferencias de 298 gramos entre las líneas de aptitud cárnica y la maternal (semana 16: HY: 2228 g \pm 21,2; GR: 2569 g \pm 20,5 e HYcol: 2568 g $\pm 20,5$ ). En la dieta HE la línea GR presentó mayor PCC al inicio (dieta HE: GR: 1422 g \pm 28,5; HYcol: $1197 \mathrm{~g} \pm 24,0$ e HY: $1123 \mathrm{~g} \pm 22,5$ ) tanto respecto a HYcol e HY como 
respecto a sí misma en la dieta C (semana 8 GR dieta C: 1268 g $\pm 17,7$; dieta HE: 1422 g $\pm 28,5)$. Posteriormente, en la dieta HE los incrementos de PCC para GR fueron menores que para HYcol, lo que se tradujo en que a partir de la semana 12 ambas líneas se igualarán (semana 12: HYcol: 2018 g \pm 18,3; GR: 1964 g \pm 18,9). La dieta HE produjo mayor PCC a lo largo de todo el ensayo para GR (semana 8: HYcol: $1197 \mathrm{~g} \pm$ 57,1; GR: 1422 g \pm 4,8; HY: 1123 g \pm 54,2 - semana 13: HYcol: 2155 g \pm 52,1; GR: 2180 g $\pm 59,4 ; \mathrm{HY}: 1826 \mathrm{~g} \pm 63,1$ ) y no tuvo ningún efecto sobre HY.

Para PCR los resultados fueron similares que para PCC/PCF, con ligeras diferencias. En la dieta C para PCR fue HYcol la que presentó un valor ligeramente superior (semana 9$1132 \mathrm{~g} \pm 33)$ a las otras dos líneas en las primeras semanas, con diferencias significativas respecto a HY (semana 9- GR: $1067 \mathrm{~g} \pm 33$; HY: $1020 \mathrm{~g} \pm 33$ ). En la dieta HE (figura 10), HYcol y GR mostraron mayor valor que HY (HYcol: 1205 g \pm 90,1; GR: $1253 \mathrm{~g} \pm 85,0 ; \mathrm{HY}: 1116 \mathrm{~g} \pm 88,1)$.

Por tanto para estas variables, a la edad habitual de sacrificio (8 semanas) con la dieta C, GR presentó mayor PCF/PCF, y con la dieta HE, GR e HYcol fueron superiores. Pero si queremos llevar a los conejos a mayor edad al sacrificio en este caso con la dieta C GR presentó mayor PCF/PCF en las semanas 8 y 9, en la semana $10 \mathrm{HYcol}$ ocupó una posición intermedia y en la semana 11 alcanzó a GR, mientras que para la dieta $\mathrm{HE}$, HYcol y GR fueron superiores a lo largo de todo el estudio.

Pla et al. (1996) observaron que para conejos de dos líneas genéticas diferentes, una seleccionada por gazapos destetados (V) y otra seleccionada por crecimiento (R) alimentados con un mismo pienso comercial (16,5\% proteína, 3,4\% grasa y $15,5 \%$ de fibra bruta respecto a MS) mostraron diferencias significativas en el peso de la canal caliente en la semana 9. Si bien, tuvo más peso la línea seleccionada por tamaño de camada (1175 $\pm 13,7 \mathrm{gr}$ ) que la línea seleccionada por velocidad de crecimiento (1110 $\pm 15,4 \mathrm{~g}$ ) al contrario que nuestro trabajo donde a la semana 9 las líneas mejoradas por velocidad de crecimiento (HYcol: $1378 \mathrm{~g} \pm 31,5$ y GR: $1498 \mathrm{~g} \pm 29,4)$ tuvieron mayores pesos de canal caliente que la línea de aptitud maternal (HY: 1267 g \pm 32,4), independientemente de la dieta ingerida. Feki et al. (1996) en un estudio que compararon las características de canal en 5 razas de conejos seleccionadas por 
diferentes criterios de calidad de canal y carne, observaron en conejos con 9 semanas que una línea seleccionada por gazapos destetados (A) tuvo mayor peso de canal caliente ( $A: 1200 \mathrm{~g} \pm 6,0$ ) que una línea seleccionada por crecimiento ( $R: 1145 \mathrm{~g} \pm 6,0)$. Según Gómez et al. (1998) la selección por tasa de crecimiento en la línea R, seleccionada entre 28 y 63 días de edad desde hace más de 20 generaciones hace que los animales presenten menor grado de madurez al sacrificio y un menor desarrollo de la canal.

Hernández (1994) comparó animales de las líneas V (seleccionada por aptitud maternal) y R (seleccionada por aptitud cárnica) con un peso vivo ente 1940 y 1990 gramos, lo que equivale a nuestros animales en la semana 8 y encontró diferencias en el peso de la canal caliente y fría, al igual que en nuestro trabajo en los conejos alimentados con la dieta HE en la semana 8.

Al-Donaib (2010) no encontró diferencias significativas en el peso de la canal caliente a las 12 semanas en conejos, procedentes de cuatro líneas genéticas distintas seleccionadas por peso de camada al destete (V-line de origen español, Saudi-1, Saudi2 and Saudi-3), y que fueron alimentados con tres dietas diferentes en las que alimentos autóctonos eran sustituidos por alimentos no autóctonos presentando las tres dietas el mismo nivel de energía digestible (2857 kcal ED/kg MS). 

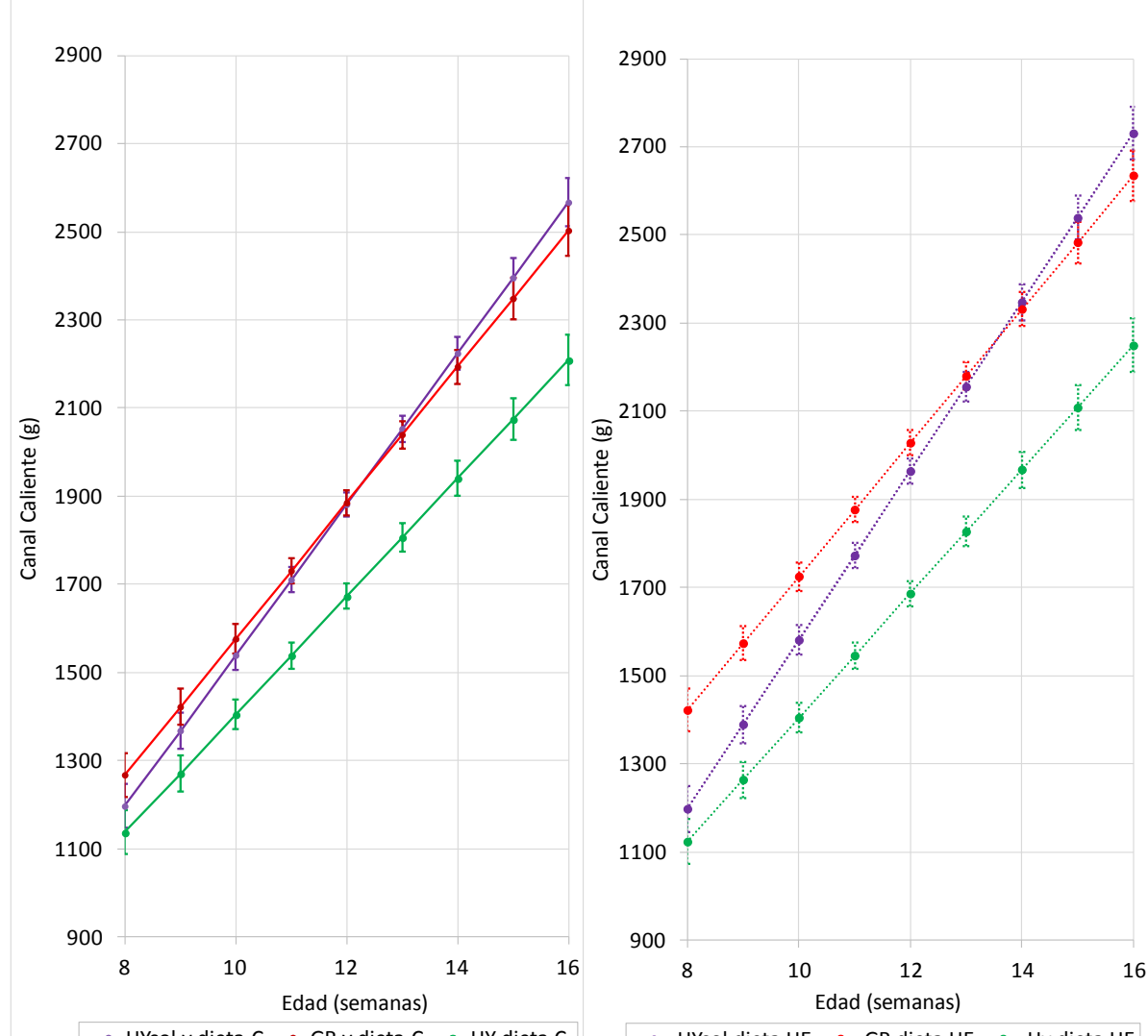

$\rightarrow$ HYcol y dieta C $\rightarrow$ - GR y dieta C $\rightarrow$ HY dieta C

$\cdots \bullet \cdots$ HYcol dieta HE $\cdots \bullet \cdots$ GR dieta HE $\cdots \bullet \cdots$ Hy dieta HE
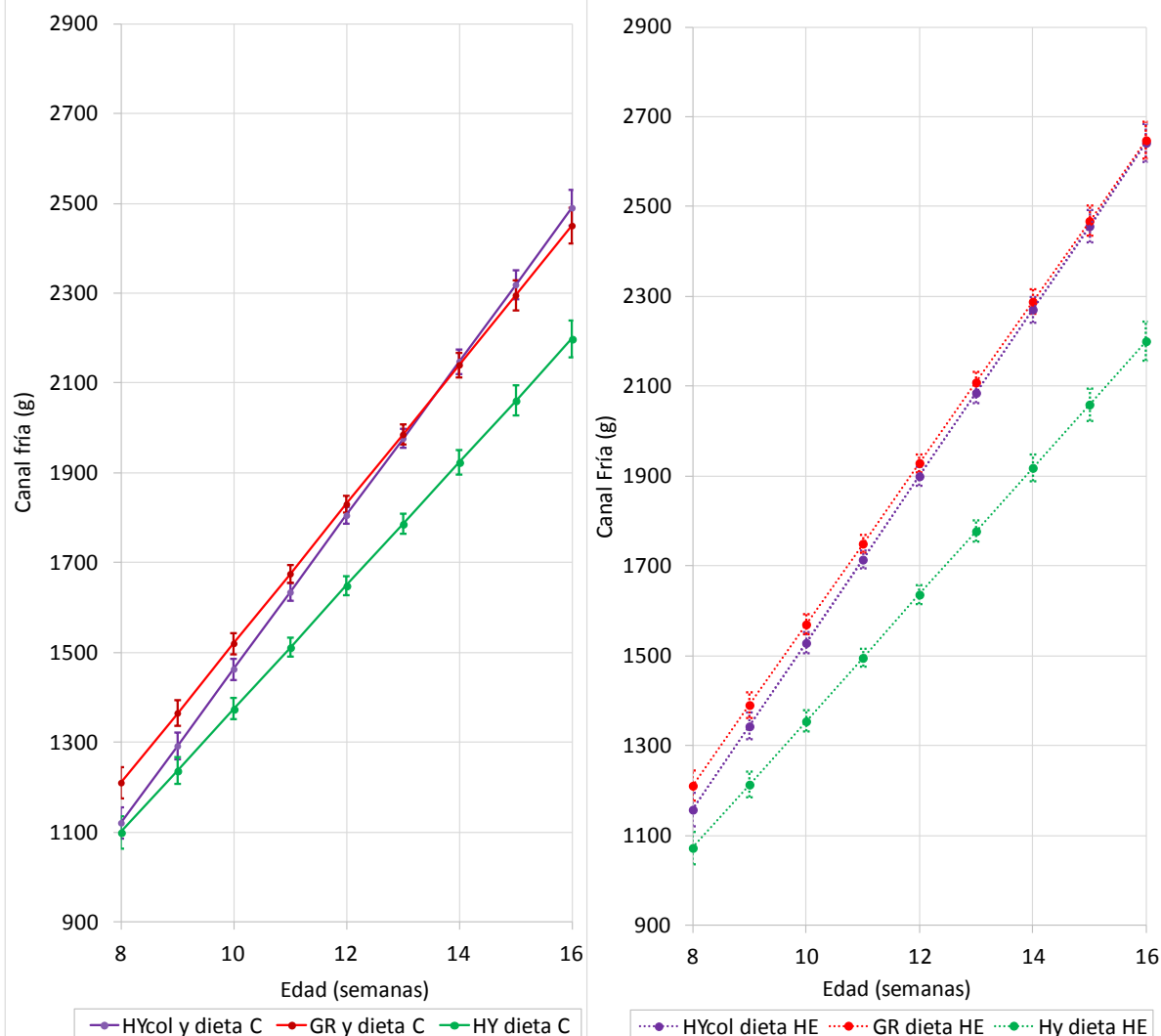

Figura 9. Evolución del Peso Canal Caliente (PCC) y del Peso Canal Fría (PCF) con la edad (semanas) en función de la línea genética (HYcol: Hyla-colored, GR: Grimaud ps 119 e HY: Hyla Grand Parental Doe) y dieta (C: control, HE: High energy) (Medias mínimo cuadráticas e intervalos de confianza). 


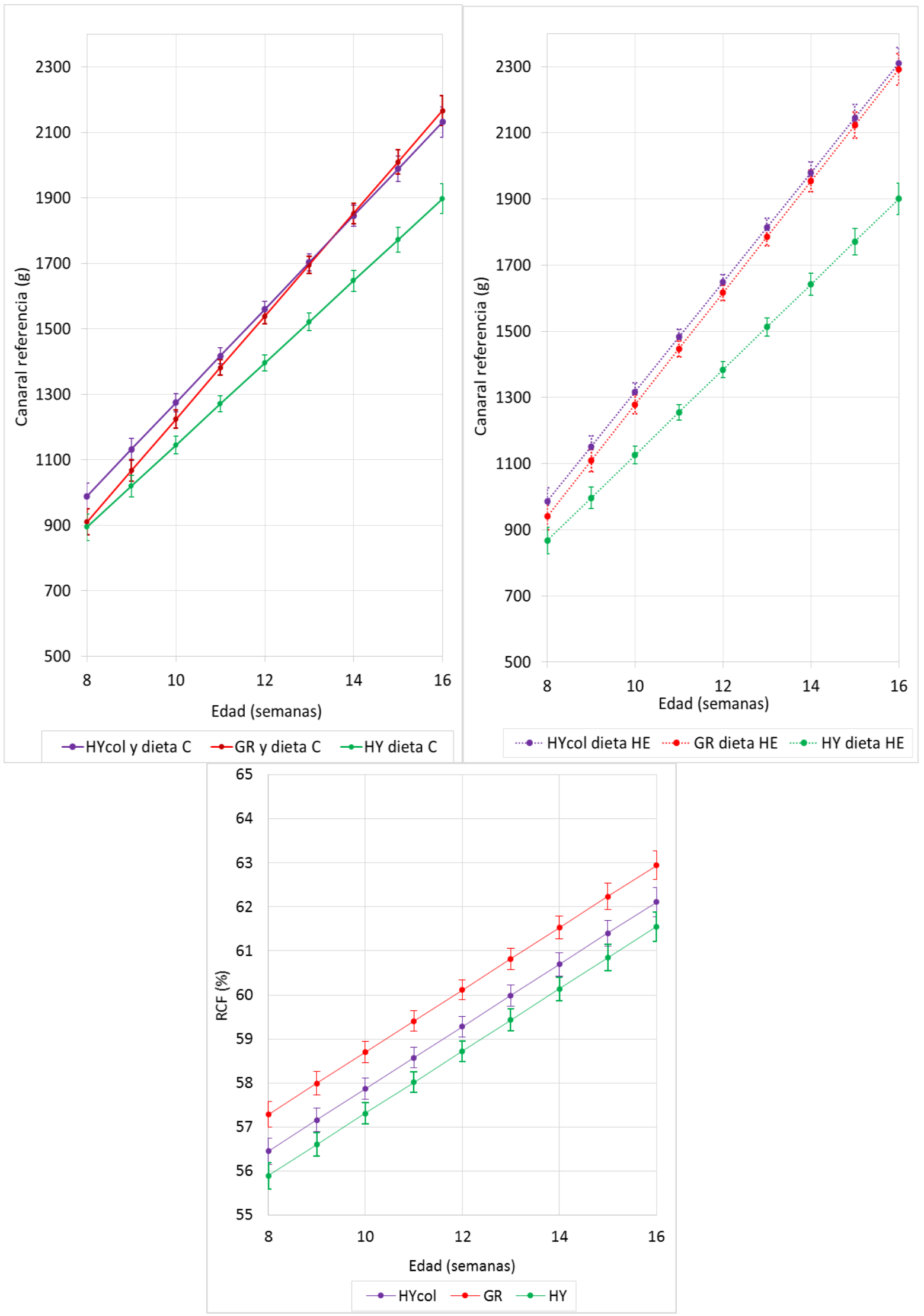

Figura 10. Evolución del Peso Canal Referencia (PCR) y del Rendimiento de Canal Fría (RCF) con la edad (semanas) en función de la línea genética (HYcol: Hyla-colored, GR: Grimaud ps 119 e HY: Hyla Grand Parental Doe) (Medias mínimo cuadráticas e intervalos de confianza). 
De acuerdo con nuestros resultados, Martínez-Vallespín et al. (2013) y Pascual et al. (2014) encontraron que las dietas con elevados niveles de fibra digestible (157 g/kg MS) disminuían el peso de la canal fría y de referencia. Pascual et al. (2014) vieron diferencias significativas en el peso de la canal fría en conejos alimentados con dos dietas con diferentes niveles de fibra a las 12 semanas para líneas seleccionadas por caracteres de crecimiento, obteniendo mayores pesos de canal con la dieta menos fibrosa (1341 $\pm 17 \mathrm{~g}$ ) que con la dieta más fibrosa (1263 $\pm 18 \mathrm{~g}$ ).

Si bien nosotros no observamos un efecto de la dieta en la línea de aptitud maternal, Dalle Zotte et al. (1998) para una línea seleccionada por prolificidad (INRA 9077) alimentada por una dieta control (L) y otra con mayores niveles de energía (H) sí obtuvieron diferencias en el peso de la canal de referencia. Con la dieta más energética en conejos sacrificados con $2,5 \mathrm{~kg}$ el peso de la canal de referencia fue $1093 \mathrm{~g} \pm 44$ gramos y con la dieta control el peso que obtuvieron fue $1040 \mathrm{~g} \pm 44$.

En el rendimiento de la canal fría (RCF, figura 9), en todas las semanas estudiadas la línea GR presentó el mayor RCF. En la semana 8 el RCF de Grimaud fue 57,4\% alcanzando en la semana 16 un valor de 62,4\% (error típico = 0,1\%). En cambio en el caso de la línea de aptitud maternal HY necesitó llegar a la semana $10(57,4 \% \pm 0,1)$ para alcanzar el RCF inicial de GR (figura 10). Igualmente, el RCF de Hyla en la semana $16(61,3 \% \pm 0,1)$ ya fue alcanzado por GR en la semana 14 . A su vez HYcol presentó un RCF intermedio si bien no se diferenció de la línea HY ni al inicio (semanas 8 y 9) ni al final (semanas 15 y 16).

En relación con nuestros resultados, Dalle Zotte et al. (1998) tuvieron mayores porcentajes de rendimiento de canal fría para animales seleccionados por prolificidad (INRA 9077: 60,2 \%) que animales seleccionados por tasa de crecimiento ( $\mathrm{Hy}+: 58,8 \%$ ) cuando eran sacrificados a los $2,5 \mathrm{~kg}$. 


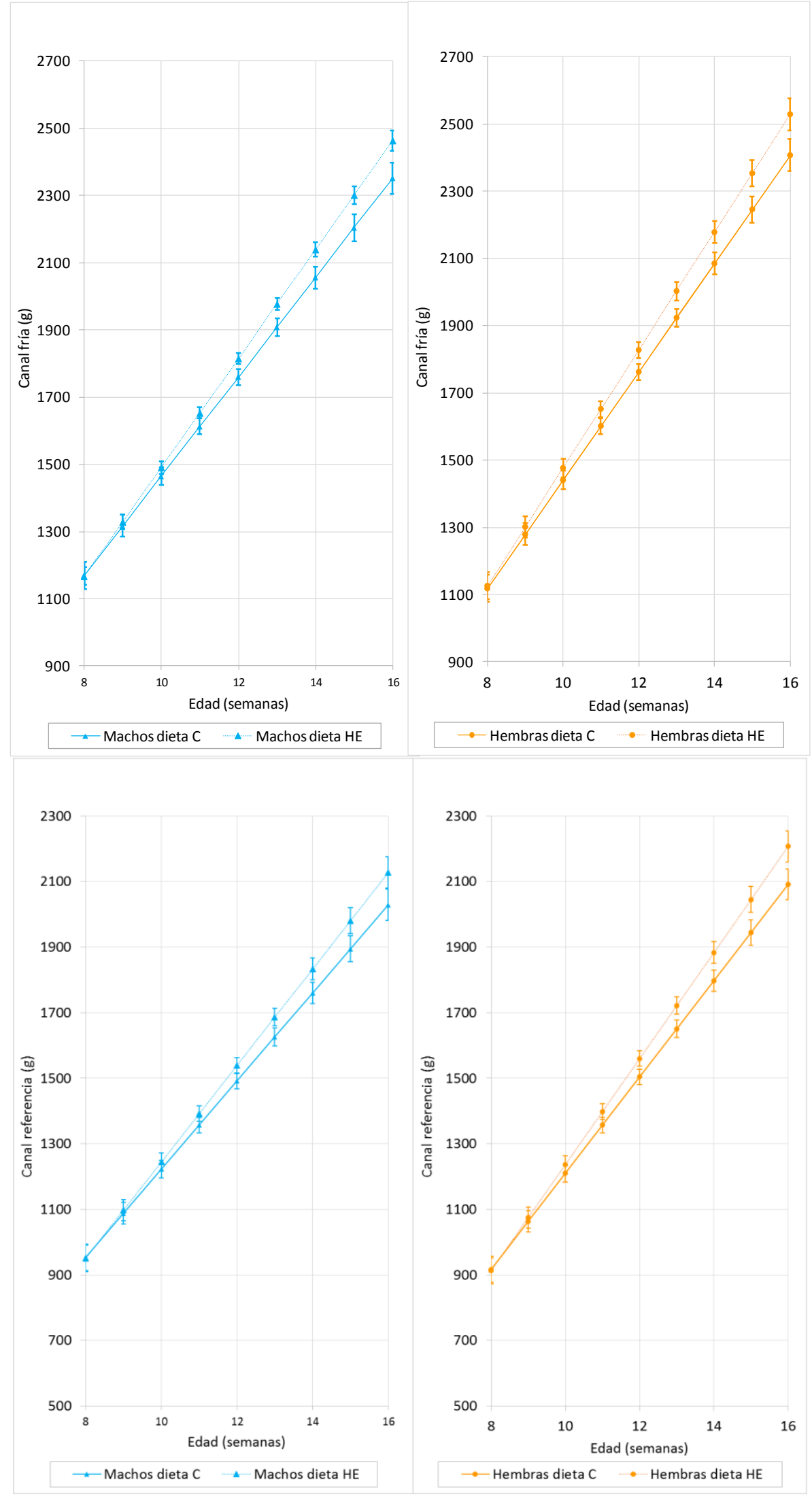

Figura 11. Evolución del Peso Canal Fría (PCF) y del Peso Canal Referencia (PCR) con la edad (semanas) en función del género ( $F$ : hembra y M: Macho) (Medias mínimo cuadráticas e intervalos de confianza). 
En cuanto al efecto del género, la canal caliente y la canal fría se comportaron igual, por lo que en el texto vamos a comentar la canal fría. Según se observa en la figura 11, no hubo diferencias significativas entre machos $(M)$ y hembras $(F)$ para PCF y PCR, si bien se observa un efecto de la dieta a partir de la semana 12 de tal forma que ambos sexos alcanzaron mayor peso de canal fría cuando eran alimentados con la dieta HE (M dieta C: $1760 \mathrm{~g} \pm$ 16,5; M dieta HE: $1815 \mathrm{~g} \pm 16,4$; F dieta C: $1763 \mathrm{~g} \pm$ 15,9; F dieta HE: $1828 \mathrm{~g} \pm 16,3$ ). Lazzaroni et al. (2009) en el peso de canal caliente y peso de canal de referencia tampoco encontraron un efecto del sexo para conejos entre 9 y 16 semanas de edad.

Por otro lado, en el efecto del género en el peso de canal de referencia hubo un paralelismo claro respecto a la canal fría, sin obervar diferencias significativas entre géneros, pero sí una tendencia a coger más peso en las últimas semanas de las hembras que los machos (semana 16, Machos - dieta C: 2029,2 g $\pm 47,0$, Hembras dieta C: 2091,3 g \pm 44,5; Machos - dieta HE: 2127,7 g \pm 48, Hembras - dieta HE: 2207,2 $\mathrm{g} \pm 46,5)$. Y respecto a la dieta control, desde la semana 13 a la semana 16 y en el caso de la dieta $\mathrm{HE}$, desde la semana 12 a la semana 16, hubo diferencias significativas y tanto machos como hembras ganaron más peso al ingerir la dieta más energética. 
En el rendimiento de la canal fría no hay diferencias significativas entre machos y hembras para ninguna de las semanas.

En nuestro trabajo, cuando consideramos el efecto de la dieta de forma conjunta para las tres líneas genéticas y los dos sexos el rendimiento de la canal no encontramos diferencias por el efecto de la dieta, al contrario que Dalle Zotte et al. (1998) que sí encontraron diferencias en el rendimiento de canal para animales sacrificados a los 2,5 $\mathrm{kg}$, obteniendo mayores porcentajes en animales alimentados por una dieta altamente energética (H: 60,2\%) que los alimentados por una dieta control (L: 58,4\%). También Margüenda et al. (2008) encontraron que un descenso en la fibra bruta de la dieta de $35 \%$ a $32 \%$ mejoraba el rendimiento de la canal.

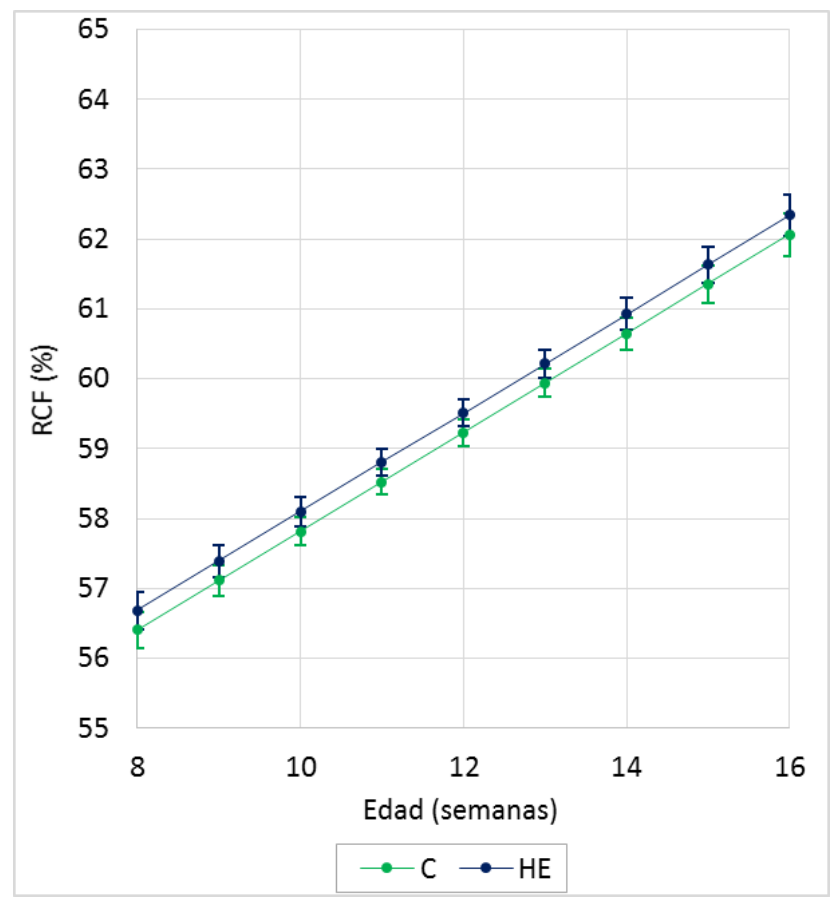

Figura 12. Evolución del Rendimiento Canal Fría (RCF) con la edad (semanas) en función de la dieta (C: control y HE: altamente energética) (Medias mínimo cuadráticas e intervalos de confianza). 


\subsection{LONGITUDES Y COMPACIDAD}

\subsubsection{Longitud de canal (CL), longitud dorsal (DL), longitud de las patas ( $T L$ ),} circunferencia lumbar (LCL)

Todas las longitudes aumentaron en todo el periodo estudiado, en promedio incrementaron $\mathrm{CL}$ en $9,08 \mathrm{~cm}$, $\mathrm{DL}$ en $6,5 \mathrm{~cm}$, $T L$ en $2,56 \mathrm{~cm}$ y $\mathrm{LCL}$ en $5,56 \mathrm{~cm}$. El incremento máximo se produjo para HYcol dieta $\mathrm{HE}$ en $\mathrm{CL}(10,14 \mathrm{~cm})$ y $\mathrm{DL}(7,45 \mathrm{~cm})$, para HYcol dieta C en TL $(2,72 \mathrm{~cm})$ y para GR dieta HE en $\operatorname{LCL}(6,28 \mathrm{~cm})$ (figura 13$)$.

CL y DL siguieron un patrón de comportamiento similar (figura 13). La línea HY presentó el menor valor para ambos caracteres y la línea HYcol los mayores valores. HYcol e HY fueron diferentes a lo largo de todo el periodo, las diferencias se muestran en la tabla 2. La línea GR presentó valores intermedios no siendo distinta de la línea HYcol hasta la semana 10 para la dieta $\mathrm{C}$ y hasta la semana 11 para la dieta $\mathrm{HE}$, las diferencias entre HYcol y GR se muestran en la tabla 2.

En LCL hubo menos diferencias significativas. Para la dieta C, GR presentó el mayor valor en las semanas 10-11-12, con diferencias que fueron aproximadamente $0,65 \pm 0,14 \mathrm{~cm}$ respecto a $\mathrm{HY}$ y de $0,35 \pm 0,14 \mathrm{~cm}$ respecto a $\mathrm{HYcol}$; e HY presentó el menor valor en las semanas 12-13-14 con diferencias promedio de $0,71 \pm 0,16 \mathrm{~cm}$ respecto a $\mathrm{GR}$ y de $0,39 \pm$ $0,16 \mathrm{~cm}$ respecto a HYcol. Para la dieta $\mathrm{HE}$, las diferencias fueron más marcadas, $\mathrm{HY}$ mostró el menor valor a partir de la semana 9 con diferencias respecto a GR de 0,76 \pm $0,20 \mathrm{~cm}$ y respecto a $\mathrm{HYcol}$ de $0,57 \pm 0,30 \mathrm{~cm}$, y en la semana 16 de 1,58 $\pm 0,30 \mathrm{~cm}$. 
Tabla 2. Diferencias entre HYcol e HY y HYcol y GR para las longitudes de la canal

\begin{tabular}{lcccc}
\hline \multicolumn{5}{c}{ HYcol-HY } \\
Dieta C & 8 & $0,81 \pm 0,30$ & $0,66 \pm 0,26$ & $0,15 \pm 0,05$ \\
& 16 & $2,27 \pm 0,34$ & $1,79 \pm 0,29$ & $0,49 \pm 0,05$ \\
Dieta HE & 8 & $1,45 \pm 0,31$ & $1,08 \pm 0,26$ & $0,37 \pm 0,05$ \\
& 16 & $2,97 \pm 0,37$ & $2,39 \pm 0,31$ & $0,58 \pm 0,06$ \\
\hline \multirow{5}{*}{ Dieta C } & 10 & $0,37 \pm 0,20$ & $0,36 \pm 0,17$ & $0,06 \pm 0,03$ \\
& 16 & $1,37 \pm 0,34$ & $1,22 \pm 0,29$ & $0,16 \pm 0,05$ \\
Dieta HE & 11 & $0,53 \pm 0,18$ & $0,44 \pm 0,17$ & \\
& 16 & $1,10 \pm 0,37$ & $1,01 \pm 0,36$ &
\end{tabular}

CL: Longitud de canal, DL: longitud dorsal, TL: longitud de las patas, LCL: circunferencia lumbar

CL es la suma de DL y TL. En la tabla 3, se puede observar que la diferencia en $C L$ entre HYcol e HY se explica tanto a través de DL o TL, sin embargo en el caso de la diferencia HYcol y GR es fundamentalmente explicada a través de $D L$, ya que prácticamente no existieron diferencias para $\mathrm{TL}$, solo en el caso de la dieta $\mathrm{C}$ en la semana 16 se observa una pequeña diferencia entre HYcol y GR.

Pla et al. (1996) cuando compararon una línea de aptitud maternal (V) y una de aptitud cárnica (R) a las 8 y 9 semanas no encontraron diferencias significativas en DL (V: 251 $\mathrm{mm} \pm 1,2$ y $\mathrm{R}: 249 \mathrm{~mm} \pm 1,1)$ pero sí en $T L(V: 78 \mathrm{~mm} \pm 0,5$ y $\mathrm{R}: 74 \mathrm{~mm} \pm 0,4)$ y en $\mathrm{LCL}(\mathrm{V}$ : $168 \mathrm{~mm} \pm 1,0$ y $\mathrm{R}: 163 \mathrm{~mm} \pm 1,0$ ), sin embargo, obtuvo mayor valor en la línea de aptitud maternal. En concordancia Gómez et al. (1998) en conejos con 2 kg de peso vivo comercial encontraron diferencias significativas entre la línea de aptitud maternal A y la línea $R$ en DL (A: $25,81 \pm 0,090 \mathrm{~cm}$ y $R: 25,25 \pm 0,090 \mathrm{~cm})$ y en TL $(A: 8,17 \mathrm{~cm} \mathrm{R:} \mathrm{7,82} \mathrm{cm}$ $\pm 0,050)$; y en $L C L$ entre dos líneas de aptitud maternal (A: 15,21 $\pm 0,055 \mathrm{~cm}$ y $\vee 15,17 \pm$ 0,055 cm) y la línea de aptitud cárnica (R: 14,80 $\pm 0,055 \mathrm{~cm}$ ), en cualquier caso obtuvo mayores valores en las líneas de aptitud maternal. 

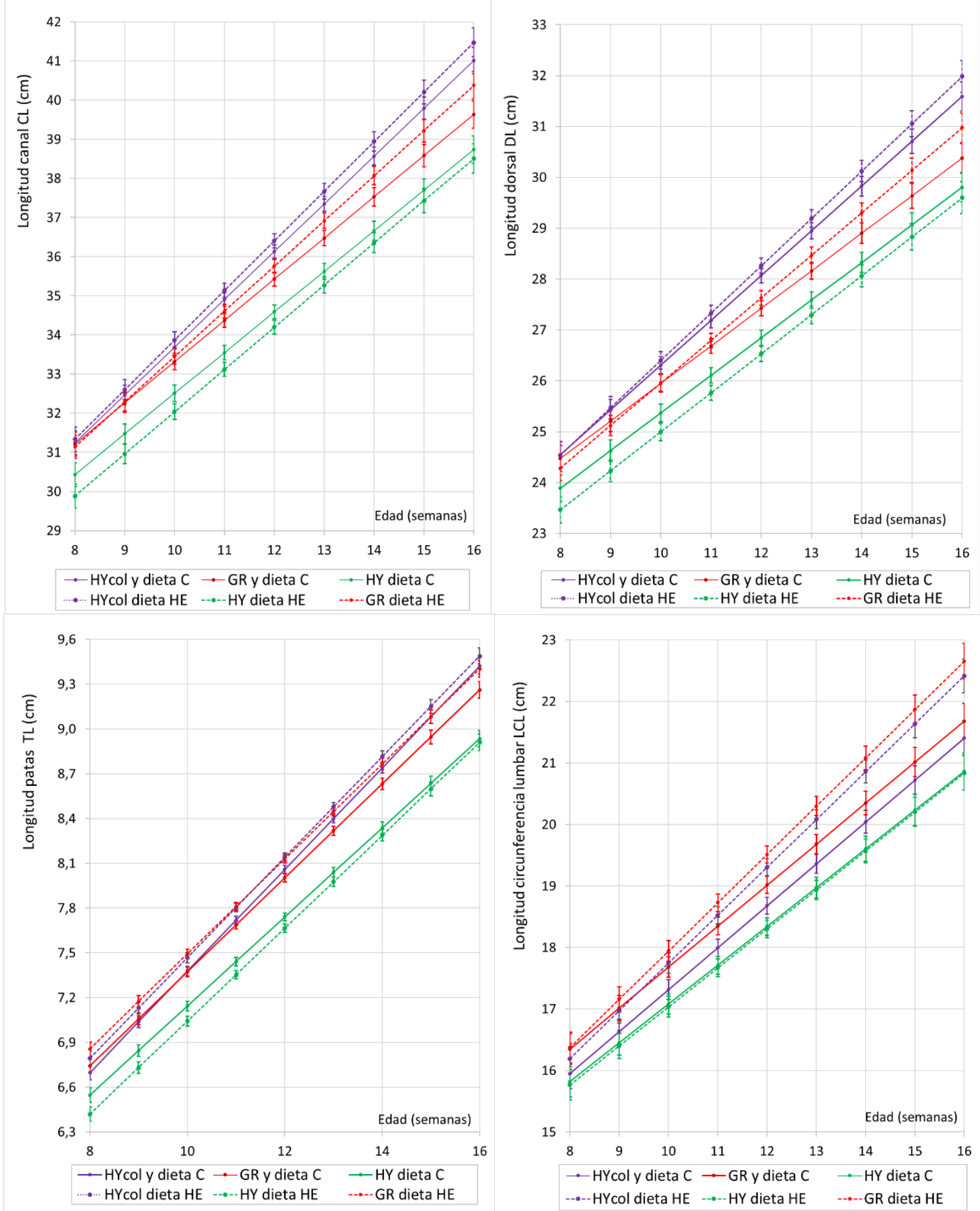

Figura 13. Evolución de la Longitud canal $\mathrm{CL}(\mathrm{cm})$, la Longitud dorsal $\mathrm{DL}(\mathrm{cm})$, la Longitud de las patas TL (cm) con la edad (semanas) en función de la línea genética (HYcol: Hyla-colored, GR: Grimaud ps 119 e HY: Hyla Grand Parental Doe) y la dieta (C: control y HE: alta energía). (Medias mínimo cuadráticas e intervalos de confianza).

Respecto al efecto de la dieta, en líneas generales se observa que en las líneas de aptitud cárnica la dieta HE supuso un incremento de las longitudes respecto a la dieta C, sin embargo en la línea de aptitud maternal HY sucedió al contrario, excepto en LCL 
donde no hubo un efecto de la dieta para la línea HY. La línea GR con la dieta HE presentó mayor $\mathrm{CL}$ a partir de la semana 13, mayor TL en todo el periodo estudiado y mayor LCL a partir de la semana 11. La línea HYcol con la dieta HE presentó mayor CL de la semana 10 a la 12, mayor TL de la semana 9 a la 13 y mayor LCL a partir de la semana 9. Mientras que la línea presentó mayores valores con la dieta C en DL de la semana 9 a la 11 y mayor TL de la semana 8 a la 12. Las diferencias para cada una de las longitudes entre dietas se pueden observar en la tabla 3.

Tabla 3. Diferencias significativas en las longitudes $(\mathrm{cm})$ entre las dos dietas: Dieta alta energía (HE) menos dieta control (C) y para las tres líneas genéticas: HYcol: Hyla-colored, GR: Grimaud ps 119 e HY: Hyla Grand Parental Doe. Se representa el rango de semanas donde las diferencias fueron significativas.

\begin{tabular}{lcccccc}
\hline & \multicolumn{2}{c}{ CL } & DL & \multicolumn{2}{c}{ TL } & LCL \\
\hline SEMANA & 13 & 16 & 8 & 16 & 11 & 16 \\
GR & $0,44 \pm 0,19$ & $0,74 \pm 0,35$ & $0,11 \pm 0,05$ & $0,14 \pm 0,06$ & $0,38 \pm 0,14$ & $0,97 \pm 0,28$ \\
SEMANA & 10 & 12 & 9 & 13 & 9 & 16 \\
HYCOL & $0,47 \pm 0,20$ & $0,39 \pm 0,18$ & $0,09 \pm 0,03$ & $0,09 \pm 0,03$ & $0,34 \pm 0,21$ & $1,01 \pm 0,30$ \\
SEMANA & & 9 & 8 & 11 & \\
HY & & $-0,40 \pm 0,21$ & $-0,34 \pm 0,15$ & $-0,13 \pm 0,05$ & $-0,08 \pm 0,03$ & \\
\hline
\end{tabular}

$\mathrm{CL}$ : Longitud de canal, DL: longitud dorsal, TL: longitud de las patas, LCL: circunferencia lumbar

\subsubsection{Compacidad de la canal}

La compacidad de la canal (GCM) aumentó a lo largo de las semanas, de valores promedio de 30,66 g/cm en la semana 8 a $54,14 \mathrm{~g} / \mathrm{cm}$ en la semana 16 .

La línea genética HY mostró el valor más bajo, HY mostró valores intermedios y GR los valores más altos, si bien hasta la semana 10 ó 11, según el tipo de dietas, estas diferencias no fueron significativas. Además, se observó un efecto de la dieta, de tal forma que las líneas HYcol y GR aumentaron su compacidad con la dieta más energética, pero no sucedió lo mismo para la línea HY. Finalmente, las hembras GR mostraron un crecimiento más rápido de la compacidad a lo largo de las semanas.

Gómez et al. (1998), a diferencia de nuestros resultados, obtuvieron menor valor de GCM en la línea de aptitud maternal $(V=28,6 \pm 0,18 \mathrm{~g} / \mathrm{cm})$ frente a la de aptitud cárnica $(\mathrm{R}=26,8 \pm 0,18 \mathrm{~g} / \mathrm{cm})$. 


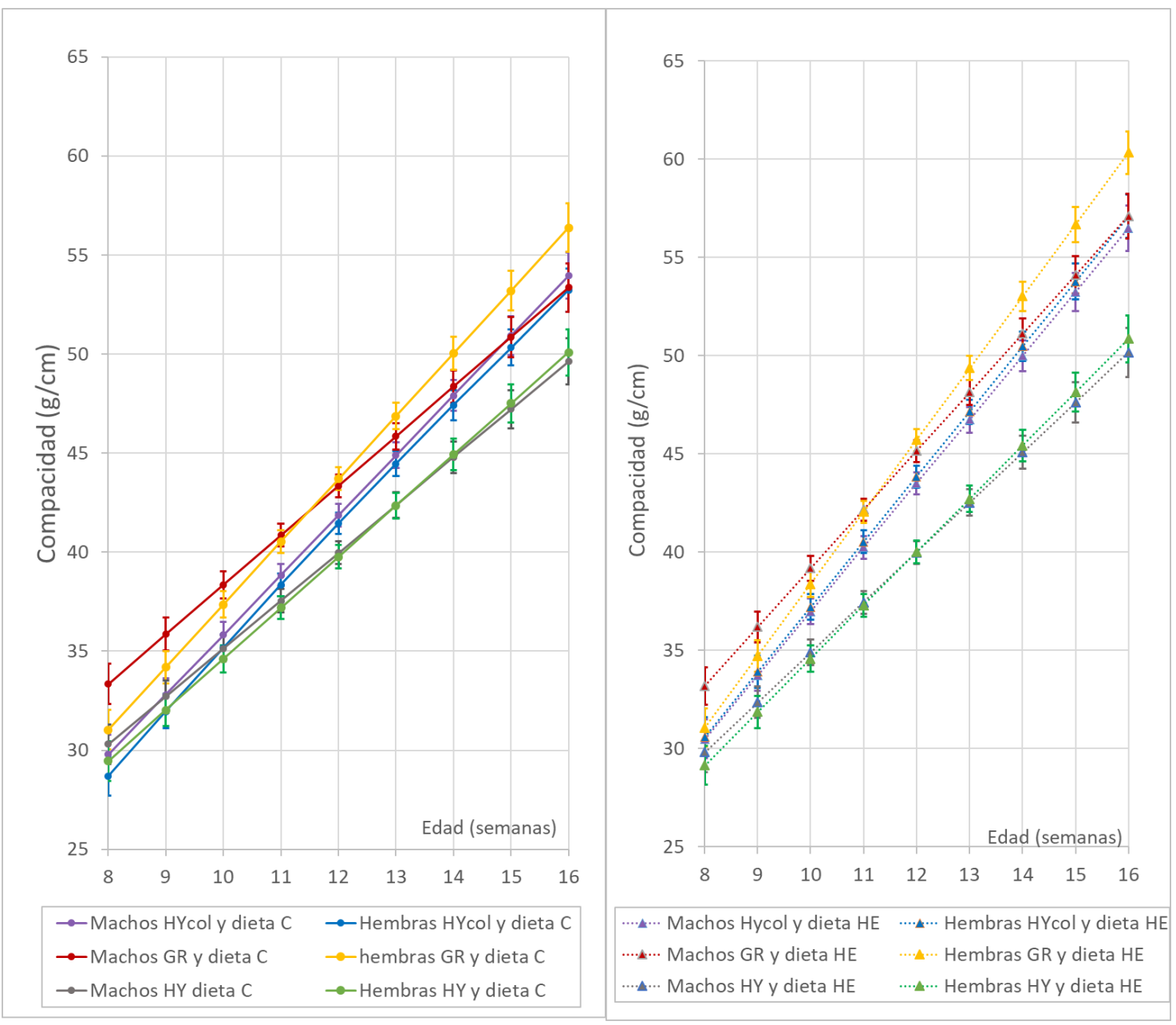

Figura 14. Evolución de las medias mínimo cuadráticas (errores estándar) de la compacidad $(\mathrm{g} / \mathrm{cm})$ según dos dietas: Dieta alta energía (HE), dieta control (C) y para las tres líneas genéticas: HYcol: Hyla-colored, GR: Grimaud ps 119 e HY: Hyla Grand Parental Doe y para los dos géneros (machos y hembras) 


\subsection{PIEL}

El desarrollo de la piel se vio afectado por la línea genética, la dieta y el género, además de múltiples interacciones (figuras 15 y 16). En cuanto a su evolución a lo largo del tiempo se observó que, en líneas generales, tiene un patrón de crecimiento casi isométrico (tabla 4). Este valor de $\mathrm{k}$ fue muy similar a los valores encontrados por Pascual et al. (2007) para conejos de 4 a 40 semanas $(1.05 \pm 0.02)$ o Deltoro y López (1985) para conejos de 6 a 20 semanas $(1.054 \pm 0.006)$. Hoy en día, la piel es un coproducto para agregar valor en la producción de conejos; algunos mercados lo demandan, especialmente el mercado chino, por lo que sería interesante un mayor desarrollo de la piel.

Tabla 4. Mínimos cuadrados estimados (MEC) y errores estándar (ES) de los coeficientes alométricos $k$ de Huxley para la piel (Piel), el conjunto de pulmones, tráquea, esófago y corazón (PTEC), hígado (Hi) y riñones $(\mathrm{Ri})$ respecto al peso vivo al sacrificio.

\begin{tabular}{ccc}
\hline COMPONENTE & MEC & ES \\
\hline Piel & 1,006 & 0,013 \\
PTEC & 0,583 & 0,013 \\
Hi & 0,540 & 0,017 \\
Ri & 0,470 & 0,013 \\
Ca & 0.717 & 0.008 \\
\hline Fuente: Martínez-Bas et al. (2018)
\end{tabular}

En el análisis de la evolución del peso de la piel en las diferentes líneas genéticas se observó globalmente que las líneas seleccionadas por crecimiento tendieron a tener un mayor de peso de piel con la edad, si bien este efecto es matizable en función de la dieta y el género.

En la dieta $\mathrm{C}$, los machos GR fueron los que presentaron un mayor peso de piel (figura 15), siendo a partir de la semana 11 diferentes a las restantes líneas genéticas y sexos (peso piel machos semana $11-\mathrm{GR}=299 \pm 7,8 \mathrm{~g}$; semana $16-441 \pm 14,2 \mathrm{~g}$ en). Las hembras GR también mostraron un alto peso de piel, con valores iguales a los machos HY e HYcol. Las hembras HYcol e HY son las que presentaron menor peso de piel a partir de la semana 11 (peso piel hembras semana $11-\mathrm{HY}=261 \pm 6,9 \mathrm{~g}$ e $\mathrm{HYcol}=267 \pm 6,8 \mathrm{~g}$; semana $16-\mathrm{HY}=360 \pm 14,6 \mathrm{~g}$ e HYcol $=382 \pm 12,8 \mathrm{~g})$. 
Para la dieta HE, GR e HYcol mostraron mayor peso de piel que HY a partir de la semana 11. Los machos tendieron a tener mayor peso de piel que las hembras, especialmente para la línea genética HY para la cual se llegaron a observar diferencias significativas a partir de la semana 14 (machos $339 \pm 9,9 \mathrm{~g}$; hembras $318 \pm 9,5 \mathrm{~g}$ ) hasta la semana 16 (machos $388 \pm 14,7 \mathrm{~g}$; hembras $359 \pm 13,9 \mathrm{~g}$ ). Lazzaroni et al. (2009) no encontraron diferencias significativas entre machos y hembras en el peso comercial de la piel de conejos Carmagnola Grey criados entre 9 y 16 semanas alimentados con un pienso comercial $(F N D=33,2 \%$ y $F A D=21,0 \%)$.

Robert et al. (2017) en el estudio comparativo de dos líneas Hyla (A y B) seleccionadas por ganancia media diaria y por rendimiento de canal encontraron diferencias significativas en el peso de piel a las 10 semanas de edad; obteniendo pesos superiores (A: $343,5 \pm 10,5 \mathrm{~g} ; \mathrm{B}: 371,2 \pm 10,3 \mathrm{~g}$ ) a los obtenidos en nuestro estudio como promedios (HYcol: 252,83 g \pm 15,78; GR: 259,35 g $\pm 15,50$; HY: 242,04 g $\pm 15,72$ ). Otros autores como Nasr et al. (2017) encontraron diferencias significativas entre una línea California (seleccionada por aptitud maternal) y la línea Rex (seleccionada por la calidad de su piel) obteniendo menor porcentaje de piel respecto al peso vivo a las 10 semanas para Rex $(16,92 \% \pm 1,46)$ que para California $(18,42 \% \pm 1,46)$.

Gómez et al. (1998) y Feki et al. (1996) encontraron diferencias en el peso de la piel en dos líneas seleccionadas por tamaño de camada al destete (líneas $\mathrm{P}$ y V) y entre una línea seleccionada por tasa de crecimiento (línea $\mathrm{R}$ ) a los 60 días; alcanzando la línea $\mathrm{R}$ más peso (354 $\pm 6,6 \mathrm{~g})$ que las líneas $V$ y $P$ con $(275$ y $270 \pm 6,6 \mathrm{~g})$ respectivamente. Por otro lado, Pla et al. (1998) encontraron que la línea A tenía mayores pesos de piel comparada con las líneas $V$ y $R$.

El efecto de la dieta fue significativo para las hembras HYcol y GR que aumentaron el peso de la piel con la dieta HE a partir de la semana 10 y 12 respectivamente (figura 15). Este efecto estuvo especialmente marcado en la línea HYcol llegándose a alcanzar una diferencia de 30,7 g en la semana 16. Pascual et al. (2014) encontraron diferencias significativas en el porcentaje de piel a las 6 y a las 9 semanas, siendo mayor el porcentaje de piel para conejos alimentados por un pienso control $(32,9 \%$ FND sobre 
MS) que para conejos alimentados con un pienso con un alto contenido en fibra $(37,4 \%$ de FND sobre MS).

En la evolución de los porcentajes de piel (figura 16) se observa que para la dieta control fue más variable su comportamiento, con tendencia $(P<0,06)$ a tener un crecimiento más tardío en la dieta HE. En la mayoría de los casos, de líneas genéticas y género, o se mantuvo el porcentaje de piel o descendió con la edad, excepto los machos GR en la dieta $C$ que aumentaron el porcentaje de piel, teniendo un crecimiento más tardío que HY. Las hembras mostraron un desarrollo de la piel ligeramente más precoz que los machos.
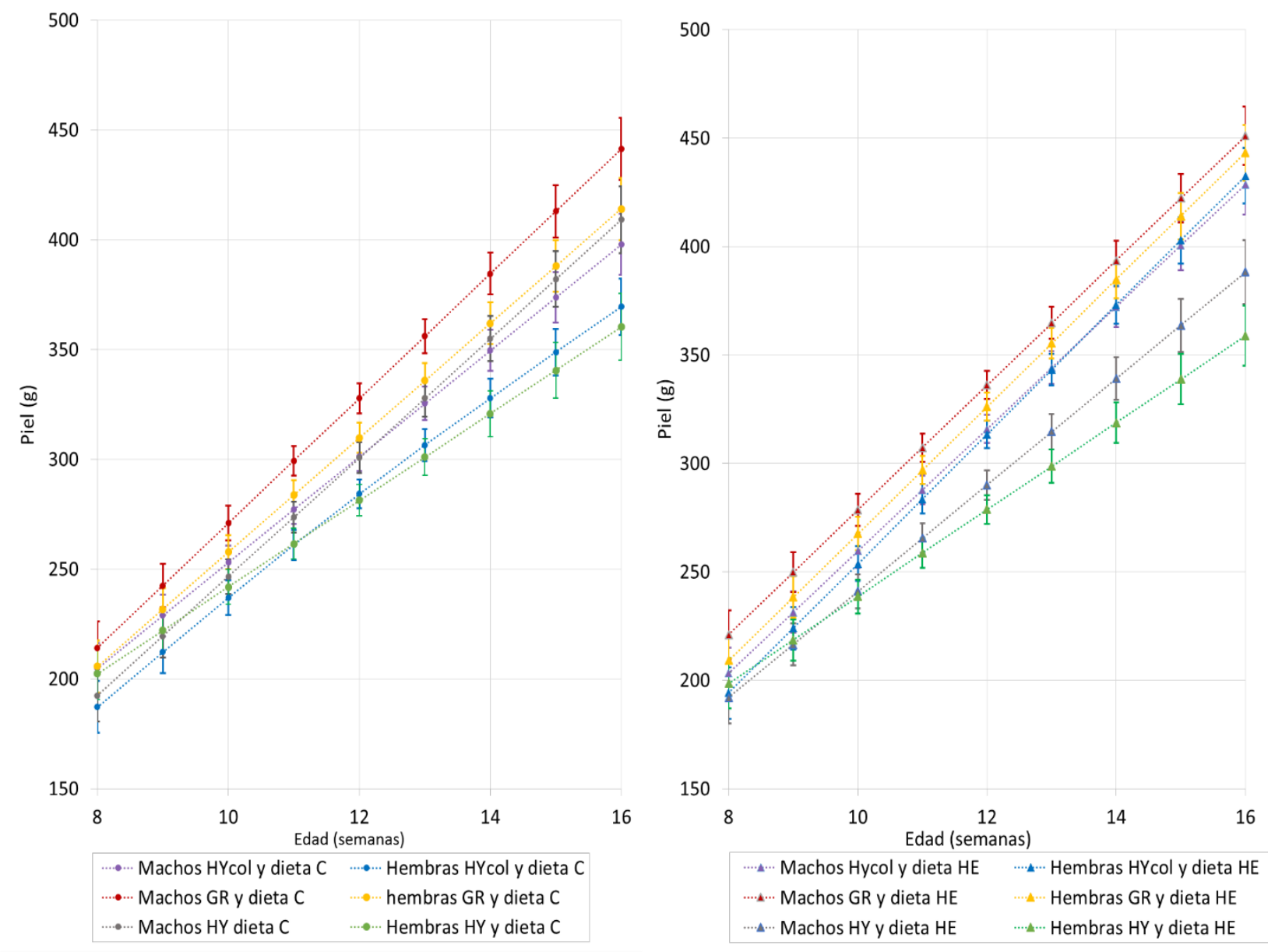

Figura 15. Evolución de las medias mínimo cuadráticas (errores estándar) del peso de la piel corregidas por el peso al sacrificio según la línea genética, la dieta y el sexo. 

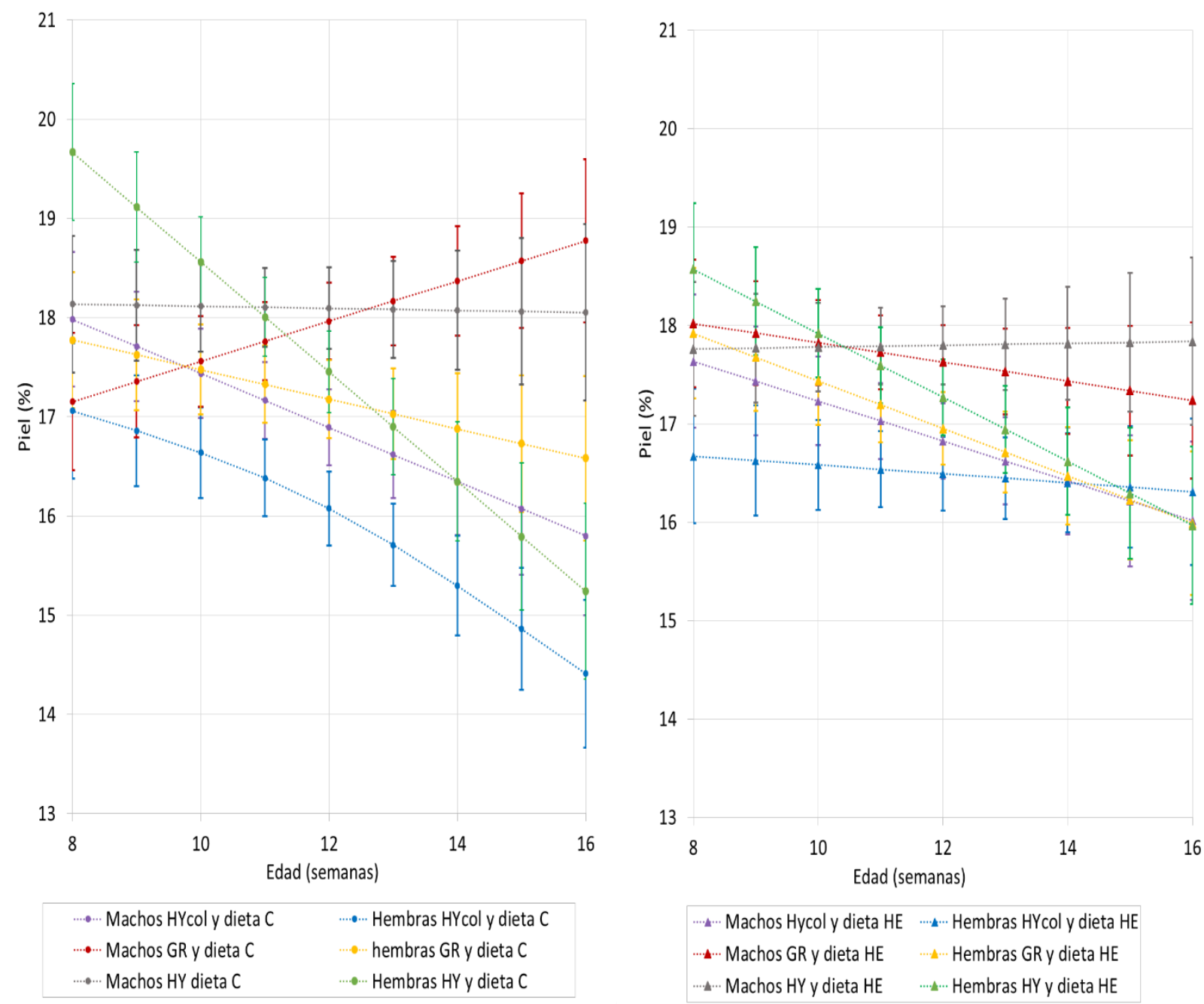

Figura 16. Evolución de las medias mínimo cuadráticas (errores estándar) del porcentaje de la piel corregidas por el peso al sacrificio según la línea genética, la dieta y el sexo.

\subsection{PULMONES, TRÁQUEA, ESÓFAGO Y CORAZÓN}

El conjunto de vísceras torácicas formado por pulmones, tráquea, esófago y corazón mostraron un desarrollo precoz $(k=0,583 \pm 0,013)$ (tabla 4). Mientras que el peso de este conjunto de vísceras torácicas aumentó con la edad (desde 28,6 $\pm 2,1$ gramos en la semana 8: hasta 48,8 $\pm 2,4$ gramos en la semana 16 ), el porcentaje disminuyó desde $2,51 \pm 0,06$ como dato promedio desde la semana 8 hasta 1,58 $\pm 0,07$ en la semana 16 .

El peso del conjunto pulmones, tráquea, esófago y corazón de las líneas mejoradas por velocidad de crecimiento ( $\mathrm{HYcol}$ y GR) fue mayor que el de la línea de aptitud maternal HY (figura 17), pero este efecto se debe al mayor PVS de estas líneas que implica igualmente un mayor peso de estas vísceras. Sin embargo, cuando se expresan como 
porcentaje esta diferencia desaparece, pudiendo incluso ser mayor el porcentaje para la línea HY que para las líneas HYcol y GR desde la semana 8 hasta la semana 11 cuando se utilizó la dieta HE.

Cuando las vísceras son expresadas en peso se observó la interacción de la línea genética y dieta, al igual que sucedía para PVS. En este sentido, las líneas mejoradas por velocidad de crecimiento ( $\mathrm{HYcol}$ y GR) mostraron mayor peso de este conjunto de vísceras a partir de la semana 11 cuando eran alimentadas con la dieta HE respecto a la dieta C, con diferencias de peso de 1,28 gramos en promedio (semana 11 - dieta C: HYcol: 32,8 g $\pm 1,2 ;$ GR: 34,1 g \pm 1,2; dieta HE: HYcol: 34,5 g $\pm 1,2 ; G R: 35,2$ g $\pm 1,2)$. En la semana 16 para HYcol (dieta C: $41,5 \mathrm{~g} \pm 2,3$; dieta HE: 44,3 g $\pm 2,5$ ) y GR (dieta C: $41,1 \mathrm{~g} \pm$ 2,4; dieta HE: 44,6 g \pm 2,4) la diferencia media de peso al tomar una dieta u otra alcanzó los 3,11 gramos. Sin embargo, la línea de aptitud maternal HY no presentó diferencias para el peso del conjunto pulmones, tráquea, esófago y corazón ingiriendo una dieta u otra (semana 12 - dieta C y HE: $32,3 \mathrm{~g} \pm 1,2$; semana 16 - dieta C: $36,7 \mathrm{~g} \pm 2,4$; dieta HE: $36,8 \mathrm{~g} \pm 2,6)$.

Gómez et al. (1998) y Feki et al. (1996) en el estudio del peso de las vísceras de la caja torácica entre una línea mejorada por velocidad de crecimiento (R) y dos líneas mejoradas por aptitud maternal ( $\mathrm{A}$ y $\mathrm{V}$ ) en conejos de $2 \mathrm{~kg}$ encontraron que la línea $\mathrm{R}$ tuvo menor peso (29 g) que las líneas $\mathrm{A}(30,2 \mathrm{~g})$ y $\vee(30,9 \mathrm{~g})$. Si bien, en nuestro caso al peso $2 \mathrm{~kg}$ (semana 8) no hubo diferencias significativas en el peso de conjunto pulmones, tráquea, esófago y corazón entre líneas genéticas alimentadas con ambas dietas (semana 8- dieta C: HYcol: 27,6 g $\pm 2,1$; GR: 29,9 g $\pm 2,1 ; \mathrm{HY}: 27,9 \mathrm{~g} \pm 2,1$ - dieta HE: HYcol: 28, g $\pm 2,2 ; \mathrm{GR}: 29,6 \mathrm{~g} \pm 2,0 ; \mathrm{HY}: 27,9 \mathrm{~g} \pm 2,1$ ). 

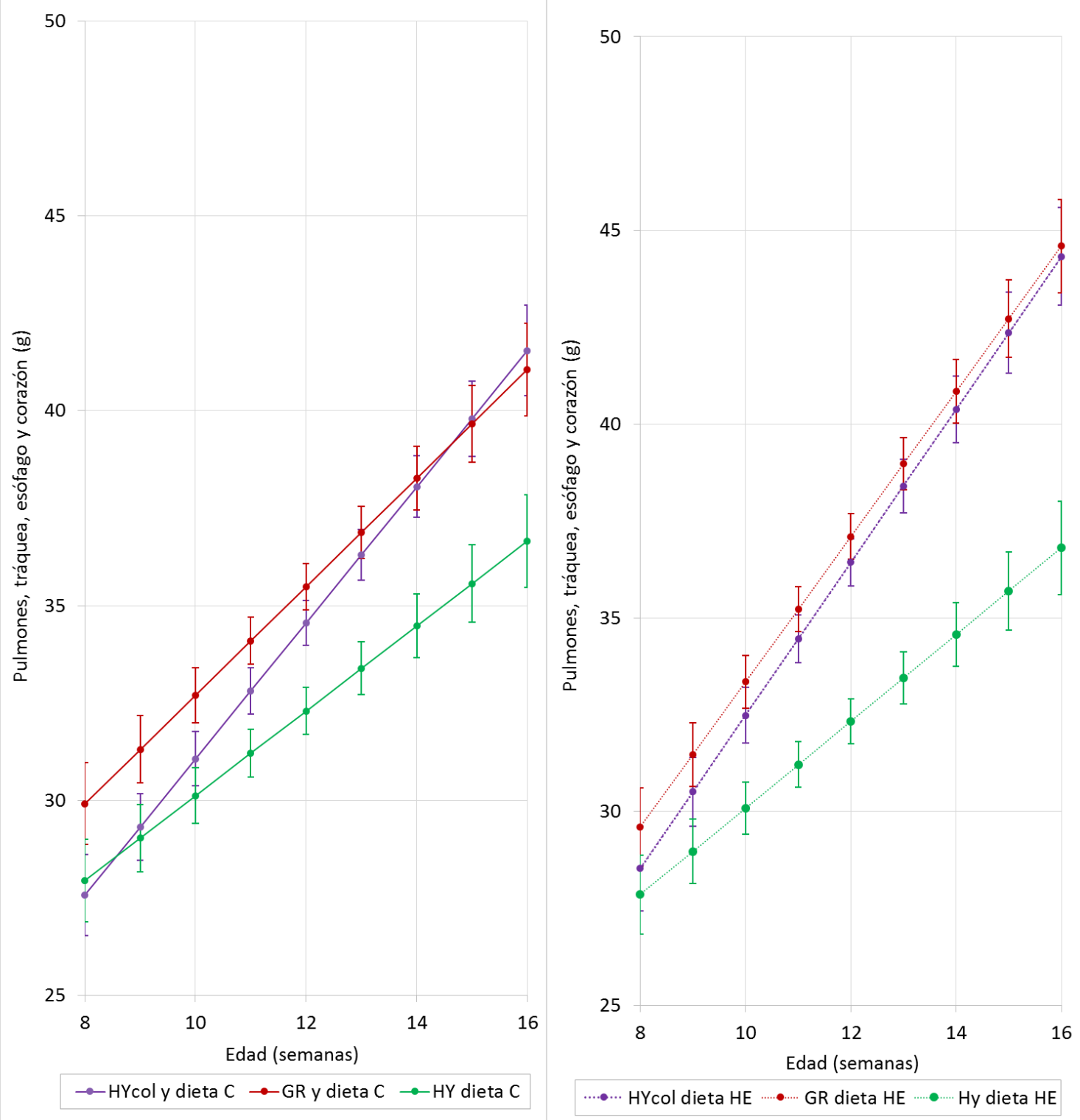

Figura 17. Evolución del peso del conjunto pulmones, tráquea, esófago y corazón con la edad (semanas) en función de la dieta (C: control y HE: altamente energética) y la línea genética (HYcol: Hyla-colored, GR: Grimaud ps 119 e HY: Hyla Grand Parental Doe) (Medias mínimo cuadráticas e intervalos de confianza). 

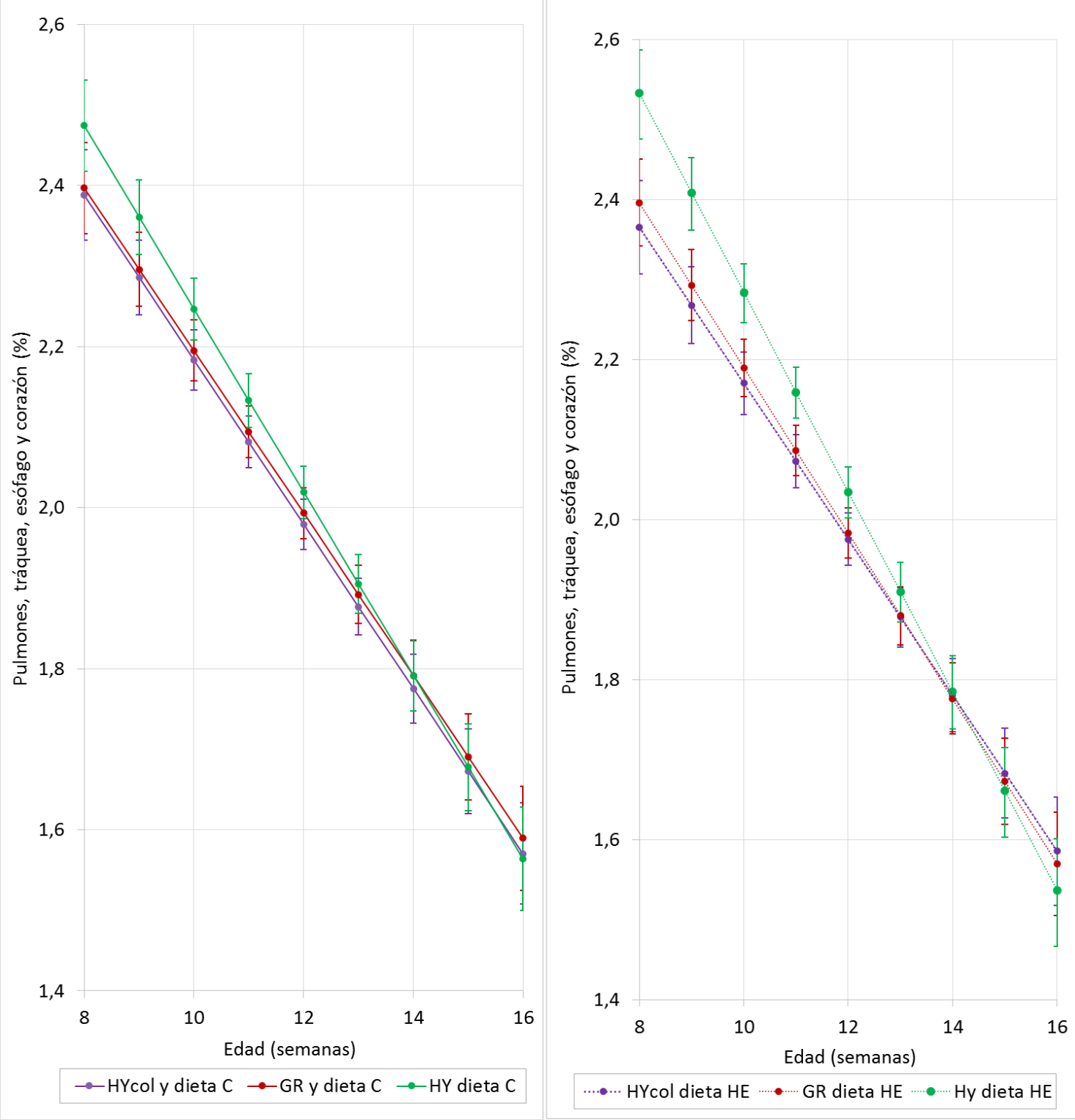

Figura 18. Evolución del porcentaje del conjunto pulmones, tráquea, esófago y corazón con la edad (semanas) en función de la dieta (C: control y HE: altamente energética) y la línea genética (HYcol: Hylacolored, GR: Grimaud ps 119 e HY: Hyla Grand Parental Doe) (Medias mínimo cuadráticas e intervalos de confianza).

Finalmente, no hubo un efecto del género sobre el peso o el porcentaje del conjunto de vísceras torácicas. 


\subsection{HÍGADO}

El hígado es un órgano de desarrollo precoz, como se observa según su coeficiente de alometría $\mathrm{k}(0,540 \pm 0,017$; tabla 4), por tanto el porcentaje del hígado respecto al peso de la canal fría disminuyó con la edad con valores que oscilaron del 5,4-5,7\% \pm 0,3\% en la semana 8 a 3,1-3,5\% $\pm 0,3 \%$ en la semana 16 (figura 20). En otros trabajos realizados en gansos (Lilja, 1981) y en conejos, tanto en líneas de aptitud cárnica como maternal, (Deltoro y López; 1985) postularon que los conejos y las aves son especies con fuerte ritmo de crecimiento y se caracterizan por el desarrollo temprano de órganos encargados de obtener la energía para los procesos de crecimiento, especialmente el hígado y el tracto digestivo. En nuestro trabajo para conejos de entre 8 y 16 semanas, el hígado presentó valores más bajos $(0,540 \pm 0,017)$ que los valores de otros autores, como Deltoro y López (1985) para conejos de 1 a 20 semanas, o Pascual et al. (2008) para conejos de 4 a 40 semanas $(0,88 \pm 0,06$ y 0,70 $\pm 0,07$, respectivamente). Estas diferencias podrían deberse a las distintas edades estudiadas. Deltoro y López (1985) encontraron $\mathrm{k}>1$ para el conejo de 1 a 7 semanas, mientras que de 8 a 10 el coeficiente alométrico era $k<1$. Algunos trabajos previos en conejo consideran cambios en los valores de k durante el crecimiento (Cantier et al., 1969; Deltoro y López, 1985), y ajustan a más de una línea recta con diferentes valores de $k$ en lugar de uno solo. Deltoro y López (1985) observaron que la mayoría de estos cambios ocurrían entre las 4 y 8 semanas de edad. Pascual et al. (2008) señalaron que el modelo de Huxley no proporciona un ajuste adecuado en componentes que logran un peso mayor en etapas previas que su peso en estado adulto, como es el caso del hígado.

Respecto al efecto de la línea genética y de la dieta, se observó una interacción entre ambos factores. Así, cuando los animales de las líneas genéticas de aptitud cárnica ( $\mathrm{HYcol}$ y GR) eran alimentados con la dieta HE presentaban un mayor peso y porcentaje de hígado (figuras 19 y 20) respecto a la dieta C, pero tal efecto no aparecía en la línea de aptitud maternal HY. Pascual et al. (2014) encontraron que al disminuir el contenido en fibra de la dieta de conejos a las 12 semanas para líneas seleccionadas por velocidad de crecimiento el porcentaje de hígado aumentaba (6,47 vs 7,54\%). Al igual que en nuestros resultados donde encontramos que HYcol y GR alimentados con la dieta con mayor contenido en fibra (en nuestro caso la dieta control) obtuvieron menor 
porcentaje (dieta C - semana 12: HYcol y GR: $4,3 \% \pm 0,1 ; \mathrm{HY}: 4,6 \% \pm 0,1$ ) que los alimentados con la dieta HE (dieta HE semana 12 HYcol: 4,6\% \pm ,1 y semana 12 GR: 4,5 $\% \pm 0,1)$. En cerdos, Weber et al. (2010) observaron una reducción en el peso del hígado cuando las hemicelulosas alimentarias aumentaron a expensas del almidón, acompañadas con menor contenido de glucógeno y triglicéridos en el hígado, lo que sugiere que hay una repartición de estos nutrientes del hígado cuando se usan dietas altas en fibra. López (1987) indicó que en animales con alta tasa de crecimiento el hígado también tiene un rápido y temprano crecimiento.

Cuando observamos el comportamiento de las diferentes líneas genéticas dentro de dieta, detectamos que la línea HY mostró un menor peso del hígado que HYcol y GR, siendo esta diferencia más marcada con la dieta HE (figura 19). Sin embargo, cuando expresamos el hígado como porcentaje las diferencias entre líneas genéticas no fueron significativas.

No hubo diferencias entre machos y hembras, tanto en el peso del hígado como en su porcentaje, de acuerdo con Lazzaroni et al. (2009). 


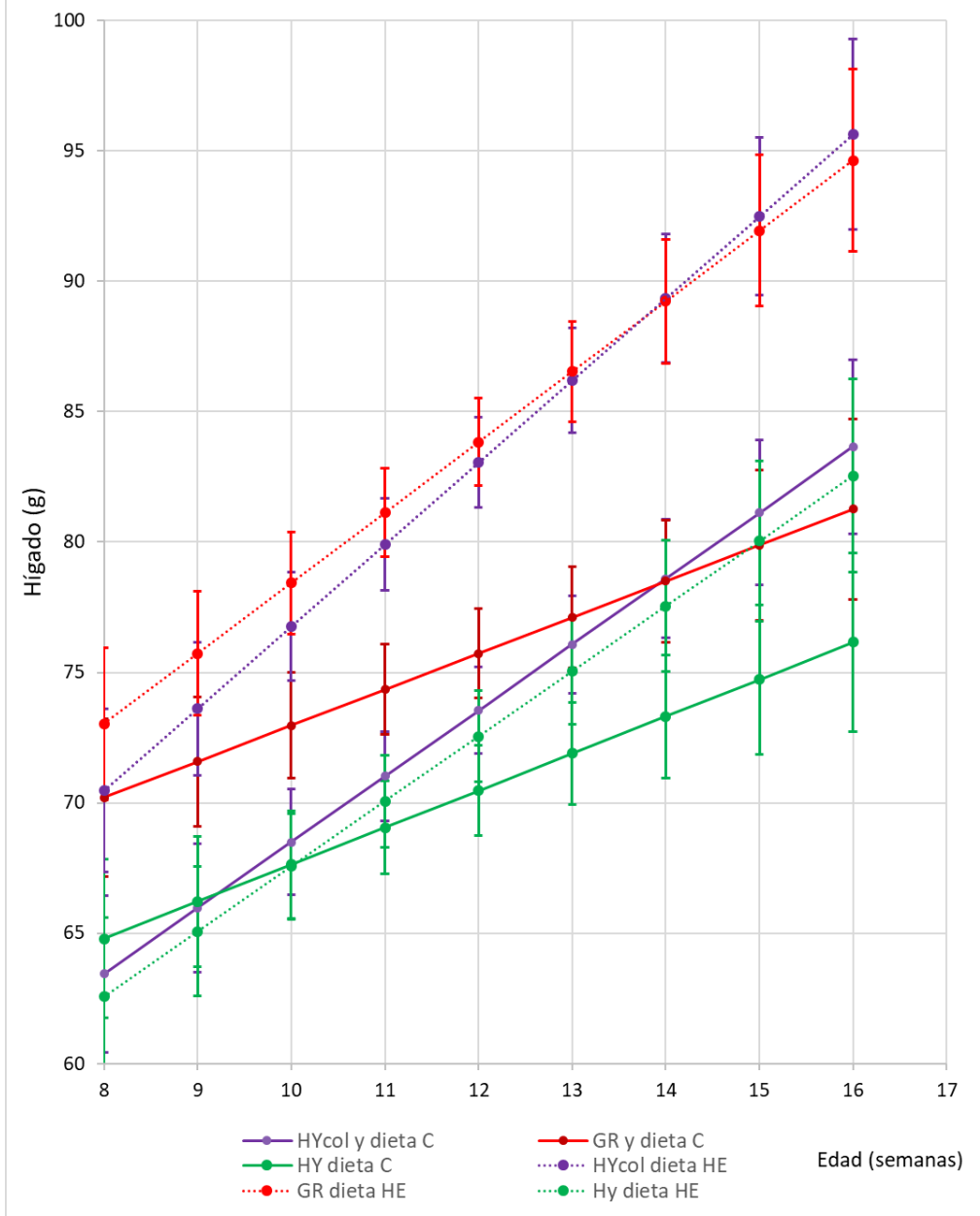

Figura 19. Evolución del peso del hígado con la edad (semanas) de las diferentes líneas genéticas y dietas (Líneas genéticas: Grimaud (GR), Hyla-colored (HYcol) e Hyla (HY) alimentadas con dos tipos de dieta (C: control y HE: altamente energética). (Medias mínimo cuadráticas e intervalos de confianza). 

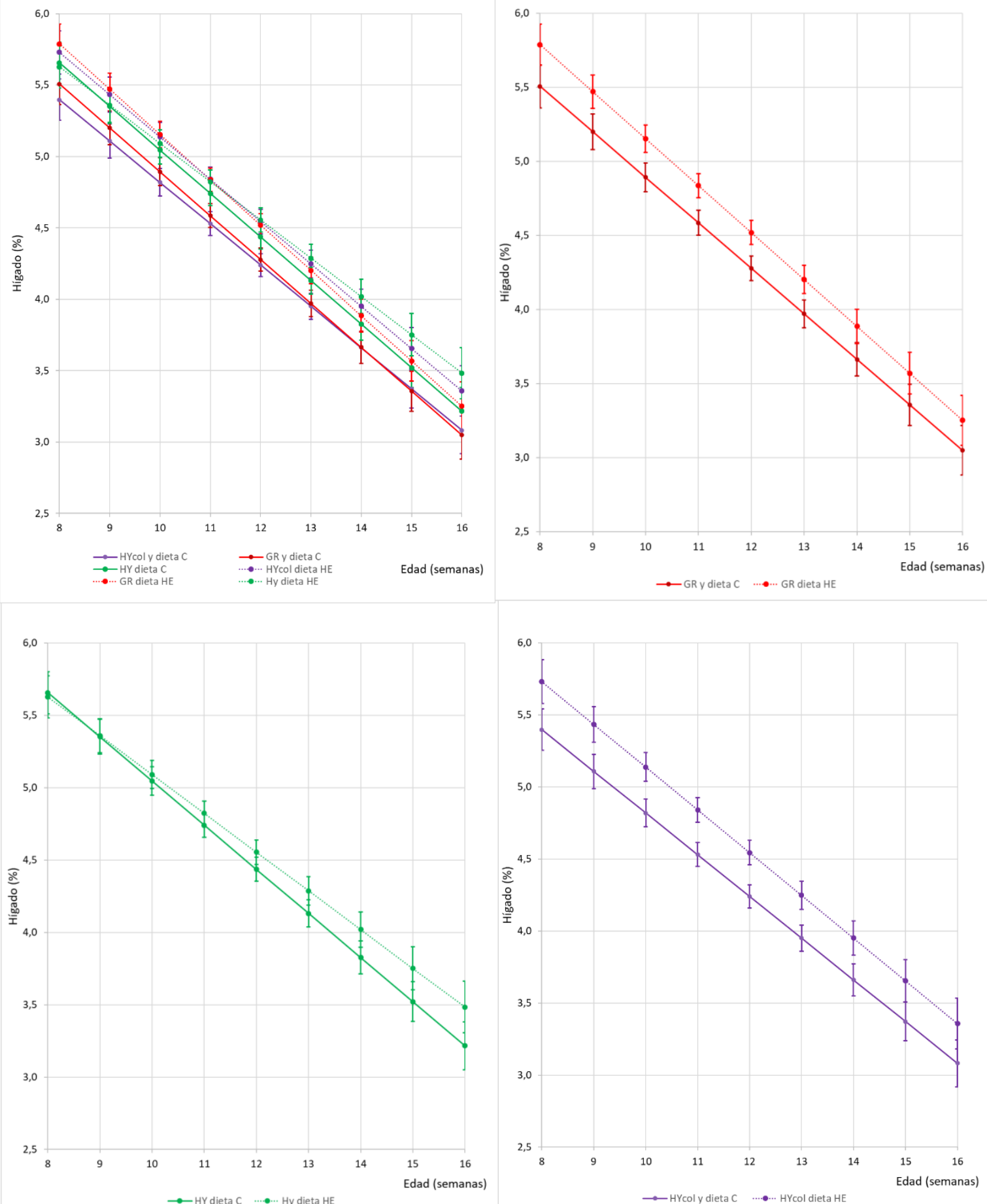

Figura 20. Evolución del porcentaje del hígado con la edad (semanas): a) Línea genética x Dieta, b) Línea genética Grimaud (GR) alimentada con los dos tipos de dieta (C: control y HE: altamente energética), c) Línea genética Hyla-colored ( $\mathrm{HYcol}$ ) alimentada con los dos tipos de dieta y d) Línea genética Hyla (HY) alimentada con los dos tipos de dieta. (Medias mínimo cuadráticas e intervalos de confianza) 


\subsection{RIÑONES}

Los riñones presentaron crecimiento precoz (alometría negativa) al igual que los otros órganos estudiados (tabla 4). En este sentido, el porcentaje de riñones descendió de la semana $8(1,3 \pm 0,02)$ a la $16(0,75 \pm 0,02 \%)$.

Se observó un efecto de la línea genética (figura 21) sobre el peso de los riñones a lo largo todo el periodo estudiado. La línea HYcol presentó el mayor valor, con una diferencia respecto a $\mathrm{GR}$ de $1 \mathrm{~g} \pm 0,24$, y respecto a HY de $2,3 \mathrm{~g} \pm 0,24$; además $\mathrm{GR}$ fue diferente respecto a HY en 1,3 g \pm 0,24. Gómez et al. (1998) y Feki et al. (1996) también obtuvieron diferencias significativas en el peso de los riñones para conejos con $2 \mathrm{~kg}$ de peso vivo comercial de dos líneas mejoradas por aptitud maternal ( $A$ y $\vee$ con 13,3 y 13,6 g respectivamente) frente a una línea de aptitud cárnica (R: 14,0 g). En nuestro trabajo, además también hubo diferencias entre las dos líneas de aptitud cárnica HYcol y GR, con pesos similares a los obtenidos por estos autores para la línea de aptitud maternal (semana 8 - HY: 14,27 g 0,27) y pesos superiores en las líneas de apttud cárnica (semana 8 HYcol: $16,57 \mathrm{~g} \pm 0,27 ; \mathrm{GR}: 15,61 \mathrm{~g} \pm 0,27)$.

Cuando los riñones fueron expresados como porcentaje respecto a PCF, la línea GR presentó el menor valor de la semana 9 a la 15 (con una diferencia de 0,08 \pm 0,02\% respecto a HYcol y de $0,05 \pm 0,02 \%$ respecto a $\mathrm{HY}$ ), mientras que HYcol seguía presentando el mayor porcentaje, aunque no era distinta a HY. Dalle Zotte et al. (2015) para dos líneas genéticas (Large, aptitud maternal y Hung, aptitud cárnica) con 12 semanas tuvieron porcentajes de riñones (Large: 0,59 \%, Hung: 0,64 \% \pm 0,004) inferiores a los nuestros que superan el 0,9\% en la semana 12 para las tres líneas genéticas (figura 21). 

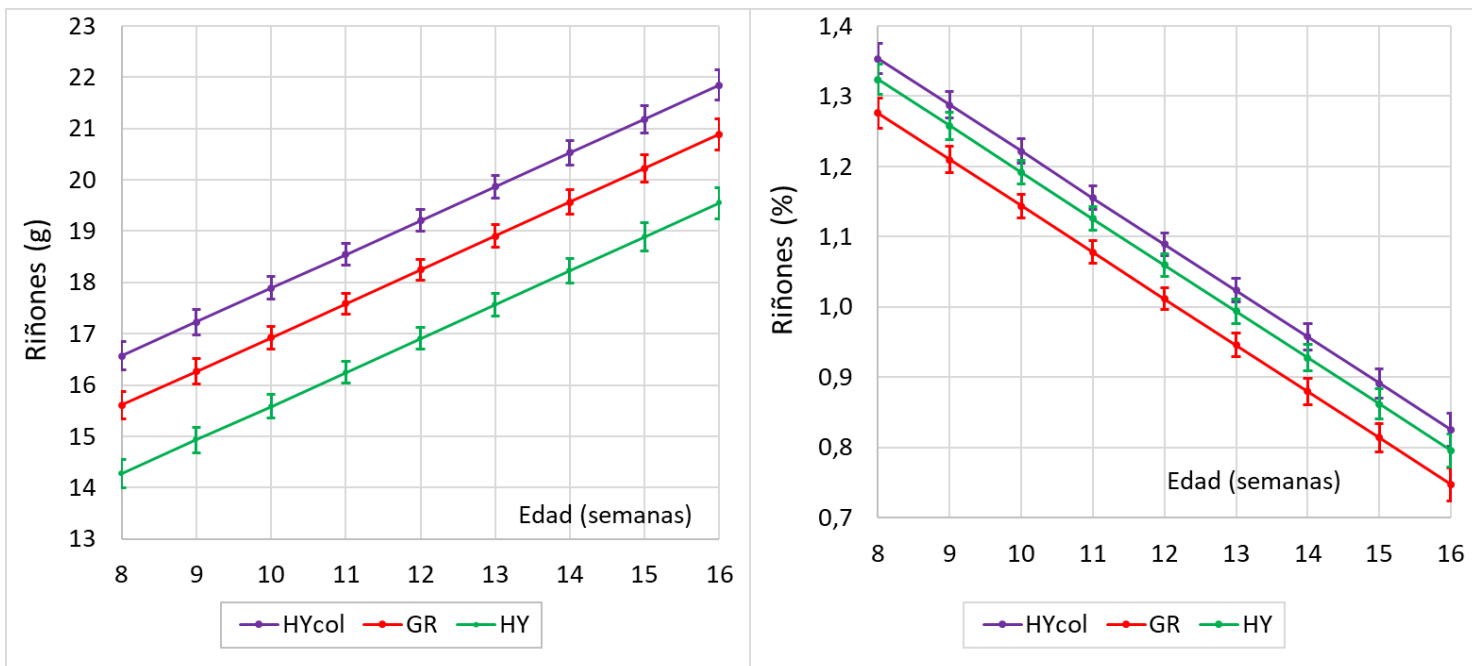

Figura 21. Evolución del peso y del porcentaje de los riñones con la edad (semanas) en función la línea genética (Grimaud (GR), Hyla-colored (HYcol) e Hyla (HY) (Medias mínimo cuadráticas e intervalos de confianza).

En el peso y porcentaje de los riñones no hubo influencia de la dieta (figura 22), al igual que Pascual et al. (2014) que no encuentran diferencias significativas en el porcentaje de los riñones en conejos alimentados con dos dietas con diferentes niveles de fibra a las 12 semanas para líneas seleccionadas por velocidad de crecimiento $(1,24 \% \pm 0,02$ vs $1,29 \% \pm 0,02)$.
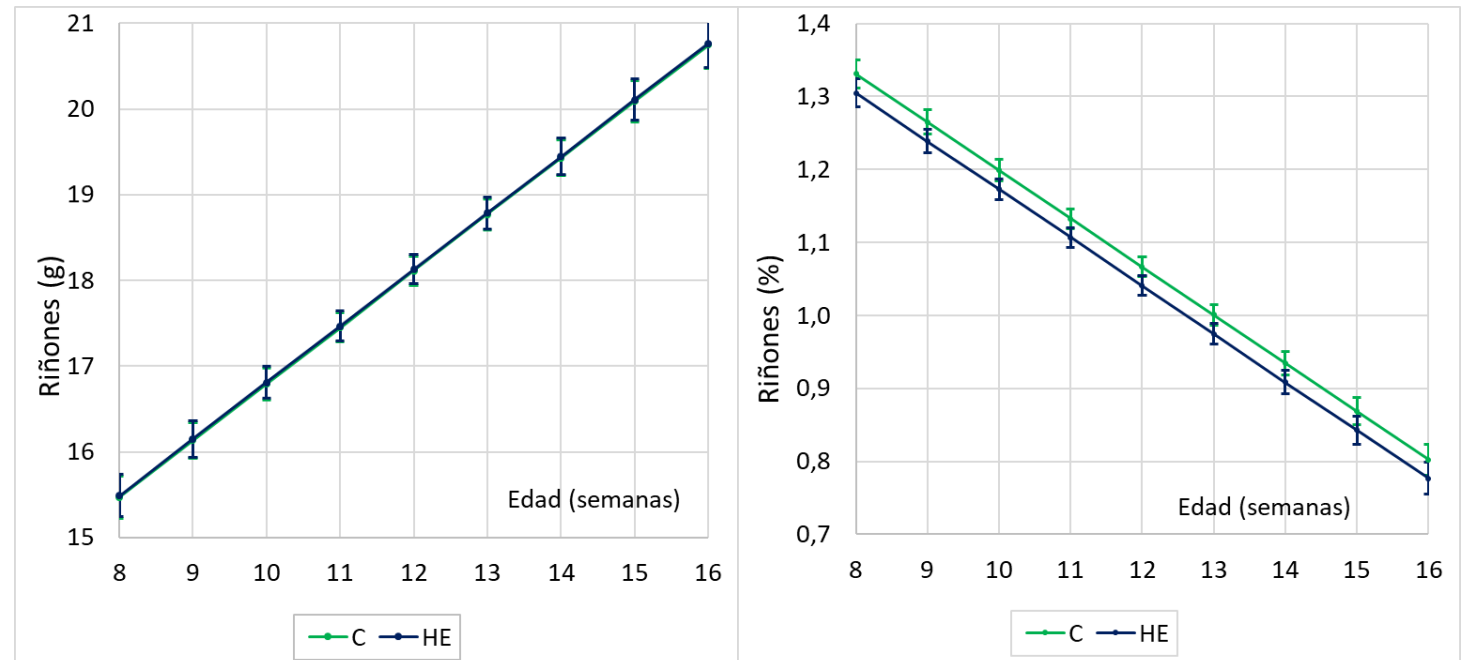

Figura 22. Evolución del peso y del porcentaje con de los riñones la edad (semanas) en función de la dieta (C: control y HE: altamente energética) (Medias mínimo cuadráticas e intervalos de confianza). 
En el desarrollo de los riñones hubo diferencias significativas entre machos y hembras, las hembras presentaron un mayor peso $(0,60 \mathrm{~g} \pm 0,2)$ a lo largo de todo el periodo estudiado y mayor porcentaje $(0,04 \% \pm 0,02)$ de la semana 9 a la 14 . Lazzaroni et al. (2009) no encontraron diferencias significativas en el porcentaje de riñones entre machos y hembras en el periodo de 9 a 16 semanas.
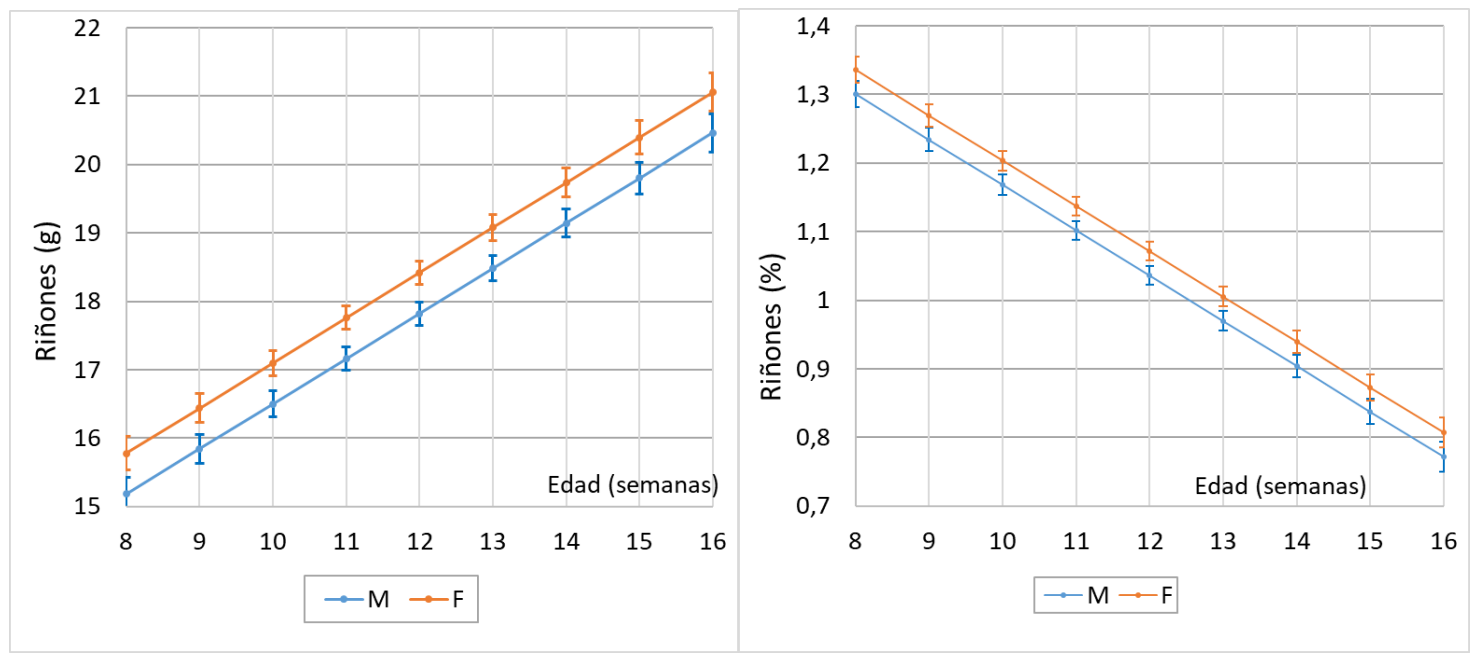

Figura 23. Evolución del peso y del porcentaje de los riñones con la edad (semanas) en función del género (M: machos y F: hembras) (Medias mínimo cuadráticas e intervalos de confianza).

\subsection{CABEZA}

En el crecimiento diferencial de las diferentes partes de la canal se observó que cabeza (tabla 4) y caja torácica (tabla 5) tuvieron un crecimiento precoz mientras que patas delanteras y traseras y lomo tuvieron crecimiento tardío (tabla 5) como se verá en el apartado de despiece de la canal (2.8.).

El patrón de crecimiento precoz para la cabeza también fue observado por Deltoro y López (1985) y Pascual et al. (2008). En el desarrollo de la cabeza (figura 24) a lo largo de todas las semanas hubo diferencias significativas entre las líneas mejoradas por velocidad de crecimiento (HYcol y GR) y la línea mejorada por aptitud maternal (HY). En el desarrollo de la cabeza, HYcol y GR siempre tuvieron pesos mayores de cabeza que HY en todas las semanas, con diferencias de 8 a 10 gramos. En la semana 8 el peso de la cabeza en HYcol fue 107,1 g $\pm 4,4$; en GR fue $105,7 \mathrm{~g} \pm 2,5$, mientras que HY fue inferior a ambos (96,4 g $\pm 2,5)$. Y en la semana 16 se repite el patrón (HYcol: 179,6 g $\pm 2,7$; GR: $178,3 \mathrm{~g} \pm 2,8$ e HY: $168,9 \mathrm{~g} \pm 2,8)$. A pesar de aumentar semanalmente el peso de la 
cabeza, el porcentaje de las tres líneas (figura 24) respecto a la canal de fría tuvo un descenso paulatino a lo largo del periodo estudiado. En la cabeza hubo diferencias significativas del porcentaje, el descenso fue mayor para GR, seguido de HYcol y finalmente HY fue el que se mantuvo por encima (semana 8: HYcol: 8,9 \% $\pm 0,03 ; G R: 8,7$ $\% \pm 0,03$ e HY: $9,3 \% \pm 0,03$; semana 16: HYcol: 7,0 \% $\pm 0,03 ; \mathrm{GR}: 6,7 \% \pm 0,03$ e HY: 7,2 \% $\pm 0,03)$. El descenso fue un $2 \%$ aproximadamente desde la semana 8 a la 16 en las tres líneas. Por tanto la línea de aptitud maternal tuvo menor peso de cabeza que las líneas de aptitud cárnica, mientras que el porcentaje de cabeza respecto a la canal fría fue mayor.

Si bien, Gómez et al. (1998) y Feki et al. (1996) no encontraron diferencias significativas en el peso de la cabeza entre dos líneas seleccionadas por tamaño de camada al destete (A y V) y otra línea seleccionada por tasa de crecimiento a los $2 \mathrm{~kg}$ de peso comercial. Al contrario que nuestros resultados $\mathrm{A}$ y $\mathrm{V}(\mathrm{A}: 106,3 \pm 0,60 \mathrm{~g}$ y $\mathrm{V}: 106,3 \pm 0,60 \mathrm{~g})$ tuvieron más tamaño de cabeza que $R(104,9 \pm 0,60 \mathrm{~g})$ a los $2 \mathrm{~kg}$ de peso comercial, que equivale a las 8 semanas de edad en nuestro trabajo (GR: 105,65 $\pm 0,22 \mathrm{~g}$, HYcol: 106,97 $\pm 0,34 \mathrm{~g}$, HY: $96,38 \pm 0,22 \mathrm{~g})$.
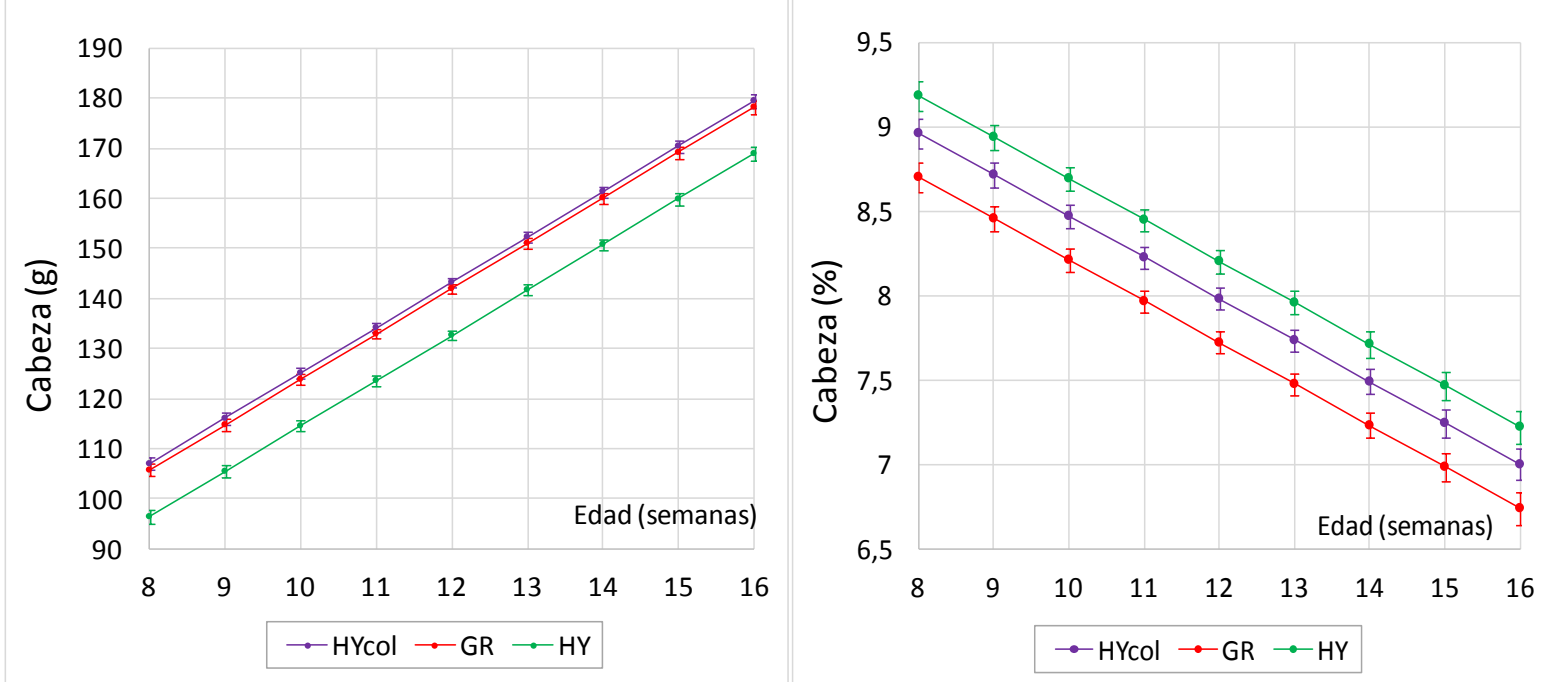

Figura 24. Evolución del peso (gramos) de la cabeza y del porcentaje respecto a la canal de referencia (\%) con la edad (semanas) en función de la línea genética (HYcol: Hyla-colored, GR: Grimaud ps 119 e HY: Hyla Grand Parental Doe) (Medias mínimo cuadráticas e intervalos de confianza). 
En el peso de la cabeza no hubo diferencias significativas al ingerir una dieta u otra (figura 25) (cabeza: semana 8 - dieta C: 102,2 g $\pm 2,3$; dieta HE: 103,9 g $\pm 2,2$; semana 16 - dieta C: $174,8 \mathrm{~g} \pm 2,5$; dieta HE: $176,4 \mathrm{~g} \pm 2,6$ ). Respecto al efecto de la dieta en el porcentaje de cabeza hubo diferencias significativas desde la semana 10 (dieta C: 7,5 \% $\pm 0,03$; dieta HE: 7,3 \% $\pm 0,03$ ) a la 13 (dieta C: 6,6 \% $\pm 0,03$; dieta HE: 6,4 \% $\pm 0,03$ ), teniendo mayores porcentajes con la dieta C.

Acorde con nuestros resultados del peso de la cabeza en la semana 12 (dieta C: 138,5 g $\pm 1,6$; dieta HE: 140,2 g \pm 1,6) y del porcentaje (dieta C: 7,0 \% \pm 0,03; dieta HE: 6,9 \% \pm 0,03), Al-Donaib (2010) no encontró diferencias significativas en el porcentaje de la cabeza para conejos con 12 semanas $(8,5 \% \pm 1,16)$ procedentes de cuatro líneas genéticas distintas seleccionadas por peso de camada al destete ( $\mathrm{V}$-line de origen español, Saudi-1, Saudi-2 and Saudi-3), y que fueron alimentados con tres dietas diferentes en las que alimentos autóctonos eran sustituidos por alimentos no autóctonos pero las tres dietas presentaban el mismo nivel de energía digestible (2857 g/kg MS). En cambio, Pascual et al. (2014) encontraron diferencias significativas en el porcentaje de cabeza en conejos alimentados con dos dietas con diferentes niveles de fibra (32,9 \% FND sobre MS vs $37,4 \%$ de FND sobre MS) a las 12 semanas para líneas seleccionadas por velocidad de crecimiento, obteniendo mayores porcentajes de cabeza los alimentados por la dieta con menor contenido en fibra ( 8,73 vs $8,14 \%$ cabeza a las 12 semanas).
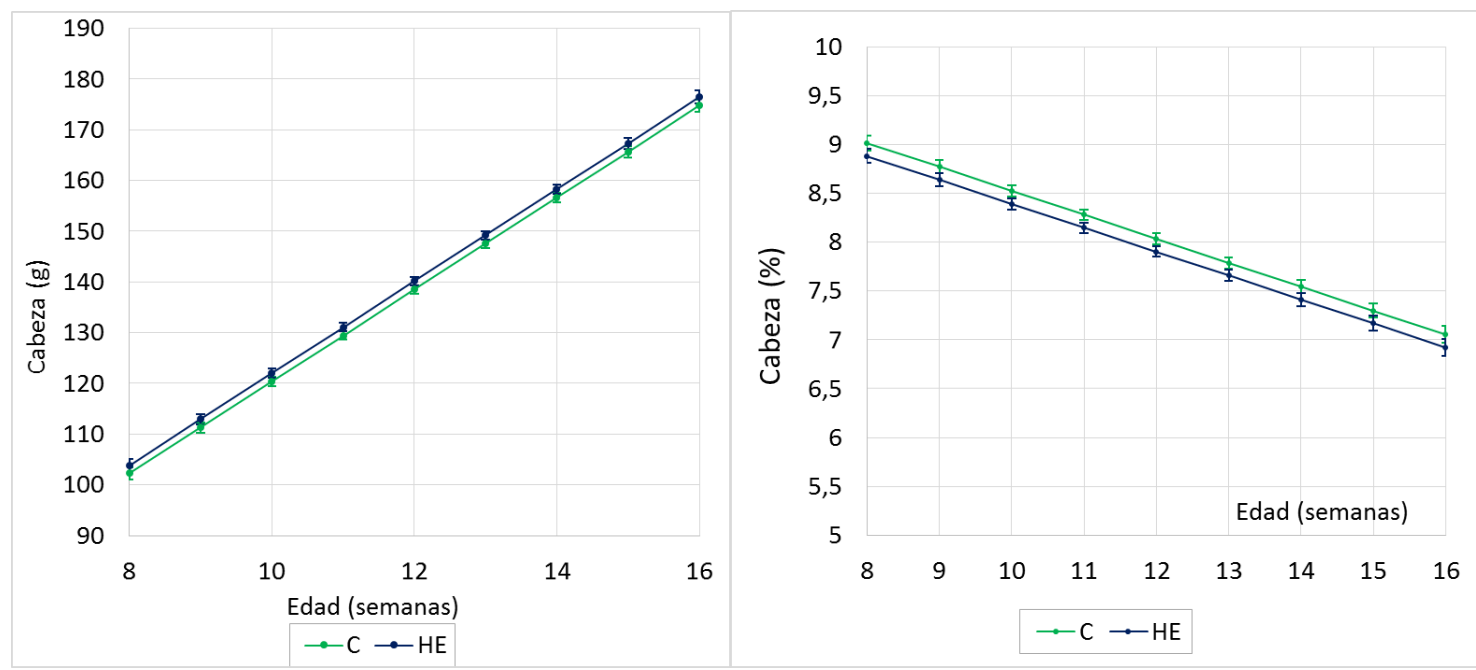

Figura 25. Evolución del peso (gramos) de la cabeza y del porcentaje con la edad (semanas) en función de la dieta (C: control y HE: altamente energética) (Medias mínimo cuadráticas e intervalos de confianza). 

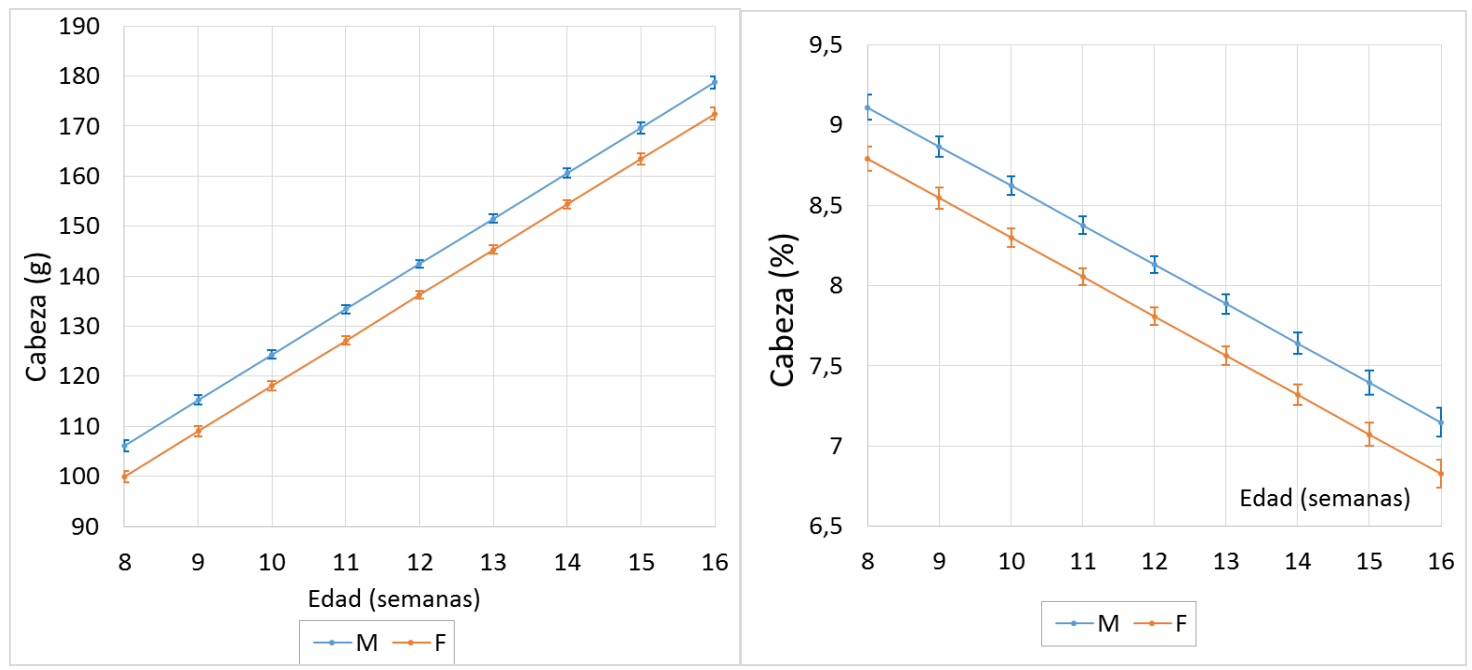

Figura 26. Evolución del peso (gramos) de la cabeza y del porcentaje) con la edad (semanas) en función del género (F: hembra y $\mathrm{M}$ : Macho) (Medias mínimo cuadráticas e intervalos de confianza).

En cuanto al efecto del género (figura 26), en el desarrollo de la cabeza hubo diferencias significativas entre machos (M) y hembras (F), siendo más pesadas las cabezas de los machos que las hembras en todo el periodo estudiado (semana 8: M 106,2 g $\pm 2,3$; F: 99,9 g $\pm 2,3$; semana 16: M: 178,7 g $\pm 2,6 ; F: 172,5 \mathrm{~g} \pm 2,6)$.

En cuanto al género, el descenso del porcentaje de cabeza de los machos presentó diferencias significativas, teniendo mayores porcentajes de cabeza respecto a la canal fría que las hembras desde la semana 8 a la 16 (figura 26) (semana 8: M: 0,92 \% $\pm 0,02$; $F: 0,87 \% \pm 0,02)$.

En el porcentaje de cabeza entre machos y hembras de 9 a 16 semanas nuestros resultados (figura 26) coincidieron con Lazzaroni et al. (2009) que encontraron diferencias significativas, siendo mayores los porcentajes de los machos $(5,4 \pm 0,37 \%)$ que las hembras (4,7 $\pm 0,21 \%)$. En nuestro caso a la semana 9 los machos tuvieron 0,88 $\% \pm 0,02$ y las hembras $0,85 \% \pm 0,02 ;$ y a la semana 16 los machos tuvieron $0,72 \% \pm$ 0,02 y las hembras $0,68 \% \pm 0,02$. 


\subsection{DESPIECE DE LA CANAL: CAJA TORÁCICA, LOMO, PATAS DELANTERAS Y TRASERAS}

En el crecimiento diferencial de las diferentes partes de la canal se observó que el conjunto de costillas y caja torácica (CT) tuvieron un crecimiento precoz mientras que patas delanteras (Pdel), traseras (Ptra) y lomo (L) tuvieron crecimiento tardío, si bien el coeficiente de alometría de las patas traseras (Ptra) fue ligeramente superior a 1 (tabla 5).

Tabla 5. Mínimos estimados cuadrados (MEC) y errores estándar (ES) de los coeficientes alométricos $k$ de Huxley para patas delanteras (Pdel), patas traseras (Ptra), caja torácica (CT) y lomo (L).

\begin{tabular}{ccc}
\hline COMPONENTE & MEC & ES \\
\hline Pdel & 1.245 & 0.009 \\
Ptra & 1.062 & 0.007 \\
CT & 0.824 & 0.014 \\
L & 1.223 & 0.015 \\
\hline Fuente: Martínez-Bas et al. (2018)
\end{tabular}

En el patrón de crecimiento de la caja torácica y costillas, Pascual et al. (2008) para conejos de 4 a 40 semanas observaron un coeficiente de alometría ligeramente mayor de $1(k=1,13 \pm 0,02)$, mientras Deltoro y López (1985) encontraron un coeficiente menor que 1 para conejos de 1 a 8 semanas $(0,995 \pm 0,004)$ y mayor que $1(1,334 \pm$ 0,008) para conejos de 9 a 20 semanas.

En las extremidades, en concreto en las patas delanteras Deltoro y López (1985) y Pascual et al. (2008) obtuvieron crecimiento isométrico; y en las patas traseras Deltoro y López (1985) encontraron que el coeficiente de alometría dependía del periodo estudiado, con valor menor que $1(k=0.825 \pm 0.005)$ de 6 a 20 semanas y mayor que 1 $(k=1.175 \pm 0.013)$ de 1 a 5 semanas.

En el crecimiento del lomo, Pascual et al. (2008) obtuvieron un coeficiente de alometría en conejos de 4 a 40 semanas muy similar al nuestro $(k=1.24 \pm 0.02)$ y Deltoro y López (1985) obtuvieron un valor próximo a $1(k=1.050 \pm 0.017)$ para conejos de 9 a 20 semanas.

Deltoro y López (1985) destacaron que las partes del cuerpo con mayores tasas de crecimiento durante la primera fase del crecimiento posnatal se ubicaron en los cuartos traseros que, de acuerdo con el patrón de características de la locomoción de los 
conejos que actúan como palanca principal de propulsión. Los que tienen mayores tasas de crecimiento durante la segunda fase se encontraban en el tronco.

Tabla 6. Medias globales y errores estándar de los porcentajes de las diferentes partes de la canal a lo largo del periodo estudiado

\begin{tabular}{lcccc}
\hline SEMANA & CAJA TORÁCICA & LOMO & PATAS DELANTERAS & PATAS TRASERAS \\
\hline $\mathbf{8}$ & $8,21(0,12)$ & $22,9(0,3)$ & $16,6(0,3)$ & $28,7(0,3)$ \\
$\mathbf{9}$ & $8,02(0,11)$ & $23,4(0,3)$ & $16,8(0,2)$ & $28,7(0,3)$ \\
$\mathbf{1 0}$ & $7,82(0,10)$ & $23,9(0,2)$ & $17,0(0,2)$ & $28,7(0,2)$ \\
$\mathbf{1 1}$ & $7,62(0,09)$ & $24,4(0,2)$ & $17,2(0,2)$ & $28,8(0,2)$ \\
$\mathbf{1 2}$ & $7,42(0,09)$ & $24,9(0,2)$ & $17,4(0,1)$ & $28,8(0,2)$ \\
$\mathbf{1 3}$ & $7,22(0,10)$ & $25,4(0,2)$ & $17,6(0,2)$ & $28,8(0,2)$ \\
\hline 14 & $7,03(0,11)$ & $25,9(0,2)$ & $17,9(0,2)$ & $28,8(0,2)$ \\
\hline 15 & $6,83(0,12)$ & $26,4(0,3)$ & $18,1(0,3)$ & $28,8(0,3)$ \\
\hline 16 & $6,63(0,13)$ & $26,9(0,4)$ & $18,3(0,3)$ & $28,9(0,4)$ \\
\hline
\end{tabular}

En la tabla 6, se muestra la evolución de las diferentes partes de la canal de la semana 8 a la 16 de edad, en la que se observa que la caja torácica disminuyó su porcentaje $(1,58$ $\%$ ), mientras que el lomo y las patas delanteras lo aumentaban (4 \% y $1,7 \%$ respectivamente) y el de las patas traseras permanecía constante.

En cuanto al efecto de la línea genética, cuando las diferentes partes de la canal son expresadas en gramos siguen el mismo patrón de comportamiento que el observado en el peso de la canal, así las líneas de aptitud cárnica HYcol y GR mostraron mayor peso de la caja torácica (figura 27), del lomo (figura 28), de las patas delanteras (figura 29) y traseras (figura 30) que la línea de aptitud maternal HY; y esta diferencia fue más marcada con la dieta HE. Si bien, en la semana 8, HYcol presentó valores intermedios para todas las partes, salvo para la caja torácica, y no fue diferente ni a HY ni a GR, al igual que sucedió con PCF. En la tabla 7 se pueden observar los valores medios obtenidos para las diferentes partes de la canal por línea genética y dieta en la semana 8 y en la semana 16. Así, la línea HYcol y GR mostraron 16 gramos más de caja torácica, 139-112 gramos más de lomo, 84-102 gramos más de patas delanteras y 118-124 gramos más de patas traseras que la línea HY respectivamente. 
Tabla 7. Medias mínimo cuadráticas (en gramos) de las diferentes partes de la canal para las líneas genéticas y dietas en la semana 8 y 16.

\begin{tabular}{|c|c|c|c|c|c|c|c|}
\hline \multicolumn{8}{|c|}{ SEMANA 8} \\
\hline & \multicolumn{2}{|c|}{$\mathrm{HY}$} & \multicolumn{2}{|c|}{ HYcol } & \multicolumn{2}{|c|}{ GR } & \\
\hline & C & HE & $\mathrm{C}$ & HE & C & HE & IC \\
\hline CAJA TORÁCICA & \multicolumn{2}{|c|}{84,7} & \multicolumn{2}{|c|}{100,7} & \multicolumn{2}{|c|}{101,0} & 4,4 \\
\hline LOMO & 245,3 & 241,0 & 252,6 & 257,4 & 275,7 & 276,5 & 10,4 \\
\hline PATAS DELANTERAS & 179,9 & 176,7 & 184,1 & 189,6 & 202,0 & 198,4 & 10,0 \\
\hline PATAS TRASERAS & 312,4 & 305,7 & 325,7 & 328,8 & 349,3 & 348,1 & 10,0 \\
\hline \multicolumn{8}{|c|}{ SEMANA 16} \\
\hline & \multicolumn{2}{|c|}{ HY } & \multicolumn{2}{|c|}{ HYcol } & \multicolumn{2}{|c|}{ GR } & \\
\hline & C & HE & C & $\mathrm{HE}$ & C & HE & IC \\
\hline CAJA TORÁCICA & \multicolumn{2}{|c|}{154,8} & \multicolumn{2}{|c|}{170,9} & \multicolumn{2}{|c|}{171,2} & 4,8 \\
\hline LOMO & 579,7 & 576,4 & 651,7 & 715,4 & 649,7 & 688,0 & 11,9 \\
\hline PATAS DELANTERAS & 393,8 & 388,6 & 449,4 & 473,0 & 452,0 & 490,3 & 11,0 \\
\hline PATAS TRASERAS & 631,7 & 631,0 & 717,0 & 748,8 & 723,3 & 755,3 & 11,6 \\
\hline
\end{tabular}

Línea genética (HYcol: Hyla-colored, GR: Grimaud ps 119 e HY: Hyla Grand Parental Doe); dieta (C: control y HE: alta energía). IC: \pm intervalo de confianza al $95 \%$ de significación.

Cuando las variables son expresadas como porcentaje respecto a PCF, la línea HYcol presentó el mayor porcentaje de lomo con la dieta HE a partir de la semana 12 siendo está diferencia del 1,2 $\pm 0,5 \%$ en la semana 16 , y presentó mayor porcentaje de patas traseras que GR con la dieta $C$ en las semanas de la 10 a la 12 si bien la diferencia fue pequeña $(0,5 \pm 0,3 \%)$. Por otro lado, GR presentó mayor porcentaje de patas delanteras que HY a partir de la semana 10 (diferencia de 0,4 $\pm 0,2 \%$ semana 10 a 0,8 $\pm 0,3 \%$ semana 16) y mayor que HYcol en las semanas 11 y 12 (diferencia $=0,3 \pm 0,1 \%$ ) en la dieta C; y mayor porcentaje que HYcol (diferencia de 0,4 $\pm 0,2 \%$ semana 10 a 0,5 $\pm 0,3 \%$ semana 16 ) e HY (diferencia de $0,4 \pm 0,2 \%$ semana 10 a $1 \pm 0,3 \%$ semana 16 ) a partir de la semana 12 en la dieta HE. En cuanto al efecto de la dieta, se observó que con la dieta HE la línea HYcol presentaba mayor porcentaje (de 0,5 $\pm 0,2 \%$ semana 12 a $1 \pm 0,4 \%$ semana 16) de lomo a partir de la semana 12 y menor porcentaje $(0,8 \pm 0,3 \%)$ de patas traseras a lo largo de todo el periodo, e HY también presentaba menor porcentaje (diferencia 0,6 $\pm 0,2 \%$ semana 11 a $1 \pm 0,4 \%$ semana 16 ) de patas traseras a partir de la semana 11. 

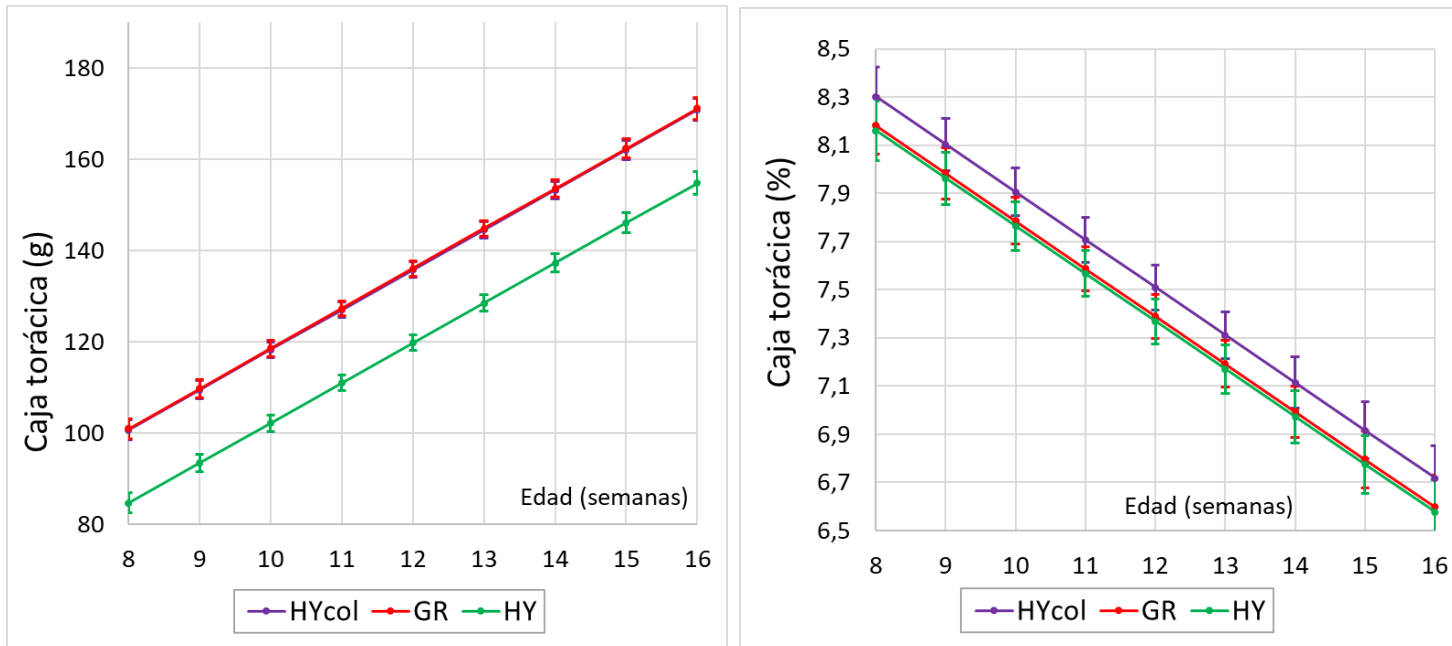

Figura 27. Evolución del peso (gramos) de la caja torácica y del porcentaje respecto a la canal fría (\%) con la edad (semanas) en función de la línea genética (HYcol: Hyla-colored, GR: Grimaud ps 119 e HY: Hyla Grand Parental Doe). Medias mínimo cuadráticas e intervalos de confianza.

Al contrario que en nuestros resultados, Gómez et al. (1998) a las 9 semanas encontraron que dos líneas mejoradas por tamaño de camada al destete (A y V) presentaban mayor peso de la caja torácica ( $\mathrm{A}: 361 \pm 0,71 \mathrm{~g}$ y $\mathrm{V}: 364 \pm 0,71 \mathrm{~g}$ ) que una línea mejorada por tasa de crecimiento ( $R: 351 \pm 0,71 \mathrm{~g})$.

Además, en nuestro trabajo no se observó un efecto de la dieta sobre el peso o el porcentaje de la caja torácica, al igual Pascual et al. (2014) que no encontraron diferencias significativas en el porcentaje de caja torácica en conejos alimentados con dos dietas con diferentes niveles de fibra a las 12 semanas para líneas seleccionadas por velocidad de crecimiento. 

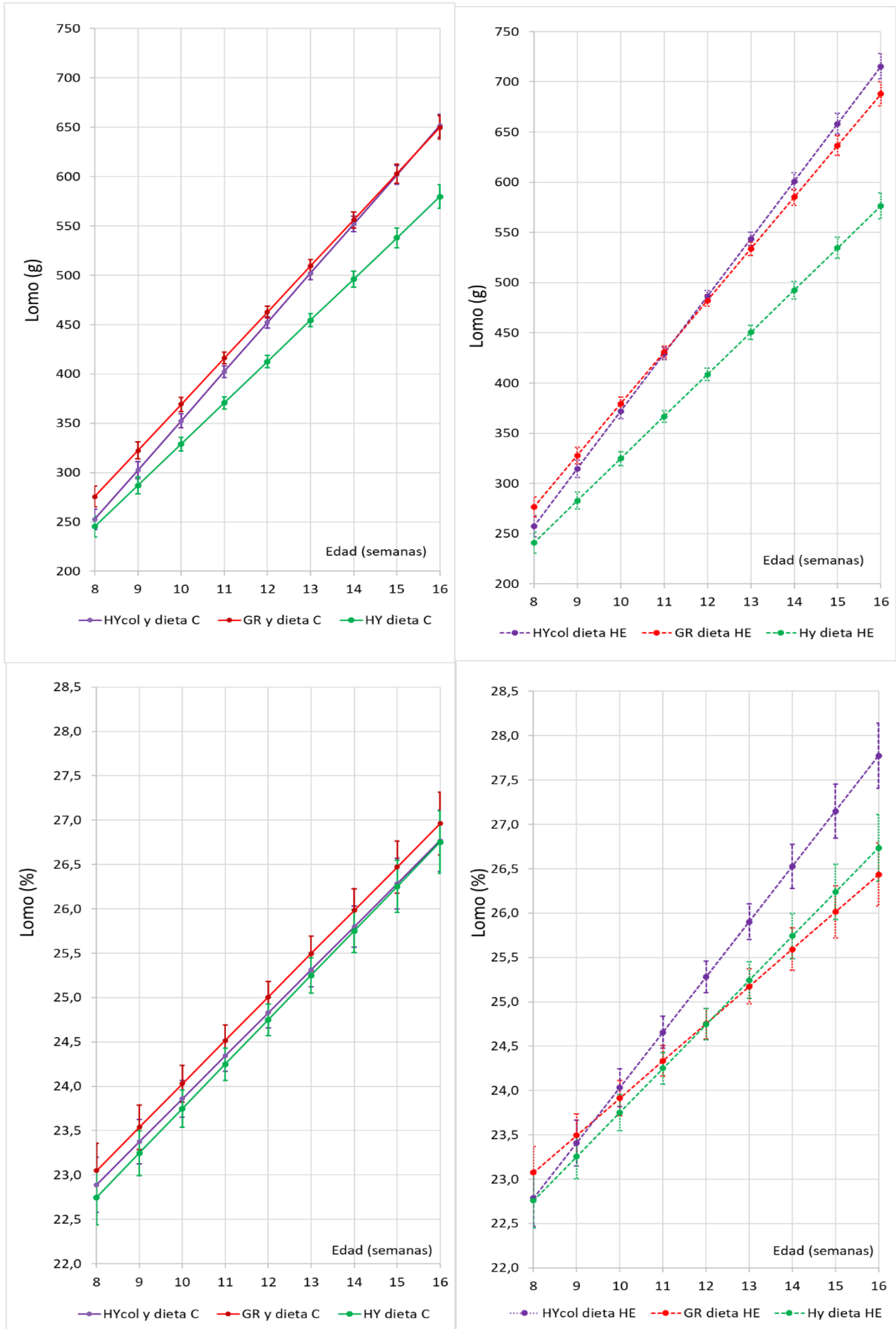

Figura 28. Evolución del peso (gramos) del lomo y del porcentaje respecto a la canal fría (\%) con la edad (semanas) en función de la línea genética (HYcol: Hyla-colored, GR: Grimaud ps 119 e HY: Hyla Grand Parental Doe) y la dieta (C: control y HE: alta energía). Medias mínimo cuadráticas e intervalos de confianza. 

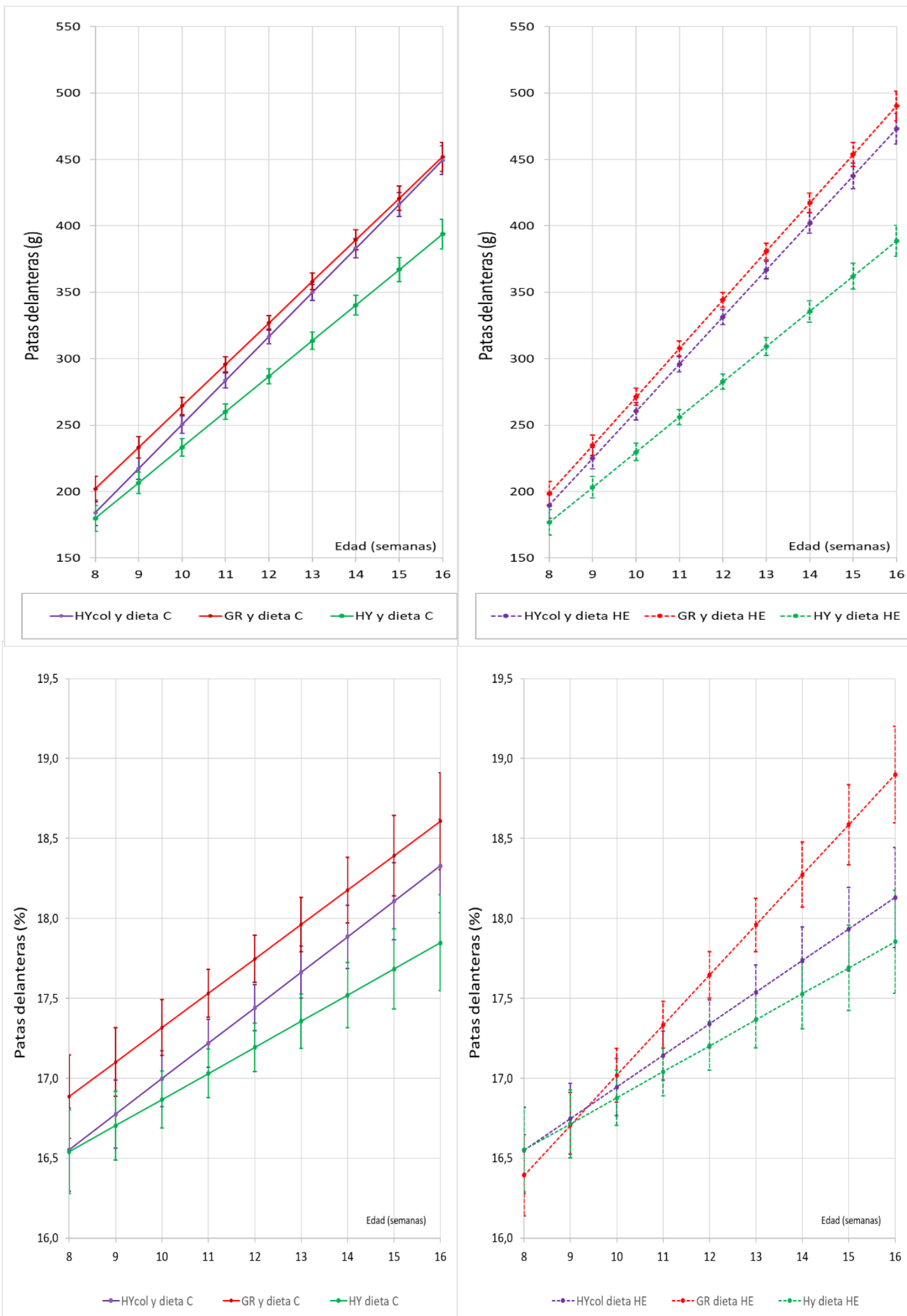

Figura 29. Evolución del peso (gramos) de las patas delanteras y del porcentaje respecto a la canal de referencia (\%) con la edad (semanas) en función de la línea genética (HYcol: Hyla-colored, GR: Grimaud ps 119 e HY: Hyla Grand Parental Doe) y la dieta (C: control y HE: alta energía). Medias mínimo cuadráticas e intervalos de confianza. 

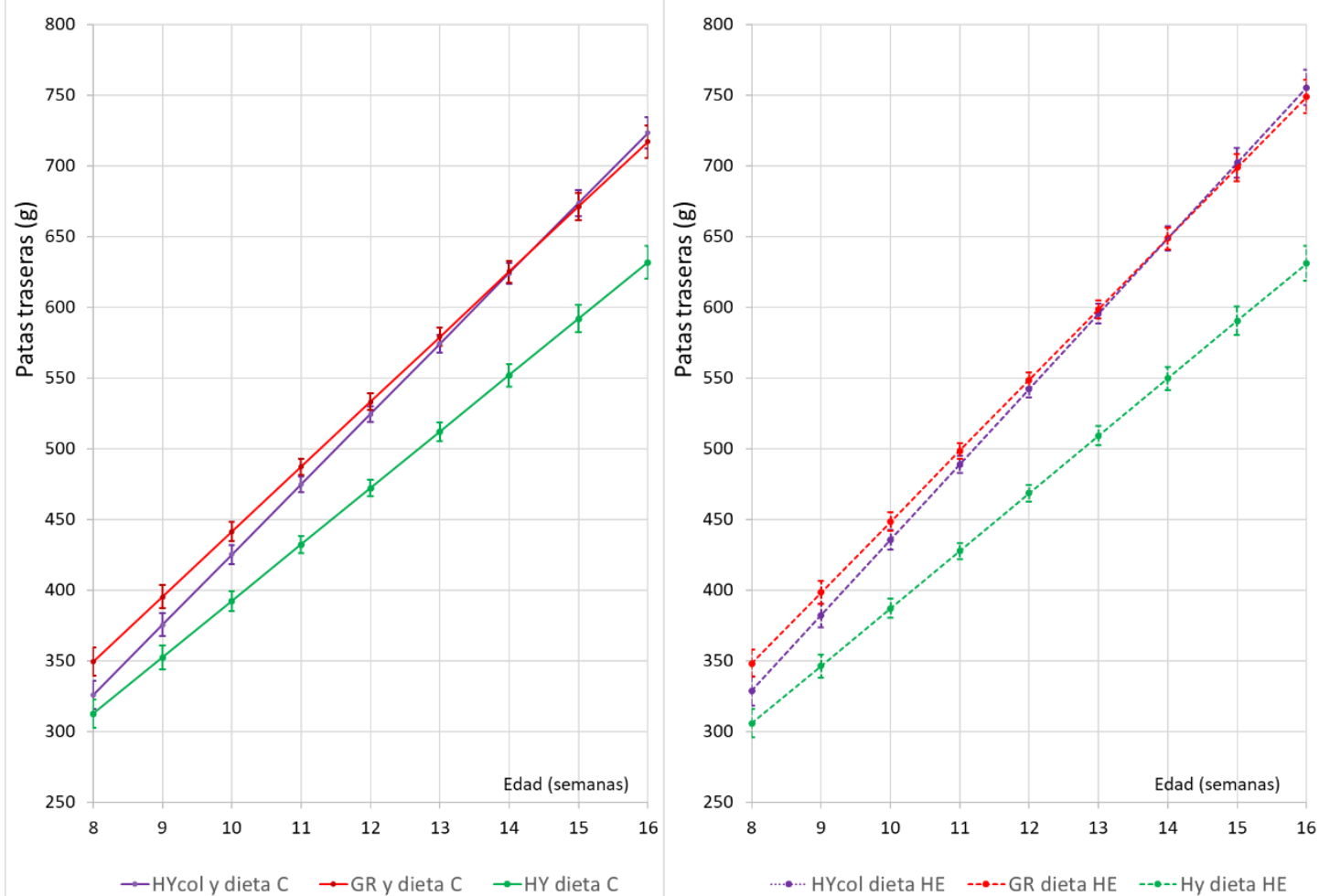

..... HYcol dieta HE $\quad$--•--GR dieta HE $\quad$--•--Hy dieta HE
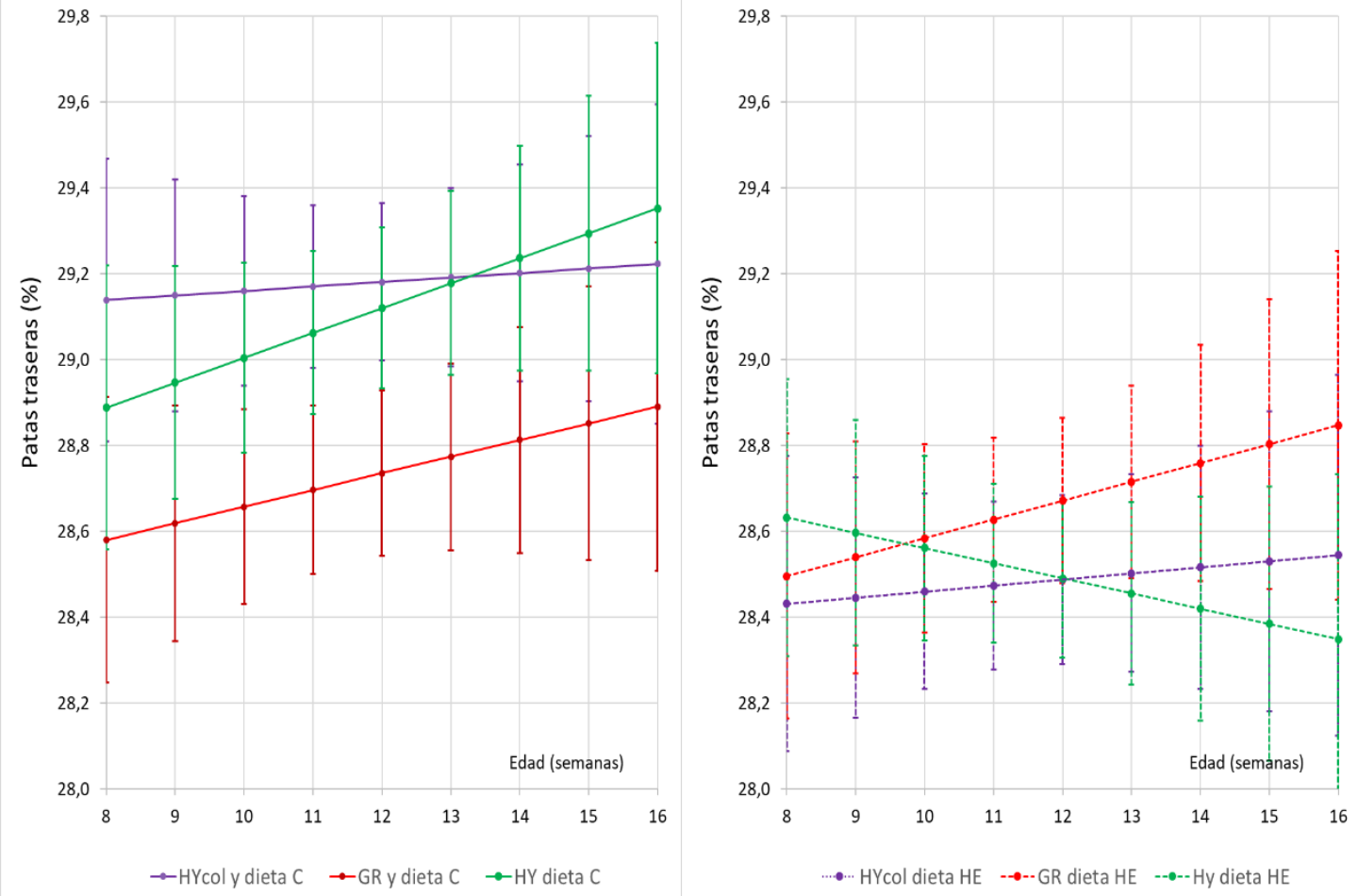

Figura 30. Evolución del peso (gramos) de las patas traseras y del porcentaje respecto a la canal fría (\%) con la edad (semanas) en función de la línea genética (HYcol: Hyla-colored, GR: Grimaud ps 119 e HY: Hyla Grand Parental Doe) y la dieta (C: control y HE: alta energía). Medias mínimo cuadráticas e intervalos de confianza. 
En cuanto al peso del lomo, Gómez et al. (1998) no encontraron diferencias significativas a las 8 semanas de edad en el peso del lomo entre líneas genéticas: dos mejoradas por tamaño de camada al destete ( $\mathrm{A}$ y $\mathrm{V}$ ) y una mejorada por velocidad de crecimiento $(R)$, al igual que observamos en el presente trabajo ya que las diferencias entre líneas empiezan a aparecer en la semana 9 para la dieta C, o semana 10 para la dieta HE. Dalle Zotte et al. (1998), al contrario que nuestros resultados en los que no observamos un efecto de la dieta en la línea de aptitud maternal, encontraron diferencias en el peso del lomo para una línea mejorada por prolificidad (INRA 9077) cuando era alimentada por una dieta control $\left(9,67 \mathrm{MJ} \mathrm{kg} \mathrm{MS}^{-2}\right)$ frente a una dieta más energética $\left(11,99 \mathrm{~kg} \mathrm{MS}^{-2}\right)$ y también tuvieron mayores pesos de lomo que otra línea mejorada por crecimiento $(\mathrm{Hy}+)$ en animales sacrificados con 2,5 kg. En cambio, Pascual et al. (2014) no encontraron diferencias significativas en el porcentaje de lomo en conejos alimentados con dos dietas con diferentes niveles de fibra a las 12 semanas para líneas seleccionadas por velocidad de crecimiento, mientras que en nuestro trabajo en GR no se observó un efecto de la dieta, pero HYcol aumentaba el porcentaje con la dieta HE.

En el peso de las patas delanteras, nuestros resultados coinciden con Gómez et al. (1998) que encontraron que la línea seleccionada por velocidad de crecimiento (R) presentaba mayor peso ( $\mathrm{R}: 166 \pm 1,1 \mathrm{~g}$ ) que la línea seleccionada por tamaño de camada al destete (V: $162 \pm 1,1 \mathrm{~g}$ ) a un peso comercial de $2 \mathrm{~kg}$. Por otro lado, Robert et al. (2017) en el estudio comparativo de caracteres de crecimiento para dos líneas Hyla ( $\mathrm{A}$ y $B$ ) seleccionadas por ganancia media diaria y por rendimiento de canal no encontraron diferencias significativas en el porcentaje de patas delanteras a las 10 semanas de edad (A: 14,8 $\pm 8,8 ; B: 14,7 \pm 6,7$ ), sin embargo, nosotros sí que observamos ligeras diferencias entre HYcol y GR pero fundamentalmente con la dieta HE y a partir de la semana 12. Lo que indica que o bien HYcol y GR son más diferentes que ambas líneas HY o bien que debe transcurrir más tiempo para que aparezcan esta diferencia. Además, al igual que en nuestros resultados, Pascual et al. (2014) no encontraron diferencias significativas en el porcentaje de patas delanteras en conejos alimentados con dos dietas con diferentes niveles de fibra (32,9 \% FND sobre MS vs 37,4 \% de FND sobre MS) a las 12 semanas para líneas seleccionadas por velocidad de crecimiento. 
En las patas traseras, Robert et al. (2017) en el estudio de dos líneas macho de Hyla (A y

B) seleccionadas por ganancia media diaria y por rendimiento de canal a las 10 semanas de edad no encontramos diferencias significativas a las 10 semanas entre las dos líneas, al igual que nuestro estudio con la dieta $\mathrm{HE}$, si bien con la dieta $\mathrm{C} H Y$ col presentó un 0,5\% más de patas traseras que GR. Por otro lado, Gómez et al. (1998) encontraron diferencias entre la línea de aptitud maternal (V) frente a la línea de aptitud cárnica (R) al peso comercial de $2 \mathrm{~kg}$, si bien, su resultado fue al contrario que el nuestro, el peso de patas traseras de la línea V (364 $\pm 1,8 \mathrm{~g}$ ) fue mayor al de la línea R (351 $\pm 1,8 \mathrm{~g})$.

En cuanto al efecto del género, en la caja torácica expresada en gramos o en porcentaje no hubo diferencias significativas entre machos y hembras a lo largo de todo el periodo estudiado (figura 31).
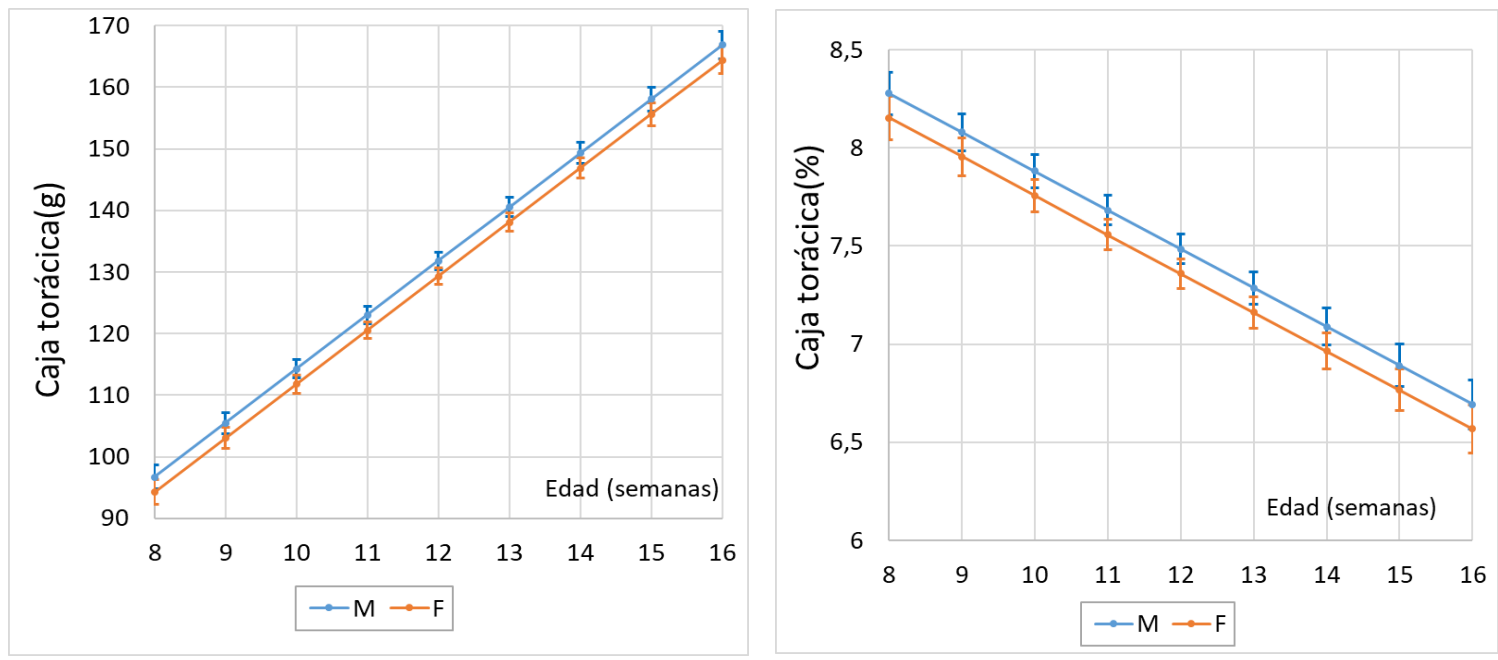

Figura 31. Evolución del peso (gramos) y del porcentaje de la caja torácica con la edad (semanas) en función del género (F: hembra y M: Macho). Medias mínimo cuadráticas e intervalos de confianza. 


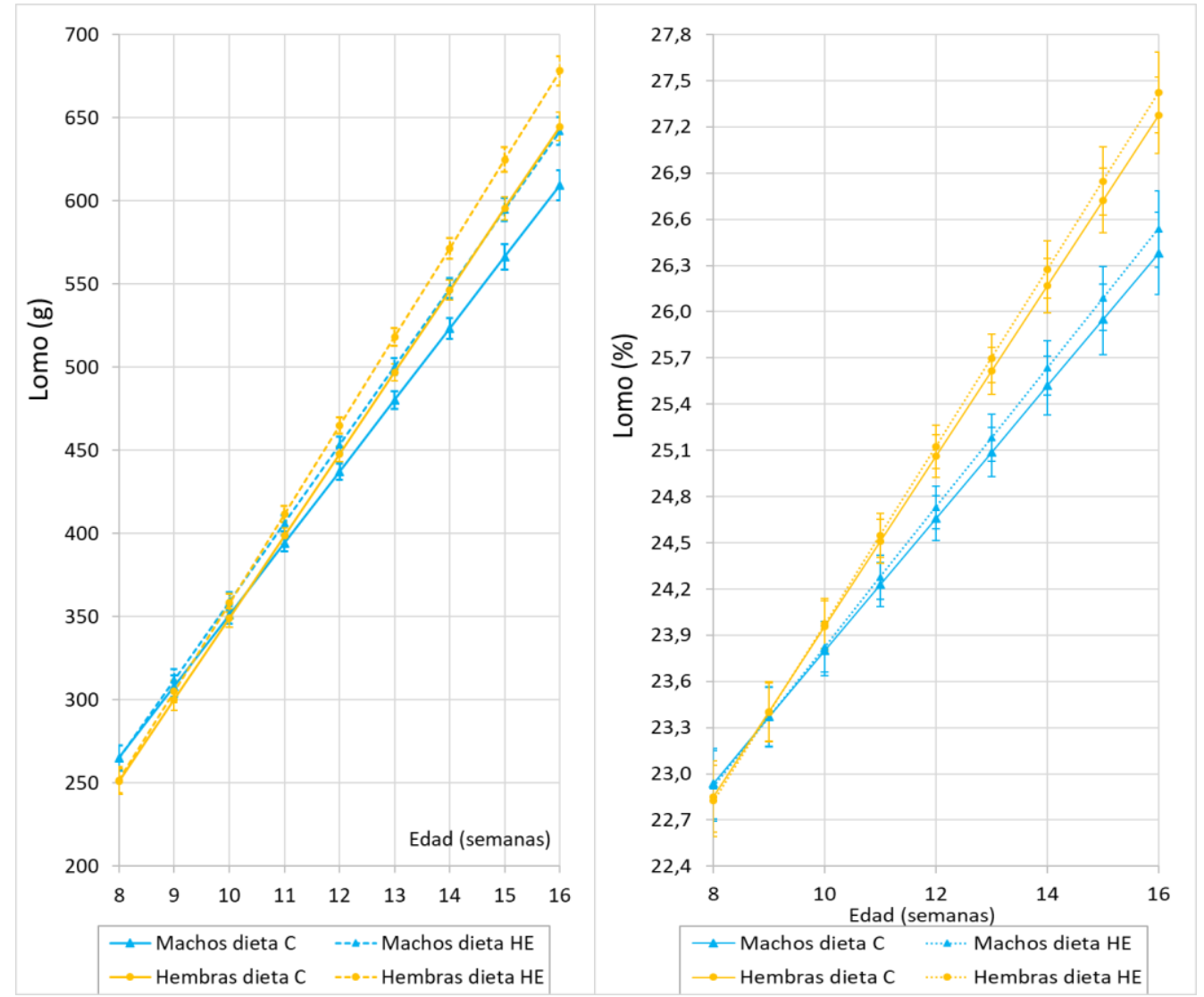

Figura 32. Evolución del peso (gramos) y del porcentaje del lomo con la edad (semanas) en función del género (F: hembra y M: Macho) y la dieta (C: control, HE: alta energía) (Medias mínimo cuadráticas e intervalos de confianza).

En el peso y porcentaje del lomo se observó que las hembras presentaban mayor peso (de 17 gramos en la semana 12 a 36 gramos en la semana 16) y porcentaje (de 0,4 $\pm 0,2$ semana 12 a $1 \pm 0,4 \%$ semana 16 ) de lomo que los machos a partir de la semana 12 (figura 32). A su vez, las hembras cuando ingerían la dieta HE daban lugar a mayor peso y porcentaje de lomo, esta diferencia es mayor cuando comparamos las hembras con la dieta HE con los machos con la dieta C. Pascual et al. (2014) no encontraron diferencias significativas en el porcentaje de lomo en conejos alimentados por dietas con distintos niveles de fibra (32,9 \% FND sobre MS vs 37,4 \% de FND sobre MS) a las 9 semanas. 

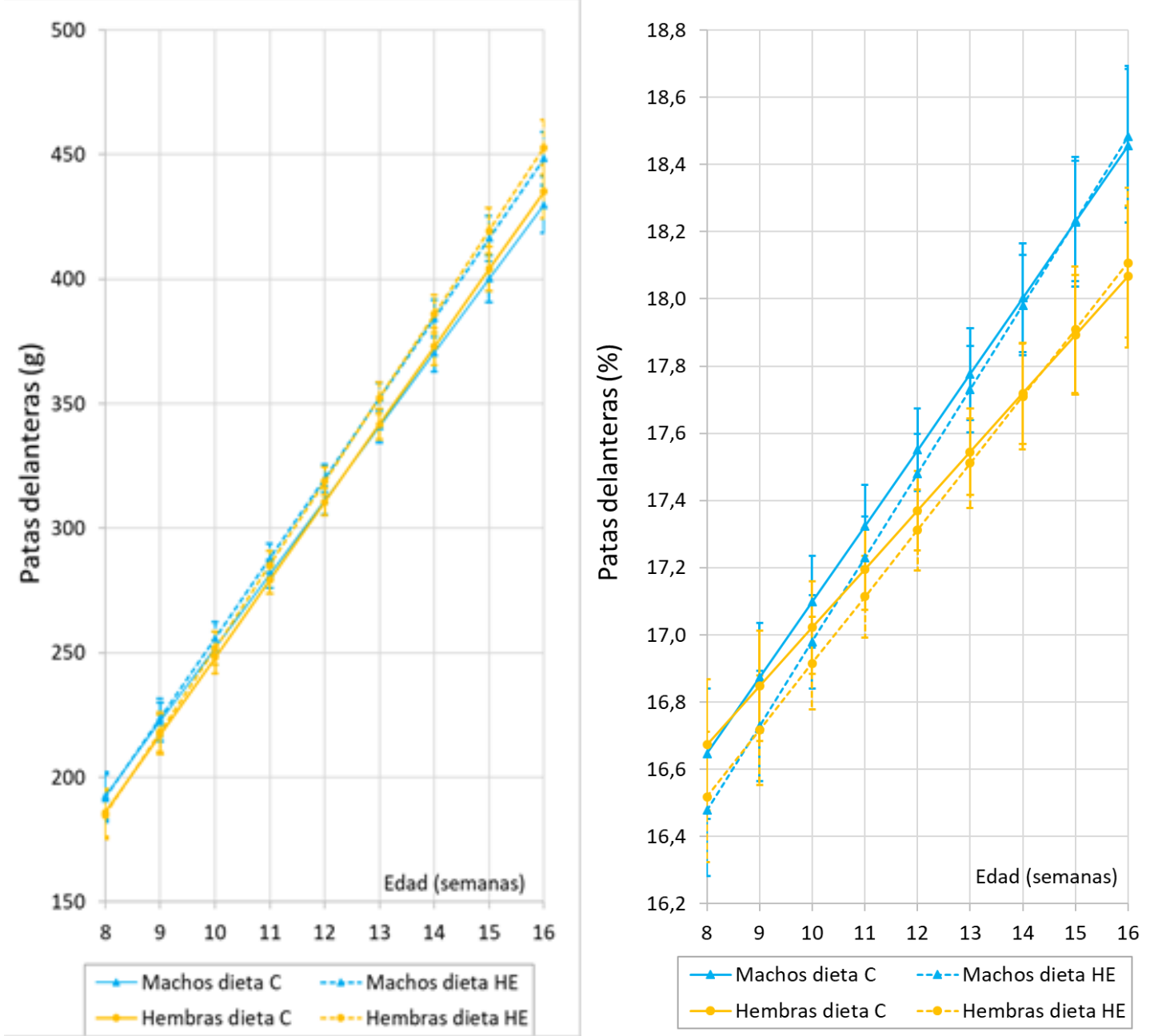

Figura 33. Evolución del peso (gramos) de las patas delanteras y del porcentaje con la edad (semanas) en función del género ( $\mathrm{F}$ : hembra y M: Macho) y la dieta (C: control, HE: alta energía). Medias mínimo cuadráticas e intervalos de confianza.

En cuanto a las patas delanteras, no hubo un efecto del género, tanto en gramos como en porcentaje (figura 33). En las patas traseras (figura 34), las hembras alimentadas con la dieta HE presentaron el mayor peso de patas traseras a partir de la semana 13 , con diferencias que oscilaron de 15 gramos en la semana 13 a 41 gramos en la semana 16 . Sin embargo, cuando se expresó en porcentaje, las hembras alimentadas con la dieta C presentaron mayor porcentaje de patas traseras que los machos (diferencia de 0,6 a 0,7 $\pm 0,2 \%$ ) y las hembras (diferencia de 0,4 a $0,5 \pm 0,2 \%$ ) alimentados con la dieta HE. Además, los machos con la dieta C presentaron mayor porcentaje de patas traseras que los machos con la dieta HE a partir de la semana 10 , con diferencias de $0,4 \pm 0,2 \%$ en la semana 10 a 0,6 $\pm 0,3 \%$ en la semana 16 . 
Lazzaroni et al. (2009) no encontraron diferencias significativas en el peso de las patas delanteras y traseras entre machos y hembras de las 9 a las 16 semanas alimentados por un mismo pienso. En nuestro caso, observamos que las hembras presentaban más peso de patas traseras que los machos con la dieta HE pero no con la dieta $\mathrm{C}$, mientras que cuando las patas traseras eran expresadas como porcentaje, dentro de dieta no se observa un efecto del género. De acuerdo con nuestros resultados, Pascual et al. (2014) observaron que con una dieta menos energética y más fibrosa (32,9 \% FND sobre MS vs $37,4 \%$ de FND sobre MS) el porcentaje de las patas traseras era mayor $(38,1 \pm 0,2 \%$ vs $37,2 \pm 0,2 \%)$.
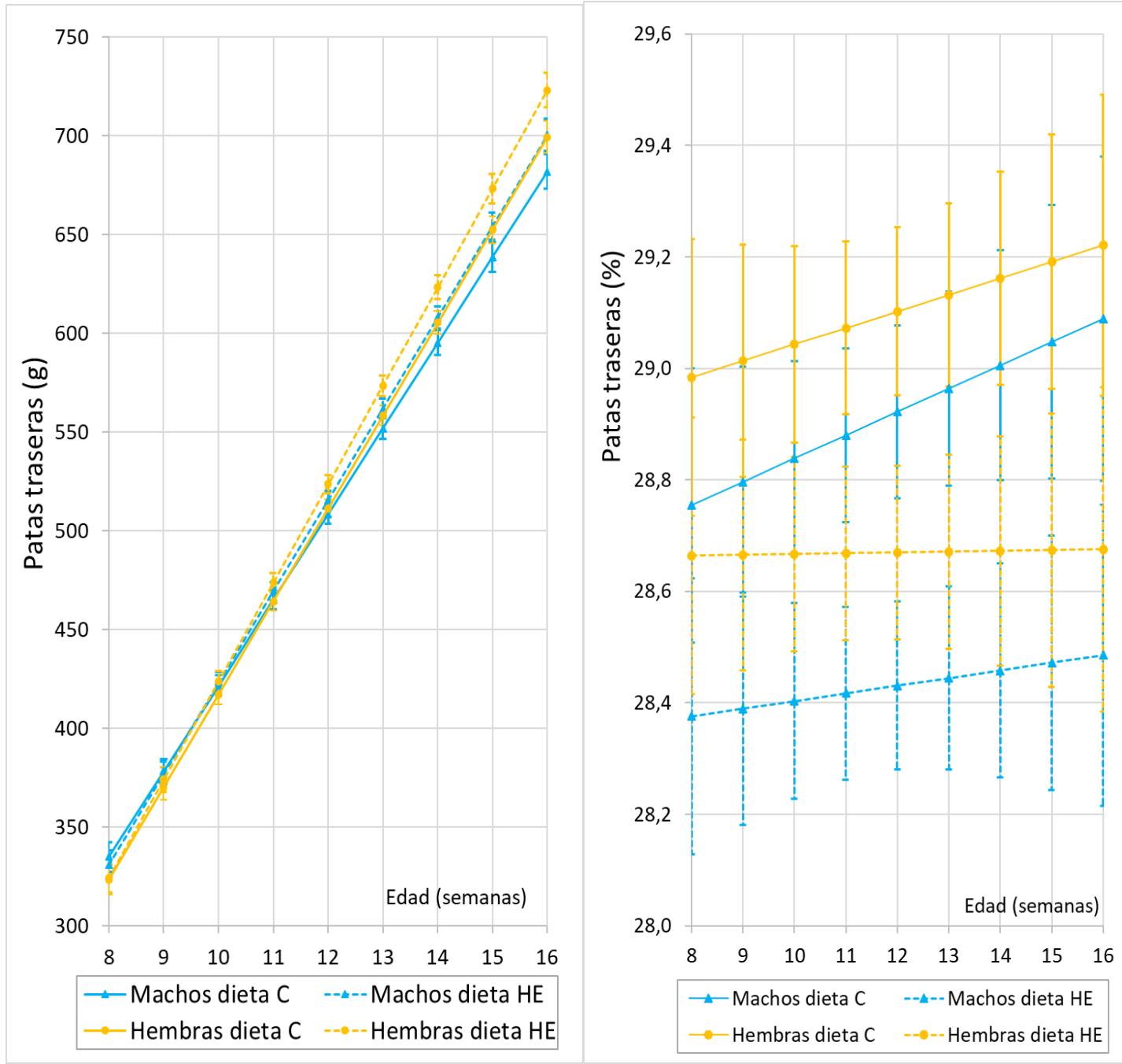

Figura 34. Evolución del peso (gramos) y del porcentaje de las patas traseras con la edad (semanas) en función del género ( $\mathrm{F}$ : hembra y $\mathrm{M}$ : Macho) y la dieta (C: control, HE: alta energía). Medias mínimo cuadráticas e intervalos de confianza. 


\subsection{RATIO MÚSCULO-HUESO}

En el crecimiento diferencial de los tejidos se obtuvo un coeficiente de alometría menor que 1 , y por tanto crecimiento precoz, para el hueso; y mayor que 1 , o crecimiento tardío, para el músculo (tabla 8). En este sentido, el ratio músculo-hueso ( $\mathrm{MH}$ ) aumentó con la edad, con valores promedio de 5,1 en la semana 8 a 8,3 en la semana 16 .

Tabla 8. Medias mínimo cuadráticas $(\mathrm{MMC})$ y errores estándar (ES) de los coeficientes alométricos $k$ de Huxley para músculo pata trasera $(\mathrm{M})$ y hueso pata trasera $(\mathrm{H})$.

\begin{tabular}{ccc}
\hline Componente & MMC & ES \\
\hline M & 1.230 & 0.008 \\
H & 0.505 & 0.013 \\
\hline Fuente Martínez-Bas et al. (2018)
\end{tabular}

Nuestros resultados de crecimiento temprano para el hueso están de acuerdo con los de Cantier et al. (1969) en conejo, y Whittemore (1998) y Fisher et al. (2003) en el cerdo. El músculo de la pata trasera derecha mostró crecimiento tardío, al igual que en Deltoro y López (1985) que observaron valores de $k 1.324 \pm 0.016$ de 1 a 5 semanas de edad y $1.208 \pm 0.003$ de 6 a 20 semanas de edad. Por otro lado, Evans y Kempster (1979), observaron el desarrollo temprano del músculo en el cerdo. Vezinhet y Prud'hon (1975) encontraron isometría entre el músculo de la pata trasera respecto al músculo total de la canal, como lo hicieron Deltoro y López (1985) entre el hueso de la pata trasera respecto al hueso total de la canal. Por lo tanto, el crecimiento tardío del músculo y el crecimiento temprano del hueso pueden hacerse extensivo a la canal entera.

En el efecto de la línea genética sobre el ratio músculo-hueso $(\mathrm{MH})$, se observó que GR presentaba una mayor valor que HYcol (diferencia de 0,25 $\pm 0,08$ ) y que HY (diferencia de $0,38 \pm 0,08$ ) en todas las semanas estudiadas (figura 35 ).

Dalle Zotte et al. (1998) no encontraron diferencias en este ratio en animales sacrificados a los $2,5 \mathrm{~kg}$ entre una línea seleccionada por prolificidad (INRA 9077) respecto a una línea seleccionada por tasa de crecimiento $(\mathrm{Hy}+)$. Mientras que en otro estudio, Dalle Zotte et al. (2015) encontraron mayor ratio $\mathrm{MH}$ a las 12 semanas entre una línea mejorada por ganancia media diaria (Large: 6,10 $\pm 0,04$ ) frente a la línea (Hung: 5,81 $\pm 0,04$ ) seleccionada por el gran tamaño que alcanzan los machos, llamados 'Gigantes Húngaros'. Estos autores expresaron que estas diferencias pueden ser debidas 
al cruce de la línea Hung con alguna raza de tamaño medio. En nuestro estudio, el valor promedio global para MH en la semana 12 fue 6,67 $\pm 0,08$.

Szendrö et al. (2015) no encontraron diferencias en este ratio entre diferentes líneas genéticas (Large: aptitud maternal, Hung: aptitud cárnica). Sin embargo, Hernández et al. (2006) encontraron mayores ratio $\mathrm{MH}$ en el caso de animales seleccionados por tasa de crecimiento.

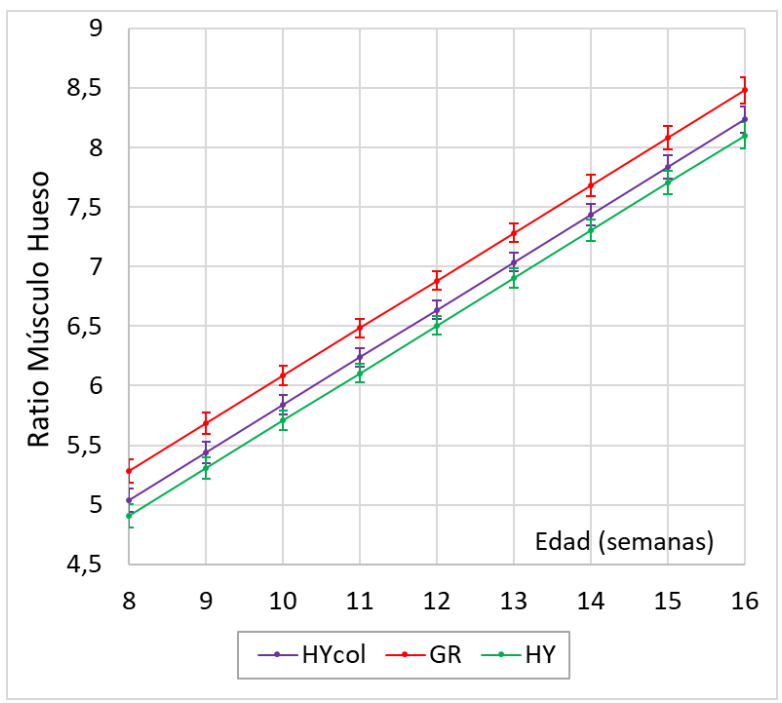

Figura 35. Evolución del ratio músculo-hueso $(\mathrm{M}-\mathrm{H})$ con la edad (semanas) en función de la línea genética (HYcol: Hyla-colored, GR: Grimaud ps 119 e HY: Hyla Grand Parental Doe) (Medias mínimo cuadráticas e intervalos de confianza).

En cuanto al efecto de la dieta de la semana 10 a la 13 incluidas hubo diferencias significativas (figura 36), los animales alimentados con la dieta más energética tuvieron mayor ratio músculo hueso en estas semanas (diferencia 0,17 $\pm 0,07$ ).

Nuestros resultados coinciden con Pascual et al. (2014) que encontraron mayor ratio $\mathrm{MH}$ a las 12 semanas con dietas con menor contenido en fibra $(5,94$ vs. 5,73$)$ para líneas seleccionadas por velocidad de crecimiento, si bien nosotros obtuvimos mayores valores de $\mathrm{MH}$ (dieta $\mathrm{C}=6,59$ y dieta $\mathrm{HE}=6,75 \pm 0,08$ ). Dalle Zotte et al. (1998) no encontraron diferencias en el ratio $\mathrm{MH}$ cuando los animales eran alimentados con una dieta altamente energética o una dieta control. 


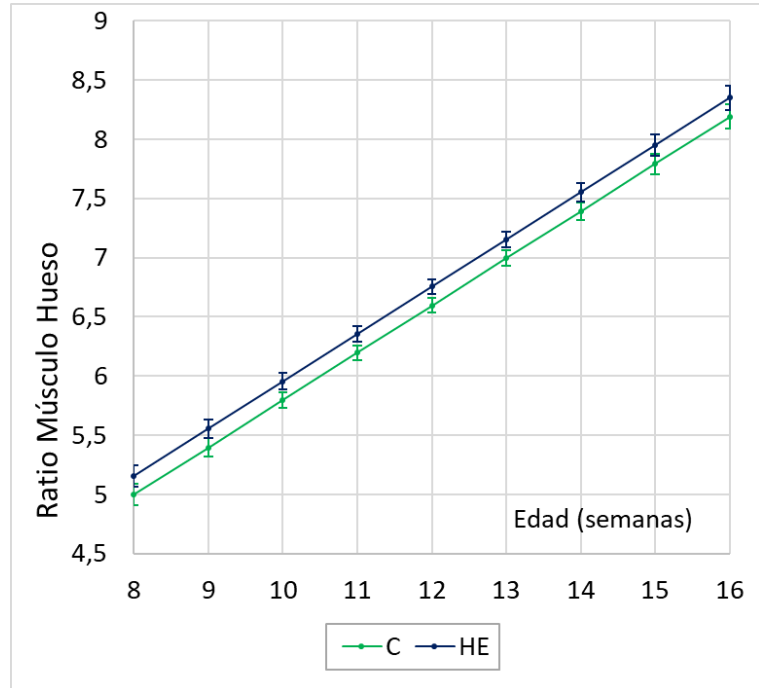

Figura 36. Evolución del ratio músculo-hueso $(\mathrm{M}-\mathrm{H})$ con la edad (semanas) en función de la dieta (C: control y HE: altamente energética) (Medias mínimo cuadráticas e intervalos de confianza).

El efecto del género indicó que desde las semanas 9 a la 15 hubo diferencias significativas entre machos y hembras, siendo el ratio menor para machos que hembras (figura 37) (diferencia 0,22 $\pm 0,09$ ).

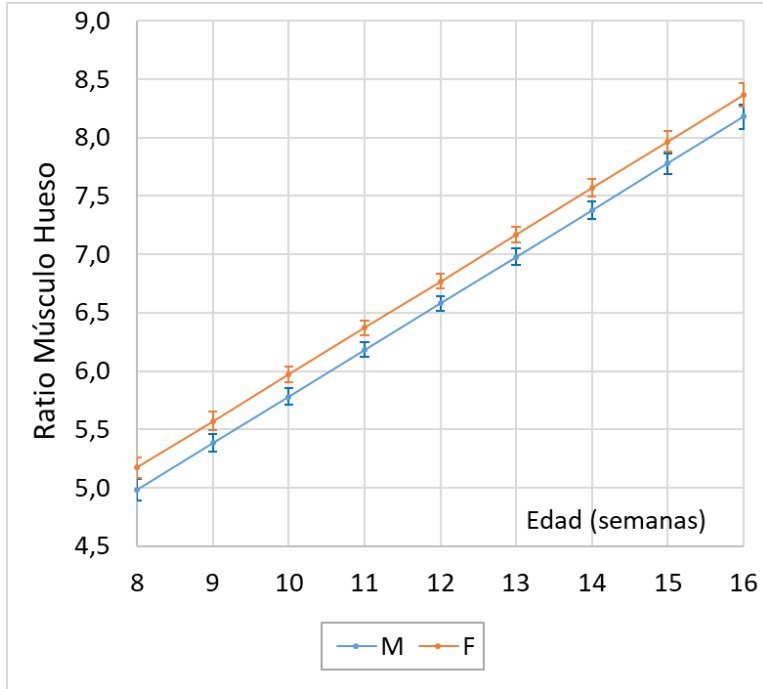

Figura 37. Evolución del ratio músculo-hueso $(\mathrm{M}-\mathrm{H})$ con la edad (semanas) en función del género ( $\mathrm{F}$ : hembra y M: Macho) (Medias mínimo cuadráticas e intervalos de confianza). 


\subsection{GRASA}

Dentro de la grasa diseccionable, la grasa inguinal, escapular y perirrenal mostraron un coeficiente de alometría mayor que uno y por tanto crecimiento tardío, siendo la grasa inguinal la primera en depositarse, después la escapular y finalmente la perirrenal (tabla 9). Cantier et al. (1969), Deltoro y López (1985) y Pascual et al. (2008) en conejos; y Fisher et al. (2003) en cerdos, también observaron un crecimiento tardío de la grasa diseccionable.

Tabla 9. Mínimos estimados cuadrados (LSE) y errores estándar (SE) de los coeficientes alométricos k de Huxley para diferentes tipos de grasa de la canal $(n=2048)$ con respecto al peso de sacrificio y para la grasa intermuscular más grasa intramuscular $(n=634)$ con respecto al peso de la pierna trasera.

\begin{tabular}{ccc}
\hline COMPONENTE & LSE & SE \\
\hline Escapular Fa & 1.669 & 0.089 \\
Inguinal Fa & 1.376 & 0.093 \\
Perirrenal Fa & 2.314 & 0.094 \\
DFa & 1.700 & 0.090 \\
IIMF & 0.493 & 0.128 \\
\hline
\end{tabular}

Escapular Fa - grasa escapular de la canal, Fa inguinal - grasa inguinal de la canal, Perirrenal Fa - grasa perirrenal de la canal. DFa - grasa diseccionable de la canal, IIMF - porcentaje intermuscular + grasa intramuscular de la carne de la pata trasera Fuente: Martínez-Bas et al. (2018)

Los depósitos adiposos tienen una doble importancia para la economía de la producción de carne. Primero, debido a que es mucho más costosa económicamente la deposición en grasa que en músculo, y en segundo lugar, debido a su distribución, contribuyen a la calidad de las canales. Por lo tanto, es interesante estudiar no solo el desarrollo general de los depósitos adiposos durante el crecimiento, sino también el desarrollo relativo de los depósitos con diferentes efectos.

A pesar de este hecho, el estudio de los depósitos de grasa intramuscular y su distribución en las canales de los animales de carne han recibido escasa atención de los investigadores en comparación con otros aspectos del crecimiento y el desarrollo.

Sólo se ha encontrado un trabajo (Vezinhet y Prud'Hon, 1975) que analizaba la evolución de varios depósitos adiposos en conejos en crecimiento de 10 días a 26 semanas de edad. En este caso, la variable de referencia fue el tejido de grasa diseccionable total, y observaron que la grasa perirrenal mostraba crecimiento tardío mientras que hubo 
crecimiento precoz en grasa subcutánea e intermuscular, con valores alométricos comprendidos entre 0,84 y 0,94 . Estos resultados pueden diferir dependiendo de la variable de referencia, Kouba et al., (2009) observaron en porcino que el coeficiente alométrico de grasa subcutánea e intermuscular disminuía cuando la variable de referencia era el peso total de grasa en el corte en comparación con el peso total del animal. Vezinhet y Prud'Hon (1975) compararon conejos y corderos y señalaron que el patrón para el desarrollo de depósitos adiposos dependía de la especie. En corderos, la grasa perirrenal y pélvica mostró crecimiento temprano y crecimiento tardío de grasa subcutánea, sin embargo, en el conejo este patrón se invirtió. La grasa intermuscular era casi isométrica para ambas especies, siendo anterior para el conejo.

En Martínez-Bas et al. (2018) observamos un efecto de la línea genética en el coeficiente de alometría de los diferentes depósitos grasos. Los conejos de las líneas GR e HYcol desarrollaron grasa escapular e inguinal posterior a la línea HY (HY - GR $=-0.253 \pm 0.100$; $\mathrm{HY}-\mathrm{HYcol}=-0.282 \pm 0.098)$. Este resultado podría explicarse porque HY es una línea materna que requerirá deposición de grasa antes para su función de reproducción. No se observaron diferencias significativas para la grasa perirrenal y toda la grasa diseccionable.

El único efecto significativo de la dieta sobre los coeficientes de alometría se encontró en la grasa escapular ( $k$ diferencias $\mathrm{HE}_{-} \mathrm{C}=0.275 \pm 0.077$ ), en la cual los conejos alimentados con la dieta HE mostraron crecimiento tardío (Martínez-Bas et al., 2018). La grasa escapular mostró un crecimiento tardío y esta deposición de grasa requeriría energía, sin embargo, cuando la energía es limitada, la deposición de grasa se restringe en la etapa de madurez posterior del conejo. Para la grasa inguinal, perirrenal y diseccionable, la tendencia fue la misma, el crecimiento posterior para la dieta $\mathrm{HE}$, pero la diferencia fue menor y no fue significativa.

\section{INTERACCIÓN LÍNEA GENÉTICA Y DIETA}

Como era de esperar el contenido en grasa expresado en gramos, de todas las fracciones de la grasa y de la grasa diseccionable en su conjunto, aumentó con la edad 
en semanas (figuras $38,41,44$ y 47). Sin embargo, cuando el contenido en grasa se expresó como porcentaje respecto al peso de la canal fría el patrón de comportamiento fue diferente para los diferentes tipos de grasas, líneas genéticas y dietas. En la mayor parte de los tipos de grasa, el porcentaje también aumentó con la edad, así ocurrió con la grasa perirrenal (figura 45) y la grasa diseccionable (figura 48), si bien en la grasa escapular (figura 39) y en la grasa inguinal (figura 42) para la línea genética HY y para la línea GR en la dieta C estos porcentajes se mantuvieron con la edad. Para la línea HYcol, tanto para la dieta HE como para la dieta C, se observa un incremento del porcentaje de todos los tipos de grasa con la edad, resultado que también se observó para GR solo con la dieta $\mathrm{HE}$.

En la tabla 10 se muestra el rango de valores promedio, en gramos y en porcentaje, para los diferentes tipos de grasa en la semana 8 y 16 para todas las líneas genéticas, dietas y sexo. El mayor incremento de deposición de grasa con la edad fue a nivel perirrenal. De hecho, como se verá más adelante, el porcentaje de grasa perirrenal fue el único que incrementó con el tiempo en la línea genética HY.

Tabla 10. Rango de valores promedio, en gramos y en porcentaje, para los diferentes tipos de grasa en la semana 8 y 16 para todas las líneas genéticas, dietas y sexo.

\begin{tabular}{lcccc}
\hline & \multicolumn{2}{c}{ PESO (GRAMOS) } & \multicolumn{2}{c}{ PORCENTAJE (\%) } \\
\hline SEMANA & $\mathbf{8}$ & $\mathbf{1 6}$ & $\mathbf{8}$ & $\mathbf{1 6}$ \\
\hline GRASA ESCAPULAR & $5,80-7,20$ & $13,60-20,92$ & $0,54-0,62$ & $0,60-0,84$ \\
GRASA INGUINAL & $8,68-10,53$ & $17,77-27,84$ & $0,76-0,85$ & $0,79-1,06$ \\
\hline GRASA PERIRRENAL & $6,29-9,68$ & $55,11-77,39$ & $0,78-1,08$ & $2,32-3,12$ \\
GRASA DISECCIONABLE & $21,66-26,90$ & $87,55-127,72$ & $2,69-3,06$ & $4,40-5,77$ \\
\hline
\end{tabular}

En las figuras 39, 42, 45 y 48 se representa la interacción línea genética x dieta para la grasa escapular, inguinal, perirrenal y diseccionable de las tres líneas genéticas y dietas, y separadas por línea genética para una mayor claridad. La dieta HE dio lugar a un mayor porcentaje de deposición de todos los tipos de grasa en las líneas de aptitud cárnica HYcol y GR, lo que no sucedió en la línea de aptitud maternal HY. Este efecto fue más marcado en la línea GR. 
En las figuras $40,43,46$ y 49 se muestra el efecto de la línea genética dentro de dieta. En la dieta C, la línea HYcol presentó en las últimas semanas mayor porcentaje de grasa escapular, y la línea HY mostró mayor porcentaje de grasa perirrenal y diseccionable a lo largo de todo el ensayo. En la dieta $\mathrm{HE}$, las líneas de aptitud cárnica depositaron mayor porcentaje de grasa escapular que la línea de aptitud maternal, mientras que para la grasa inguinal, perirrenal y diseccionable solo la línea GR presentó mayor porcentaje que la línea HY, siendo los porcentajes iguales para las líneas HYcol e HY.

El porcentaje de grasa diseccionable guarda gran similitud con la evolución de la grasa perirrenal, ya que el peso de grasa perirrenal es una buena predicción en el total de grasa diseccionable (Varewyck y Bouquet, 1982 y Hernández et al., 1994).

En conclusión, parece que en líneas generales la línea HY presenta menores valores de porcentaje de los diferentes tipos de grasa que las líneas HYcol y GR. Si bien debido a que el efecto de la dieta es menos marcado en $\mathrm{HYcol}$, presentó valores similares a HY de grasa inguinal, perirrenal y diseccionable con la dieta HE. Además, se observó que la línea HY mostró mayor porcentaje de grasa perirrenal con la dieta $C$, siendo la única grasa cuyo porcentaje aumenta con la edad en esta línea indicando que esta grasa presenta mayor valor funcional. 


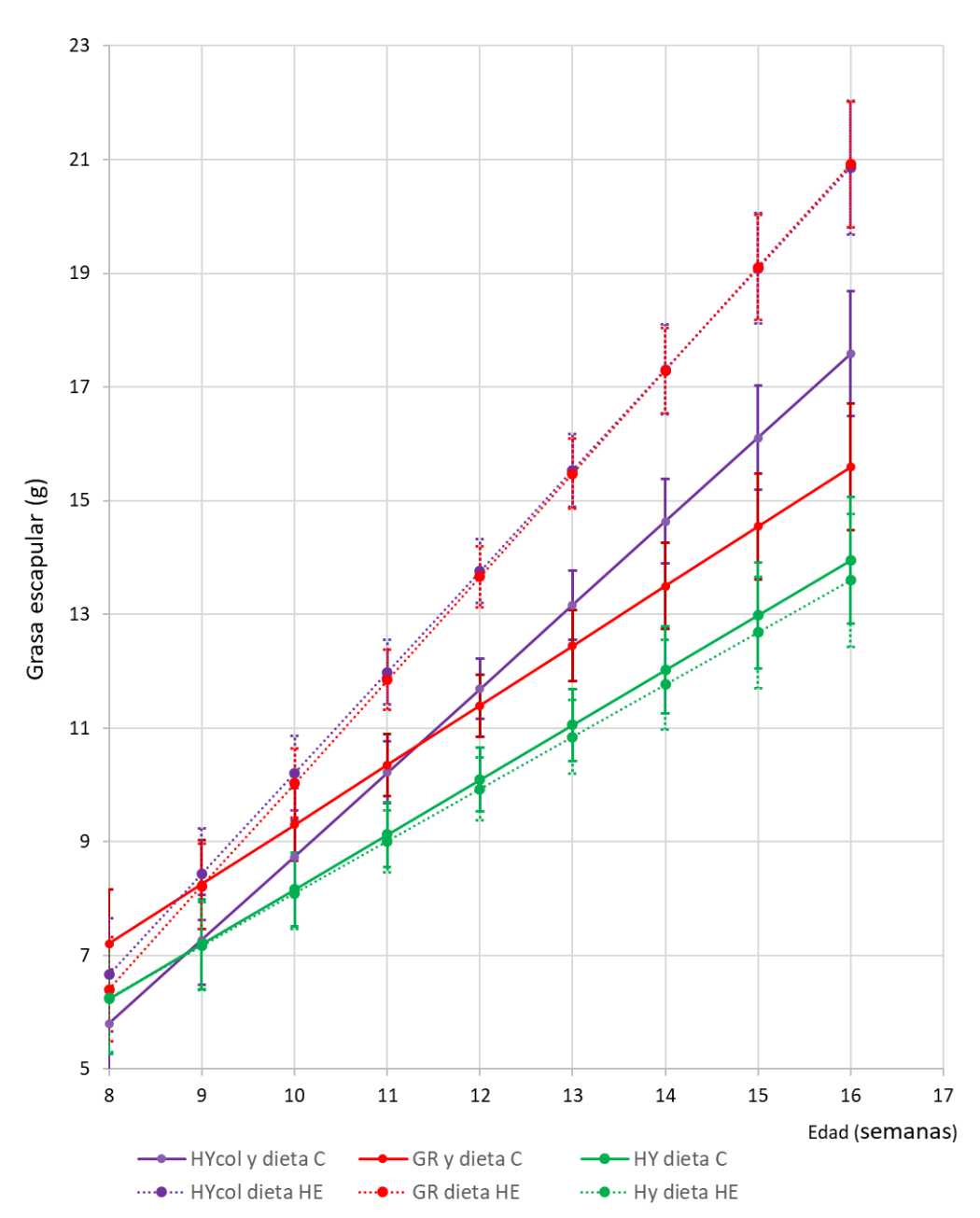

Figura 38. Evolución del peso de grasa escapular (gramos) con la edad (semanas) en función de la línea genética (HYcol: Hyla-colored, GR: Grimaud ps 119 e HY: Hyla Grand Parental Doe) y dieta (C: control y HE: altamente energética) (Medias mínimo cuadráticas e intervalos de confianza). 

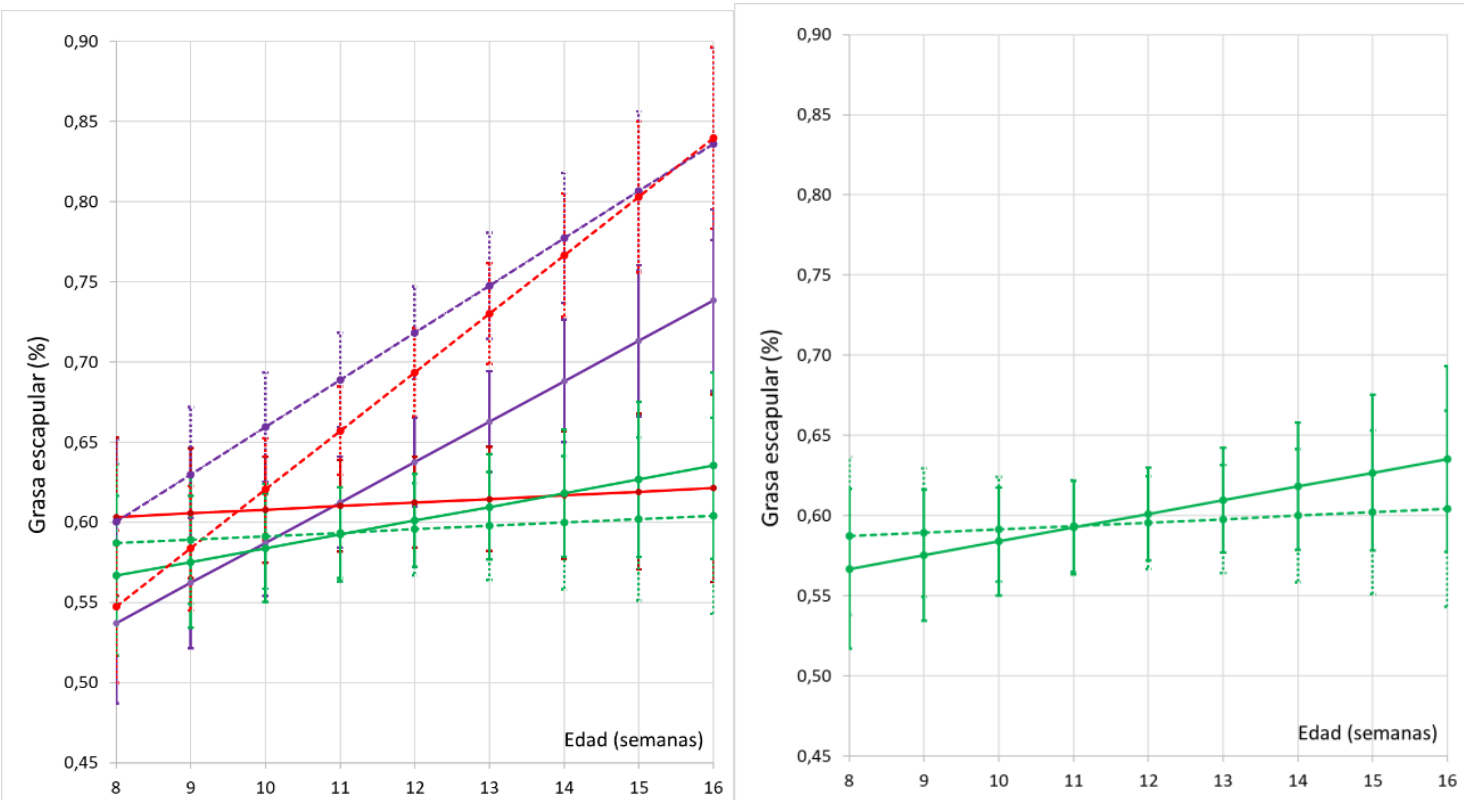

$\rightarrow$ HYcol y dieta C $\rightarrow$ GR y dieta C $\rightarrow$ HY dieta C

$\quad-$ HYcol dieta HE $\quad$ - - GR dieta HE $\quad$ - - Hy dieta HE
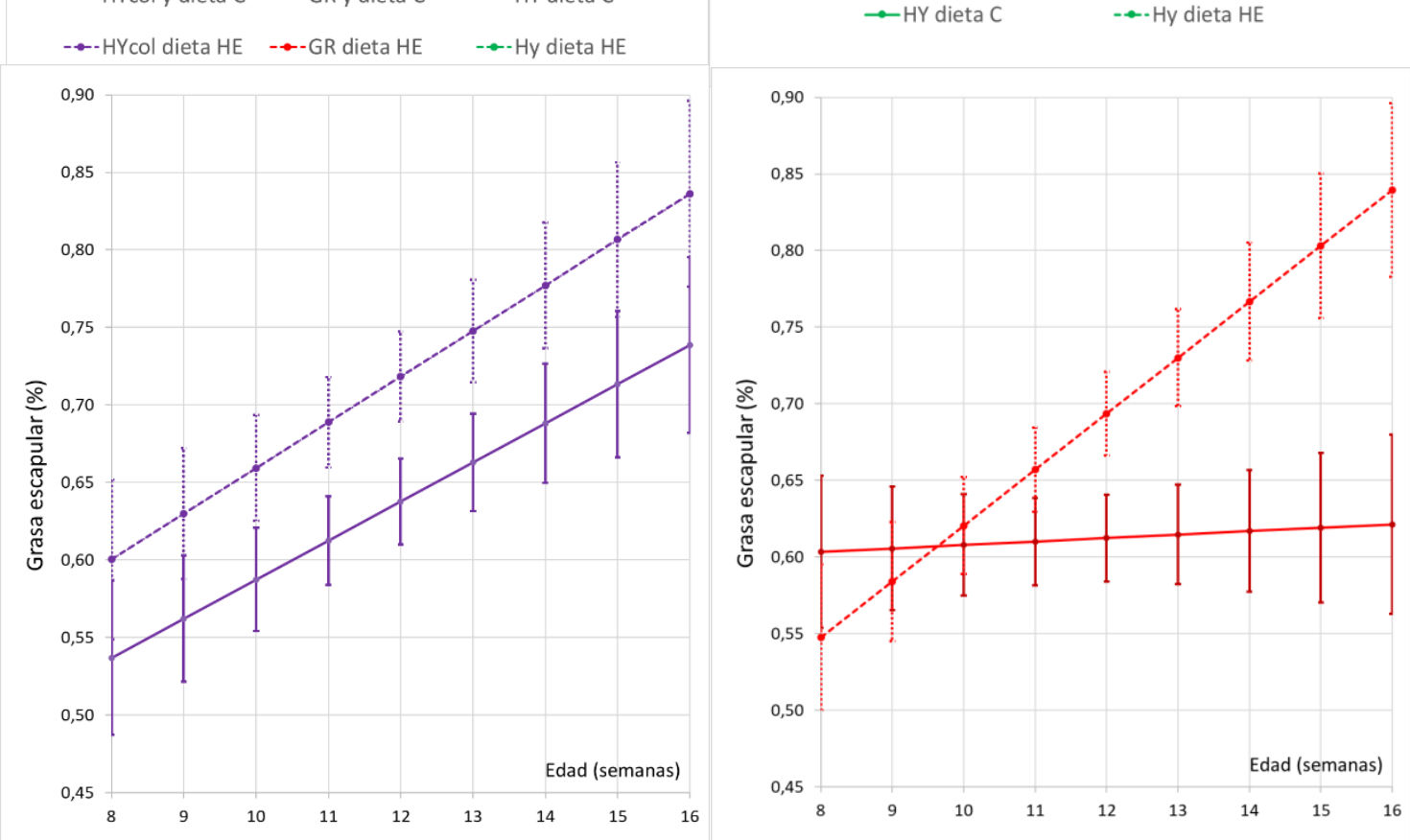

$\rightarrow$ HYcoly dieta C $\quad-\rightarrow$ HYcol dieta HE

$\rightarrow$ GR y dieta $\mathrm{C} \quad \rightarrow-$ GR dieta HE

Figura 39. Interacción línea genética $x$ dieta: Evolución del porcentaje de grasa escapular con la edad (semanas) para las diferentes líneas genéticas (HYcol: Hyla-colored, GR: Grimaud ps 119 e HY: Hyla Grand Parental Doe) y dietas (C: control y HE: altamente energética) y desglosada para las tres líneas genéticas por separado (Medias mínimo cuadráticas e intervalos de confianza) 

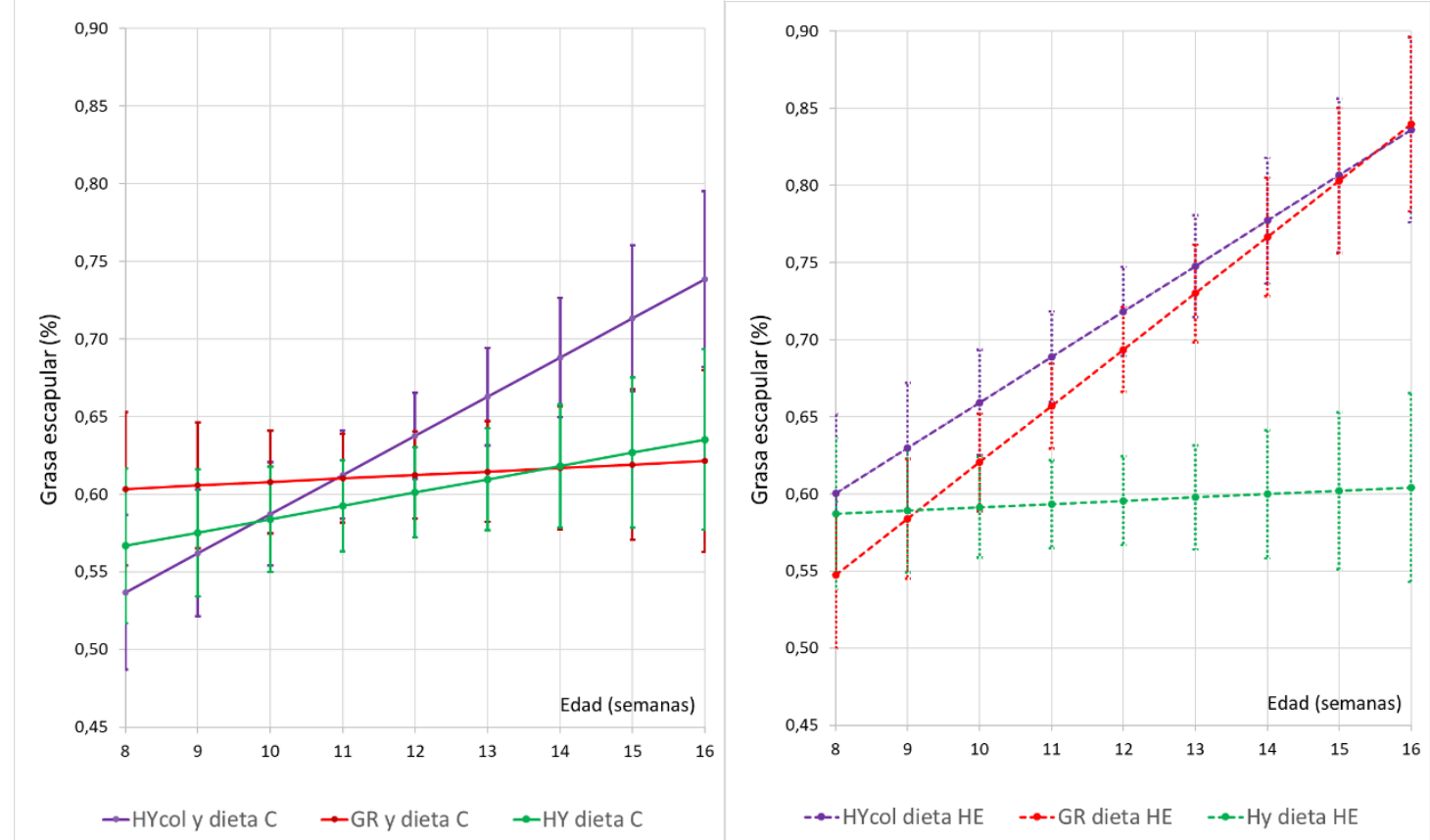

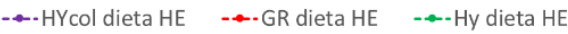

Figura 40. Evolución del porcentaje de grasa escapular con la edad (semanas) de las líneas genéticas (HYcol: Hyla-colored, GR: Grimaud ps 119 e HY: Hyla Grand Parental Doe) para cada dieta (C: control y HE: altamente energética) (Medias mínimo cuadráticas e intervalos de confianza).

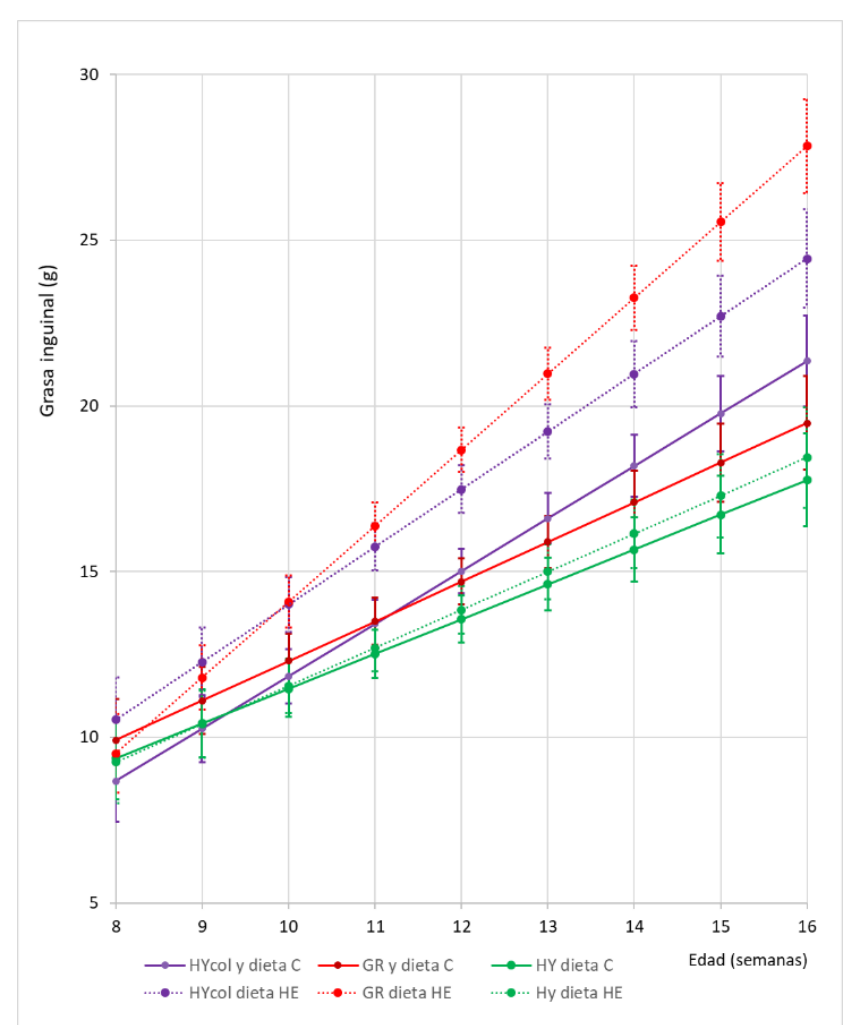

Figura 41. Evolución del peso de grasa inguinal (gramos) con la edad (semanas) en función de la línea genética (HYcol: Hyla-colored, GR: Grimaud ps 119 e HY: Hyla Grand Parental Doe) (Medias mínimo cuadráticas e intervalos de confianza). 

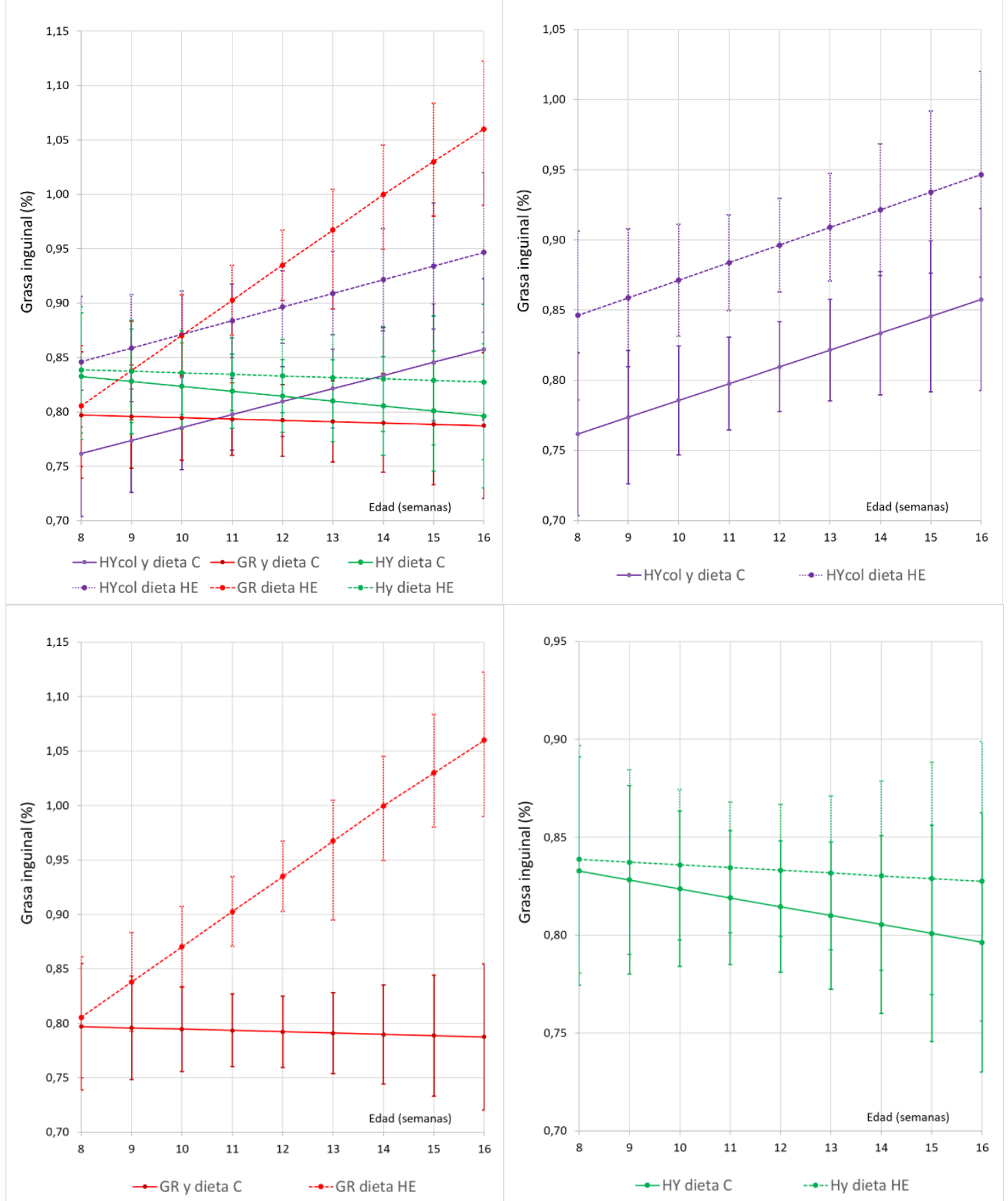

Figura 42. Interacción línea genética $x$ dieta: Evolución del porcentaje de grasa inguinal con la edad (semanas) para las diferentes líneas genéticas (HYcol: Hyla-colored, GR: Grimaud ps 119 e HY: Hyla Grand Parental Doe) y dietas (C: control y HE: altamente energética) y desglosada para las tres líneas genéticas por separado. Se representa Medias mínimo cuadráticas e intervalos de confianza. 

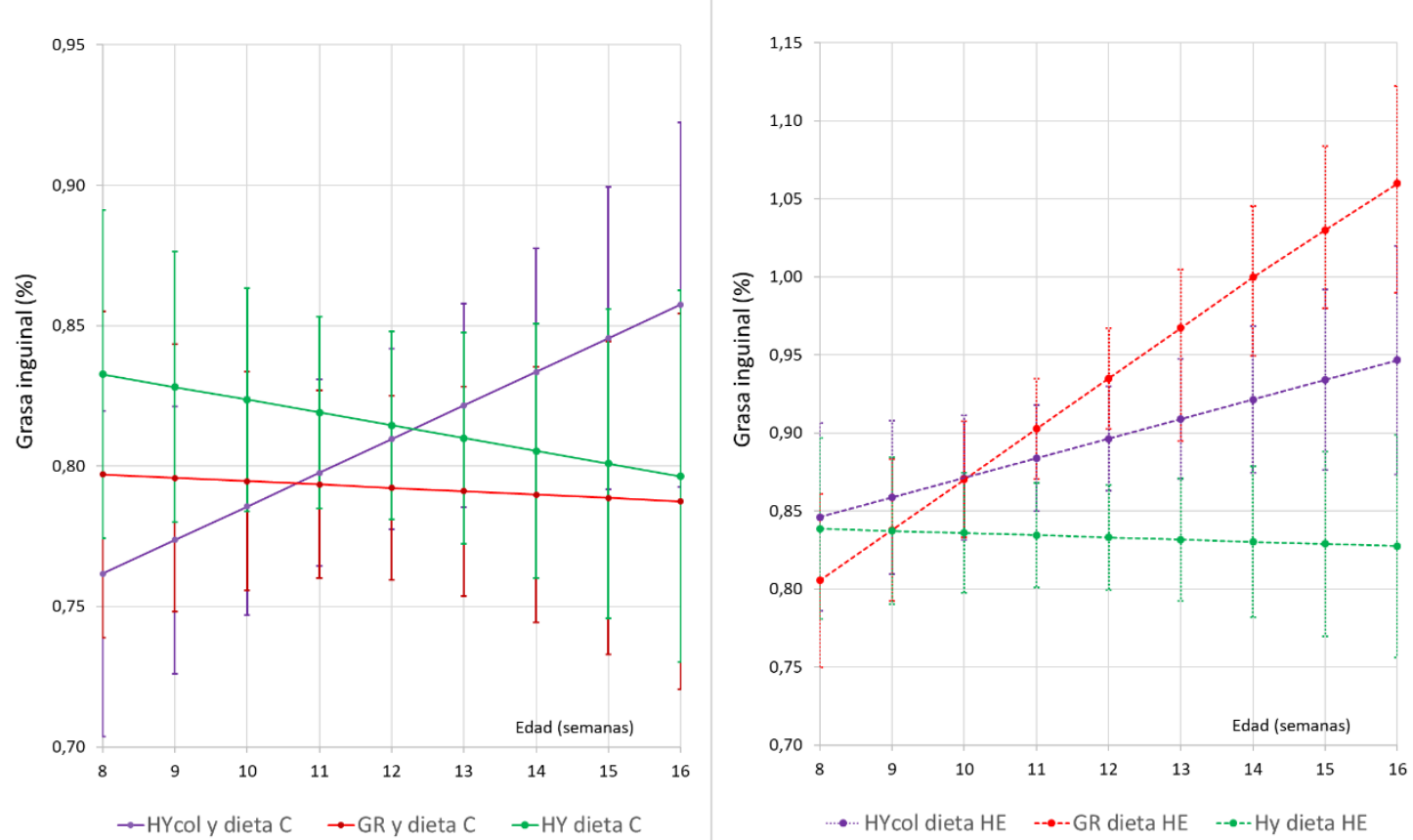

Figura 43. Evolución del porcentaje de grasa inguinal con la edad (semanas) en función de la línea genética (HYcol: Hyla-colored, GR: Grimaud ps 119 e HY: Hyla Grand Parental Doe) (Medias mínimo cuadráticas e intervalos de confianza). 

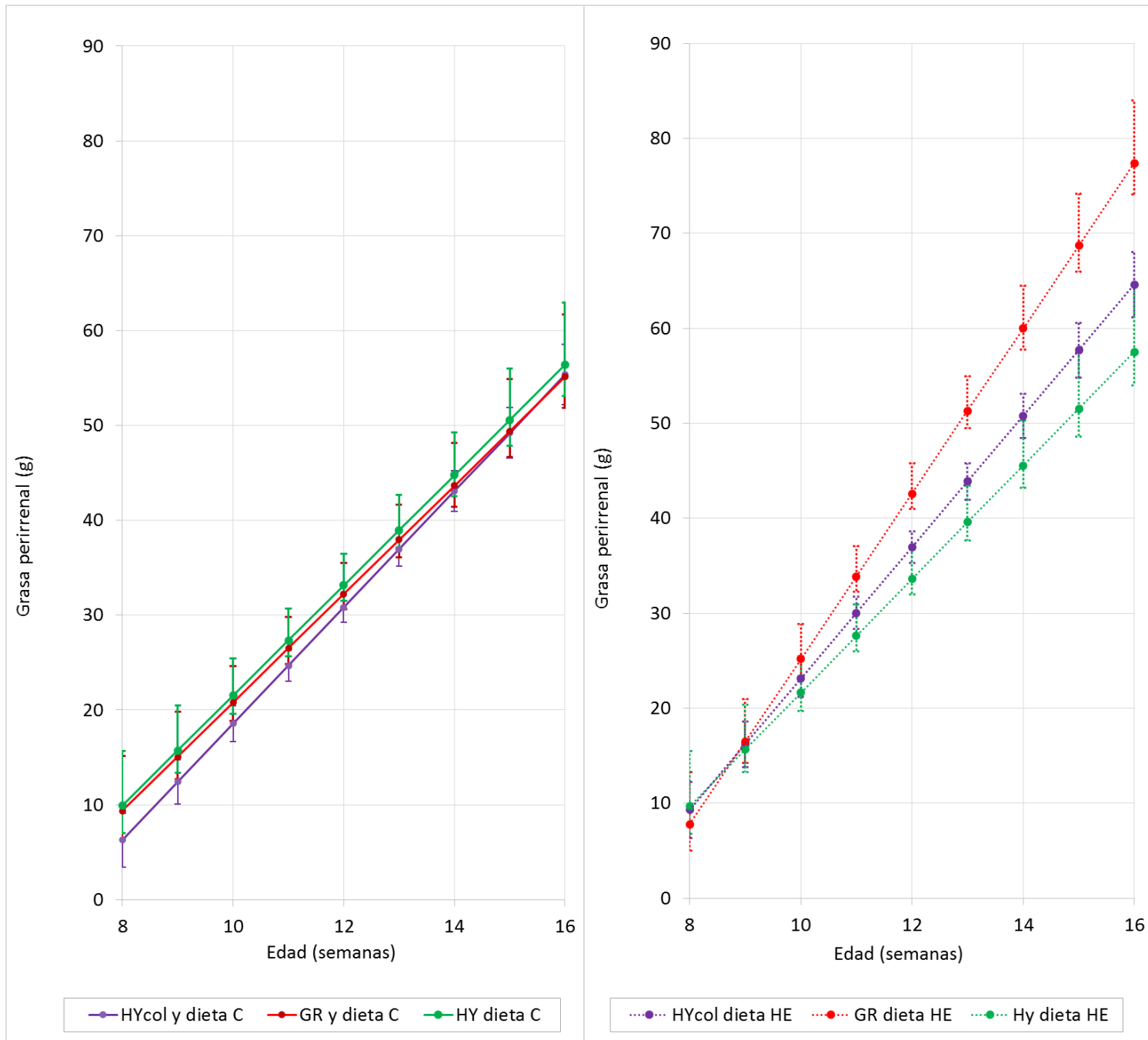

Figura 44. Evolución del Peso de grasa perirrenal (gramos) con la edad (semanas) en función de la línea genética (HYcol: Hyla-colored, GR: Grimaud ps 119 e HY: Hyla Grand Parental Doe) (Medias mínimo cuadráticas e intervalos de confianza). 

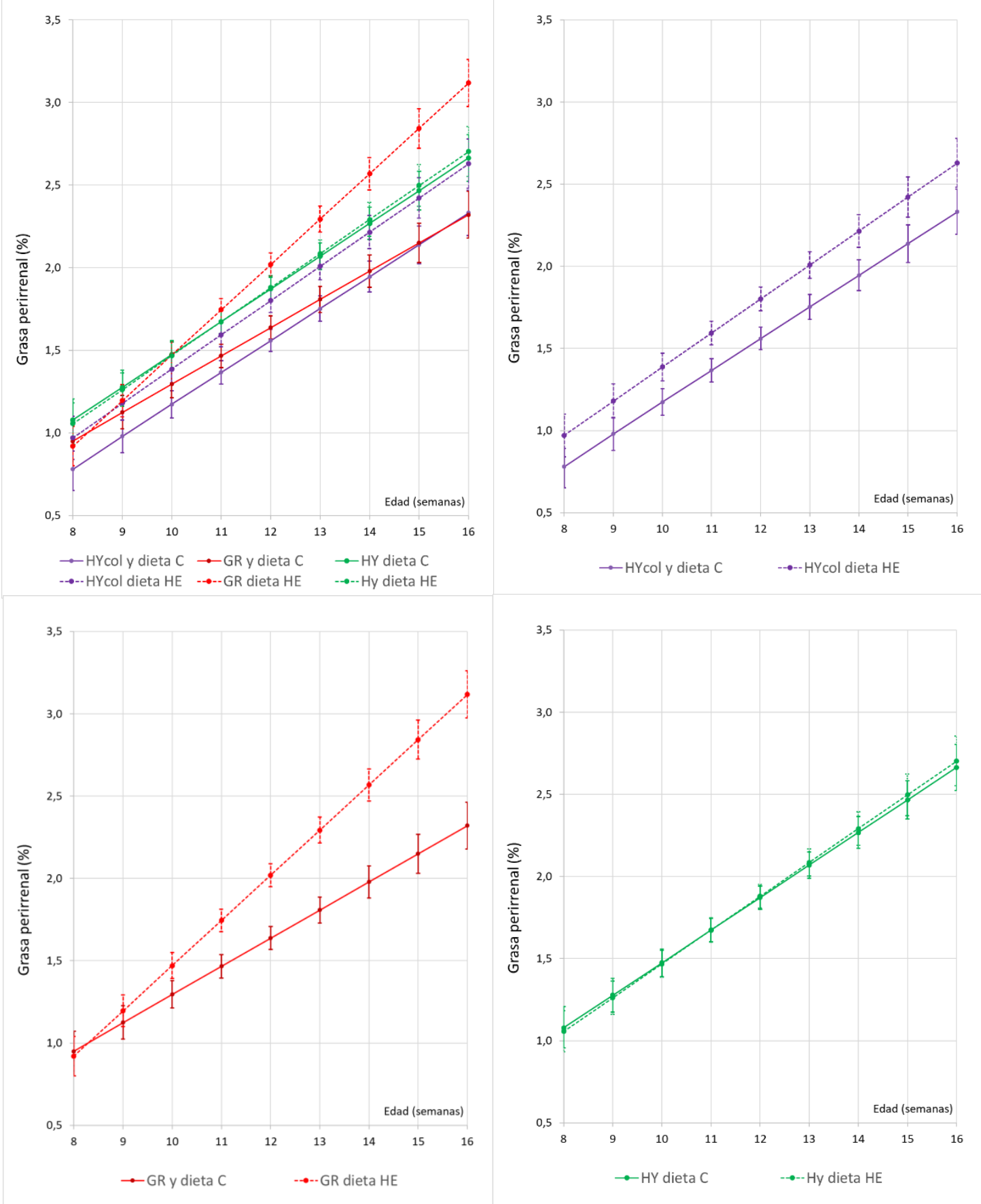

Figura 45. Interacción línea genética $x$ dieta: Evolución del Peso de grasa perirrenal (gramos) con la edad (semanas) en función de la línea genética (HYcol: Hyla-colored, GR: Grimaud ps 119 e HY: Hyla Grand Parental Doe) (Medias mínimo cuadráticas e intervalos de confianza). 


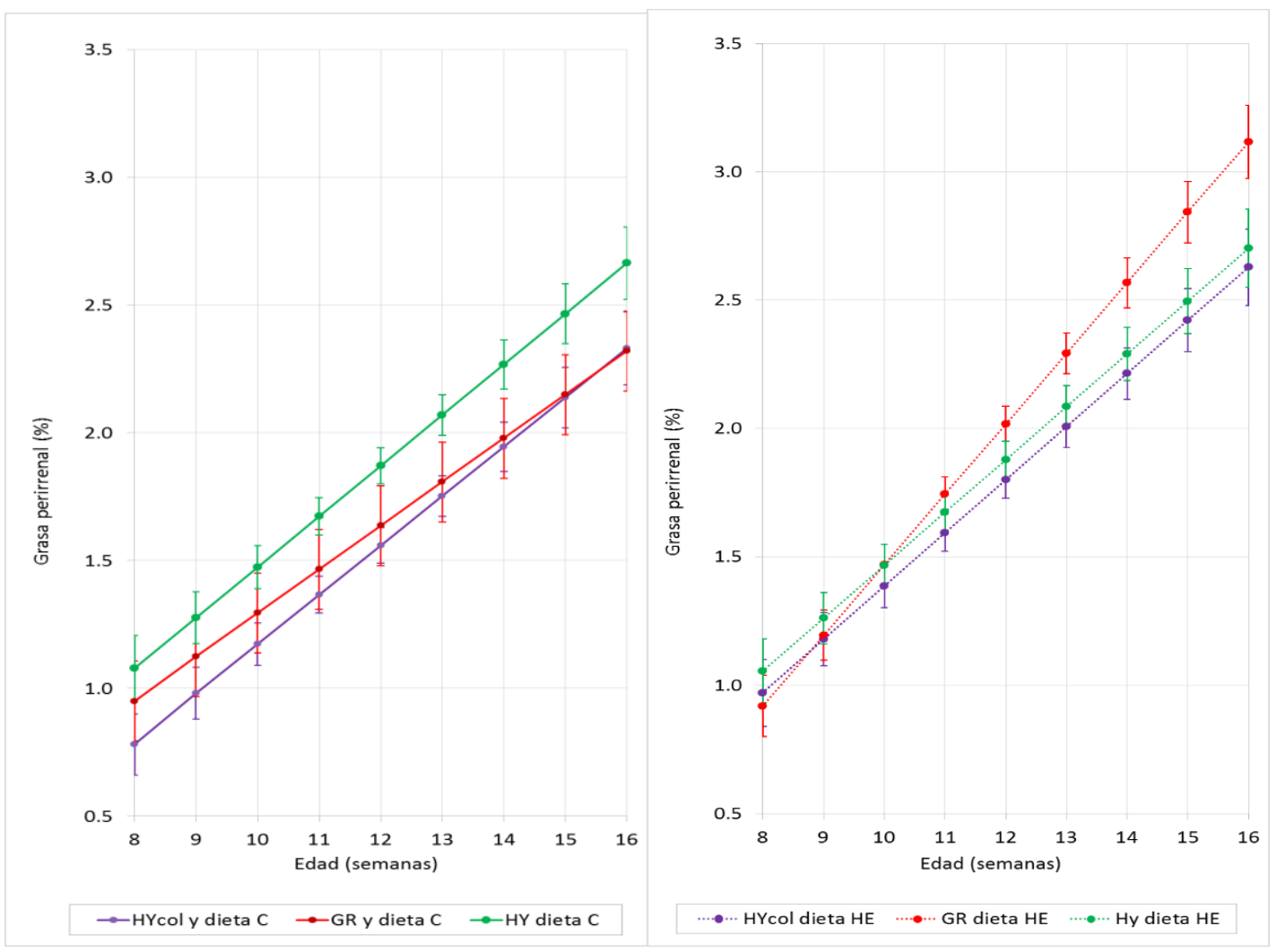

Figura 46. Evolución del porcentaje de grasa perirrenal con la edad (semanas) en función de la línea genética (HYcol: Hyla-colored, GR: Grimaud ps 119 e HY: Hyla Grand Parental Doe) (Medias mínimo cuadráticas e intervalos de confianza). 


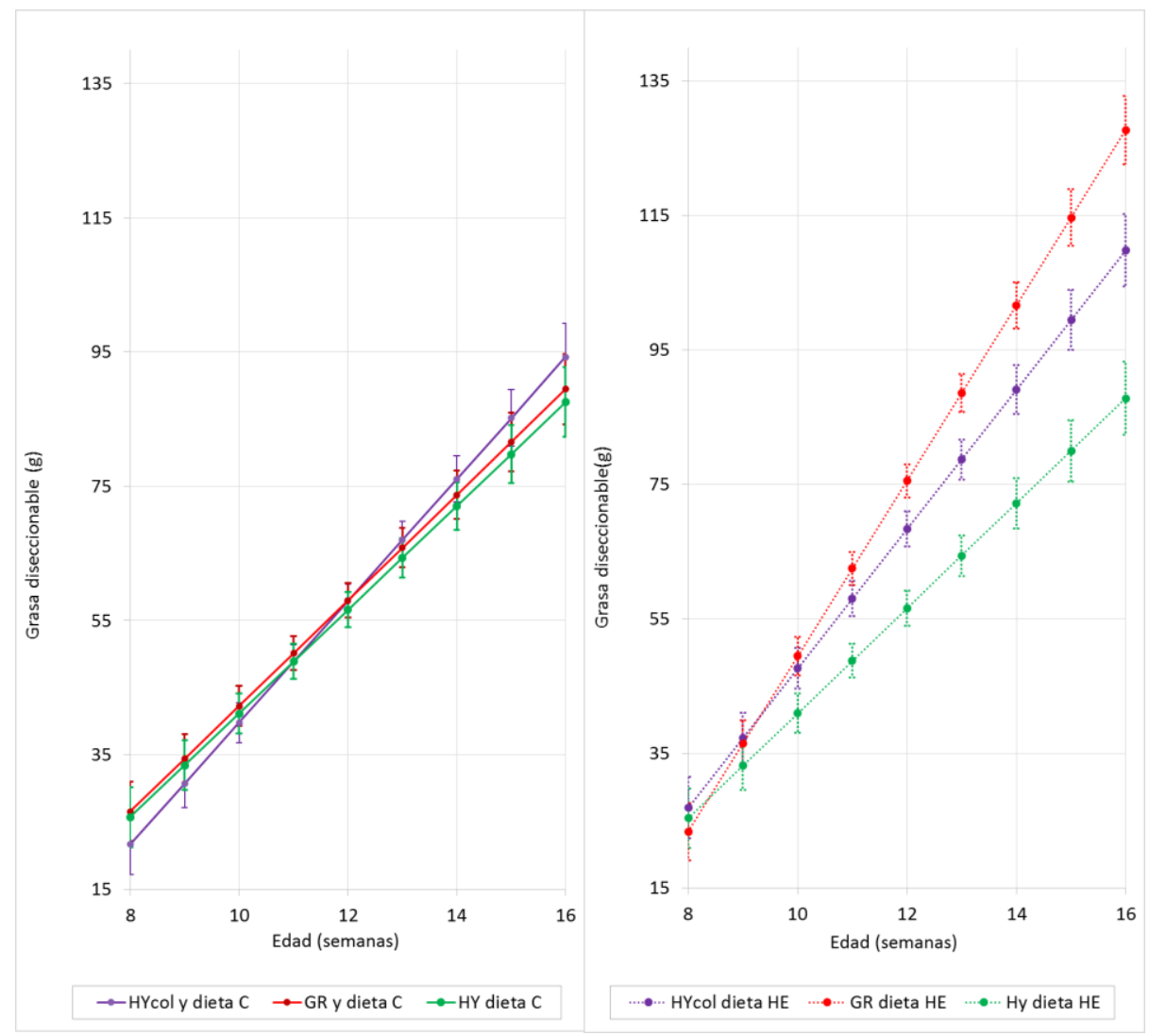

Figura 47. Evolución del Peso de grasa diseccionable (gramos) con la edad (semanas) en función de la línea genética (HYcol: Hyla-colored, GR: Grimaud ps 119 e HY: Hyla Grand Parental Doe) (Medias mínimo cuadráticas e intervalos de confianza). 

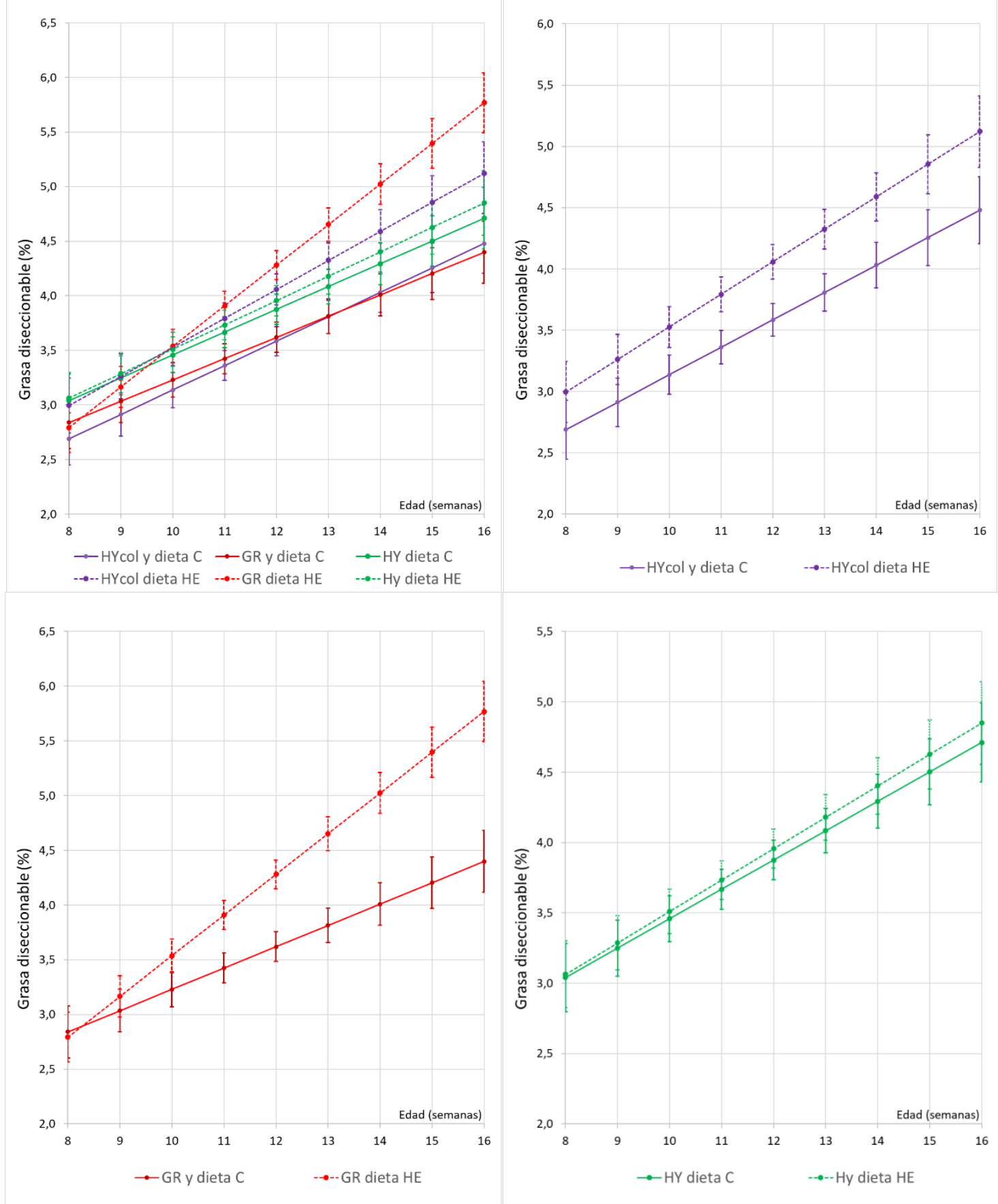

Figura 48. Interacción línea genética $x$ dieta: Evolución del Peso de grasa diseccionable (gramos) con la edad (semanas) en función de la línea genética (HYcol: Hyla-colored, GR: Grimaud ps 119 e HY: Hyla Grand Parental Doe) (Medias mínimo cuadráticas e intervalos de confianza). 

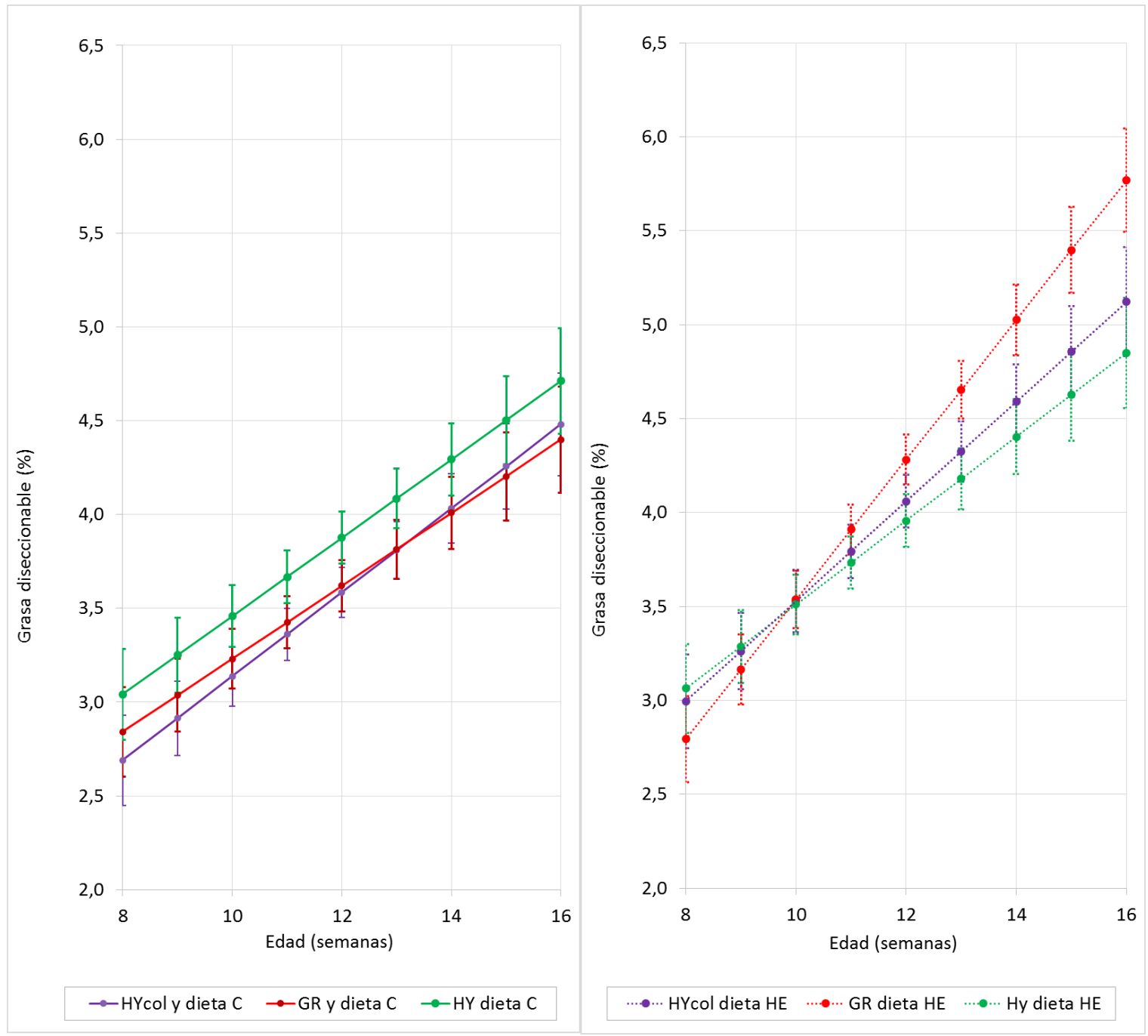

Figura 49. Evolución del porcentaje de grasa diseccionable con la edad (semanas) en función de la línea genética (HYcol: Hyla-colored, GR: Grimaud ps 119 e HY: Hyla Grand Parental Doe) (Medias mínimo cuadráticas e intervalos de confianza).

Dalle Zotte et al. (1998) obtuvieron resultados superiores a los nuestros para la suma del porcentaje de grasa escapular y perirrenal en conejos sacrificados a los $2,5 \mathrm{~kg}$ de peso comercial entre una línea de aptitud maternal (INRA 9077) y una línea híbrida comercial seleccionada por velocidad de crecimiento $(\mathrm{Hy}+)$, observando más porcentaje INRA $9077(3,2 \pm 0,7 \%)$ que $\mathrm{Hy}+(2,3 \pm 0,7 \%)$. En nuestro caso para conejos de $2,5 \mathrm{~kg}$ (a las 9 semanas) la suma de porcentaje de grasa escapular y perirrenal más elevado lo obtuvimos con la línea HYcol $(1,8 \pm 0,1 \%)$.

Dalle Zotte et al. (2015) encontraron diferencias significativas en la grasa perirrenal y escapular a las 12 semanas entre dos líneas genéticas, una seleccionada por ganancia media diaria (Large) y otra línea (Hung) procedente de los 'Gigantes Húngaros' que se 
usa para mejorar el rendimiento productivo, observando mayor porcentaje de grasa perirrenal y escapular en la línea Large (perirrenal 1,64 $\pm 0,04 \%$ vs. 1,45 $\pm 0,04 \%$ y escapular $0,50 \pm 0,01 \%$ vs. 0,63 $\pm 0,01 \%)$.

Gómez et al. (1998) compararon dos líneas genéticas seleccionadas por aptitud maternal ( $A$ y $V$ ) con una seleccionada por crecimiento $(R)$ en animales sacrificados con un peso comercial de $2 \mathrm{~kg}$ criados en lugares diferentes y con diferentes días hasta el destete (experimento 1: Universidad Politécnica de Valencia - 28 días y experimento 2: Institud de Recerca i Tecnologia Agroalimentàries de Cataluña - 32 días) y obtuvieron mayores pesos de grasa perirrenal las líneas mejoradas por aptitud maternal (A: 14,60 \pm 0,40 g y $\vee: 15,9 \pm 0,40$ g) que la línea seleccionada por velocidad de crecimiento ( $R: 12 \pm$ 0,40 g); y no encontraron diferencias significativas para la grasa escapular alimentados con la misma dieta (16 \% proteína, 3,4 \% grasa, 15,5 \% fibra y $15 \%$ almidón).

Hernández et al. (2006) encontraron que a las 9 semanas la línea seleccionada por tasa de crecimiento al destete a las 4 semanas $(R)$ tendía a depositar más porcentaje de grasa (escapular, perirrenal e inguinal) que las otras líneas seleccionadas por tamaño de camada con 30 y 33 generaciones de selección ( $\mathrm{A}$ y V). El total de la grasa diseccionable fue de hasta $10 \%$ mayor para la línea R cuando fue comparada con V. Nuestros valores de grasa diseccionable para las 3 líneas genéticas alimentadas con la dieta HE (16 \% proteína bruta, $17 \%$ fibra bruta y $3 \%$ de grasa) coinciden con estos autores a las 9 semanas, ya que obtuvieron $3,22 \%$ de valor medio con una dieta con $16 \%$ proteína cruda, $15,5 \%$ fibra y $3,4 \%$ de grasa.

Pascual et al. (2014) encontraron diferencias significativas en el porcentaje de grasa perirrenal y escapular en conejos a las 12 semanas para líneas seleccionadas por velocidad de crecimiento y alimentados con dos dietas con diferentes niveles de fibra, indicando que una reducción en el porcentaje de grasa diseccionable puede deberse al incremento en fibra altamente digestible a expensas de una disminución de almidón. Aunque Xiccato et al. (2013) no encontró ningún efecto del nivel de la fibra soluble según la proporción de almidón en el porcentaje de la grasa diseccionable en su estudio comparativo de caracteres de canal y carne para conejos agrupados en distintas 
densidades por jaula (12 vs 16 animales $/ \mathrm{m}^{2}$ ) a las 11 semanas de edad; obteniendo un 2 $-2,2 \% \pm 0,7$ de esta grasa.

En nuestro caso a las 9 semanas no encontramos diferencias significativas entre las líneas genéticas en ninguno de los depósitos de grasa, y posteriormente los resultados son totalmente dependientes de la dieta. Así, para la dieta $\mathrm{C}$ no hubo diferencias en la grasa perirrenal entre las tres líneas genéticas estudiadas cuando es expresada en gramos, sin embargo como porcentaje la línea de aptitud maternal HY presentó mayor valor que las líneas de aptitud cárnica; mientras que para la grasa escapular en gramos HY mostró menores valores y en porcentaje no hubieron diferencias. Para la dieta HE, a partir de la semana 12 la línea GR presentó mayor porcentaje de grasa perirrenal y la línea HY menor porcentaje de grasa escapular. A la luz de todos estos resultados, podemos concluir: a) las líneas de aptitud cárnica son más dependientes de la dieta en la deposición de grasa; y b) la grasa perirrenal juega un papel funcional en el metabolismo energético ya que para dietas menos energéticas las líneas de aptitud maternal conservan este tipo de grasa. 


\section{INTERACCIÓN GÉNERO Y DIETA}

No se encontraron diferencias entre machos y hembras para la grasa escapular (figura 50), perirrenal (figura 51) y en la grasa diseccionable (figura 53), tanto en gramos como en porcentaje, y para ambas dietas.
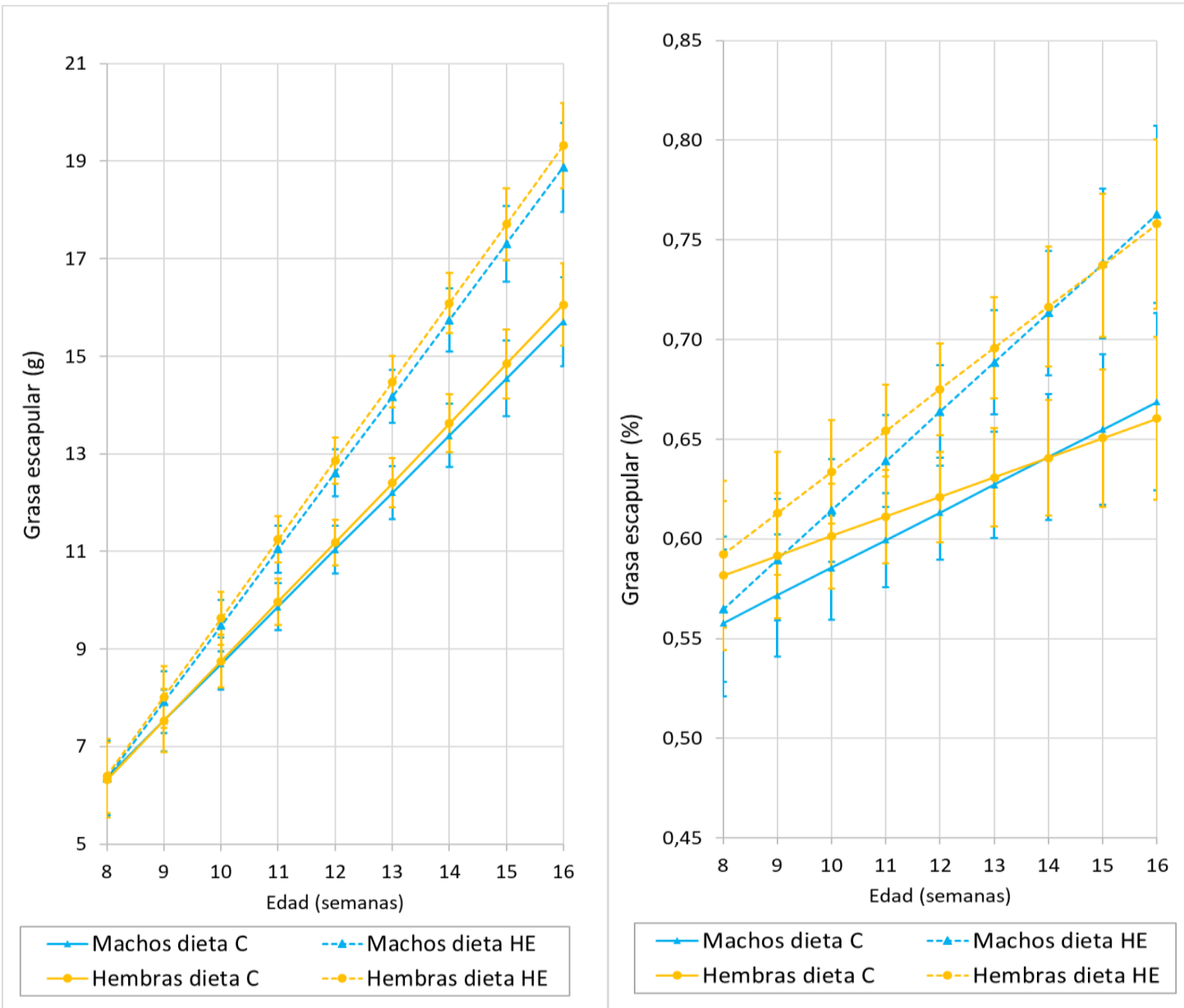

Figura 50. Evolución del Peso de grasa escapular (gramos) y del porcentaje con la edad (semanas) en función en función del género (F: hembra y M: Macho) (Medias mínimo cuadráticas e intervalos de confianza). 


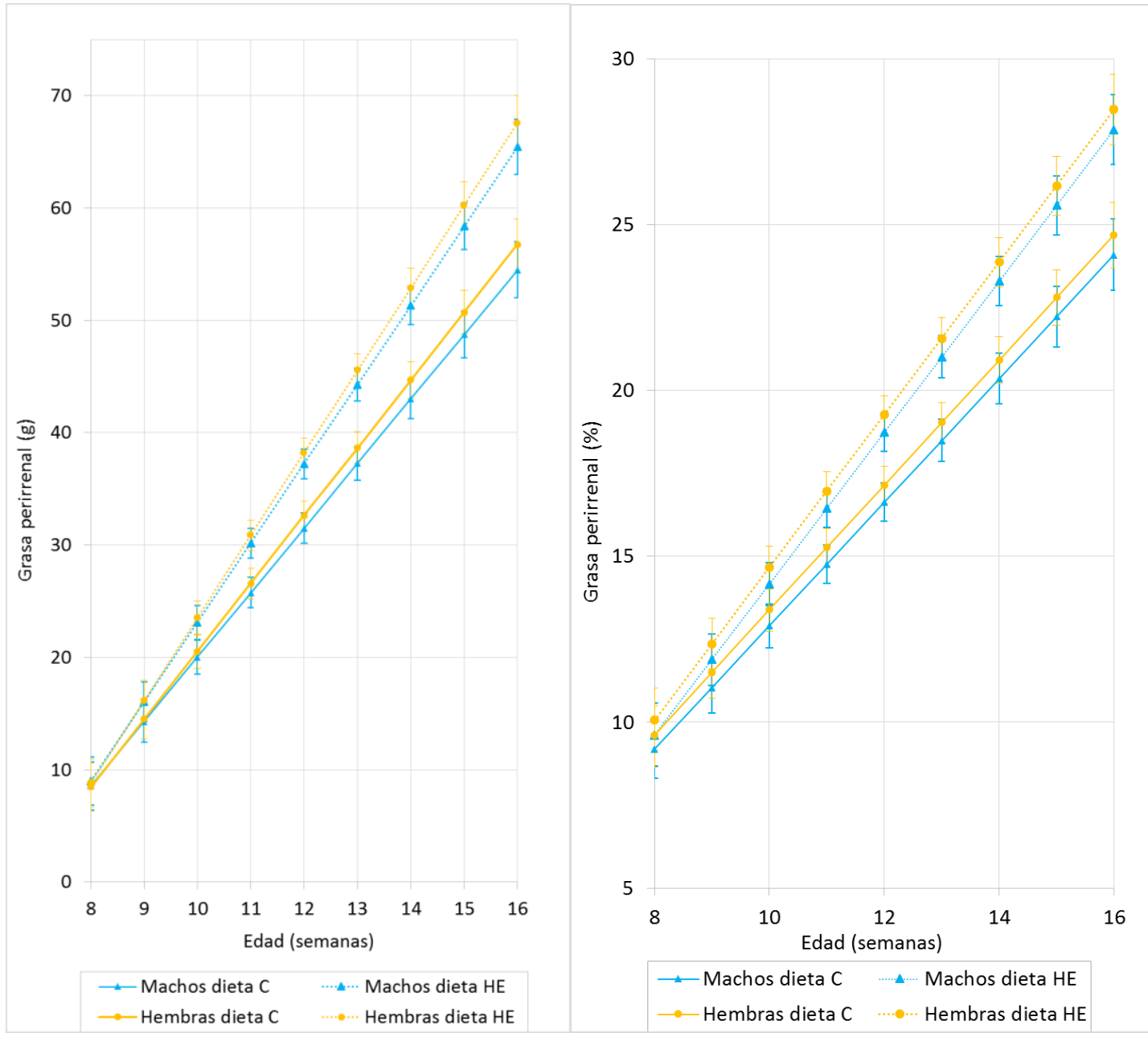

Figura 51. Evolución del Peso de grasa perirrenal (gramos) y del porcentaje con la edad (semanas) en función en función del género ( $F$ : hembra y $M$ : Macho) (Medias mínimo cuadráticas e intervalos de confianza).

Respecto a la grasa inguinal (figura 52) comenzaron a depositar más grasa las hembras que los machos a partir de la semana 13 en el caso de la dieta control, y a partir de la semana 11 para la dieta HE. Además se observa un cambio en la tendencia en la deposición de grasa inguinal en los machos en función de la dieta. Con la dieta C los machos disminuyeron el porcentaje de grasa, mientras que con la dieta HE aumentaron el porcentaje de grasa inguinal.

Hernández et al. (2006) a partir de la semana 9 ya encontraron diferencias significativas entre machos y hembras en el depósito de grasa inguinal, depositando las hembras un $0,21 \%$ más de grasa inguinal que los machos. En nuestro caso, se observa un diferencia entre machos y hembras de $0,15 \%$ en la semana 16 con la dieta HE y de $0,13 \%$ con la 
dieta C. Si bien y acorde con nuestros resultados, Hernández et al. (2006) no encontraron diferencias entre machos y hembras para la grasa perirrenal a las 9 semanas.

En contraste, Lazzaroni et al. (2009) sí encontraron diferencias significativas ( $P>0,01)$ entre machos y hembras en el peso de grasa perirrenal (hembras: $1,6 \% \pm 0,57$; machos: $1,1 \% \pm 0,71$ ) y grasa diseccionable (hembras: $4,0 \% \pm 1,35$; machos: $3,0 \% \pm 1,64$ ) de conejos Carmagnola Grey criados entre 9 y 16 semanas alimentados por un pienso comercial.

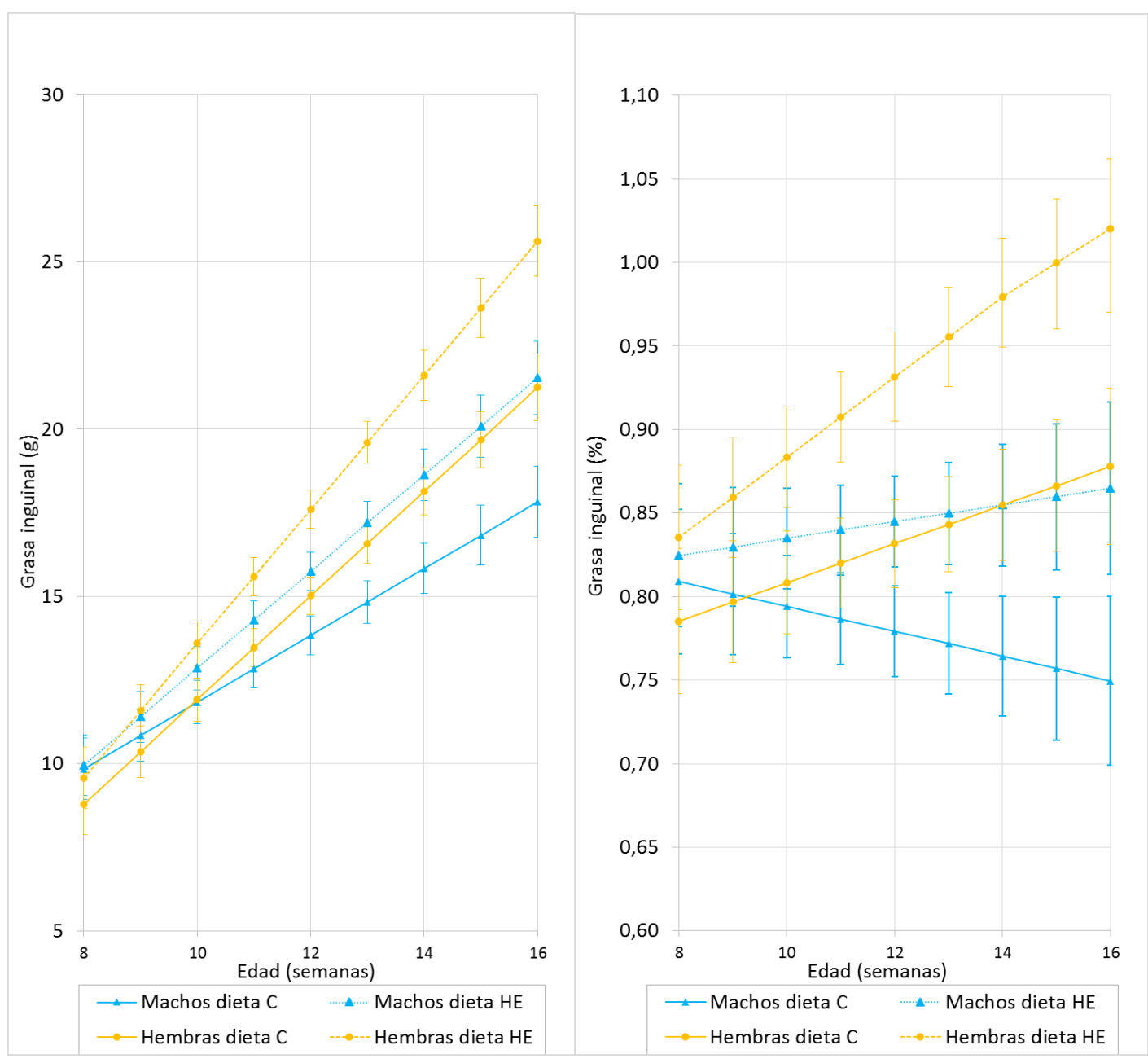

Figura 52. Evolución del Peso de grasa inguinal (gramos) y del porcentaje con la edad (semanas) en función en función del género (F: hembra y $M$ : Macho) (Medias mínimo cuadráticas e intervalos de confianza). 


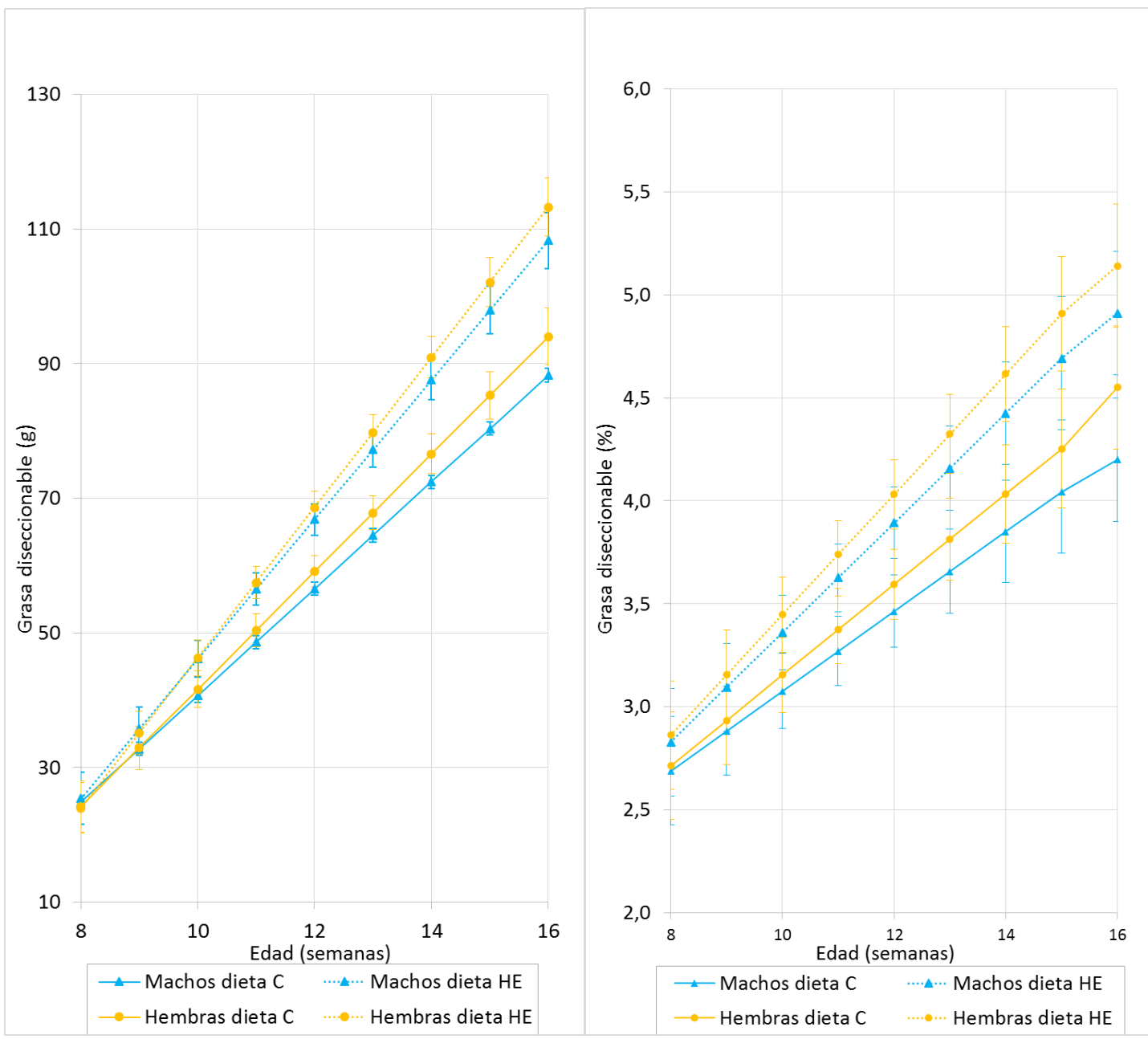

Figura 53. Evolución del Peso de grasa diseccionable (gramos) y evolución del porcentaje de la grasa diseccionable con la edad (semanas) en función en función del género (F: hembra y M: Macho) (Medias mínimo cuadráticas e intervalos de confianza). 


\section{3_CARACTERES DE CALIDAD DE CARNE}

\subsection{PH A LOS 45 MINUTOS Y A LAS 24 HORAS POST MORTEM}

El pH a los 45 minutos post mortem (p.m.) en el Biceps femoris (pHBf_45') descendió en 0,5 con la edad al sacrificio de los conejos de la 8 a la semana 16 , partiendo de valores iniciales que oscilaron entre 6,76 para la línea Hycol a 6,85 para GR e HY (figura 54). El descenso en el pH conforme avanza la edad se explica por un metabolismo glucolítico más acelerado, que en el sacrificio se traduce en una mayor producción de ácido láctico y consecuentemente en un mayor descenso del pH post mortem (Dalle Zotte et al., 2005). Por otro lado, pH mayores de 6,0 aumentan el riesgo de proliferación de microorganismos proteolíticos (Dalle Zote, 2002).

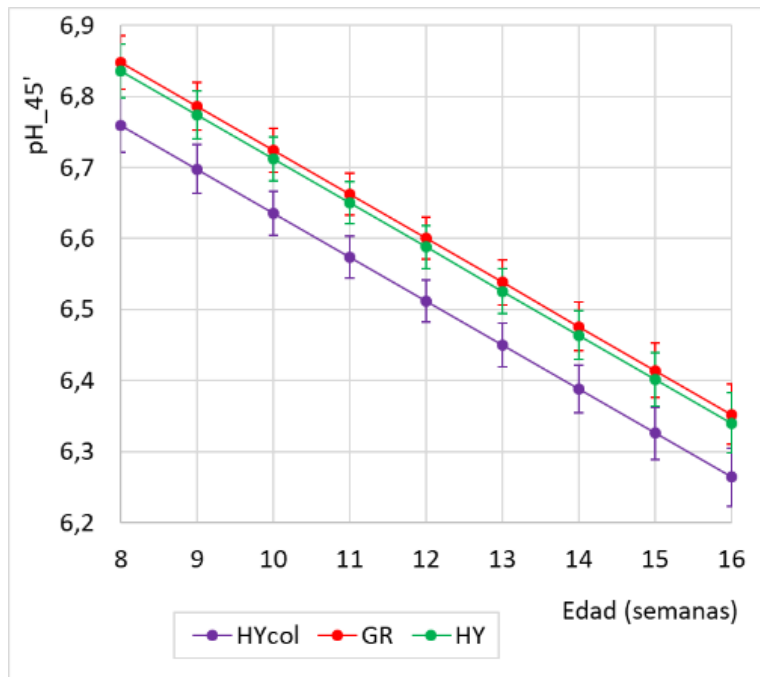

Figura 54. Evolución del pH a los 45 minutos en el Biceps femoris con la edad (semanas) para las diferentes líneas genéticas (HYcol: Hyla-colored, GR: Grimaud ps 119 e HY: Hyla Grand Parental Doe). Medias mínimo cuadráticas e intervalos de confianza.
Se observaron diferencias significativas entre las líneas genéticas. La línea HYcol presentó valores menores, con diferencias de 0,1 a lo largo del periodo estudiado, que las otras dos líneas HY y GR. Esto puede ser debido a un metabolismo energético diferente de la línea HYcol, que a su vez estaría relacionado con el menor IT observado para esta línea.

Otras diferencias en el $\mathrm{pH}$ entre líneas seleccionadas por tasa de crecimiento y tamaño de camada han sido encontradas por Pla et al., 1998 en el $\mathrm{pH}$ a las 24

horas; Blasco \& Piles, 1990). Estos autores compararon dos líneas seleccionadas por tamaño de camada al destete ( $\mathrm{A}$ y $\mathrm{V}$ ) con una línea seleccionada por ganancia media diaria desde el destete hasta las 9 semanas de edad (R), alimentadas por una misma dieta (16 \% proteína bruta, 15,5\% fibra y 3,4 \% grasa) sacrificados desde 4 a 9 semanas, y encontraron diferencias significativas entre las líneas $A(5,71 \pm 0,016)$ y $\vee(5,69 \pm$ 
$0,016)$ respecto a la $\mathrm{R}(5,77 \pm 0,016)$ en el $\mathrm{pH}$ del Biceps femoris a las 24 horas p.m. En cambio, Dalle Zotte et al., (1998) estudiaron dos líneas genéticas (INRA 9077 seleccionada por prolificidad e $\mathrm{Hy}+$ un híbrido comercial seleccionado por tasa de crecimiento) alimentadas por dos dietas con diferentes niveles de fibra bruta $(\mathrm{H} 17,8$ y $\mathrm{L}$ $22,5 \% \mathrm{MS}$ ) y encontraron que el $\mathrm{pH}$ del músculo de la pata no estaba afectado por el origen genético cuando los animales se sacrificaban a la misma edad y peso, en su caso al alcanzar los 2,5 kg de peso vivo.

No hubo efecto del tipo de dieta ni del género en el pHBf_45' (figura 55).
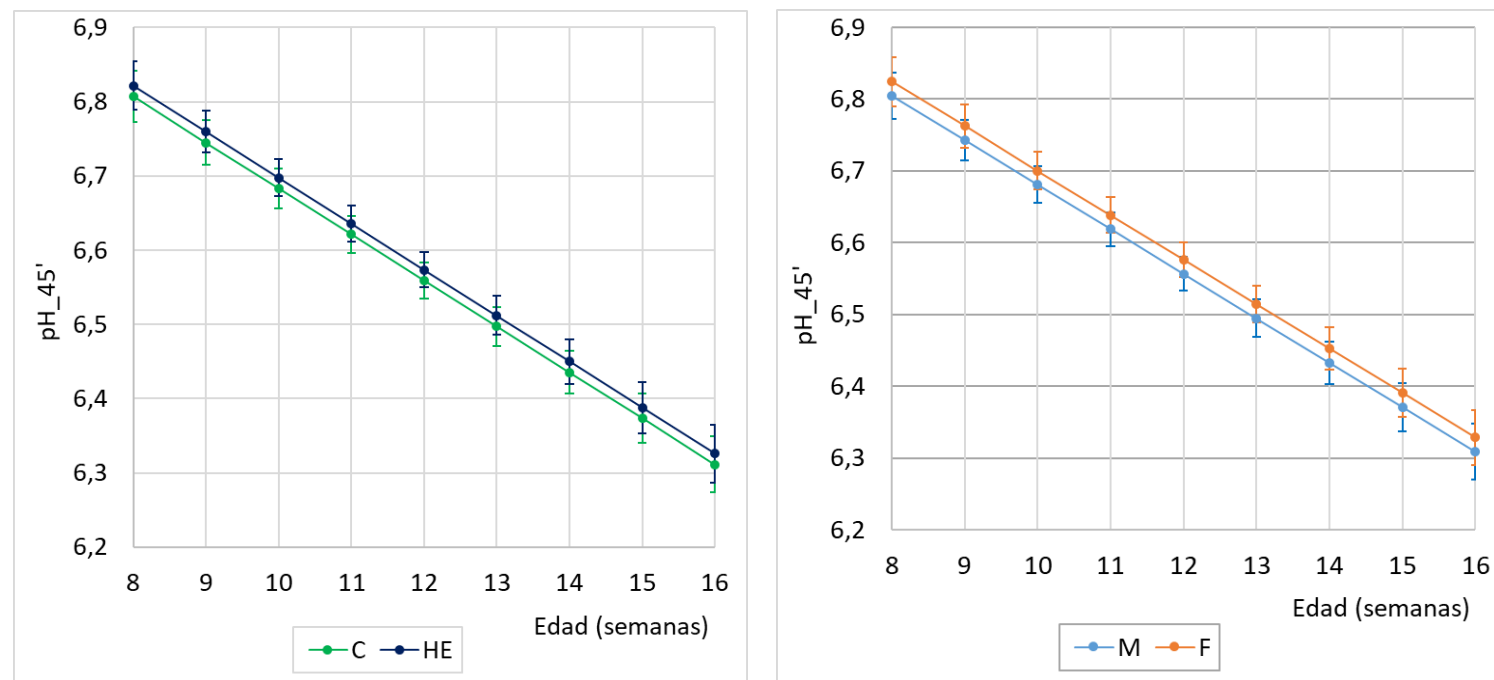

Figura 55. Evolución del pH a los 45 minutos en el Biceps femoris con la edad (semanas) para las diferentes dietas ( $\mathrm{C}$ : control y $\mathrm{HE}$ : altamente energética) y según el género ( $\mathrm{M}$ : machos, $\mathrm{F}$ : hembras). (Medias mínimo cuadráticas e intervalos de confianza).

Lazzaroni et al. (2009) tampoco encontraron diferencias significativas entre machos y hembras en el $\mathrm{pH}$ a los 60 minutos p.m. (M: 6,3 $\pm 0,18$; F: 6,4 $\pm 0,15$ ) para conejos Carmagnola de 16 semanas de edad. Además, tampoco observaron un efecto de la densidad (0,12 $\mathrm{m}^{2} /$ animal; 0,25 $\mathrm{m}^{2} /$ animal) en el $\mathrm{pH}$ a los 60 minutos p.m. En nuestro caso los valores de $\mathrm{pH}$ a los 45 minutos para machos y hembras (M: 6,31 $\pm 0,08 ; \mathrm{F}: 6,33$ $\pm 0,08$ ) fueron similares (figura 55) a los obtenidos por Lazzaroni et al. (2009) a los 60 minutos.

Respecto al pH medido en el Biceps femoris a las 24 horas p.m. (pHBf_24h), se observó un descenso respecto a los 45 minutos p.m. de 0,8-0,65 unidades dependiendo de la 
línea y la dieta. Además, también se observa un descenso del pH con la edad (figura 56) en las líneas de aptitud cárnica GR e HYcol, siendo más marcado para la línea HYcol con la dieta $\mathrm{HE}$, mientras que este descenso fue inexistente para la línea HY.

Por tanto, se encontró una interacción línea genética y dieta (figura 56), de tal forma que con la dieta $\mathrm{C}$ no hubo diferencias significativas entre líneas genéticas, sin embargo, con la dieta HE la línea HYcol presentó un pH más bajo que HY y GR a partir de la semana 11, aunque a partir de la semana 14 no fue diferente a GR. Así, a partir de los valores de $\mathrm{pH}$ observados podemos concluir que, las líneas genéticas presentaron un metabolismo glucolítico p.m. diferente y este, a su vez, se vio afectado por la alimentación, observándose que dietas más energéticas condujeron a una aceleración del metabolismo mayor con la edad. 

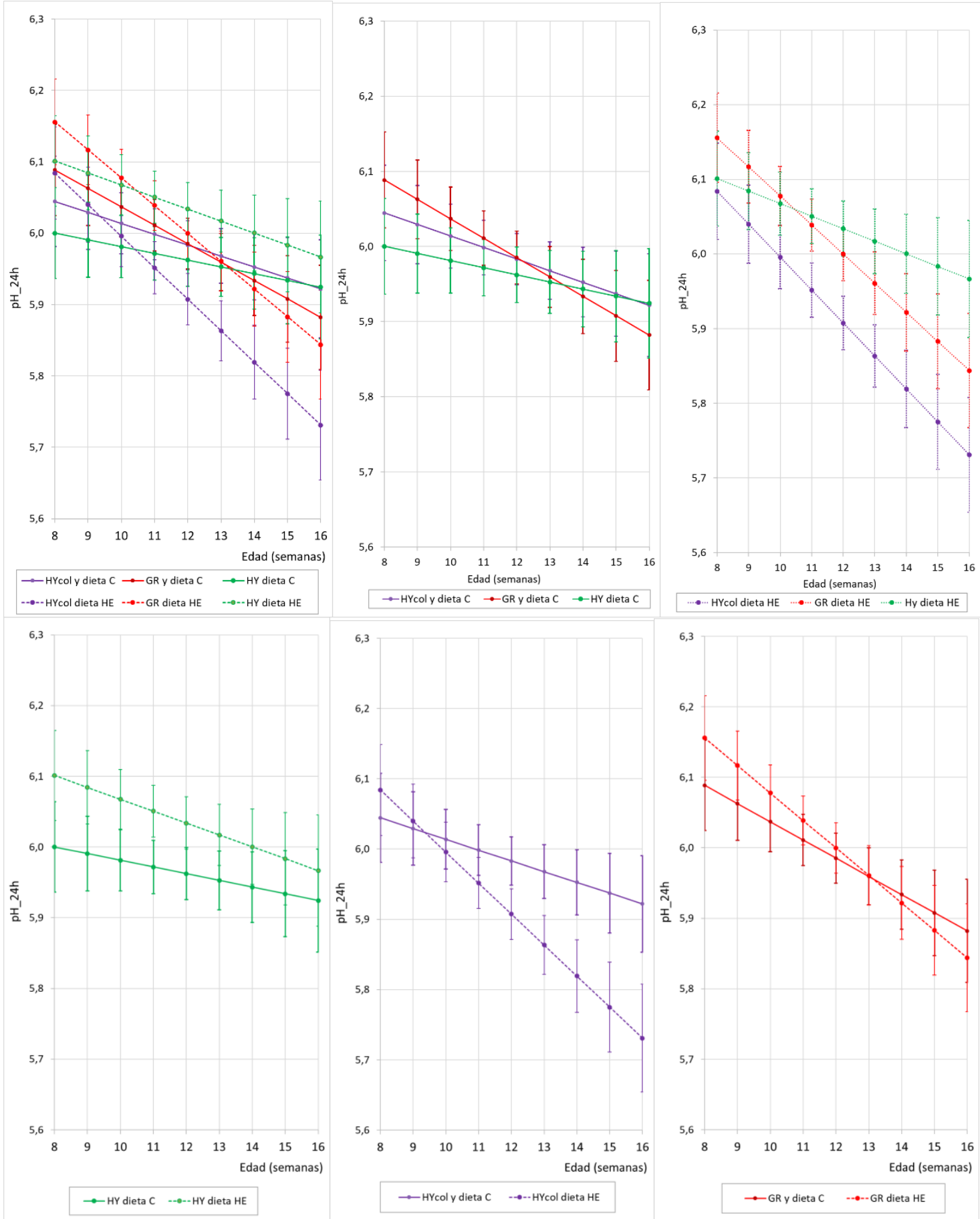

Figura 56. Evolución del pH a las 24 horas post mortem en el Biceps femoris con la edad (semanas) para las diferentes líneas genéticas (HYcol: Hyla-colored, GR: Grimaud ps 119 e HY: Hyla Grand Parental Doe).y las diferentes dietas (C: control y HE: altamente energética). (Medias mínimo cuadráticas e intervalos de confianza).

Otros autores midieron el pH en diferentes líneas genéticas y dietas en la semana 9 y 10 , edades en las que nosotros no observamos un efecto de línea o de dieta. Así, Dalle Zotte 
et al. (1998) tampoco encontraron diferencias en el pH a las 24 horas post mortem entre una línea genética mejorada por velocidad de crecimiento $(\mathrm{Hy}+: 5,76 \pm 0,11)$ y una mejorada por prolificidad (INRA 9077: 5,80 $\pm 0,11$ ) alimentadas con una dieta control (9,67 MJ kg MS-1; 22,5 \% fibra bruta) y una dieta más energética (11,99 MJ kg MS ${ }^{-1} ; 17,8$ \% fibra bruta) para conejos sacrificados con 2,5 kg de peso vivo, que es el peso que en nuestro caso alcanzaron a las 10 semanas de edad. Nuestros valores de $\mathrm{pH}$ a las 10 semanas para las tres líneas alimentadas con ambos piensos (figura 56) fueron superiores a los de Dalle Zotte et al. (1998), con valores promedio entre 5,98 - 6,08.

Igualmente, Pascual et al. (2014) tampoco encontraron diferencias significativas en el pH a las 24 horas en el Longissimus lumborum de animales de 9 semanas de edad procedentes de líneas seleccionadas por velocidad de crecimiento y alimentados con dos dietas con niveles de fibra diferentes. Los valores obtenidos por Pascual et al. (2014) fueron inferiores $(5,65$ y $5,66 \pm 0,01)$ a los obtenidos en nuestro ensayo para la semana 9 (valores promedio 5,99-6,12).

Nasr et al. (2017) mostraron que el pH a las 24 horas p.m. oscilaba entre 5,58 y 5,96 \pm 0,14 para conejos con 10 semanas de nueve genotipos de un cruce factorial de las razas New Zealand White, California y Rex.

Finalmente, también se observó interacción entre el género y la dieta para (pHBf_24h), de tal forma que las hembras alimentadas con la dieta HE presentaron mayores valores de $\mathrm{pH}$ en las semanas de la 9 a la 12 que los machos dieta HE, y esta diferencia fue solo significativa en la semana 9 y 10 respecto a las hembras dieta $C$ y machos dieta $C$ (figura 57).

Lazzaroni et al. (2009) no encontraron diferencias significativas entre machos y hembras en el pH a las 24 horas (M: 5,9 $\pm 0,03 ; \mathrm{F}: 5,8 \pm 0,02$ ) para conejos Carmagnola con 16 semanas criados a dos densidades diferentes (0,12 m2/animal; 0,25 m2/animal). En nuestro caso los valores de $\mathrm{pH}$ a las 16 semanas fueron inferiores tanto para machos como para hembras alimentados con ambas dietas (figura 57) 


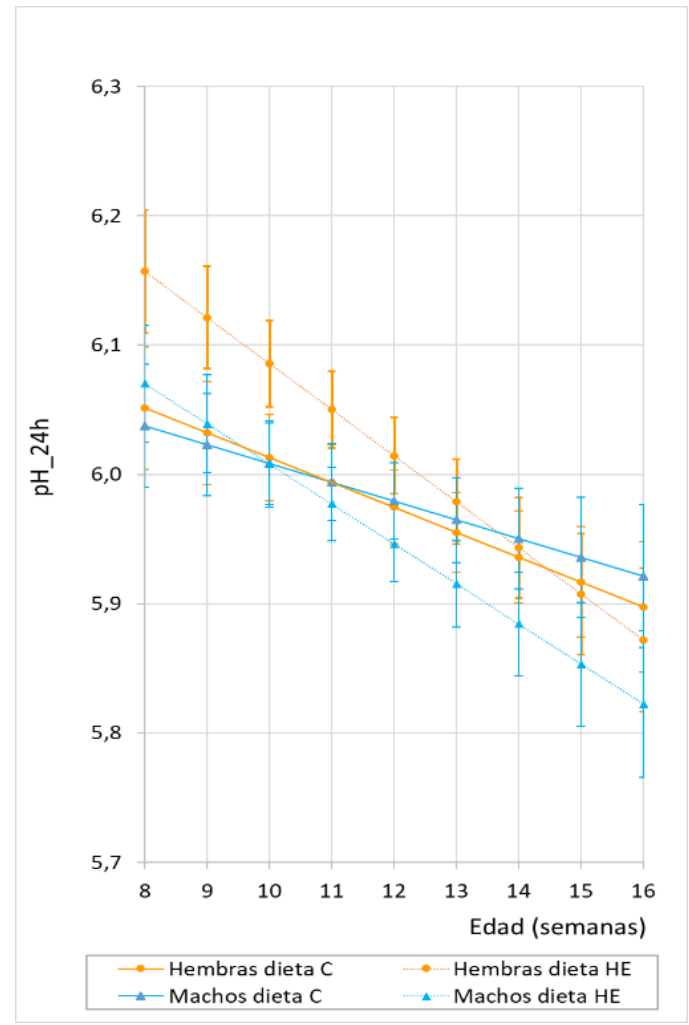

Figura 57. Evolución del pH a las 24 horas post mortem en el Biceps femoris con la edad (semanas) para los diferentes géneros ( $\mathrm{M}$ : macho, F: hembra) y las diferentes dietas (C: control y HE: altamente energética). (Medias mínimo cuadráticas e intervalos de confianza).

\subsection{COLOR}

El color se midió sobre la superficie del lomo mediante las coordenadas $L^{*}, a^{*}$ y b* en el espacio de color CIELAB. En la luminosidad L* del lomo se detectó un diferente patrón de comportamiento de las líneas genéticas en función de la alimentación. Así, para la dieta C la línea HY mostró mayor luminosidad que HYcol, mientras GR se situaba en posición intermedia. Sin embargo, para la dieta HE no hubo diferencias significativas entre las líneas genéticas. La mayor luminosidad observada en la línea maternal HY está de acuerdo con los resultados observados por Dalle Zotte et al. (2015) que compararon una línea Large seleccionada por ganancia media diaria hasta el destete $\left(L^{*}=50,5 \pm\right.$ $0,34)$ frente a una línea Hung (procedente de una raza tradicional llamada gigante húngaro) seleccionada para mejorar caracteres de crecimiento $\left(L^{*}=52,0 \pm 0,34\right)$ a las 12 semanas de edad, si bien los valores de $L^{*}$ fueron inferiores a los nuestros a las 12 semanas de edad que mostraron un valor promedio entre 57 y 58 . Igualmente, Pla et al. (1998) encontraron mayor valor de L* entre dos líneas seleccionadas por tamaño de 
camada al destete (A: 50,67; V: 50,01 $\pm 0,35)$ y otra línea seleccionada por ganancia media diaria ( $R: 49,01 \pm 0,35)$ con 9 semanas de edad.
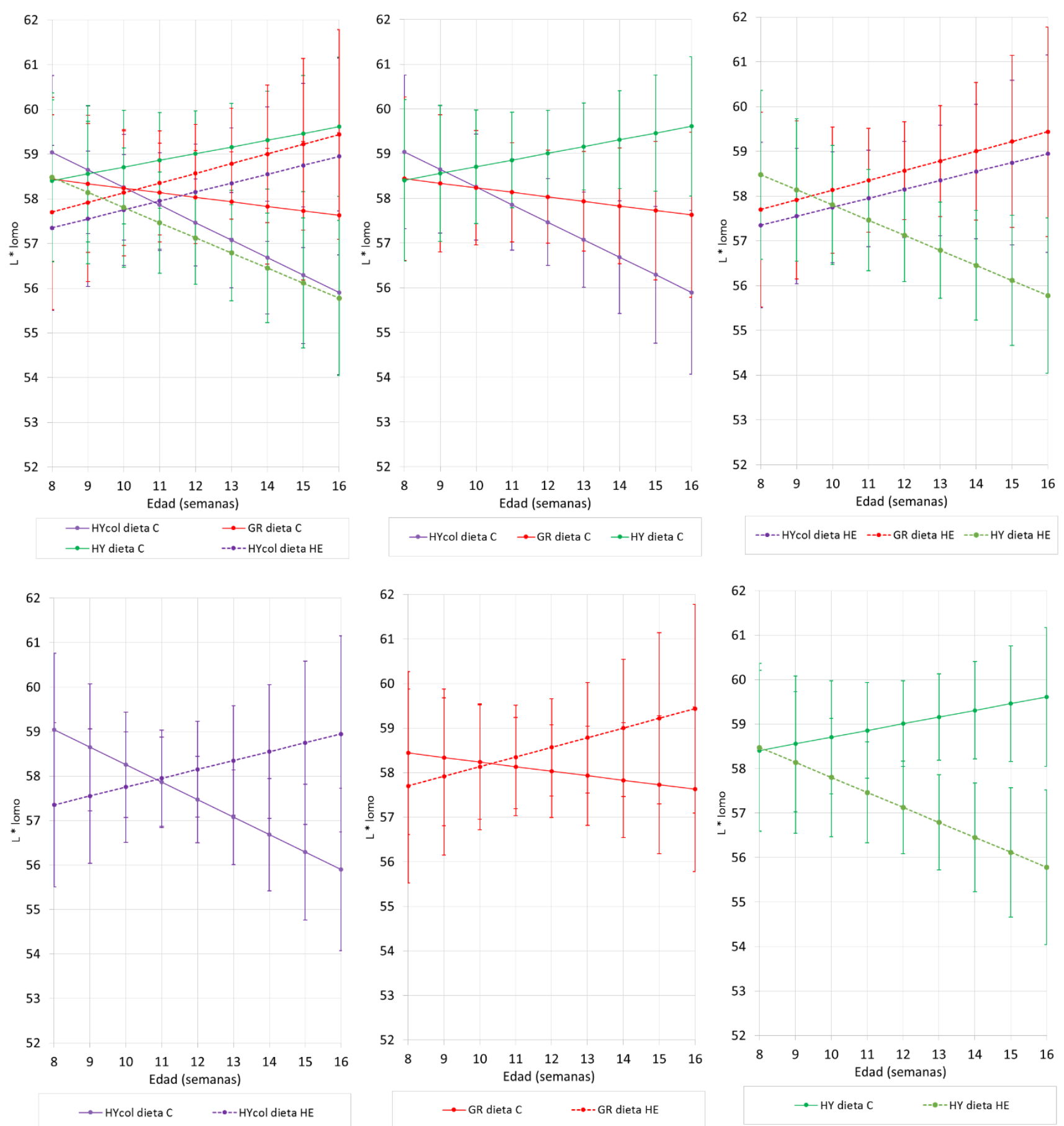

Figura 58. Evolución del color (coordenada $L^{*}$ ) con la edad (semanas) para las diferentes líneas genéticas (HYcol: Hyla-colored, GR: Grimaud ps 119 e HY: Hyla Grand Parental Doe), las diferentes dietas (C: control y HE: altamente energética). (Medias mínimo cuadráticas e intervalos de confianza). 
Nasr et al. (2017) que estudiaron tres razas puras y sus cruces (New Zealand NZW, Californian CA y Rex RX) seleccionadas por aptitud maternal por el número de gazapos al destete con conejos de $\mathbf{2 8 0 0}$ gramos promedio de peso vivo no encontraron efecto de la línea genética en $L^{*}, a^{*}$ y $b^{*}$. En su estudio el valor de $L^{*}$ más alto fue con el cruce de $\operatorname{CAxRX}(49,10 \pm 3,09)$ mientras que nuestros resultados de $L^{*}$ para pesos de 2800 gramos (en torno a las 12 semanas) fueron superiores; aun en el caso de nuestro valor más bajo a las 12 semanas obtenido por Hyla alimentada por la dieta HE $(57,1 \pm 1,04)$.

Nasr et al. (2017) pusieron de manifiesto la alta habilidad de la carne de conejo para la desnaturalización de la mioglobina y reflejar la luz y Bianospino et al. (2008) indicaron que la selección por tasa de crecimiento también puede afectar al metabolismo de la mioglobina.

En cuanto al efecto del género, no se encontraron diferencias significativas en la luminosidad del lomo entre machos y hembras. Al igual que Lazzaroni et al. (2009) cuando estudiaron el efecto del género en conejos de 9 a 16 semanas de la línea California CA seleccionada por tamaño de camada al destete (Valores de L* para hembras: $48,7 \pm 2,65$; y para machos: $47,4 \pm 2,66$ ). 

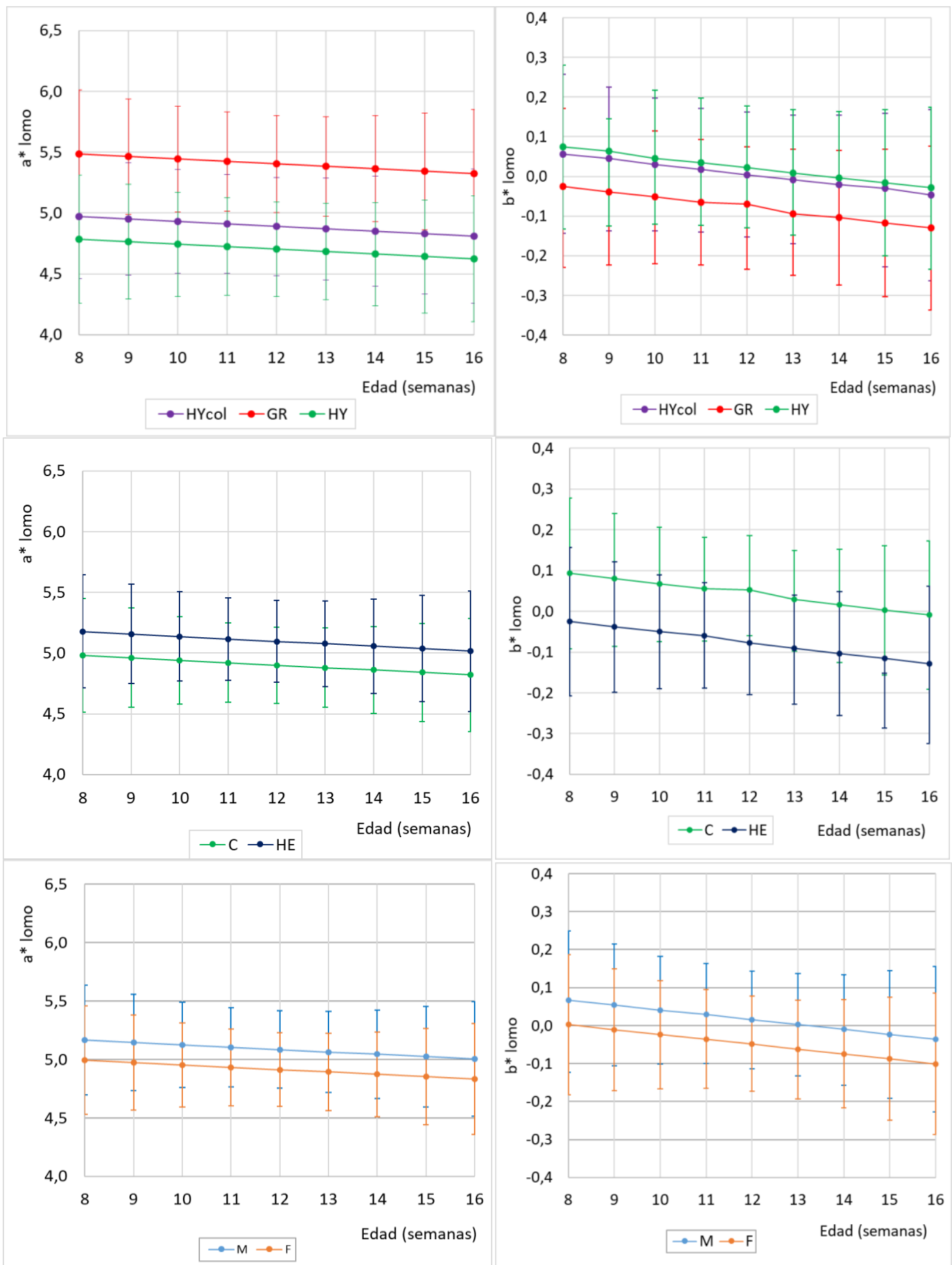

Figura 59. Evolución del color (coordenadas $\mathrm{a}^{*}$ y $\mathrm{b}^{*}$ ) con la edad (semanas) para las diferentes líneas genéticas (HYcol: Hyla-colored, GR: Grimaud ps 119 e HY: Hyla Grand Parental Doe), las diferentes dietas (C: control y HE: altamente energética) y ambos sexos (M: macho, F: hembra). (Medias mínimo cuadráticas e intervalos de confianza).

En el tono rojo $\left(a^{*}\right)$ y el amarillo $\left(b^{*}\right)$ de la carne no se encontró un efecto de línea genética, dieta o género. Dalle Zotte et al. (2015) sí que encontraron mayor valor de a* de la línea de aptitud cárnica Large $\left(a^{*}=4,99 \pm 0,19\right)$ que la línea Hung de aptitud 
maternal $\left(a^{*}=4,18 \pm 0,19\right)$ a las 12 semanas de edad. Además nuestra línea Grimaud (mejorada por velocidad de crecimiento) tuvo el mismo valor de $b^{*}$ a las 12 semanas que la línea mejorada por velocidad de crecimiento (Large: $-0,07 \pm 0,10$ ) estudiada por Dalle Zotte et al. (2015) también a las 12 semanas. Los demás autores tuvieron valores más altos tanto de a* como de b*. En el caso de Nasr et al. (2017) para el cruce de dos líneas puras de Rex x New Zealand White a las 10 semanas de edad llegó a alcanzar valores de $b^{*}$ de $8,30 \pm 0,88$, sin obtener diferencias significativas.

Xiccato et al. (2011) que estudiaron el efecto de disminuir la concentración de proteína cruda (de 162 a $152 \mathrm{~g} / \mathrm{kg}$ ) incrementando el ratio de fibra soluble-almidón (de 0,2 hasta 1,5) en conejos de la línea Grimaud sacrificados a los 75 días. Encontraron que el nivel de proteína no afectó a las características de carne, mientras que el incremento del ratio fibra soluble-almidón si produjo un descenso ligero en los parámetros de color, descendiendo en el caso de $b^{*}$ desde 1,64 hasta $0,38 \pm 2,18$. Nuestros valores de $b^{*}$ para Grimaud a las 11 semanas fueron inferiores $(-0,07 \pm 0,139)$. En el caso del efecto de la dieta obtuvimos para $\mathrm{C} 0,06 \pm 0,11$ y para $\mathrm{HE}-0,06 \pm 0,12$ valores diferentes a Xiccato et al. (2011).

Lazzaroni et al. (2009) que en animales de 9 a 16 semanas de la raza Carmagnola no encontraron diferencias significativas aunque obtuvieron mayores valores de $b^{*}$ y $L^{*}$ en las hembras ( $\left.b^{*}: 5,2 \pm 0,93 ; L^{*}: 48,7 \pm 2,65\right)$ que los machos $\left(b^{*}: 4,6 \pm 1,39 ; L^{*}: 47,4 \pm\right.$ 2,66 ), mientras que para a* fue al contrario (machos: 10,7 $\pm 2,10$; hembras: $10,5 \pm 2,21$ ).

La apariencia de la carne de conejo afecta a la primera impresión y el atractivo hacia el consumidor (Combes et al., 2008). Los presentes resultados de tonalidad de rojo (a*) y amarillo (b*) son comparables con los resultados obtenidos por Nasr et al (2017) que reflejan una buena calidad de carne. En cambio nuestros resultados de luminosidad ( $\left.L^{*}\right)$ son algo más elevados a otros autores, (Nasr et al., 2017, Lazzaroni et al., 2009, Ramirez et al., 2004, Pla et al., 1998). 


\subsection{TEXTURA: FUERZA MÁXIMA AL CORTE (MSF) Y EN EL RENDIMIENTO DE FUERZA INICIAL (IYF)}

En la fuerza máxima al corte (MSF) y en el rendimiento de fuerza inicial (IYF) se observó una interacción línea genética y dieta. En general se encontró que con la edad se producía un incremento de la dureza de la carne, salvo para la línea HYcol con la dieta C que disminuyeron ambos valores de MSF e IYF. Dentro de dieta C, la línea HYcol de la semana 8 a la 10 mostró mayor MSF e IYF que GR y la semana 15 y 16 menores valores de IYF que GR e HY, mientras que para MSF las diferencias no llegaron a ser significativas. Para la dieta HE las líneas fueron iguales y tampoco hubo diferencias significativas entre ambos sexos.
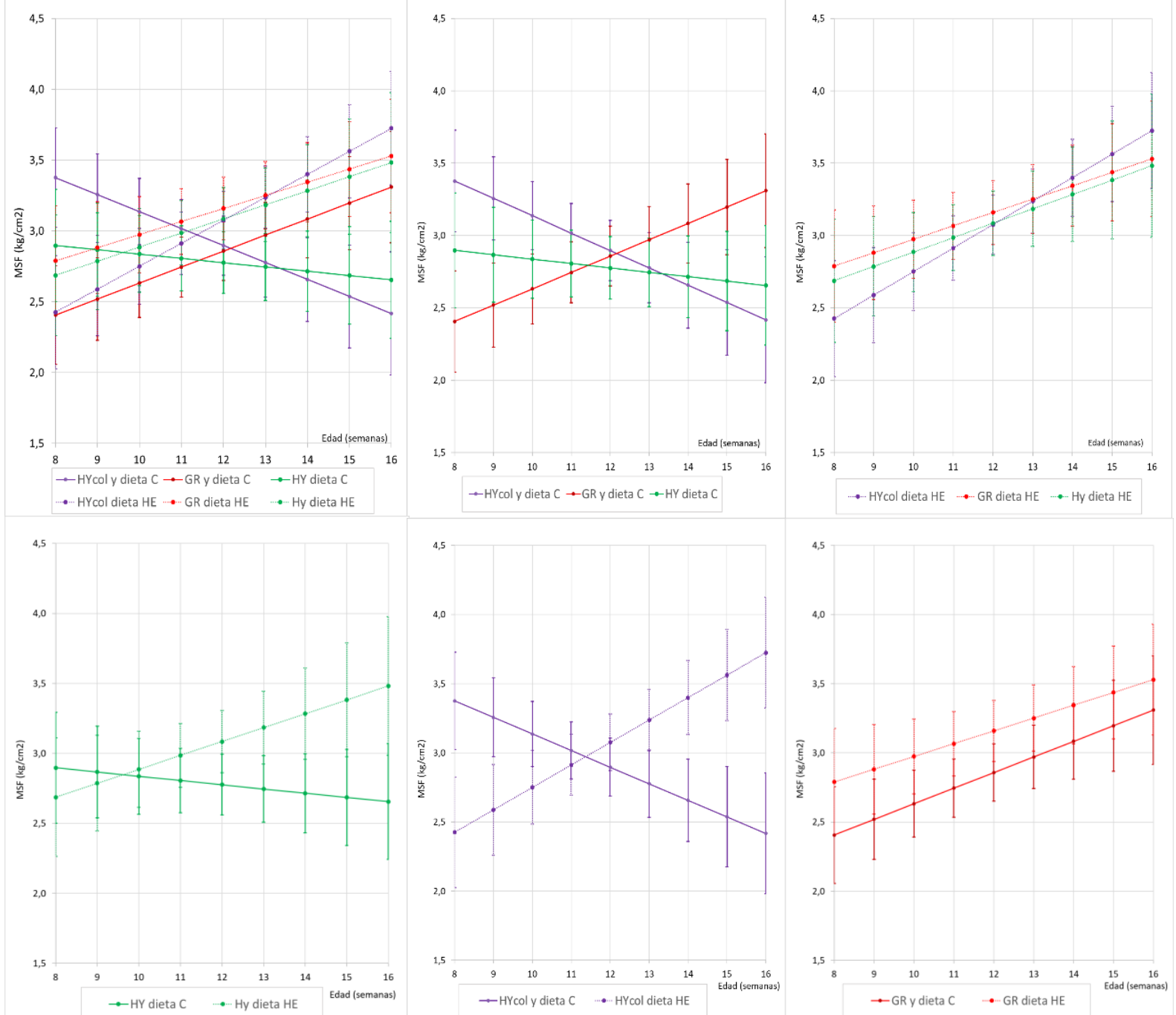

Figura 60. Evolución de la fuerza máxima al corte (MSF) con la edad (semanas) para las diferentes líneas genéticas (HYcol: Hyla-colored, GR: Grimaud ps 119 e HY: Hyla Grand Parental Doe) y las diferentes dietas (C: control y HE: altamente energética). (Medias mínimo cuadráticas e intervalos de confianza). 

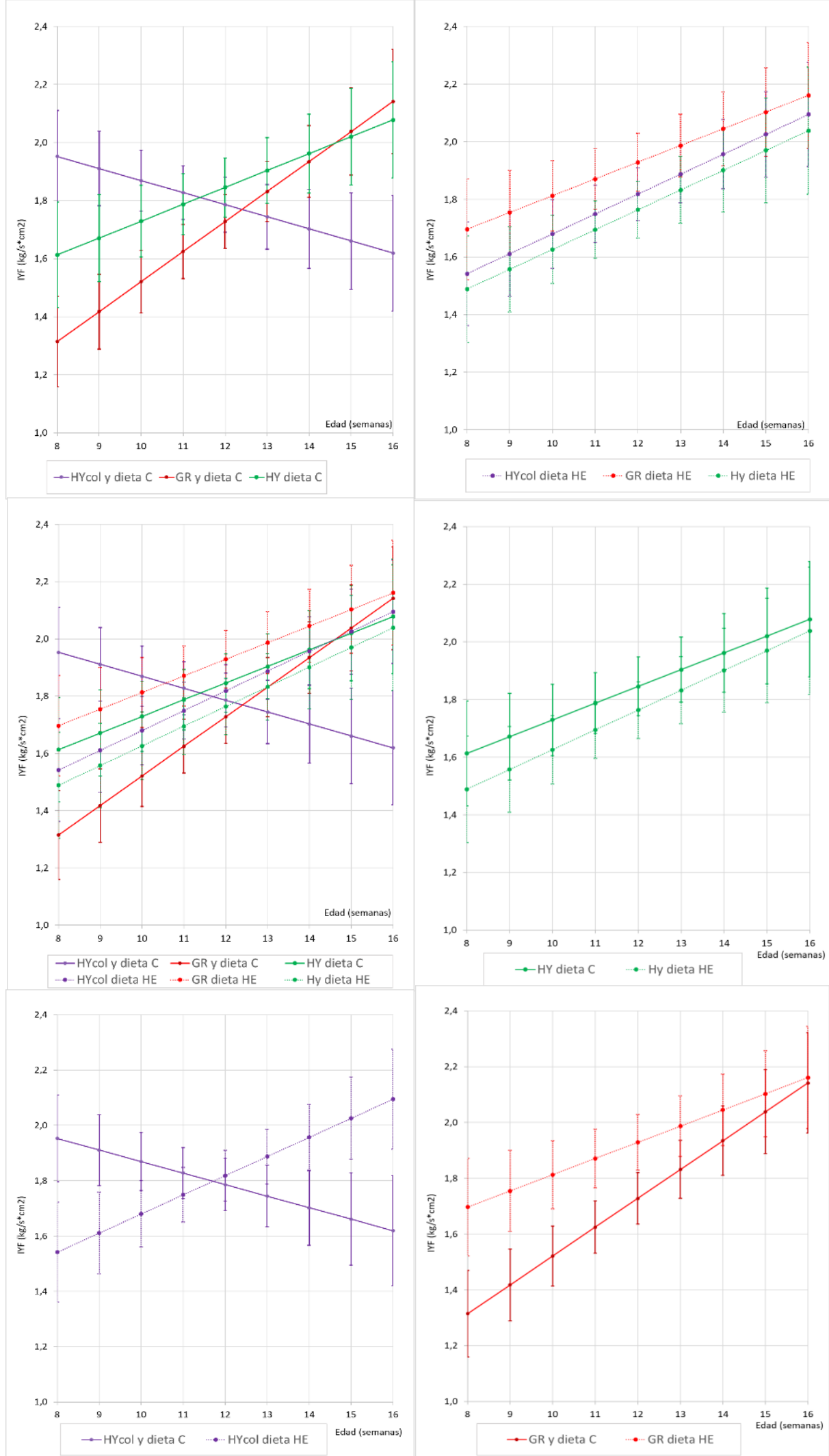

Figura 61. Evolución de rendimiento de fuerza inicial (IYF) con la edad (semanas) para las diferentes líneas genéticas (HYcol: Hyla-colored, GR: Grimaud ps 119 e HY: Hyla Grand Parental Doe) y las diferentes dietas (C: control y HE: altamente energética). (Medias mínimo cuadráticas e intervalos de confianza). 
De acuerdo con Mфller (1980) la fuerza máxima de corte está relacionada con la resistencia del tejido conectivo y la fuerza de rendimiento está relacionada con la resistencia miofibrilar en carne de vacuno. En estudios relacionados con carne de conejo la mayoría de los autores (Pla, Guerrero, Guardia, Oliver y Blasco, 1998) obtuvieron valores similares tanto para la fuerza máxima de corte (MSF) como para el rendimiento de fuerza inicial (IYF). También, y con valores muy similares, Ramírez et al. (2004) obtuvieron MSF 3,88 y $3,99 \mathrm{~kg} / \mathrm{cm}^{2} \pm 0,15$ e IYF entre 1,34 y $1,69 \mathrm{~kg} / \mathrm{cm}^{2} \pm 0,07$ para animales de un grupo control y de un grupo seleccionado por tasa de crecimiento a las 9 semanas. Aunque sólo encontraron diferencias significativas en IYF, indicando que la carne del grupo selección presentó más resistencia al corte $\left(1,69 \mathrm{~kg} / \mathrm{cm}^{2} \pm 0,07\right)$ que la carne del grupo control $\left(1,34 \mathrm{~kg} / \mathrm{cm}^{2} \pm 0,07\right)$. Mientras que Pla et al. (1998) en el estudio de dos líneas seleccionadas por tamaño de camada al destete ( $\mathrm{y}$ V) frente a una línea seleccionada por ganancia media diaria desde el destete (R) a las 4 semanas hasta las 9 semanas por una misma dieta (16 \% proteína cruda, 15,5 \% fibra bruta y 3,4 \% de grasa) obtuvieron valores de MSF superiores a los nuestros y encontraron diferencias significativas entre $A\left(4,75 \mathrm{~kg} / \mathrm{cm}^{2} \pm 0,13\right)$ y $R\left(5,25 \mathrm{~kg} / \mathrm{cm}^{2} \pm 0,13\right)$. En el caso de IYF encontraron diferencias significativas entre $A\left(4,71 \mathrm{~kg} / \mathrm{cm}^{2} \pm 0,13\right)$ respecto a $V\left(5,10 \mathrm{~kg} / \mathrm{cm}^{2} \pm 0,13\right)$ y $R\left(5,20 \mathrm{~kg} / \mathrm{cm}^{2} \pm 0,13\right)$. Lo que indica que la línea $A$ es más tierna en relación con las otras líneas, siendo la línea $\mathrm{V}$ una carne de terneza intermedia. Las diferencias en los parámetros de terneza según Pla et al. (1998) pueden venir dadas por una combinación del efecto de la grasa intramuscular y de la proteína. Y también opinan que las diferencias en estos parámetros vienen dadas por el origen genético más que por la madurez del animal.

En un experimento llevado a cabo en la terneza de la pechuga de aves de diferentes edades, Schreurs et al. (1995) encontraron que las diferentes líneas de gallinas tenían diferentes capacidades proteolíticas, siendo las líneas de crecimiento más rápido las que menor degradación de proteína miofibrilar tenían, esto explica los valores bajos de IYF. 


\subsection{COMPOSICIÓN QUÍMICA}

En la composición química de la carne procedente de la pierna trasera se analizó humedad, proteína, grasa inter e intra muscular y colágeno. Con la edad, el porcentaje de humedad descendió (valores promedio globales 73,3\% semana 8 a 71,9\% semana 16; figura 62) mientras que el porcentaje de grasa inter-intramuscular aumentaba (valores promedio globales $3,3 \%$ semana 8 a $4,7 \%$ semana 16 ; figura 63 ), el porcentaje de proteína lo hacía ligeramente (valores promedio globales 22,7\% semana 8 a 23,3\% semana 16; figura 63) y el porcentaje de colágeno prácticamente permanecía constante (valores promedio globales $1,3 \%$ semana 8 a 1,4\% semana 16 ; figura 64 ).
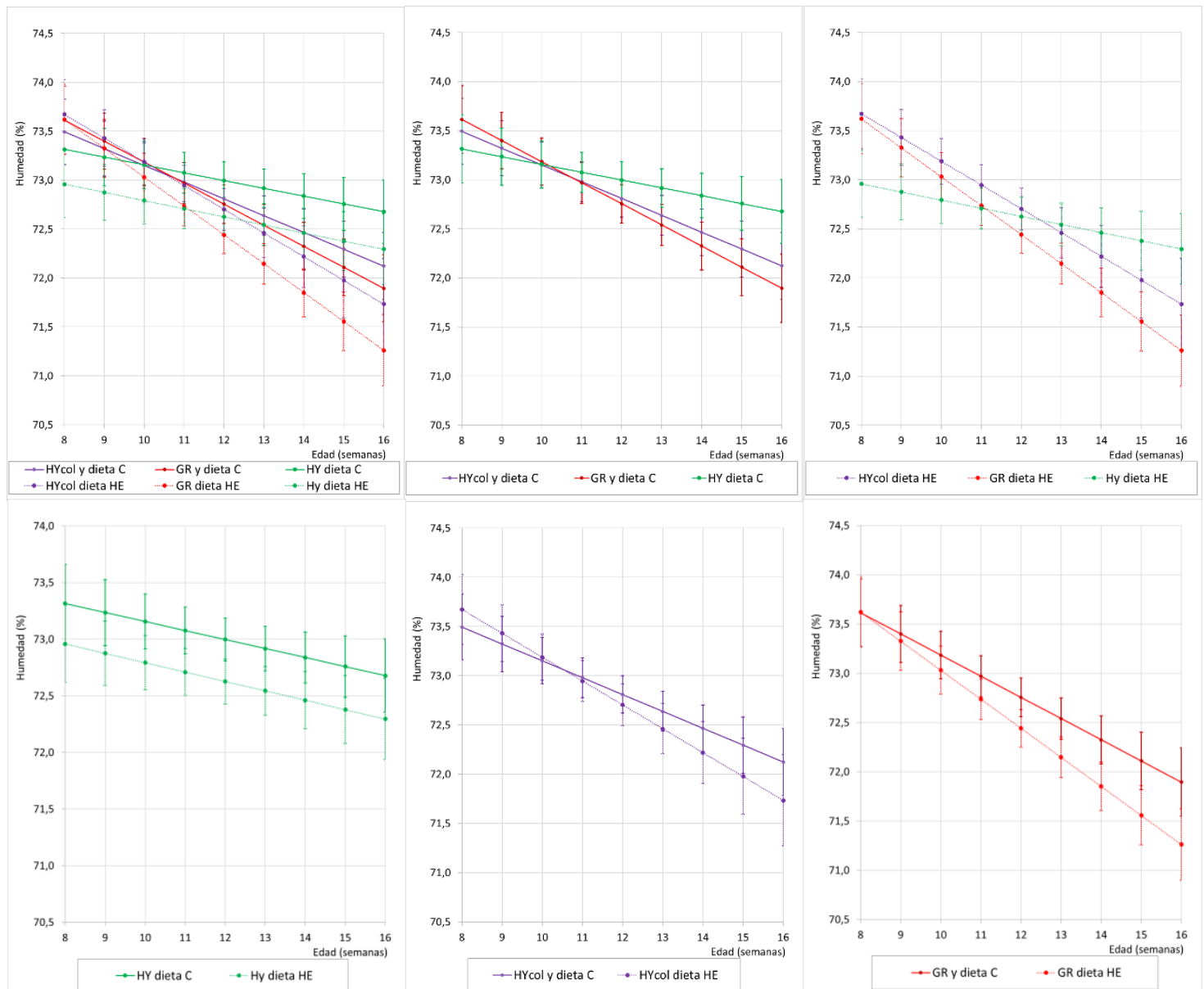

Figura 62. Evolución del porcentaje de humedad con la edad (semanas) para las diferentes líneas genéticas (HYcol: Hyla-colored, GR: Grimaud ps 119 e HY: Hyla Grand Parental Doe) y las diferentes dietas (C: control y HE: altamente energética). (Medias mínimo cuadráticas e intervalos de confianza). 

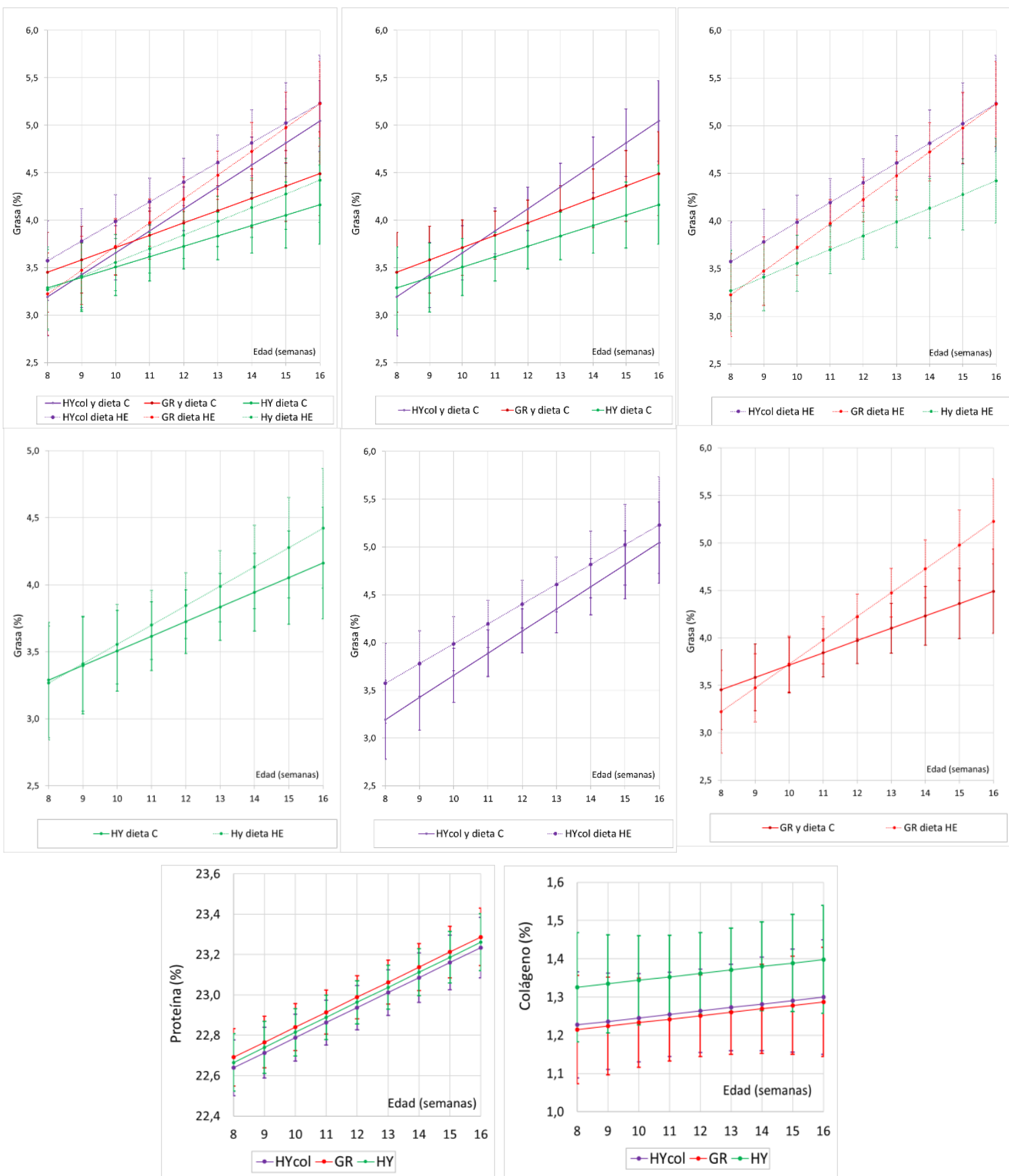

Figura 63. Evolución del porcentaje de grasa, proteína y colágeno con la edad (semanas) para las diferentes líneas genéticas (HYcol: Hyla-colored, GR: Grimaud ps 119 e HY: Hyla Grand Parental Doe) y las diferentes dietas (C: control y HE: altamente energética). (Medias mínimo cuadráticas e intervalos de confianza). 
Respecto al efecto de la línea genética solo se encontraron diferencias significativas para el porcentaje de humedad y de grasa inter-intramuscular, mientras que el porcentaje de proteína presentó valores promedio muy similares entre líneas genéticas, y en el porcentaje de colágeno aunque la línea HY parece mostrar valores promedio ligeramente superiores a HYcol y GR las diferencias fueron pequeñas $(0,1 \%)$ y no llegaron a ser significativas. Hay que considerar que en estas variables el número de datos de los que se disponía fue inferior a las variables anteriores, lo que dio lugar a mayores errores de las estimas. En cuanto a las diferencias entre líneas que se encontraron, GR tenía menor porcentaje de humedad que HY, diferencia que solo fue significativa de la semana 14 a la $16(0,5-0,8 \%)$, mientras que HYcol se situaba en posición intermedia. En la grasa inter-intramuscular en la dieta C HYcol presentó mayor porcentaje que HY de la semana 14 a la $16(0,6-0,9 \%)$, mientras que en la dieta HE se mostró una tendencia a ser mayor el porcentaje de grasa en HYcol y GR que en HY pero la diferencia no llegó a ser significativa.
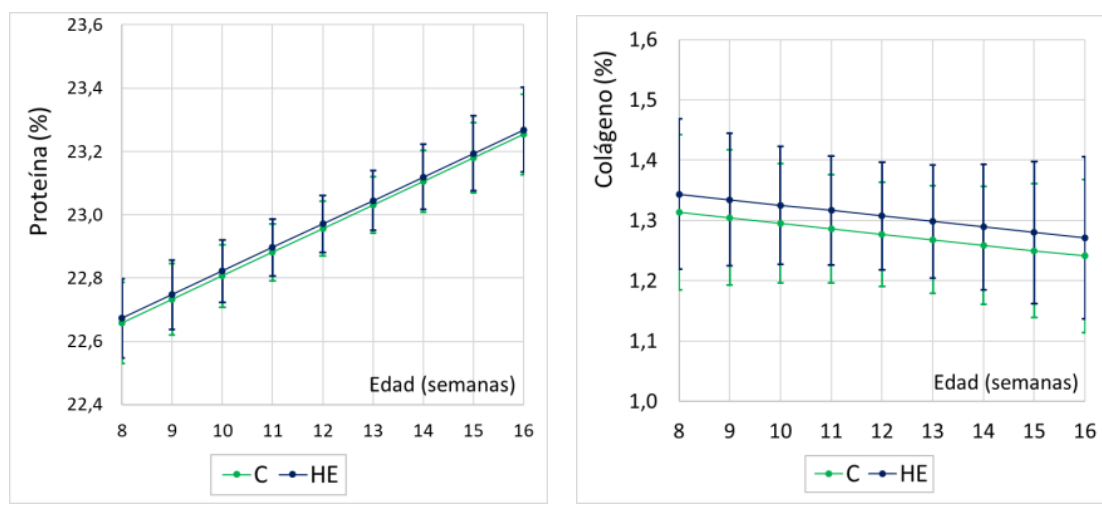

Figura 64. Evolución del porcentaje de proteína y colágeno con la edad (semanas) para las diferentes dietas (C: control y HE: altamente energética). (Medias mínimo cuadráticas e intervalos de confianza).

Pascual et al. (2007) que evaluaron el efecto en parámetros de calidad carne según la selección por tasa de crecimiento y el descenso asociado al aumento de madurez en el sacrificio, obtuvieron para conejos con $2 \mathrm{~kg}$ PVS valores de 74,6 \% 0,8 de humedad, $20,7 \% \pm 0,4$ de proteína y 3,7 \% $\pm 0,7$ de grasa, sin encontrar diferencias significativas en el contenido de grasa y humedad. Aunque observaron que una reducción en el grado de madurez (ya que sacrificaron animales con 2000 gramos \pm 200 ) pudo hacer 
variar estos porcentajes mientras que el contenido de proteína parece mantener constante.

En cuanto al efecto de la dieta, no se encontraron diferencias significativas para ninguna de las variables de composición química, aunque exista una tendencia a aumentar el porcentaje de grasa y disminuir es de humedad con la dieta HE, sobre todo en HY para la humedad y grasa, y en GR para la grasa.

Pascual et al. (2014) en su estudio que comparaban dos dietas con diferente nivel de energía en conejos de 12 semanas procedentes de líneas seleccionadas por velocidad de crecimiento, obtuvieron menor porcentaje de humedad $(72,9 \% \pm 0,2$ vs. $73,7 \% \pm$ $0,2)$ y mayor porcentaje de grasa $(4,71 \% \pm 0,14$ vs $9,81 \% \pm 0,15)$ de la carne de la pata trasera con el pienso más energético, mientras que no obtuvieron diferencias en el porcentaje de proteína $(21,1 \% \pm 0,1$ vs $21,2 \% \pm 0,1)$.

Dalle Zotte al. (2015) no encontraron diferencias significativas en contenido de agua y grasa entre Large (seleccionada por ganancia media diaria) y Hung (procedente de una raza tradicional llamada gigante húngaro) seleccionada para mejorar caracteres de crecimiento con valores a las 12 semanas de edad de agua 73,7 \% $\pm 0,06$ en Large y $73,8 \% \pm 0,06$ en Hung y de grasa $2,45 \%$ y $2,41 \% \pm 0,08$ en Large y Hung respectivamente. Mientras que sí encontraron diferencias en los valores de proteína (Large - 21,9\% \pm 0,03; Hung $-21,8 \% \pm 0,03$ ).
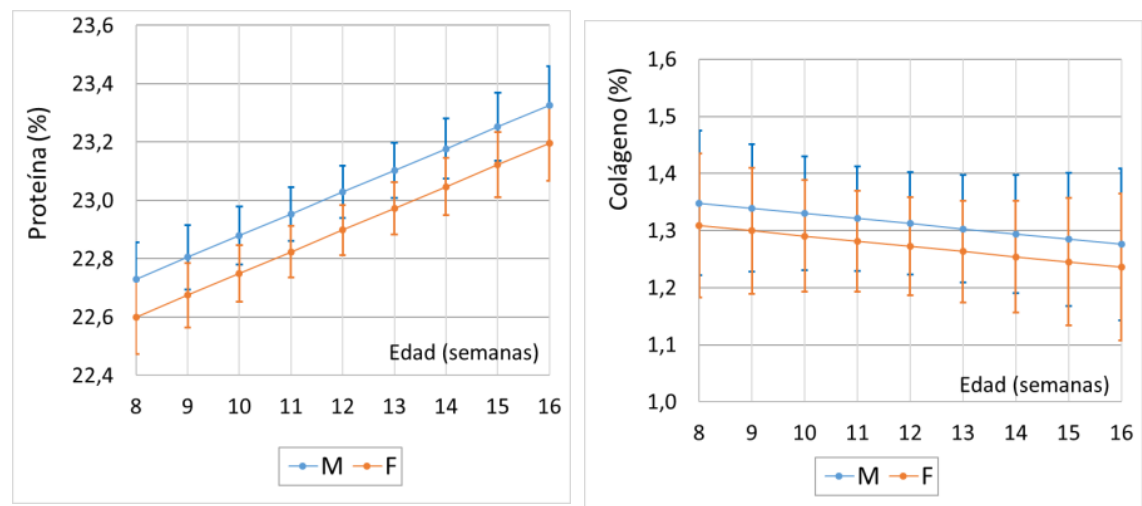

Figura 65. Evolución del porcentaje de proteína y colágeno con la edad (semanas) según el género (M: machos y F: hembras). (Medias mínimo cuadráticas e intervalos de confianza). 
Cardinali et al. (2015) que estudiaron la suplementación de orégano (O), romero (OR) y vitamina $E(E)$ en las dietas comunes para ver su efecto en caracteres de canal y carne en animales con 80 días de edad, vieron que el contenido de humedad tuvo diferencias significativas entre la dieta $\mathrm{E}$ respecto a $\mathrm{O}$ y OR. Fue superior para las dietas $\mathrm{O}$ (dieta estándar $+0,2 \%$ de orégano) y OR (dieta estándar $+0,2 \%$ de romero) comparadas con E (dieta estándar + 150 ppm de vitamina E). Ya que la vitamina $\mathrm{E}$ y el romero parecen promover el desarrollo de tejido muscular en detrimento de la cantidad de agua del mismo, de modo que los valores obtenidos de porcentaje de agua fueron: $0-74,8 \% \pm$ 0,89; OR $-74,7 \% \pm 0,89$ y $E-73,2 \% \pm 0,89$. Por otro lado, sus valores de proteína a los 80 días fueron desde $23,5 \% \pm 0,83$ en la dieta con orégano suplementado hasta $25,0 \%$ $\pm 0,83$ en las dietas con suplemento de romero y de vitamina $E$, mientras que nuestros valores para ambas dietas a la semana 12 fueron algo inferiores (C: 22,96 \% $\pm 0,09$; HE: $22,87 \% \pm 0,09)$. En cambio nuestros valores de grasa fueron bastante superiores (desde 3,97 a $4,12 \% 0,23$ ) a los suyos que fueron desde $0,40 \%$ a $0,50 \% \pm 0,14$ con las dietas con suplementos de vitamina $\mathrm{E}$ y de orégano respectivamente. Esta diferencia viene dada porque el contenido de grasa de sus dietas va desde $81,2 \mathrm{~g} / \mathrm{kg}$ en la dieta menos grasa (suplemento de orégano) a $84,6 \mathrm{~g} / \mathrm{kg}$ en la dieta más grasa (suplemento de vit E); mientras que nuestras dietas tienen $2,5 \%$ (C) y $3 \%$ (HE) sobre 2100 y 2400 $\mathrm{kcal} / \mathrm{kg} \mathrm{ED}$, lo que corresponde a 42 y $60 \mathrm{~g} / \mathrm{kg}$ de contenido en grasa en $\mathrm{C}$ y $\mathrm{HE}$ respectivamente.

Pla et al. (1998) que estudiaron el contenido en proteína, grasa y humedad en la carne de la pata trasera en dos líneas seleccionadas por tamaño de camada al destete ( $\mathrm{A}$ y V) y otra línea seleccionada por ganancia media diaria (R) con 9 semanas de edad encontraron que $\mathrm{A}$ y $\mathrm{V}$ fueron diferentes a $\mathrm{R}$ en el contenido de grasa, proteína $\mathrm{y}$ humedad. Los valores de humedad fueron A: 74,01; V: 73,97 y R: 74,59\% $\pm 0,09$, los de proteína fueron A: 20,$75 ; \mathrm{V}: 20,80$ y $R: 20,59 \% \pm 0,04$; y los de grasa fueron $A: 3,25 ; \mathrm{V}$ : 3,45 y $R: 2,91 \% \pm 0,08$. Mostrando que la línea mejorada por ganancia media diaria $(R)$ tuvo mayor contenido de humedad y menor contenido de grasa que las líneas seleccionas por tamaño de camada al destete. Comparado con nuestros resultados a las 9 semanas no hubo diferencias significativas en el contenido de grasa, proteína y humedad. 


\subsection{PERFIL DE ÁCIDOS GRASOS}

Los principales ácidos grasos (a partir de ahora FA = fatty acid) encontrados en la carne de conejo fueron el palmítico (C16:0) con valores promedio para la dieta control de 27,7 \%, el oleico (C18:1) de 24-25,6\%, el linoleico (C18:2) de 20,4-24\% y el esteárico (C18:0) de 8,1-8,5\%, con un total de ácidos grasos saturados (SFA) que ascendía a 42,7 $\%$ y de insaturados (UFA) a 55\% (tablas 11 y 12). En cambio, Lazzaroni et al. (2009) en su estudio de ácidos grasos en Carmagnola gris a las 16 semanas para dos sistemas de cría (0,12 vs 0,25 m²/animal) alimentados por una misma dieta (91,7\% MS, $12,2 \%$ fresno, 20,9 \% proteína cruda, 3,2 \% extracto de éter, 32,2 \% fibra neutro detergente y 21 \% de fibra ácido detergente sobre MS) y según el género obtuvieron los valores más altos en C:16; C18:0 y C18:1. Otros autores (Lazzaroni et al, 2009; Carrilho et al. 2009, Dalle Zotte et al. 2002, 2015) también obtuvieron estos porcentajes mayoritarios en el perfil de ácidos grasos de la carne de conejo. En el caso de Lazzaroni et al. (2009) sus valores de ácido palmítico (C16:0) y de ácido oleico (C18:1) fueron más elevados que los nuestros a las 12 semanas tanto para machos (C16:0 - 34,76\% $\pm 3,52 ;$ C18:1 - 27,73 $\% \pm 2,59)$ como para hembras (C16:0 - 34,44 \% $\pm 2,03$; C18:1 - 27,86 \% $\pm 2,43$ ). En cambio nuestros valores de ácido esteárico (C18:0) fueron mayores a las 12 semanas (tabla 12) que los obtenidos por Lazarroni et al. (2009) (machos: 5,72 \% $\pm 1,13$; hembras: $6,00 \% \pm 0,78$ ). Aunque estos porcentajes sean diferentes la suma de SFA para Lazarroni et al. (2009) es muy próxima a nuestros resultados (machos: 45,18 \% \pm 3,10; hembras: $42,42 \% \pm 2,02$ ). Por otro lado, Dalle Zotte et al. (2015) en su estudio entre una línea seleccionada por ganancia media diaria (Large) frente a una línea Hung (procedente de una raza tradicional llamada gigante húngaro) con dos dietas (una dieta control frente a una con suplementación de heno) con 12 semanas obtuvieron valores muy próximos a los nuestros en el oleico (Large: $27,8 \%$; Hung: $27,1 \% \pm 0,21$ ), aunque tuvieron menor porcentaje de palmítico (Large: $23,9 \%$; Hung: $24,0 \% \pm 0,21$ ) y esteárico (Large: 7,47 \%; Hung: 7,68 \% $\pm 0,10$ ) y mayores de linoleico (Large: $22,3 \%$; Hung: $22,6 \% \pm 0,26)$.

Si bien, se observó que con la dieta HE el palmítico aumentaba al $29 \%$ y el linoleico disminuía al $17,8 \%$ en la semana 12 , y el global de SFA aumentaba al $45 \%$ mientras que los UFA disminuían a 52,8\%. Esta evolución en el perfil de FA a lo largo de 
las semanas estudiadas está de acuerdo con el perfil de FA de la dieta, ya que la dieta HE tenía un mayor porcentaje de palmítico $(21,7$ vs $28,2 \%)$ y menor de linoleico $(31,9$ vs $42,0 \%)$ que la dieta $\mathrm{C}$. En la dieta $\mathrm{HE}$, su mayor porcentaje de palmítico y menor de linoleico deriva fundamentalmente de su mayor contenido de aceite de palma y menor de cascarilla de soja respectivamente.

Los FA de cadena corta fueron poco abundantes. El ácido cáprico (C10:0) con valores de $0,8 \%$ y el ácido laurico (C12:0) de 0,85\%, los que disminuyeron desde la semana 8 , más próxima al destete, a la semana 12 a valores de $0,3 \%$ y $0,4 \%$ respectivamente. Según Carrilho et al. (2009) las cadenas cortas de FA están asociadas con la leche ingerida antes del destete, mostrando altos niveles de estos FA ya que son característicos de la leche (Maertens et al., 2006).

En cuanto al efecto de la línea genética, no se encontraron diferencias significativas en el contenido en grasa inter-intramuscular ni en la semana 8 ni en la 12 , como ya se observó en el apartado de composición química (3.4.). Sin embargo, sí que se detectaron diferencias entre líneas en el perfil de FA. En la semana 8 se encontró que GR mostraba el mayor porcentaje de palmítico, esteárico y palmitoleico y el menor de linoleico, aunque no llegó a ser la diferente a la línea HY para el palmitoleico. Además, la línea HY mostró mayor porcentaje de esteárico y menor porcentaje de palmítico que la línea HYcol. Las diferencias en cualquier caso fueron pequeñas, con valores que oscilaron entre el 3\% para el linoleico, el 2\% para el palmítico, 1\% para el palmitoleico y $0,6 \%$ para el esteárico. En la semana 12 , los resultados fueron similares, aunque en el esteárico las líneas HY e HYcol no fueron diferentes, en el palmitoleico no hubo diferencias entre líneas, y en el linoleico HYcol presentó igual valor que GR, siendo HY la que mostró el mayor porcentaje. Estas pequeñas diferencias entre líneas genéticas entre la semana 8 y semana 12 , pueden ser debidas al efecto que la dieta pueda tener sobre cada línea genética, ya que para cada línea genética la mitad de los animales eran alimentados con la dieta $\mathrm{C}$ y la otra mitad con la dieta $\mathrm{HE}$, si bien la interacción entre línea genética y dieta no apareció significativa, lo que puede ser debido al menor tamaño muestral para la determinación de FA.

Un FA en el que se encontraron diferencias significativas en la semana 8, aunque su porcentaje era minoritario, pero que destaca su importancia por sus beneficios en el 
sistema circulatorio, fue el docosahexanoico o DHA (C22:6). Para este FA, la línea HY mostró el mayor porcentaje, pero esta diferencia fue pequeña $(0,05-0,07 \%)$ y desapareció en la semana 12.

De modo global, también se observó que la línea GR presentaba mayor porcentaje de SFA $(4,7 \%)$ y menos de UFA $(3,5 \%)$ que la línea HY, mostrando la línea HYcol valores intermedios, salvo en la semana 12 en la que HYcol y GR presentaron igual porcentaje de UFA. En la semana 12 la diferencia entre líneas para el porcentaje de UFA se incrementó, tomando valores de 4,4 \% entre GR e HY, y de 5,7\% entre HYcol e HY.

Lazzaroni et al. (2009) encontraron diferencias significativas para el linoleico para dos sistemas de cría con diferentes densidades (0,12 vs 0,25 $\mathrm{m}^{2} /$ animal) en conejos de la raza Carmagnola con 16 semanas de edad. Así, consideraron el efecto positivo en los PUFA como consecuencia de la concentración de ácido linoleico (C18:2n6) en la reducción de los trastornos cardiovasculares y el colesterol a mayor cantidad de espacio por jaula $(P<0,001)$. El sumatorio de ácidos insaturados muestra que a la semana $12, \operatorname{HY}(56,734 \% \pm 0,854)$ tiene mayores niveles que $\mathrm{HYcol}(51,077 \% \pm 0,980)$ y GR $(52,368 \% \pm 0,789)$. Carrilho et al. (2009) que estudiaron el efecto en animales Hyla de tres dietas con diferentes niveles de fibra (dietas A, B y C: 14,28; 18,04 y 20,48 \%) y por tanto de energía (dietas A, B y C: 2227; 2169 y 1917 kcal/kg MS de ED) desde el destete hasta que alcanzaban los pesos de 1,6; 2 y 2,3 $\mathrm{kg}$ y obtuvieron resultados promedio de insaturados $(55,80 \% \pm 1,23)$ similares a los nuestros, encontrando diferencias significativas en la dieta A y B para los diferentes pesos ( $A-1,6 \mathrm{~kg}$ : 58,65 \%

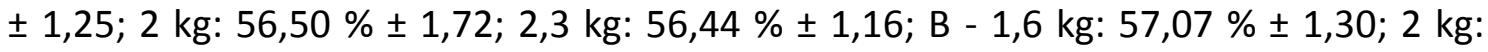
$54,87 \% \pm 1,25 ; 2,3 \mathrm{~kg}: 55,22 \% \pm 1,89)$.

Ramírez et al. (2005) estudiaron el efecto de la selección por crecimiento durante 14 generaciones sobre la composición de FA de la carne de la pata para conejos de 9 semanas de edad (dieta de $16 \%$ de proteína bruta, $15,5 \%$ de fibra y 3,4\% de grasa) y encontraron diferencias en el porcentaje de ácido palmítico (C16:0) y ácido palmitoleico (C16:1n7), presentando valores más altos en la línea seleccionada por crecimiento al igual que en nuestros resultados. El ácido palmítico (C16:0) en nuestro trabajo tuvo valores superiores (HYcol: 28,02 \% \pm 0,05; GR: 28,67 \% \pm 0,05; HY: 26,56 \% $\pm 0,06$ ) a Ramírez et al. (2005) (control: $25,38 \% \pm 0,24$; selección: $26,50 \% \pm 0,25$ ) lo 
que probablemente es debido a diferencias en la dieta en ambos trabajos, en la dieta de Ramírez et al. (2005) el porcentaje de ácido palmítico fue 17,7\%, mientras que en trabajo nuestro trabajo fue $21,7 \% 28,2 \%$ en las dietas C y HE respectivamente. Los valores de ácido palmitoleico a las 8 semanas para las tres líneas genéticas (HYcol: 1,78 $\% \pm 0,05$; GR: $2,75 \% \pm 0,07$ e HY: $1,99 \% \pm 0,08$ ) fueron muy similares a los observados por Ramírez et al. (2005) resultados (control: 2,08 \% \pm 0,12; selección: 2,79 \% $\pm 0,13$ ). Sin embargo, en el porcentaje de ácido esteárico Ramírez et al. (2005) no encontraron diferencias significativas entre la línea seleccionada $(6,91 \% \pm 0,14)$ y la línea control $(7,19 \% \pm 0,13)$ mientras que en nuestro ensayo las tres líneas genéticas fueron

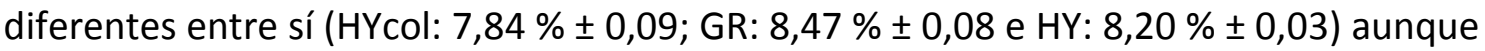
para este ácido no se observa un efecto de la selección por crecimiento ya que la línea de aptitud maternal se sitúa en posición intermedia.

Un método para medir la calidad nutricional de la carne es según el ratio de la suma de PUFA:SFA (P:S) que debe ser 0,45 o mayor (Lazzaroni et al., 2009); en nuestro caso tanto a las 8 como a las 12 semanas el ratio PUFA/SFA es mayor a 0,45 (tablas 11 y 12 ). Lazzaroni et al. 2009 también obtuvieron este ratio (machos: 0,49 \pm 0,14; hembras: $0,44 \pm 0,05$ ) Otro método para evaluar la calidad de la carne es según el ratio omega 6/omega 3; que según Gasperlin et al. (2009) debe ser menor de 4. Este ratio y el ratio $\mathrm{P}: \mathrm{S}$ es muy alto en carne de conejo, debido al alto contenido en ácido linoleico (C18:2n6). Ramírez et al. (2005) encontraron que el efecto de la selección por velocidad de crecimiento durante 14 generaciones afectó al ratio P:S, con un descenso de un $1 \%$ por cada generación, y mejoraba el ratio omega 6: omega 3 . Además sus valores en la línea seleccionada de la raza California con 9 semanas $(10,67 \pm 0,72)$ coinciden con nuestro valor de ratio omega 6/omega para Hyla a las 12 semanas $(11,344 \% \pm 3,29)$. Hernández et al. (2008) que estudiaron tres líneas genéticas, $R$ seleccionada por velocidad de crecimiento y $\mathrm{V}$ y $\mathrm{A}$ seleccionadas por tamaño de camada al destete alimentadas por una misma dieta (16 \% proteína bruta, 15, \% fibra bruta y $3,4 \%$ de grasa) en el contenido del ácidos grasos de la carne de la pata de conejo de 9 semanas de edad no encontraron diferencias significativas entre líneas para el C18:1. Además una de las líneas seleccionadas por tamaño de camada al destete $(A)$ tuvo menor cantidad de C:16 que $V$ (seleccionada también por tamaño de 
camada al destete) y la línea seleccionada por velocidad de crecimiento $(R)(P<0,01)$, pero $A$ tuvo más cantidad de $C 18: 2$ que $V$ y $R(P<0,01)$. También la línea $R$ tuvo menor C:18 que $V(P<0,05)$. Explican que estos cambios en la composición de ácidos grasos tanto en la carne como en la grasa de conejo pueden estar afectados por la selección por la tasa de crecimiento.

El porcentaje de ácidos omega 6, en nuestro caso, al igual que Carrilho et al. (2009) fue paralelo al porcentaje de PUFA y sus valores fueron más elevados a las 8 semanas que a las 12 semanas; probablemente porque la composición de la dieta de las madres de la lactancia es rica en cereales que son ricos en omega 6. Coincidiendo con Carrilho et al (2009) los animales más próximos al destete tuvieron menor contenido en omega 3 y su aumento posterior con la edad es muy leve, ya que después del destete la incorporación de pienso a la dieta incrementa el contenido de ácido $\alpha$-linolénico (C18:3n3); consecuentemente disminuye el ratio omega 6 - omega 3. Excepto a las 12 semanas que la línea Grimaud tuvo mayor ratio omega 6- omega 3 que a las 8 semanas.

Respecto al efecto de la dieta en el ratio n6/n3 tanto en la semana 8 (tabla 11) como en la semana 12 (tabla 12), no encontramos diferencias significativas al ingerir una dieta u otra. Según el Departamento de Salud y Seguridad Social en Reino Unido (1994) recomienda un máximo valor de 4 en el ratio omega 6 - omega 3; ya que el ácido linoleico (C18:2n6) y $\alpha$ - linolénico (C18:3n3), precursores de los ácidos omega 6 y omega 3 respectivamente, compiten del mismo modo por las enzimas responsables del metabolismo de elongación de cadenas de PUFA (Combes, 2004).

El ratio omega 6/omega 3 desciende considerablemente conforme avanza el estado de madurez. Y no hay efecto de la línea genética, la dieta o la edad en el porcentaje de ácido oleico (C18:1n9) que conlleva niveles bajos de colesterol e incidencia reducida de las enfermedades cardiovasculares.

En cuanto al efecto de la dieta, en el perfil de FA de la carne de conejos a las 8 semanas de edad prácticamente no hubo diferencias, lo que es razonable ya que el cambio de dieta se realizó en la semana 7 de edad y solo llevaban una semana con la dieta C o HE. Así, en la semana 8 solo se encontraron pequeñas diferencias en el ácido araquídico (C20:0) y en el gadoleico (C20:1). En la semana 12 , se encontró que la dieta 
HE daba lugar a un incremento (1,2\%) del palmítico y del palmitoleico, y se observó una tendencia a disminuir (2,6\%) el linoleico, pero esta diferencia no llegó a ser significativa. En cambio, Carrilho et al. (2009) observaron que la dieta con mayor cantidad mayor cantidad de porcentaje de PUFA en la composición de su dieta (A: 34,60 \% - B: $28,64 \%$ ) tuvo mayor porcentaje de PUFA en la carne (dieta A: 33,65\% \pm 2,74 - dieta B: 29,76 \% \pm 3,15); ya que el perfil de ácidos grasos de la grasa intramuscular estuvo relacionado con la composición del porcentaje de PUFA de la dieta. Además Cobos et al., 1995 encontraron que los diferentes niveles de fibra modifican ligeramente el porcentaje de ácidos grasos en conejos entre $2-2,5 \mathrm{~kg}$. De acuerdo con Carrilho et al. (2009) a menor contenido en fibra y más niveles de energía en la dieta se desarrolla más cantidad de ácido mirístico (C14:0), ácido palmítico (C16:0) y ácido esteárico (C18:0). Aunque en nuestro estudio no hubo efecto de la dieta en PUFA y MUFA para dos dietas con niveles diferentes de fibra (C: $25 \%$; HE: $17 \%)$.

Estos ácidos grasos saturados según la FAO (2012) afectan de manera diferente a las concentraciones de colesterol; C14:0 y C16:0 incrementan el colesterol de las LDL, mientras que C18:0 no tiene este efecto.

Nuestros valores de grasa inter-intramuscular fueron superiores ya desde la semana 8 a los obtenidos por Carrilho et al. (2009), que obtuvieron un máximo de 1,27 \% $\pm 0,23$ para conejos con $2,3 \mathrm{~kg}$ de peso vivo alimentados por una dieta con 4,55\% de grasa bruta sobre MS, frente a 1,19 \% $\pm 0,24$ de animales alimentados con una dieta de 4,10 \% de grasa bruta sobre MS. Su estudio fue al contrario que nuestros resultados, ya que obtuvieron mayor grasa intramuscular en conejos recién destetados con 1,6 kg (P $<0,001)$. Según Carrilho et al (2009) el estrés del destete pudo provocar un aumento en el consumo del pienso lo que provocó mayor porcentaje de grasa intramuscular.

La alometría negativa del desarrollo de la grasa intramuscular $(0,493 \pm 0,128)$ en relación con el desarrollo de la canal de referencia se ha mostrado en la primera fase de vida de razas como (New Zealand, California) (Carrilho et al. 2009) pero no en líneas HYcol, Grimaud o Hyla. Gondret et al (1998) que estudiaron la relación de la edad del conejo $(2,4,5,6,9,11,14,17$ y 20 semanas de edad) con el contenido en grasa intramuscular encontraron una reducción del porcentaje de grasa intramuscular desde 
la semana 5 a la semana 14, incrementando rápidamente en semanas posteriores. Según estos autores aunque la selección por tasa de crecimiento no está clara que produzca mayores cantidades de grasa a mayor peso comercial del animal, sí que cuando partimos de una misma edad y comparamos líneas mejoradas por velocidad de crecimiento con líneas de aptitud maternal, las líneas de aptitud maternal suelen ser menos pesadas a igualdad de edad, por lo que el contenido en grasa intramuscular sería menor. En nuestro caso a las 12 semanas (tabla 12) Hyla sí tuvo menor porcentaje de grasa intramuscular teniendo menor peso vivo al sacrificio (2909 g \pm 29 ) que Grimaud (3006 g \pm 24 ) e HYcol (2987 $\mathrm{g} \pm 20$ ), pero a las 8 semanas aunque no hubo diferencias significativas entre líneas genéticas Hyla tuvo mayor porcentaje que las dos líneas mejoradas por velocidad de crecimiento siendo su peso vivo al sacrificio el mayor de las tres líneas a las 8 semanas (Hyla: $1848 \mathrm{~g} \pm 12,32$ - Hyla-colored: $1844 \mathrm{~g} \pm$ 10,41 y Grimaud: $1823 \mathrm{~g} \pm 10,91)$.

El efecto de la línea genética se ve más pronunciado a mayor edad del conejo tanto en SFA, MUFA como PUFA. Respecto a los ácidos de mayor interés nutricional, el mayor contenido de ácido palmítico (C16:0) (que incrementa los niveles de colesterol total y LDL) lo obtuvimos a las 12 semanas con la dieta menos fibrosa (HE). 
Tabla 11. Contenido de grasa intramuscular (\%) y perfil de ácidos grasos (\%) de la carne de la pata trasera según línea genética y la dieta a las 8 semanas de edad. (Media mínimo cuadrática \pm error estándar).

\begin{tabular}{|c|c|c|c|c|c|c|c|c|c|c|}
\hline & \multicolumn{6}{|c|}{ LÍNEA GENÉTICA } & \multicolumn{4}{|c|}{ DIETA } \\
\hline & \multicolumn{2}{|c|}{ HYcol } & \multicolumn{2}{|c|}{ GR } & \multicolumn{2}{|c|}{ HY } & \multicolumn{2}{|c|}{ C } & \multicolumn{2}{|c|}{ HE } \\
\hline & MMC & SE & MMC & SE & MMC & SE & MMC & SE & MMC & ES \\
\hline $\begin{array}{l}\text { grasa } \\
\text { intramuscular }\end{array}$ & 3,30 & 0,84 & 3,17 & 0,85 & 3,42 & 0,84 & 3,24 & 0,83 & 3,35 & 0,85 \\
\hline C10:0 & 0,82 & 0,02 & 0,83 & 0,02 & 0,69 & 0,03 & 0,80 & 0,02 & 0,77 & 0,02 \\
\hline C12:0 & 0,87 & 0,03 & 0,84 & 0,04 & 0,82 & 0,05 & 0,85 & 0,06 & 0,84 & 0,05 \\
\hline C14:0 & 2,66 & 0,35 & 3,20 & 0,42 & 2,70 & 0,22 & 2,84 & 0,24 & 2,87 & 0,35 \\
\hline C15:0 & 0,73 & 0,01 & 0,84 & 0,06 & 0,79 & 0,09 & 0,80 & 0,06 & 0,77 & 0,06 \\
\hline C16:0 & $28,02^{\mathrm{a}}$ & 0,05 & $28,67^{b}$ & 0,05 & $26,56^{c}$ & 0,06 & 27,69 & 0,05 & 27,80 & 0,33 \\
\hline C17:0 & 0,73 & 0,05 & 0,83 & 0,06 & 0,76 & 0,05 & 0,77 & 0,04 & 0,77 & 0,04 \\
\hline C18:0 & $7,84^{a}$ & 0,09 & $8,47^{b}$ & 0,08 & $8,20^{c}$ & 0,03 & 8,07 & 0,41 & 8,28 & 0,06 \\
\hline C20:0 & $0,06^{a}$ & 0,00 & $0,10^{b}$ & 0,01 & $0,10^{b}$ & 0,01 & $0,91^{y}$ & 0,02 & $0,08^{2}$ & 0,02 \\
\hline C16:1n7 & $1,78^{a}$ & 0,05 & $2,75^{b}$ & 0,07 & $1,99^{\mathrm{ab}}$ & 0,08 & 2,26 & 0,57 & 2,09 & 0,79 \\
\hline C18:1n9 & 24,24 & 1,20 & 23,39 & 0,98 & 24,36 & 0,77 & 23,86 & 0,35 & 24,13 & 0,25 \\
\hline C20:1n9 & $0,14^{a}$ & 0,02 & $0,26^{b}$ & 0,01 & $0,24^{b}$ & 0,02 & $0,19^{y}$ & 0,01 & $0,24^{2}$ & 0,01 \\
\hline C22:1n9 & $0,04^{a}$ & 0,00 & $0,09^{b}$ & 0,02 & $0,09^{b}$ & 0,01 & 0,07 & 0,01 & 0,08 & 0,01 \\
\hline C24:1n9 & $0,00^{a}$ & 0,00 & $0,00^{a}$ & 0,00 & $0,01^{b}$ & 0,00 & 0,01 & 0,00 & 0,00 & 0,00 \\
\hline C18:2n6 & $24,68^{a}$ & 0,32 & $21,88^{b}$ & 0,87 & $25,07^{a}$ & 0,45 & 24,08 & 0,95 & 23,67 & 0,89 \\
\hline C18:3n3 & 1,64 & 0,98 & 1,67 & 0,87 & 1,63 & 0,88 & 1,75 & 0,68 & 1,55 & 0,54 \\
\hline$C 20: 3 n 6$ & 0,08 & 0,03 & 0,22 & 0,05 & 0,22 & 0,05 & 0,19 & 0,01 & 0,16 & 0,03 \\
\hline$C 20: 4 n 6$ & 2,46 & 0,12 & 2,40 & 0,13 & 2,64 & 0,11 & 2,66 & 0,21 & 2,34 & 0,23 \\
\hline C22:6n3 & $0,03^{a}$ & 0,01 & $0,05^{a}$ & 0,01 & $0,10^{b}$ & 0,01 & 0,04 & 0,01 & 0,06 & 0,02 \\
\hline$\Sigma$ Saturados SFA & $42,12^{\mathrm{ab}}$ & 0,76 & $44,05^{a}$ & 0,77 & $40,74^{b}$ & 0,66 & 42,93 & 0,92 & 42,50 & 0,96 \\
\hline $\begin{array}{l}\Sigma \text { Monoinsat } \\
\text { MUFA)) }\end{array}$ & 26,46 & 2,53 & 26,81 & 1,20 & 26,89 & 0,99 & 26,60 & 1,00 & 26,81 & 1,10 \\
\hline$\Sigma$ Poliinsat PUFA & 28,89 & 1,47 & 26,26 & 1,93 & 29,67 & 1,51 & 28,74 & 1,87 & 27,79 & 1,72 \\
\hline$\Sigma$ Insaturados & $55,36^{\mathrm{ab}}$ & 0,89 & $53,07^{b}$ & 0,79 & $56,56^{a}$ & 0,85 & 55,34 & 2,88 & 54,60 & 2,82 \\
\hline$\Sigma$ Sat/Insat & 0,76 & 0,85 & 0,830 & 0,97 & 0,721 & 0,77 & 0,78 & 0,32 & 1,53 & 0,34 \\
\hline$\Sigma$ PUFA/SFA & 0,69 & 1,95 & 0,60 & 2,52 & 0,73 & 2,29 & 0,67 & 2,02 & 0,78 & 0,34 \\
\hline$\Sigma$ Omega 6 & $27,22^{a}$ & 0,65 & $24,53^{b}$ & 0,66 & $27,93^{a}$ & 0,43 & 26,94 & 1,18 & 26,18 & 1,16 \\
\hline$\Sigma$ Omega 3 & 1,67 & 0,08 & 1,73 & 0,09 & 1,74 & 0,01 & 1,80 & 0,67 & 1,61 & 0,56 \\
\hline$\Sigma \mathrm{n} 6 / \mathrm{n} 3$ & 16,28 & 3,21 & 14,21 & 2,21 & 16,08 & 1,25 & 15,01 & 1,69 & 16,26 & 2,06 \\
\hline
\end{tabular}

Línea genética: HYcol - Hyla colored, GR - Grimaud, HY - Hyla. Dieta: HE - High energy diet, C - Control diet. MMC: Media mínimo cuadrática, SE: error estándar.

$a, b, c=$ diferentes letras dentro de la fila representan diferencias entre líneas genéticas. $y, z=$ diferentes letras dentro de la fila representan diferencias entre dietas. 
Tabla 12. Composición de grasa intramuscular (\%) y composición de ácidos grasos (\%) en la grasa intramuscular en la carne de la pata según la línea genética y la dieta a las $\mathbf{1 2}$ semanas. (Media mínimo cuadrática \pm error estándar).

\begin{tabular}{|c|c|c|c|c|c|c|c|c|c|c|}
\hline \multicolumn{11}{|c|}{12 SEMANAS } \\
\hline \multirow[t]{2}{*}{ Ác. graso } & \multicolumn{2}{|c|}{ HYcol } & \multicolumn{2}{|l|}{ GR } & \multicolumn{2}{|c|}{ HY } & \multicolumn{2}{|c|}{ C } & \multicolumn{2}{|c|}{ HE } \\
\hline & MMC & ES & MMC & SE & MMC & ES & MMC & ES & MMC & ES \\
\hline $\begin{array}{l}\% \text { grasa } \\
\text { intramuscular }\end{array}$ & 4,04 & 0,48 & 4,20 & 0,87 & 3,84 & 0,47 & 3,91 & 0,47 & 4,15 & 0,49 \\
\hline C10:0 & 0,36 & 0,03 & 0,28 & 0,02 & 0,28 & 0,01 & 0,31 & 0,01 & 0,30 & 0,01 \\
\hline C12:0 & 0,48 & 0,03 & 0,39 & 0,03 & 0,39 & 0,00 & 0,43 & 0,03 & 0,42 & 0,02 \\
\hline C14:0 & 4,24 & 0,54 & 2,91 & 0,31 & 2,67 & 0,54 & 3,59 & 0,15 & 3,95 & 0,18 \\
\hline C15:0 & $0,96^{a}$ & 0,06 & $0,81^{a}$ & 0,03 & $0,70^{b}$ & 0,02 & 0,88 & 0,06 & 0,77 & 0,04 \\
\hline C16:0 & $28,05^{b}$ & 0,34 & $30,34^{a}$ & 0,25 & $26,70^{c}$ & 0,06 & $27,8^{y}$ & 0,06 & $28,97^{2}$ & 0,05 \\
\hline C17:0 & $0,96^{a}$ & 0,03 & $0,86^{a}$ & 0,06 & $0,78^{b}$ & 0,05 & 0,88 & 0,05 & 0,86 & 0,06 \\
\hline C18:0 & $8,52^{a}$ & 0,06 & $9,28^{b}$ & 0,09 & $9,07^{b}$ & 0,09 & 8,50 & 0,85 & 9,41 & 0,90 \\
\hline C20:0 & 0,15 & 0,03 & 0,12 & 0,01 & 0,11 & 0,06 & 0,13 & 0,05 & 0,12 & 0,05 \\
\hline C16:1n7 & 3,74 & 0,04 & 3,58 & 0,09 & 3,46 & 0,10 & 2,99 & 0,99 & 4,20 & 1,00 \\
\hline C18:1n9 & 24,21 & 1,40 & 26,10 & 0,78 & 26,69 & 0,44 & 25,65 & 1,02 & 25,68 & 1,32 \\
\hline C20:1n9 & $0,53^{a}$ & 0,04 & $0,27^{b}$ & 0,02 & $0,32^{a b}$ & 0,07 & 0,26 & 0,01 & 0,49 & 0,14 \\
\hline C22:1n9 & 0,15 & 0,02 & 0,13 & 0,04 & 0,10 & 0,07 & 0,12 & 0,02 & 0,13 & 0,05 \\
\hline C24:1n9 & $0,00^{a}$ & 0,00 & $0,00^{a}$ & 0,00 & $0,00^{b}$ & 0,05 & 0,00 & 0,00 & 0,00 & 0,00 \\
\hline C18:2n6 & $17,45^{a}$ & 0,23 & $18,76^{\mathrm{a}}$ & 0,88 & $21,07^{b}$ & 0,06 & 20,38 & 0,79 & 17,81 & 0,85 \\
\hline C18:3n6 & 0,00 & 0,02 & 0,05 & 0,03 & 0,01 & 0,02 & 0,02 & 0,01 & 0,02 & 0,00 \\
\hline C18:3n3 & 2,11 & 0,78 & 0,95 & 0,77 & 2,03 & 0,08 & 1,66 & 0,44 & 1,73 & 0,54 \\
\hline C20:3n6 & 0,17 & 0,04 & 0,12 & 0,07 & 0,19 & 0,05 & 0,15 & 0,02 & 0,17 & 0,02 \\
\hline C20:4n6 & 1,82 & 0,21 & 2,04 & 0,31 & 2,35 & 0,21 & 2,39 & 0,88 & 1,74 & 0,74 \\
\hline C22:6n3 & 0,02 & 0,01 & 0,03 & 0,01 & 0,04 & 0,01 & 0,03 & 0,01 & 0,03 & 0,01 \\
\hline$\Sigma$ Saturado & $43,96^{a b}$ & 1,18 & $45,26^{a}$ & 0,81 & $40,81^{b}$ & 0,84 & 42,71 & 1,30 & 44,97 & 1,34 \\
\hline$\Sigma$ Monoinsat MUFA & 29,52 & 1,66 & 30,42 & 1,07 & 31,03 & 0,87 & 29,35 & 2,19 & 31,30 & 2,61 \\
\hline$\Sigma$ Poliinsat PUFA & $21,56^{a}$ & 1,29 & $21,95^{a}$ & 2,07 & $25,70^{b}$ & 0,43 & 24,63 & 2,14 & 21,50 & 2,17 \\
\hline$\Sigma$ Insaturado & $51,08^{a}$ & 0,98 & $52,37^{a}$ & 0,79 & $56,74^{b}$ & 0,85 & 53,98 & 4,34 & 52,80 & 4,78 \\
\hline$\Sigma$ Sat/Insat & 0,86 & 1,20 & 0,87 & 1,02 & 0,72 & 0,98 & 0,79 & 0,30 & 0,85 & 0,28 \\
\hline$\Sigma$ PUFA/SFA & 0,86 & 0,38 & 0,86 & 0,26 & 0,72 & 0,65 & 0,79 & 0,30 & 0,85 & 0,28 \\
\hline$\Sigma$ Omega 6 & 19,43 & 0,50 & 20,97 & 1,29 & 23,62 & 0,34 & 22,94 & 1,69 & 19,74 & 1,62 \\
\hline$\Sigma$ Omega 3 & 2,13 & 0,79 & 0,98 & 0,78 & 2,08 & 0,09 & 1,70 & 0,45 & 1,76 & 0,55 \\
\hline$\Sigma \mathrm{n} 6 / \mathrm{n} 3$ & $9,14^{a}$ & 0,63 & $21,46^{b}$ & 1,65 & $11,34^{\mathrm{ab}}$ & 3,92 & 13,53 & 3,73 & 11,20 & 2,95 \\
\hline
\end{tabular}

Línea genética: HYcol - Hyla colored, GR - Grimaud, HY - Hyla. Dieta: HE - High energy diet, C - Control diet. MMC: Media mínimo cuadrática, SE: error estándar.

$a, b, c=$ diferentes letras dentro de la fila representan diferencias entre líneas genéticas. $y, z=$ diferentes letras dentro de la fila representan diferencias entre dietas. 


\section{CONCLUSIONES}

- Para las líneas HYcol y GR presentaron mayor peso vivo al sacrificio, que Hyla para ambas dietas estudiadas y además el cambio a una dieta más energética (HE) suponía un incremento del ritmo de crecimiento para estas líneas, pero no para HY. Por tanto, el tipo de dieta resulta decisivo para que las líneas que tienen un mayor potencial de crecimiento puedan expresarlo. las hembras presentaron mayor PVS que los machos a partir de la semana 10, y mayor GMD a partir de la semana 13.

- La línea genética HYcol presentó menor IT que la línea HY en las semanas de la 9 a la 13 ambas inclusive; a partir de la semana 13 la precisión de la estima empeoró, debido a que disminuyó el número de datos, y la diferencia HYcol-HY no llegó a ser significativa. Respecto a la línea GR presentó un valor de IT intermedio no llegando a ser diferente a ambas líneas Hyla

- De la semana 10 a la 14 incluidas los conejos que fueron alimentados con la dieta HE presentaron menor IT que los alimentados con la dieta C (figura 4), con diferencias que oscilaron de 0,46 en la semana 10 a 0,76 en la semana 14 .

- El efecto del género las hembras desde la semana 11 a la semana 16 tienen mayor peso al sacrificio y de la semana 11 y 12 tienen índices de transformación inferiores a los machos.

- Las líneas mejoradas por velocidad de crecimiento tienen mayores peso de canal caliente, fría y de referencia, mayor compacidad (en todas las semanas), desarrollan mayor cantidad de piel (de la semana 10 a la 12), más hígado (en todas las semanas) y más cabeza (en todas las semanas) que la línea de aptitud maternal, y esta diferencia se incrementa cuando son alimentados con la dieta HE. En Hyla no hubo ningún cambio en el desarrollo del hígado por la dieta.

- En el peso de los riñones hay diferencias entre las tres líneas genéticas, siendo de mayor a menor peso Hyla colored, Grimaud e Hyla en todas las semanas. Mientras que Grimaud disminuye menos su porcentaje de riñones respecto a la canal fría que HYcol e Hyla. 
- Las hembras Grimaud muestran más compacidad y desarrollan la piel y los riñones ligeramente antes que los machos a lo largo de las semanas. Los machos desarrollan más peso de cabeza que las hembras en todas las semanas.

- En el despiece de la canal, a partir de la semana 9 las líneas de aptitud cárnica HYcol y Grimaud muestran mayor peso de la caja torácica, del lomo, de las patas delanteras y traseras que la línea de aptitud maternal Hyla; y esta diferencia es más marcada con la dieta HE.

- En el porcentaje del despiece respecto al peso de la canal fría, la línea HYcol presenta mayor porcentaje de lomo con la dieta HE (a partir de la semana 12) y mayor porcentaje de patas traseras que Grimaud con la dieta $C$ en las semanas de la 10 a la 12. Mientras que, Grimaud presenta mayor porcentaje de patas delanteras que Hyla a partir de la semana 10.

- En el despiece, las hembras con la dieta HE desarrollan más peso y porcentaje de lomo (en todas las semanas) y mayor peso de patas traseras a partir de la semana 13 que los machos.

- En el desarrollo de la caja torácica (tanto en peso como porcentaje) y del ratio músculo-hueso no se observa efecto de la dieta ni del género, pero sí hay efecto de la línea genética, en el caso de la caja torácica, desarrollan más peso las líneas de aptitud cárnica que la línea maternal a lo largo de todas las semanas, mientras que en el ratio músculo-hueso Grimaud tiene más ratio que HYcol e Hyla en todas las semanas estudiadas.

- La dieta HE genera mayor porcentaje de deposición de todos los tipos de grasa en las líneas de aptitud cárnica Hyla-colored y Grimaud, lo que no sucede en la línea de aptitud maternal Hyla. Este efecto fue es más marcado en la línea Grimaud. La grasa perirrenal en las tres líneas genéticas es la que más aumentó su peso y porcentaje con la edad.

- Con la dieta C, Hyla y Grimaud mantienen sus porcentajes de grasa escapular e inguinal más o menos constantes a lo largo de las semanas.

- La línea de aptitud maternal presenta menores valores de porcentaje de los diferentes tipos de grasa que las líneas HYcol y GR. Si bien debido a que el 
efecto de la dieta es menos marcado en HYcol, presentó valores similares a HY de grasa inguinal, perirrenal y diseccionable con la dieta $\mathrm{HE}$.

- Respecto a características de calidad de carne la línea Hycol presenta menores valores de $\mathbf{p H}$ que Hyla y Grimaud.

- En cuanto al color, con la dieta HE hay cambios en la luminosidad. Siendo la carne más luminosa la de Hyla con la dieta C.

- Respecto a la textura, con la edad se produce un incremento de la dureza de la carne salvo para la línea HYcol con la dieta $\mathrm{C}$ porque disminuyen ambos valores de MSF e IYF. Para la dieta HE las líneas fueron iguales y tampoco hubo diferencias significativas entre ambos sexos.

- Con la dieta HE hay tendencia a aumentar el porcentaje de grasa intramuscular y disminuir es de humedad de la composición química de la carne de la pata, destacando HY para la humedad y grasa, y en GR para la grasa.

- Los principales ácidos grasos encontrados en la carne de conejo fueron el palmítico (C16:0), el oleico (C18:1), el linoleico (C18:2) y el esteárico (C18:0). El efecto de la línea genética se ve más pronunciado a mayor edad del conejo tanto en SFA, MUFA como PUFA. El mayor contenido de ácido palmítico (C16:0) es a las 12 semanas con la dieta menos fibrosa (HE). 


\section{BIBLIOGRAFÍA}

Al-Donaib, S.N. (2010). Effect of diets on growth, digestibility, carcass and meat quality characteristics of four rabbits breeds. Saudi Journal of Biological Sciences, 17, 83 - 93.

Bianospino, E., Moura, A. S. A. M. T., Wechsler, F.S., Fernandes, S. \& Dal-Pai-Silva, M. (2008). Age-related changes in muscle type frequencies and cross-sectorial áreas in straightbreed and crossbred rabbit. Animal, 2, 1627 - 1632.

Bianospino, E., Wechsler, F.S., Fernandez, S., Roça, R.O. \& Moura A.S.A.M.T. (2006). Growth, carcass and meat quality traits of straightbred and crossbred Botucatu rabbits. World Rabbit Science, 14, 237 - 246.

Blasco, A. (2017). Bayesian data analysis for animal scientists. The basics. (1 ${ }^{\text {st }}$ Ed.) Springer.

Blasco, A. Nagyb, I. \& Hernández, P. (2018). Genetics of growth, carcass and meat quality in rabbits. Meat Science, 145, 178-185.

Blasco, A. \& Ouhayoun, J. (1993). Harmonization of criteria and terminology in rabbit meat research. World Rabbit Science, 4(2): 93-99.

Blasco, A. \& Piles, M. (1990). Muscular pH of the rabbit. Annales de Zootechnie, 39, 133 $-136$.

Cantier, A., Vezinhet, R., Rouvier, R. \& Dauzier, L. (1969). Allométrie de croissance chez le lapin (O. Cuniculus). 1. Principaux organes et tissues. Annales de Biologie Animale, Biochimie et Biophysique, 9: 5- 39.

Cardinali, R., Cullere, M., Dal Bosco, A., Mugnai, C., Rugerri, S., Mattioli, S., Castellini, C., Trabalza Marinucci, M. \& Dalle Zotte, A. (2015). Oregano, Rosemary and vitamin E dietary supplementation in growing rabbits: Effect on growth performance, carcass traits, bone development and meat chemical composition. Livestock Science, 175, $83-$ 89.

Carrilho, M.C., López, M. \& Campo, M.M. (2009). Effect of of the fattening diet on the development of the fatty acid profile in rabbits from weaning. Meat Science, 83: 88-95. 
Combes, S.M, González, I., Déjean, S., Baccini, A., Jehl, N., Juin, H. \& Larzul, C. (2008). Relationship between sensory and physicochemical in meat of rabbit from three different breeding systems using canonical correlation analysis. Meat Science, 80, 835 $-841$.

Combes, S. (2004). Valeur nutritionelle de la viande de lapin. Inra Productions Animales, 17(5): 373-383.

Dalle Zotte, A., Remignon, H. \& Ouhayoun, J. (2005). Effect of feed rationing during post-weaning growth on meat quality, muscle energy metabolism and fibre properties of Biceps femoris muscle in the rabbit. Meat Science, 70, $301-306$.

Dalle Zotte, A. \& Ouhayoun, J. (1998). Effect of genetic origin, diet and weaning weight on carcass composition, muscle physicochemical and histochemical traits in the rabbit. Meat Science, 50, $471-478$.

Dalle Zotte, A., Ouhayoun, J., Parigi-Bini, R. \& Xiccato, G. (1996). Effect of Age, Diet and Sex on Muscle Energy Metabolism and on Related Physicochemical Traits in the rabbit. Meat Science, 43, $15-24$.

Dalle Zotte, A., Szendrö. K., Gerencsér, Zs., Szendrö., Zs., Cullere, M., Odermatt, M., Radnai, I., \& Matics, Zs. (2015). Effect of genotype, housing system and hay supplementation on carcass traits and meat quality of growing rabbits. Meat Science, $110,126-134$.

Deltoro, J., López, A. M. (1985). Allometric changes in rabbits. Journal of Agricultural Science, 105: 339-346.

Bates, D., Maechler M., Bolker B. \& Walker, S. (2015). Fitting Linear Mixed-Effects Models Using Ime4. Journal of Statistical Software, 67(1), 1 - 48. <doi:10.18637/jss.v067.i01>.

Evans, D. G. \& Kempster, A. J. (1979). The effects of genotype, sex and feeding regimen on pig carcass development. Journal of Agricultural Science, 93: 339-347.

Faraway , J. (2014) Linear Models with $R$, Chapman \& Hall, $2^{\text {nd }}$ edition. 
FAO. (2012). Estudio FAO alimentación y nutrición. Grasas y ácidos grasos en nutrición humana. Consulta de expertos. 2008. Ginebra. ISBN 978-92-5-3067336.

Feki, S., Baselga, M., Blas, E., Cervera, C. \& Gómez, E.A. (1996). Comparison of growth and feed efficiency among rabbit lines selected for different objectives. Livestock Production Science, 45, $87-92$.

Fisher, A. V., Green, D.M., Whittemore, C. T., Wood, J. D. \& Schofield, C. P. (2003). Growth of carcass components and its relation with conformation in pigs of three types. Meat Science, 65: 639-650.

Gidenne, T. \& Jehl, N. (1995). Effect of fibre level reduction and gluco-oligosacharide addiction on the growth performance and caecal fermentation in the growing rabbit. Animal Feed Science and Technology, 56, 253 - 263.

Hernández, P., (1994). Ecuaciones de predicción para estimar el contenido de carne y grasa en dos líneas de conejos de diferente velocidad de crecimiento. Tesis de licenciatura. Universidad Politécnica de Valencia, España.

Hernández, P., Ariño, B., Grimal, A. \& Blasco, A. (2006). Comparison of carcass and meat characteristics of three lines selected for litter size or growth rate. Meat Science, $73,645-650$

Hernández, P., Cesari, V. \& Blasco, A. (2008). Effect of genetic rabbit line son lipid content, lipolytic activities and fatty acid composition of hind leg meat and perirenal fat. Meat Science, 78: 485-491.

Huxley J.S. (1932). Problems of relative growth. London: Methuen.

Kouba, M., Bonneau M. (2009). Compared development of intermuscular and subcutaneous fat in carcass and primal cuts of growing pigs from 30 to $140 \mathrm{~kg}$ body weight. Meat Science, 81: 270-274.

Lazzaroni, C., Biagini, D. \& Lussiana, C. (2009). Fatty acid composition of meat and perirenal fat in rabbits from two different rearing systems. Meat Science, 83, 135 139. 
Lilja, C. (1981). Postnatal growth and organ development in the goose. Growth, 45: 329-341.

López, A.M. (1987). Estudios sobre el crecimiento en conejo. Tesis doctoral. Universidad Politécnica de Valencia, España.

Margüenda, I., Carabaño, R., García-Rebollar, P., Fragkiaddakis, M., Sevilla, L., Vadillo, S. 2008. Effects of dietary type and level of fiber on carcass yield and its microbiological characteristics. In: 9th World Rabbit Congress, June 10 - 13 (2008). Verona, Italy, pp. $1387-1397$.

Martínez-Bas, A.M., Kessler, M. \& Armero, E. (2018). The relative growth in rabbits: the effects of genetic line, diet and gender. World rabbit science. Accepted on July 2018.

Martínez-Vallespín, B, Martínez-paredes, E., Ródenas, L., Moya, V.J., Cervera. C., Pascual, J.J. \& Blas, E. (2013). Partial replacement of starch with acid detergent fibre and/or neutral detergent soluble fibre at two protein levels: effects on ileal apparent digestibility and caecal enviroment of growing rabbits. Livestock Science, 154, 123 130.

Mínguez, C., Sánchez, J.P., Hernández, P., Ragab, M., El Nagar, A.G. \& Baselga, M. (2017). Genetic analysis of meat quality traits in maternal lines of rabbit and their diallel cross. Meat Science, 131, $1-8$.

MØller, A. (1980). Analysis of Warner-Bratzler shear forcé pattern with regard to myofibrilar and connective tissue components of tenderness. Meat Science, 5, 247 260.

Nasr, M.A.F., Abd-Elhamid, T., Hussein, M.A. (2017). Growth performance, carcass characteristics, meat qulity and muscle amino-acid profile of different rabbits breeds and their crosses. Meat Science, 134, $150-157$.

O’Fallon, J.V., Busboom, J.R., Nelson, M.L. \& Gaskins, C.T. (2007). A direct method for fatty acid methyl ester synthesis; Application to wet meat tissues, oils, and feedstuffs. Journal Animal Science, 85, 1511 - 1521. 
Papadomichelakis, G., Karagiannidou, A., Anastasopoulus, V. \& Fegeros, K. (2010). Effect of high dietary digestible fibre content on the fatty acid composition of two muscles in fattening rabbits. Livestock Science, 129, $159-165$.

Pascual, M. (2007). Effect of selection for growth rate on carcass composition and meat quality in rabbits. PhD. Universitat Politècnica de València.

Pascual, M., Pla. M., (2007). Changes in carcass composition and meat quality when selecting rabbits for growth rate. Meat Science, 77, 474-481.

Pascual M., Pla M., Blasco A. (2008). Effect of selection for growth rate on relative growth in rabbits. Journal of Animal Science, 86: 3409-3417.

Pascual, M., Soler, M.D., Cervera, C., Pla, M., Pascual, J.J. \& Blas, E. (2014). Feeding programmes base on highly-digestible fibre weaning diets: Effects of health, growth performance and carcass and meat quality in rabbits. Livestock Science, 169, 88 - 95.

Pla, M., Guerrero, L., Guardia, D., Oliver, M.A. \& Blasco, A. (1998). Carcass characteristics and meat quality of rabbit lines selected for different objectives: I. Between lines comparison. Livestock Production Science, 54, 115 - 123.

Pla, M., Hernández, P. \& Blasco, A. (1996). Carcass composition and meat characteristics of two rabbit breeds of different degrees of maturity. Meat Science, 44 , $85-92$.

R Core Team (2017). R: A language and environment for statistical computing. Roundation for Statistical Computing, Vienna, Austria. URL https://www.Rproject.org/.

Ramírez, J.A., Ángels Oliver, M., Pla, M., Guerrero, L., Ariño, B., Blasco, A., Pascual, M. \& Gil, M. (2004). Effect of selection for grwth rate on biochemical, quality and texture characteristics of meat from rabbits. Meat Science, 67, 617-624.

Ramírez, J.A., Díaz, I., Pla, M., Gil, M., Blasco, A. \& Àngels Oliver, M. (2005). Fatty acid composition of leg meat and perirenal fat of rabbits selected by growth rate. Food Chemistry, 90, $251-256$. 
Robert, R., Thiébot, C. \& Garreau, H. (2017). Etude comparative du poids et de la proportion de la peau et des pieces de découpe de deux lignées mâles du souche Hyla. $17^{\text {èmes }}$ Journées de la Recherche Cunicole. Novembre 21 - 22. Le Mans. France.

Szendrö, K., Szendrö, Zs., Matics, ZS., Dalle Zotte, A., Odermatt, M., Radnai, I. \& Gerencsér, Zs. (2015). Effect of genotype, housing system and hay supplementation on performance and ear lesions of growing rabbits. Livestock Science, 174, $105-112$.

Schreurs, F.J.G., Van der Heide, D., Leenstra, F.R. \& De Wit, W. (1995). Endogenous proteolytic enzymes in chicken muscles. Differences among strains with different growth rates and protein efficiences, Poultry Science, 74, $523-537$.

Tumová, E., Bízkova, Z., Skrivanová, V., Chodová, D., Martinec, M. \& Volek, Z. (2014). Comparisons of carcass and meat quality among rabbit breeds of different sizes, and hybrid rabbits. Livestock Science, 165, 8 - 14 .

Tumová, E., Martinec, M., Volez, Z., Härtlová, H., Chodová, D. \& Bízková, Z. (2013). A study of growth and some blood paramters in Czech rabbits. World Rabbit Science, 21, $251-256$.

Varewyck, H. \& Bouquet, Y. (1982). Relations entre la composition tissulaire de la carcasse de lapins de boucherie et celle des principaux morceaux. Annales de Zootechnie, 31 (3): $257-268$.

Vezinhet, A. \& Prud'hon M. (1975). Evolution of various adipose deposits in growing rabbits and sheeps. Animal Production, 20: 363-370.

Weber, T.E., Trabue S.L., Ziemer C.J. \& Kerr, B.J. (2010). Evaluation of elevated dietary corn fiber from corn germ meal in growing female pigs. Journal of Animal Science, 88, 192-201.

Whittemore, C. T. (1998). The Science and practice of pig production. (2nd ed.) Oxford. Longman Scientific and Technical.

Xiccato, G., Trocino, A., Filiou, E., Majolini, D., Tazzoli, M. \& Zuffellato, A. (2013). Bicellular cage vs. collective pen housing for rabbits: Growth performance, carcass and meat quality. Livestock Science, 155, $407-414$. 
Xiccato, G., Kongsro, A., Majolini, D., Fragkiadakis, M. \& Tazzoli, M. (2011). Effect of decreasing dietary protein level and replacing starch with soluble fibre on digestive physiology and performance of growing rabbits. Animal 5, $1179-1187$. 